\title{
Dynamic graciloplasty - (patho)physiology of failure and success
}

Citation for published version (APA):

Geerdes, B. P. (1997). Dynamic graciloplasty - (patho)physiology of failure and success. [Doctoral Thesis, Maastricht University]. Universitaire Pers Maastricht. https://doi.org/10.26481/dis.19970117bg

Document status and date:

Published: 01/01/1997

DOI:

10.26481/dis.19970117bg

Document Version:

Publisher's PDF, also known as Version of record

\section{Please check the document version of this publication:}

- A submitted manuscript is the version of the article upon submission and before peer-review. There can be important differences between the submitted version and the official published version of record.

People interested in the research are advised to contact the author for the final version of the publication, or visit the DOI to the publisher's website.

- The final author version and the galley proof are versions of the publication after peer review.

- The final published version features the final layout of the paper including the volume, issue and page numbers.

Link to publication

\footnotetext{
General rights rights.

- You may freely distribute the URL identifying the publication in the public portal. please follow below link for the End User Agreement:

www.umlib.nl/taverne-license

Take down policy

If you believe that this document breaches copyright please contact us at:

repository@maastrichtuniversity.nl

providing details and we will investigate your claim.
}

Copyright and moral rights for the publications made accessible in the public portal are retained by the authors and/or other copyright owners and it is a condition of accessing publications that users recognise and abide by the legal requirements associated with these

- Users may download and print one copy of any publication from the public portal for the purpose of private study or research.

- You may not further distribute the material or use it for any profit-making activity or commercial gain

If the publication is distributed under the terms of Article $25 \mathrm{fa}$ of the Dutch Copyright Act, indicated by the "Taverne" license above, 


\section{Dynamic Graciloplasty:}

(patho)physiology of failure and success 
(C) B.P. Geerdes, Eindhoven 1996

ISBN 9090101772

Design figures: J. de Jonge, Bakken Research Center, Maastricht. Vormgeving en druk: Datawyse I Universitaire Pers Maastricht 


\section{Dynamic Graciloplasty (patho)physiology of failure and success}

\section{PROEFSCHRIFT}

ter verkrijging van de graad van doctor aan de Universiteit Maastricht, op gezag van de Rector Magnificus Prof. mr. M.J. Cohen, volgens het besluit van het College van Decanen, in het openbaar te verdedigen op vrijdag 17 januari 1997 om 16.00 uur

door

Bastiaan Petrus Geerdes

geboren te Heerlen op 18 januari 1965 


\section{Promotor:}

Prof.dr. P.B. Soeters

\section{Co-promotores:}

Dr. C.G.M.I. Baeten

Dr. E. Heineman

\section{Beoordelingscommissie:}

Prof. dr. F. Spaans (voorzitter)

Prof. dr. J.W. Arends

Prof. dr. J. Christiansen (University of Copenhagen)

Prof. dr. R.A. Janknegt

Prof. dr. R.D. Madoff (University of Minnesota)

These studies were financially supported by the The Ministry of Trade and Industry ("Stipt"), the Exccutive Health Insurance Board ("Ontwikkelingsgeneeskunde") and the University Hospital Maastricht.

The major financial support by Medtronic Interstim for the publication of this thesis is gratefully acknowledged. 


\section{FACULTAS MEDICA}

Hij die het mes en het lancet hanteert kan onverschrokken zijn wanneer hij vreest met heilige vrees. Het edelste, de geest, wordt in dit uur beveiligd of gedeerd.

Zie het gelaat van wie zich niet verweert, een open boek. Wie, zelfverblind, niet leest richt diep het letstel aan dat niet geneest. Hij heeft de adel van het ambt onteerd.

Gezegend die het weten van zijn grens belijdt: zijn hand vertoont die vaste trek, zijn ziel de schroom die adeldom verraadt.

Met instrumenten werkend aan een mens opent hij nog de sluitklink van het hek waardoor de ander naar de vrijheid gaat.

(Ida Gerhardt, De Hovenier 1961)

Aan mijn ouders Aan Myriam. 
(2. 


\section{Contents}

1. Introduction 9

2. Anal dynamic graciloplasty in the treatment of intractable fecal incontinence 41

3. Double dynamic graciloplasty for total anorectal reconstruction 55

3.1 Total anorectal reconstruction with a double dynamic graciloplasty after abdominoperineal reconstruction for low rectal cancer 57

3.2 Double dynamic graciloplasty after traumatic destruction of the rectum and sphincters 69

4. Dynamic graciloplasty: complications and management 75

5. Muscle preservation 85

5.1 Assessment of ischaemia of the distal part of the gracilis muscle during transposition for anal dynamic graciloplasty $\quad 87$

5.2 Vascular and stimulation delays in dynamic musculoplasty. an experimental study in rabbits 95

6. Pediatric incontinence and the dynamic graciloplasty 111

6.1 Recent developments in the treatment of pediatric incontinence 113

6.2 Dynamic myoplasty for treatment of incontinence in growing individuals 127

6.3 Simultaneous treatment of fecal and urinary incontinence in children with spina bifida using a double dynamic graciloplasty 139

7. General discussion and summary 147

Samenvatting 157

Dankwoord 163

Publications 167

Curriculum Vitae $\quad 169$ 

Chapter 1

\section{INTRODUCTION}

Part of this chapter will be published under the tirle:

Fecal Incontinence and the Dynamic Graciloplasty. Geerdes BP and Baeten CGMI.

Perspectives in Colon and Rectal Surgery (in press) 


\section{Introduction}

Fecal incontinence can be defined as involuntary excretion of stools at an inappropriate time or in an inappropriate place more than twice a month. ${ }^{1}$ It is an unpleasant and debilitating problem that can profoundly affect someone's personal and social life. ${ }^{2}$ The prevalence in the British population has been reported to be 4.2 per 1000 in men aged 15-64 and 10.9 per 1000 men aged 65 or over; in women this was 1.7 and 13.3 per 1000 respectively. ${ }^{1}$ In a more recent American report the prevalence was 23 per $1000 .^{3}$ This difference reflects the uncertainty regarding the prevalence, possibly caused by the fact that many patients are reluctant to admit that they are incontinent, while doctors arc reluctant to embarrass patients by asking about it. ${ }^{4}$ However, when asked specifically the reported information on inconrinence is reasonably consistent and can provide reliable prevalence estimates. 5 The direct cost of fecal incontinence is based on prevalence rares, number of incontinent episodes, nursing time, incontinence supplies and laundry requirements and was calculated to be $\$ 9771$ per patient per year. ${ }^{6} \mathrm{~A}$ figure concerning costs made for treatment of diarrhea, prevention and treatment of breakdown of skin, increased incidence of female genital infection and bacteriuria, stoma care in patients where a stoma was created for incontinence or the loss of productive capacity due to the incapability to work is lacking. ${ }^{7}$ Elderly patients constitute the majority of this group ${ }^{2,8}$ and incontinence is often a reason to become institurionalized.

Good continence depends on several anatomical, physiological, and psychological entities: mental function, stool volume and consistency, colonic transit, rectal distensibility, anal sphincter function, pelvic floor function, anorectal sensation and anorectal reflexes. ${ }^{9}$ Deficiency of one, and often more than one, of these entities can lead to incontinence.

Anatomy, physiology and pathophysiology

\section{The rectum}

According to Gray ${ }^{10}$ the rectum received its name for being somewhat less flexuous than any orher part of the intestinal canal. The rectum has a length of $15-20 \mathrm{~cm}$, is S-shaped in the saggital plane, and has three flexures in the coronal plane: an upper and a lower convex flexure to the right and a middle convex flexure to the left. The proximal junction is usually at the same level as the third sacral vertebra and corresponds to the caudal end of the sigmoid mesocolon and the disappearance of the appendices epiploicae and sacculations. "Three transverse folds (the valves of Houston) partly encircle the upper part of the recrum. The rectal contribution to fecal incontinence includes the ability of the rectum to act as a reservoir. (figure 1)

The capacity of the rectum depends upon its initial volume and the compliance of the recral wall. Recral compliance, defined as the change in rectal volume per unit change 
in rectal pressure, shows a considerable individual variation depending on age, sex, day-to-day difference ${ }^{12}$ and probably also because the present measurement techniques are less accurate. ${ }^{13}$ Compliance was found to be decreased in patients with fecal incontinence ${ }^{14}$, active ulcerative colitis ${ }^{15}$ and radiation proctitis. ${ }^{16}$ The rectal mucosa contains numerous, non-myelinated, nerve fibers. Sensation of rectal distension travels with the pelvic splanchnic nerves to $\$ 2$ and S3, nociceptive information travels in both parasympathetic and sympathetic systems. ${ }^{11,17}$

Another role of the rectum is coordination of motility and initiation of defecation. Therefore it possesses the ability to show rapid initial expansion on distension, rectal reflex contractions cause a temporarily reversed or retarded inflow and finally virtually no motility is produced despite continued distension ${ }^{18}$ (= accomodation response). During the sampling response the upper part of the internal anal sphincter relaxes to allow the rectal content to come into contact with the somatic sensory area in the anal canal in order to assess the nature of the content. At this moment we will become aware of filling of the rectum. Controlled defecation occurs when a moderate stimulus from the full rectum reaches consciousness by release of cortical inhibition. When the rectal stimulus is greater and combined with stimulation of the anal canal urgency, controlled defecation takes place. ${ }^{19}$ The contribution of rectal contractions to the expulsion of feces during defecation is of less importance compared with, for instance, raised intra-abdominal pressure.

\section{The anal canal}

An anatomical and a surgical anal canal can be distinguished. The anatomical anal canal extends from the dentate line to the anal verge and is approximately $2.1 \mathrm{~cm}$ in length. ${ }^{20}$ The surgical anal canal is defined as that portion of the terminal intestine that extends from the level the rectum passes through the pelvic viscera aperture (the anorectal ring) to the anal verge $e^{21}$ and has an average length of $4.2 \mathrm{~cm}^{20}$ The anorectal ring is a fibromuscular band composed of the upper portion of the internal sphincter, longitudinal muscle, deep external sphincter, and puborectalis. (figure 1)

Embryologically the anal canal is formed by two swellings: the bulbus analis and the bulbus terminalis which become resp. the zona columnaris (columns of Morgagni) and the zona intermedia (the pecten). At the junction of both swellings, the place of the former anal membrane, the entodermal hindgut and the ectodermal anal pit or proctodeum meet. ${ }^{22}$ The distal ends of the anal columns (of Morgagni) fuse as the anal valves, enclosing the pocket-like anal sinuses. Although there is a considerable range in the histology of this region ${ }^{23}$, we can distinguish a gradual change from the rectal simple columnar epithelium to a stratified columnar epithelium just above the anal columns, a zigzag change to stratified squamous epithelium at the anal valves and a third change to the perianal true skin at the intersphincteric line. The hemorrhoidal plexus, surrounding the anal canal, functions as cavernous bodies contributing to the water- and air-tightness of the anal canal. From $10-15 \mathrm{~mm}$ above the anal valves downward, 
sensibility is provided by the epithelium which has a rich sensory nerve supply made up nt both free and organized nerve endings (Meissner's corpuscles, Golgi-Mazzoni bodies and Krauze end-bulbs). ${ }^{24}$ This epithelium is extremely sensitive to pain, to heat and cold, touch and movement of an object. ${ }^{24}$

The muscular cuft surrounding the anal canal can be divided in a pelvic floor and an internal and external anal sphincter divided by the anal longitudinal muscle.

\section{The internal anal sphincter (LAS)}

The internal anal sphincter is formed by a thickening of the circular layer of smooth muscle of the rectum and constitutes the proximal 3 to $4 \mathrm{~cm}$ of the anal canal. (figure 1) This innermost muscle wall is approximately $5 \mathrm{~mm}$ thick, increasing with age..$^{25} \mathrm{At}$ rest the IAS generates a low-frequency electric activity resulting in a tonic contraction which is largely responsible for the resting anal pressure. ${ }^{26}$ Parasympathetic nerve supply is reccived from the sacral outflow (S2-S3 - pelvic plexus) and sympathetic supply from the thoracicolumbar outflow of the spinal cord (L.5 - hypogastric nerves). ${ }^{27}$ At rest tonic excitatory sympathetic discharge ( $\alpha$-adrenergic) is responsible for the resting pressure ${ }^{27}$, as well as parasympatheric discharge. ${ }^{28}$ The parasympathetic fibers are however probably predominantly responsible for relaxation of the IAS. Electrical stimulation of the presacral sympathetic nerves ( $\beta$-adrenergic) causes also relaxation of the LAS." Intrinsic innervation by the enteric nervous system is by non-cholinergic, non-catecholaminergic nerves, using purinergic or peptidergic transmitters. Transmitters that have been identified within the IAS are: vasoactive intestinal peptide (VIP), neuropeptide-Y (NPY), galanin, calcitonin-gene related peptide (CGRP), substance-P and nitric oxide synthase (NOS). These neurotransmitters seemed to be unaffected in patients with neurogenic fecal incontinence. ${ }^{30}$ In a group of these patients electromechanical dissociation and abnormal relaxation of the IAS exist. ${ }^{31}$ This may be explained by decreased responses to noradrenaline and isoprenaline ${ }^{32}$. which can be due to an altered sensitivity of the $\alpha$-adrenoceptors. ${ }^{33}$

\section{The external anal sphincter (EAS)}

The EAS is a complex of striated muscle fibers surrounding the anal canal, according to the classical classification divided into three layers: a subcutaneous, a superficial and a deep layer. ${ }^{34}$ The subcutaneous part, situated in the perineal space inferolateral of the LAS, is a multifascicular ring of muscle without distinct attachments. The superficial part is an ellips of fibers passing from the central tendineus part of the perineum to the anococcygeal raphe which is attached to the dorsal aspect of the coccyx. The deep part is a group of annular fibers blending anteriorly with the perineal muscles and intimately related with the puborectal muscle. A more recent classification distinguishes two layers: a superficial (combining the old subcutaneous and superficial) and a deep layer.(figure 1) There are sex differences in the form of the EAS, and thickness decreases with age. ${ }^{25,35}$ 
The cell bodies of the neurons controlling the EAS lie at $S 2$ in the ventral horn of the spinal cord, called Onuf's nucleus. ${ }^{22}$ The motor fibers to the EAS travel in the pudendal nerve (S2 and S3) and in the perineal branch of S4. ${ }^{36}$ Tonic discharges in the cells of Onuf s nucleus maintain striated sphincter muscle tone, even during sleep. This resting level of activity increases briskly in response to changes in posture or intra-abdominal pressure via a spinal reflex. ${ }^{37}$ Distension of the colonic/rectal wall is a potent inhibitory stimulation for tonic activity. ${ }^{38}$ When the reservoir function of the rectum is nearing capacity and voluntary deferment or elimination must occur, the EAS is capable of voluntary, phasic, contractions increasing the closure pressure 2 to 3 fold. ${ }^{39}$ This increased pressure can be maintained for 50 seconds in adults and 30 seconds in children, and even less when the rectum is very full. ${ }^{37}$ Normally this is sufficient to push the stool back in to the rectum and postpone defecation, up to the moment rectal capacity and/or defense mechanisms are overloaded and defecation is started.

\section{The pelvic floor}

The pelvic floor musculature, or levator ani, consists of a complex series of muscles, which are under constant dynamic activity. ${ }^{37}$ Anatomically the levator ani muscle can be subdivided in a pubo-, ileo-, and ischiococcygeus muscle. Functionally the levator ani has two different parts: the diaphragmatic portion and the pubovisceral portion. ${ }^{40}$ The diaphragmatic portion is formed by the ileococcygeus muscle and consists of a thin muscular sheet that rises from the pelvic sidewall on either side of the arcus tendineus and ischial spine and inserts into a midline raphe behind the rectum. The pubovisceral portion, and more important part of the pelvic floor, consist of the innermost muscle fibers forming an $\mathrm{U}$-shaped band, arising from the pubic bone and passing behind the rectum to form a supporting sling. ${ }^{41}$ This sling, or puborectalis muscle, has also to be considered as part of the levator ani (and not as a part of the external anal sphincter) since they have a common embryological origin. ${ }^{42}$ Innervation is by the direct branches of the spinal cord segments S3 and S4, somatic fibers which run to the origin of the levator ani on its abdominal face. ${ }^{43}$ The muscle is under constant tonic contraction and thereby responsible for creation of the anorectal angle. In rest an angle of $60-105^{\circ}$ exists between the rectum and the anal canal. The anorectal angle would have a funcrion in the maintenance of continence by creating a flap valve in the rectum when contracted. Its function is questioned however ${ }^{44}$ and seems to be of sole importance in semi-solid and solid stools. ${ }^{45}$ Unclarity exists concerning the anatomy and function of the anal longitudinal muscle, which may have a role as skeleton which supports and binds the rest of the internal and external sphincter complex together. It would serve as an aid during defecation by everting the anus, as a support to the hemorrhoidal cushions, and as a determining factor in the ramification of sepsis. ${ }^{46}$ (figure 1) 


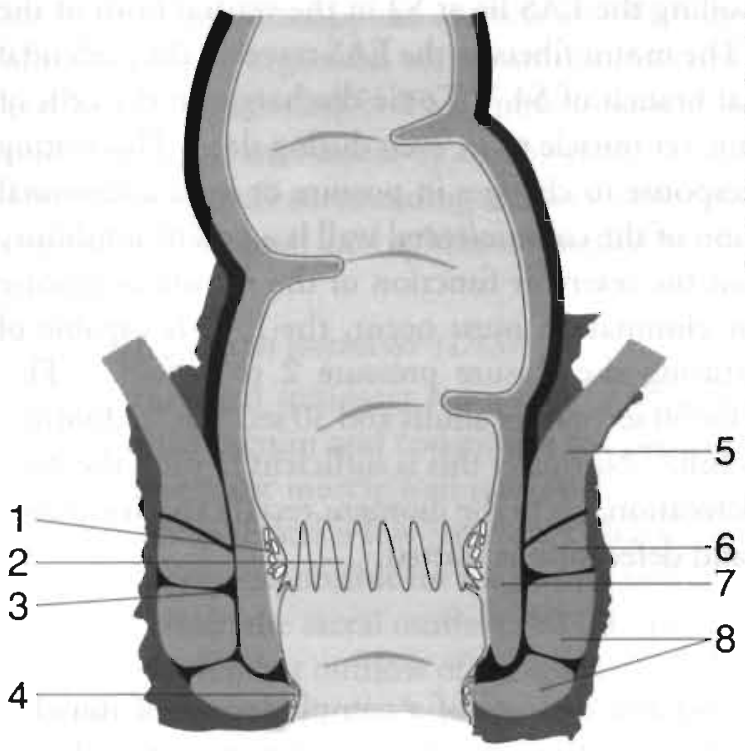

Figure 1. The anatomy of the anorectal region. $1=$ internal haemorrhoidal plexus, $2=$ anal papillae (Morgagni), $3=$ anal longitudinal muscle, $4=$ external haemorrhoidal plexus, $5=$ levator ani muscle, $6=$ puboreccalis muscle, $7=$ internal anal sphincter, $8=$ external anal sphincter.

\section{The RectoAnal Inhibitory Reflex}

Rectal filling results in a reflex relaxation of the internal anal sphincter. This reflex has a local intramural parhway ${ }^{29}$, mediated by nonadrenergic non-cholinergic and nitric oxide nerves. ${ }^{47}$ But it is also modulated by the autonomic nervous system. ${ }^{28}$ Its role is both in anorectal sampling and defecation. When the internal sphincter relaxes, the rectal contents gain access to the specialized sensory epithelium of the anal canal, which allows discrimination of the consistency of the anorectal content (gas, liquid or solid) after each filling period (several times an hour). ${ }^{48}$ After sampling the internal anal sphincter will contract again. IAS relaxation does however not result in incontinence because simultaneously the EAS contracts, which is called the excitatory or inflation reflex. ${ }^{49}$ Excitatory and inhibitory components of rectoanal reflexes may selectively be abolished in neurogenic or traumatic insults to visceral and somatic anal sphincters, resulting in altered rectoanal reflex patterns..$^{50}$

\section{Sensibility}

There is a close association between the perception of rectal sensation and the contractile activities of the external anal sphincter. This suggests that the EAS response to rectal distension is heavily modulated by conscious mechanisms and supports an important role for rectal sensation in the preservation of continence. The association with IAS relaxation is less close. ${ }^{51}$ Still, only in 10 percent of patients with idiopathic fecal incontinence impaired rectal sensarion was found..$^{51}$ 
The receptors in the epithelium of the anal canal, as described before, are able to provide information on touch, pain, movement and temperature and use this to sample the anorectal content. ${ }^{24,52}$ Although touch is an important sensation, there is evidence that the discrimination between gas, liquid and solid is dependent on temperature receptors. ${ }^{53}$ Compared to a control group, incontinent patients were found to have a significantly decreased sensibility to temperature change. ${ }^{53}$ Other investigators state that temperature differences between the rectum and the anal canal are too small for conscious appreciation at all. ${ }^{54}$ Numerous studies point out the importance of anorectal sensation for a successful outcome of surgery for anal incontinence.

\section{Motility}

The functions of the colon are to mix and promote dehydration of fecal material and to transport it to the anorectum. This is achieved by colonic segmentation and motor activity which propels the colonic material forward and backward over relatively short distances. ${ }^{55}$ Therefore, colonic motility is responsible for the volume, consistency and the speed at which stool is delivered at the anorectum. It was found that even in normal healthy subjects stool volume and consistency affected the efficiency of evacuation. ${ }^{56}$ Parients with poor sphincter function and poor sensation, but who have a single bowel movement at a predictable time can be perfectly continent, whereas patients with normal sphincrer function and sensation can be incontinent due to abnormal colonic motility. This group can be divided into two categories: those who have extremely abnormal slow colonic morility (chronic constipation) and patients with severely increased bowel morility (enterocolitis, ulcerative colitis after total colectomy, total colonic agangliosis).

Investigation

\section{Clinical history and examination}

The clinical history and physical examination form the most important tools to be properly informed about the patients' form of incontinence. A detailed history should contain information about the general health condition, physical and mental development, diet, drugs, possible contributing factors, urge to defecate, discrimination, onset of incontinence, defecation frequency, stool volume and consistency, amount and frequency of loss of stool, incontinence of urine and the use of protection material such as diapers.

Inspection of the general condition of the anal region and digital examination of the anorectum will yield information about the existence of a flabby anus or stenosis, the elasticity of the anal introitus, the intactness and the strength of the anal sphincters, the function of the pelvic floor i.e. the puborectal muscle, and the sensitivity of the anorectum. ${ }^{57}$ A low maximal basal pressure (LAS) is correlated with leakage, gaping of 
the anus on traction of the anal verge, and decreased resting tone on digital examination. ${ }^{58} \mathrm{~A}$ decreased maximum squeeze pressure (EAS) is correlated with incontinence en route to the toilet, urgency, both urge and stress incontinence of urine, reduced voluntary contraction in the EAS and the puborectal muscle on digital examination, and a reduced or absent anorectal angle. ${ }^{58}$ Digital examination can very well predict the manometric findings of specialist anorectal physiology studies. ${ }^{59}$ Nevertheless, in patients with fecal incontinence or constipation, further colorectal physiology testing does add valuable information which permits definitive diagnosis of a treatable condition, so that optimal treatment can be given. ${ }^{60}$

\section{Anal manometry}

Anal manometry is the most appropriate tool to study anorectal physiology. Using perfused or solid-state multi-channel catheters, it can provide information about the basal resting pressure (IAS), the maximal squeeze pressure (EAS), the maximal duration of squeeze pressure, the length of the high pressure zone, and rectal compliance. ${ }^{61}$ Intrarectal inflation of a latex balloon or the balloon retaining test ${ }^{62}$ evaluate the conscious rectal sensitivity threshold, the distending volume eliciting a call to stool, the maximum rectal capacity and the presence or absence of the rectoanal inhibitory reflex. Profilometry (rapid pull-through, three dimensional, eight-channel radial manometry) provides information on the symmetry of the anal sphincters. ${ }^{63}$ Both the resting pressure and the squeeze pressure are decreased with age and lower in woman compared to men. ${ }^{64}$ Manometry is useful in the diagnosis of incontinence, constipation, morbus Hirschsprung $^{65}$, anal atresia ${ }^{66}$, congenital megacolon, and spina bifida ${ }^{67}$. When comparing manometric findings with clinical symptoms the following relationships were suggested, decreased resting pressures with the need to wear a pad, decreased squeeze pressures with the inability to postpone defecation, decreased duration of squeeze pressure with interference of incontinence with social activities, an increased volume required to elicit the rectoanal inhibitory reflex with urinary symproms, and reduced length of the anal canal with rectal prolaps. ${ }^{68}$ Although manometry is highly objective, it is unable to predict continence in disease or after surgery. ${ }^{69}$ It is a very useful tool in the follow-up of individual patients and in systematically evaluating results from operations.

\section{Defecography}

After introduction of barium contrast in the rectum the patient strains in order to expel the contrast. Simultaneous radiological imaging (defecography) provides information concerning the physiology of defecation by showing: the anorectal angle, the function and possible descendence of the pelvic floor, the capability to void completely and the occurrence of rectal wall abnormalities such as prolapse, cele, and intussusception. ${ }^{70.7}$ 


\section{Anal endosonography}

In patients who have an accessible anal canal anal endosonography is an elegant imaging technique, without the disadvantage of radiation exposure. It allows visualization of the thickness and intactness of the internal and external anal sphincter, the pelvic floor and adjacent structures. ${ }^{73-74}$ The thickness of the external anal sphincter, the puborectal muscle and the levator ani complex exhibit a significant correlation with age. ${ }^{75}$ Linear relationships can be found between resting pressure and thickness of the IAS. ${ }^{76}$

\section{Magnetic resonance imaging}

This technique shows the position and extent of pelvic and anal musculature. ${ }^{77}$ It is unable to visualize the internal anal sphincter. In patients with characteristic features or $\mathrm{x}$-ray evidence of sacral agenesis, anorectal, and genitourinary anomalies or other complex malformations of the caudal region it allows further evaluation. ${ }^{78}$

\section{Electromyography (EMG)}

EMG provides useful clinical information about the function of the pelvic floor musculature, especially the external anal sphincter and the puborectalis muscle, in rest and during squeezing and straining. ${ }^{79}$ Using the single fiber EMG technique, quantification of the fiber density is a useful parameter for assessing reinnervation of previously damaged pudendal nerve. ${ }^{80}$ Pudendal nerve terminal motor latency (PNTML) provides information about the neurogenic function of the pelvic floor and the anus. ${ }^{81}$ Another method to investigate damage to the pudendal nerve is by magnetic stimulation of the nerve roor $S 3$, which would be more accurate and less painful. ${ }^{82}$ Because of the painful insertion of needles, EMG recordings in children are usually integrated in manometry recordings with the use of surface electrodes attached to the perianal skin.

Investigation of anal sensation using mucosal electrosensitivity can be done by observation of somatosensory evoked potentials after an anal stimulus in neonates ${ }^{83}$, or by introduction of a specially constructed probe which administers an increasing electrical current until a threshold of sensation is reporred by the patient. ${ }^{84,85}$

\section{Solid Marker Studies}

Ten small radio-opaque Silastic tubing fragments are given orally on 3 subsequent days and a plain abdominal film is taken on day 5 . Then the number of markers is counted in the right colon, left colon and rectosigmoid. It is a well-tolerated and useful technique in establishing the diagnosis of constipation. 86 


\section{Causes of fecal incontinence}

Since cuntinence is a cumplex and multifactorial process, inconcinence can present in various degrees and with different pathophysiology, and therefore treatment has to be chosen carcfully.

The age at which the central nervous system is sufficiently marure to coordinate the very cumplex pelvic sensory and motor mechanisms is uncertain. Nor only the maturity of the central nervous system and the mental function of the individual are important, but also social as well as cultural factors play their role.?

In patient.s with gastroenteritis, diarthea causes a disturbance of stool volume and colonic transit time which can lead to fecal incontinence although a normal functioning sphincter mechanism is present.

The causes of long-standing fecal incontinence can be divided into: anorectal malformations, perine:al traumia, pudendal nerve lesions and low-motor neuron lesions.

\section{Anorectal malformations}

Embryologically, the congenital malformation anal atresia can be viewed as an agenesis of the dorsal part of the cloacal membrane which blocks the normal shift of this part and the adjacent gut to the body surface of the tail groove ${ }^{87}$ There is a close relationship between the extent of the cloacal plate defect and the type of the anorectal malformation. The puborectal and external sphincter muscles develop independently at their normal sites although they are often malformed, in seriousness depending on the degree of the anal orifice ectopia. Even the internal sphincter muscle is often present and is spread out as a wide disc surrounding the proximal part of the fistula. ${ }^{88}$ Most patients with low anorectal anal atresia will achieve continence. Patients with high anal atresia are given a colostomy at birth and at the age of 6 months - 1 year the anorectum and the pelvic floor are reconstructed by a posterior saggital anorectoplasty (PSARP) ${ }^{89}$ Despite this perfect anatomical reconstruction patients seldom become continent. ${ }^{90}$ Even when the internal sphincter can be saved, 30 percent of the patients remain incontinent. ${ }^{91}$ Poor anorectal sensibility and abnormal bowel motility are probably responsible for poor outcome. 92

\section{Perineal Trauma}

Trauma is most often the cause of fecal incontinence and results in a mechanical defect of the anal sphincters and/or damage to its innervation. Traumatic incontinence can be the result of an obstetric trauma, surgery for e.g. anal fissures ${ }^{93}$, hemorrhoids ${ }^{94,95}$, fistulas $^{96}$ and abscesses, or a direct trauma. Vaginal delivery is a major cause of anal-sphincter disruption. ${ }^{97,98}$ Endosonography has revealed that 35 percent of women after delivery have a defect of the external anal sphincter, the internal anal sphincter or both. ${ }^{97,99}$ Especially forceps deliveries are harmful. ${ }^{100}$ 


\section{Neurogenic fecal incontinence}

In neurogenic or idioparhic fecal incontinence the pelvic floor and the external anal sphincter are weakened due to damage of the pudendal nerve as demonstrated by EMG. ${ }^{80,101,102}$ The pudendal nerve, with its motor and sensory components ${ }^{103}$, can be damaged by a traction injury or direct trauma (obstetric ${ }^{104}$, iatrogenic). Pudendal neuropathy does not always have immediate effects but can progress with time $e^{35,105,106}$ and cause incontinence later in life. ${ }^{107}$ Incontinence does not only result from progression of neurogenic muscle weakness, but occurs when there is also a diminished internal anal sphincter tone and reduced rectal compliance. ${ }^{108}$

\section{Low-motor neuron lesions (LMNL)}

In LMNL the neuropathy is secondary to a congenital (myelomeningocoele) ${ }^{109}$ or acquired (tethered cord syndrome) ${ }^{110}$ disease. Myelomeningocele (MMC) is commonly associated with neurological, orthopedic, anorectal and urological malformations. In MMC the neural tube defect involves the nerve tracts descending from the lower spinal cord. Anorectal function in MMC patients is determined by the degree of striated muscle paralysis in the pelvic floor and the effect of spinal nerve loss on the autonomic innervation of the intestinal smooth muscles. ${ }^{27}$ Internal anal sphincter function and pressure are more reduced in patients with damage high in the spinal cord than in patients with low spinal lesions, probably due to a more affected excitatory sympathetic nerve supply provided via the hypogastric nerve plexus (L5). ${ }^{27}$ External anal sphincter function is severely affected in all children due to sacral root dysfunction. When the lesion is below $\mathrm{L} 2$ the cauda equina is most often affected. Agnarsson et al ${ }^{111}$ found that some of these children can have high anal pressures. Weak abdominal muscles or a relatively high anal sphincter pressure causing ineffective straining may hinder defecation. Anorectal sensibility is almost exclusively affected in children with a high lesion. Due to the low pressure zone of the anal canal almost all children are able to defecate a rectal balloon from the inert and distended rectum.

\section{Treatment options in fecal incontinence}

\section{Conservative treatment}

Most patients can be treated very well conservatively. A high-fiber diet or bulkforming agents to improve stool volume and consistency or the use of cleansing enemas are effective.

Biofeedback has proven to be successful in increasing the voluntary contraction amplitude of the external anal sphincter and the pelvic floor ${ }^{112}$, recto-anal sensitivity ${ }^{113}$ and the condination of the internal and external anal sphincter responses to rectal distension. Prerequisites are an intact anal sphincter, intact innervation, a strong 
motivation, and maturity. Patients who are incontinent due to medical problems may benefit less from biofeedback. ${ }^{114-116}$ The use of electrical stimulation of the sphincter complex by an anal plug ${ }^{117}$ or an implanted neurostimulator ${ }^{118}$ is an old method claiming good results in parients with partial fecal incontinence. ${ }^{119}$ Neurogenic fecal incontinence cannot be treated in this way. ${ }^{120}$

\section{Classical surgical treatment}

In parients with a mechanical defect of the anal sphincter the overlapping sphincteroplasty is the operation of choice ${ }^{121}$ resulting in restoration of a normal squeeze pressure. ${ }^{122}$ Functional and physiologic data show excellent results although age, duration of incontinence, interval after primary repair, number of previous operations, limited improvement of the external anal sphincter morphology ${ }^{123}$ and certainly pudendal nerve damage can strongly affect the outcome. ${ }^{124-127}$ In complicated cases sphincteroplasty can be combined with a levatorplasty ${ }^{128}$ or a transposition of one limb of the puborectal muscle around the anal canal. ${ }^{129}$

Postanal repair was introduced by Parks in $1959^{130}$ for the treatment of patients with neurogenic fecal incontinence. In theory, improvement of function of the voluntary anal sphincter muscles is achieved by increasing the sphincter length and restoring the anorectal angle and the flap valve of the puborectalis. In fact, post-anal repair does not appear to restore the anorectal angle, nor the resting and squeeze pressure, rectal sensation or capacity. ${ }^{131}$ Improvement is reported in sphincter length ${ }^{131}$ and the urgency experienced. ${ }^{132}$ Short term results are often good, but in the long run full continence is rarely achieved ${ }^{133-135}$ especially in patients with an impaired pudendal nerve function and incontinence for solid stools only. ${ }^{136}$ It has been demonstrated that the neuromuscular damage progresses after surgery which may be responsible for this phenomenon. When an anterior levatorplasty and an internal sphincter plication are added, the total pelvic floor repair, results are improved and complete continence is achieved in two thirds of the patients. ${ }^{137}$

When none of the treatment modalities mentioned above are successful a permanent colostomy is created. Besides the colostomy, another possibility remains: the crearion of a new anal sphincter using an artificial sphincrer or autologous tissue.

The implantation of an artificial sphincter was first developed for the permanent colostomy. Due to a high complication rate and malfunction, the effect was unsarisfactory. ${ }^{138,139}$ When good results were achieved with an artificial urinary sphincter the same model was used in fecal incontinence with equally good results. ${ }^{140.141}$ Unfortunately only limited numbers of patients were treated with a short follow up. 


\section{Musculoplasty}

The use of autologous material, smooth muscle or skeletal muscle is preferable however and can eventually be combined with electrical stimulation.

\section{Smooth muscle}

The creation of a new anal sphincter with the use of a free smooth muscle collar is an attractive idea. In contrast to skeletal muscle, smooth muscle is able to maintain a continuous state of contraction for long periods of time. About $10 \mathrm{~cm}$. of free, denervated and pre-stretched large bowel are folded around the colon-stump as a cuff. Good results were reported ${ }^{142-144}$, although it is difficult to understand that continence would completely rely upon internal sphincter function. Furthermore, due to deprivation of circulation this cuff tends to scar. ${ }^{145}$

\section{Free autogenous muscle transplantation}

Free autogenous muscle transplantation with denervated and de-vascularized muscle showed good results in experimental studies. ${ }^{146}$ There appeared to be revascularisation and reinnervation from the surrounding muscles, although this could not be confirmed in another experimental study. ${ }^{147}$ In clinical studies the palmaris longus muscle was used as a new puborectal sling and, with small numbers, the long-term results ranged from poor ${ }^{145}$ to excellent. ${ }^{148-150}$ The difficulty was the tightness of the sling, not too tight in order to prevent necrosis and not too loose in order to stimulate reinnervation.

Most widely used for the creation of a new anal sphincter are transposed skeletal muscles. Precondition is that this muscle should not be essential for locomotion and/or posture. Furthermore, site, muscle mass and the position of the neuro-vascular bundle should allow easy mobilization and transposition in order to preserve a healthy and functional muscle. Muscles that may be suitable for sphinteroplasty are the sartorius, the gracilis and the gluteus maximus muscles.

\section{Sartorius muscle}

In animal experiments the sartorius muscle proved to be excellent when used to create a new sphincter. ${ }^{151}$ In humans, due to its segmental vascularisation which restricts the arch of rotation if the muscle is transposed, the sartorius muscle appears to be less well suited. ${ }^{152}$

\section{Gluteus maximus}

The gluteus maximus arises from the outer surface of the os ileum, the sacrum, the coccyx and the sacrotuberous ligament and inserts to the ileotibeal tract and the gluteal tuberosity of the femur ${ }^{153}$. Motor innervation occurs via the inferior gluteal nerve (L5, 
Table i. Non-stimulated Gluteoplasty.

\begin{tabular}{|c|c|c|c|c|c|c|c|c|}
\hline \multirow[t]{2}{*}{ Aurhors } & \multirow[t]{2}{*}{ Year } & \multirow[t]{2}{*}{$\mathrm{n}$} & \multirow{2}{*}{$\begin{array}{l}\text { Follow-up } \\
\text { (ycars) }\end{array}$} & \multicolumn{5}{|c|}{ Succes* } \\
\hline & & & & I & II & III & IV & V \\
\hline Bruining ${ }^{157}$ & 1981 & 1 & 0.5 & 1 & & & & \\
\hline Prochiantz 158 & 1982 & 13 & $?$ & 2 & 2 & 3 & 1 & 5 \\
\hline Hentz 159 & 1982 & 2 & $0.5-0.8$ & 1 & & 1 & & \\
\hline Pearl 161 & 1991 & 7 & ? & 1 & 1 & 4 & & 1 \\
\hline Devesa 160 & 1992 & 10 & $0.5-5$ & 1 & 2 & 2 & 4 & 1 \\
\hline Christiansen 164 & 1995 & 7 & $1-2.3$ & & & 3 & & 4 \\
\hline
\end{tabular}

* Continence was classified from I to V according to a standardized scoring ${ }^{163}$ Score I means continence to solids, liquids and flatus, score II: continence to solids and liquids but not to flatus, score III: continence to solids but occasional episodes of liquid incontinence, score IV: occasional episodes of incontinence of solids and score V: frequent episodes of incontinence of solids and liquids.

S1-2), therefore, incontinence due to spina bifida or myelomeningocele cannot be treared by glureoplasty. Vascularisation is from both the superior and inferior gluteal artery, both dominant pedicles. ${ }^{152}$ The gluteus muscle is not important for posture or ordinary walking, but running, walking stairs and rising from a seated position depend upon its activity. ${ }^{153}$ The choice for the gluteus maximus to recreate an anal sphincter is a logical one because it is a powerful muscle that often is used as an accessory muscle to continence. The use of the gluteus muscle was first reported by Chetwood ${ }^{154}$ in 1902 and further developed by Schoemaker ${ }^{155}$ and Bistrom. ${ }^{156}$ After the Second World War this technique was abandoned until it was re-explored in the 1980's s $^{15-159}$ and underwent several modifications since. ${ }^{160,161}$ Using the inferior fibers of bilateral gluteus maximus muscles, the distal part of each muscle is split and wrapped around the anal canal. Devesa reported improved results if only one musle was split, wrapped and fixed to the orher mobilized muscle. ${ }^{160}$ In a canine model even better results were demonstrated using a single gluteus muscle. ${ }^{162}$ Results of the treatment are shown in table 1 , data were converted to one standardized scoring system. ${ }^{163}$

Compared to the graciloplasty the gluteoplasty is technically a more complicated procedure, especially due to difficult identification of the nerve. Because active contraction of the gluteoplasty is more logical and forceful this seems the procedure of choice if no electrical stimulation is planned, although this could not be confirmed in all clinical studies. ${ }^{164}$ When electrically scimulated the (dynamic) gluteoplasty demands a higher amplitude while producing a poorer contraction compared to the dynamic graciloplasty (personal communication Devesa). Contrary to the gracilis muscle the gluteus maximus muscle is an important muscle in daily use, therefore, if muscle function is impaired or painful this may pose problems to the patient. 


\section{Gracilis muscle}

The gracilis muscle is the most superficial adductor on the medial side of the thigh. It arises from the outer surface of the inferior ramus of the pubis and ischium and its insertion is in the pes anserinus at the upper part of the medial shaft of the tibia ${ }^{153}$. Innervation is from the anterior division of the obturator nerve (L2-L4) which enters the muscle at the postero-lateral side as a main trunk and three branches. ${ }^{165}$ The main (and proximal) vascular pedicle arises from the profunda femoris and the minor (and more distal) pedicles come from the superficial femoral artery and the obturator artery. Intramuscular anastomoses between the proximal and distal pedicles have been demonstrated by radiocontrast injection. ${ }^{166}$ The gracilis muscle is one of the adductors of the thigh and a flexor of the hip (if the knee is extended) but it has no important function in humans.

The possibility to use the gracilis muscle for sphinteroplasty was first explored in 1952 by Pickrell* 167 in the treatment of children with fecal incontinence due to a neurogenic cause (spina bifida, meningocele). ${ }^{168,169}$ Stimulated by the results of Stone ${ }^{170,171}$, using fascia strips attached to the glutei, he introduced the anal (and later the urinary) ${ }^{172}$ graciloplasty. Because of its superficial position and the proximal neurovascular supply, the muscle is easy accessible and can be dissected free distally without damage to the muscle. Since 1952, this technique has been applied on a wide scale with mixed results ${ }^{145,173-180}$ (Table 2). Although active contraction of the muscle is forceful enough to hold up stool, long-standing adduction of the leg is an uncomfortable procedure making it impossible to reach the toilet. After a while patients may be able to have a voluntary, isolared, contraction of the gracilis muscle (instead of the whole adductor group), all day continence is seldom achieved. This is also due to the fact that the gracilis, like all skeleral muscles, has a majority of rype II, fast twitch, non fatigue resistant muscle fibers. These fibers are unable to execute a sustained contraction. In the conventional graciloplasty it was therefore necessary to make a tight loop to achieve continence. The graciloplasty then resembled an autologous, elastic, Thiersch wire instead of a real neo-sphincter. The hypothesis that the gracilis muscle would only contract if the rectum filled with feces, possibly induced by a conditional or proprio-

\footnotetext{
* Kenneth Leroy Pickrell (1910-1984) Pickrell was born in Old Forge, Pennsylvania, as the son of a coal miner. When he was 14 years old he attended Barber School and was apprenticed as a barber. He would support his family and himself throughout college and medical school by working off hours as a barber. He graduated from Johns Hopkins medical school in 1935 and became surgical house officer in the same hospital. He served as chief resident in neurosurgery, general surgery, and plastic surgery. He was offered a senior staff position at Duke University, Durham, North Carolina. Later he was appointed professor of Surgery and chief of Plastic Surgery and would fulfill this position for the next 31 years. He wrote over 175 publications covering many aspects of surgery in general. His use of the innervated gracilis muscle for rectal incontinence was an early major contribution to plastic surgery involvement in muscle transposition.
} 
Table 2. Non-stimulated Graciloplasty

\begin{tabular}{|c|c|c|c|c|c|c|c|c|}
\hline \multirow[t]{2}{*}{ Authors } & \multirow[t]{2}{*}{ Year } & \multirow[t]{2}{*}{$\mathrm{n}$} & \multirow{2}{*}{$\begin{array}{l}\text { Follow-up } \\
\text { (years) }\end{array}$} & \multicolumn{5}{|c|}{ Succes* } \\
\hline & & & & 1 & II & III & IV & V \\
\hline Pickrell 169 & 1952 (Ped) & 4 & $0.5-7$ & 4 & & & & \\
\hline Raffensperger 173 & 1979 (Ped) & 7 & $1-15$ & 3 & & & 3 & 1 \\
\hline Corman i74 & 1980 & 13 & $0.3-4$ & 5 & 4 & 3 & & 1 \\
\hline Holschneider ${ }^{145}$ & 1981 (Ped) & 41 & $1-11$ & 5 & 15 & 13 & & 8 \\
\hline Leguit 175 & 1985 & 10 & $0.5-17$ & 2 & 5 & 2 & & 1 \\
\hline Yoshioka 176 & 1988 & 6 & $1-1.5$ & & & & & 0 \\
\hline Christiansen 177 & 1990 & 13 & $0.3-3$ & & 6 & & 4 & 2 \\
\hline Sonnino 178 & 1991 & 7 & $0.5-12.5$ & 4 & & 3 & & \\
\hline Faucheron 179 & 1994 & 22 & $0.5-11$ & 1 & 11 & & 2 & 8 \\
\hline Kumar 180 & 1995 & 10 & $0.5-3.3$ & & 9 & 1 & & \\
\hline
\end{tabular}

* Continence was classified from I to $\mathrm{V}$ according to a standardized scoring; (Ped) = pediatric patients

ceptive reflex, has never been proven. The muscle keeps the anal orifice closed continuously and is stretched open by actual suaining during defecation. ${ }^{175}$ Because of this mechanical outlet barrier, defecation regularly has to be achieved with the help of enemas.

If the loop around the anal canal would be performed less tight and closure of the anal canal would only depend upon active, sustained, contraction a new dynamic sphincter would have been created. Sustained voluntary contractions of such a new dynamic sphincter is however impossible.

\section{Dynamic graciloplasty}

A normal external anal sphincter shows a predominance ( 80 percent) of type I, fatigue resistant, muscle fibers. ${ }^{181}$ The gracilis muscle only has 43 percent of type I muscle fibers ${ }^{181}$ which explains why this muscle cannot perform a sustained contraction. In 1960 it was found that when a nerve of a type I, slow twitch, fatigue resistant muscle was connected to a type II, fast twitch, farigue prone muscle these muscle fibers would transform likewise and vice versa. ${ }^{18}$ ? It is the motor neuron that determines the physiological, histochemical and biochemical characteristics of the innervated fibers. Later, electrical stimulation of the nerve proved to have the same effect upon the muscle. ${ }^{183}$ Chronic low-frequency stimulation induces a transformation from fast to slow muscle fibers and chronic high-frequency stimulation from slow to fast muscle fiber. ${ }^{184}$

For the treatment of fecal incontinence and rectal prolaps in children and adults Caldwell reported in 1965 the clectrical stimulation of the external sphincter with an 
implantable receiver and an external power supply. ${ }^{118,185}$ Reasonable to good results were scored but problems with the equipment resulted in a failure of the technique. The first electrical stimulation of a transposed gracilis muscle with such a receiver was reported by the pediatric surgeons Dickson and Nixon in 1968 and their goal was to achieve a sustained contraction when stool arrived. ${ }^{186}$ Unfortunately, only preliminary data were published. A new avenue in the development of the dynamic graciloplasty was the development of the cardiomyoplasty, electrically stimulated muscle for cardiac assistance $^{187}$ and its clinical application. ${ }^{188}$ In cardiomyoplasty or aortomyoplasty the latissimus dorsi muscle is wrapped around the hearr ${ }^{189}$, the ascending ${ }^{190}$ or descending aorta $^{191}$ in order to improve the heart-pump in patients with end stage cardiomyopathy. In 1986 Baeten implanted the first neurostimulator in an anal atresia patient who had been treared with a conventional graciloplasty 10 years before. ${ }^{192}$ She had a good acrive contraction of the gracilis muscle but was still incontinent. The idea was to induce a change from fast-twitch, fatiguable (type II) muscle fibers in to slow-twitch, fatigue-resistant (type I) muscle fibers. Active contraction was changed into stimulation induced contraction. Independently the technique was developed by Williams. ${ }^{151,163}$

Both methods depend on stimulation of the obturator nerve, Williams fixes the electrode directly on the nerve whereas Baeten fixes the electrode intramuscularly close to the nerve branches inside the muscle. ${ }^{193-196}$ The advantage of direct nerve stimulation is the total recruitment of all motor units with the lowest possible energy demand, resulting in a maximum contraction and a prolonged battery-life. However, it is questionable whether maximum contraction is necessary or desirable. For closure of the anal canal less force is sufficient, and a prolonged tetanic contraction of the whole muscle may threaten muscle and colon integrity by inducing ischaemia. Dissection and direct stimulation of the obrurator nerve may cause irreversible damage to the nerve resulting in failure of treatment. Electrode displacement is another potential disadvantage, necessitating re-intervention. ${ }^{193}$ Intramuscular fixation of the electrodes is an easy procedure, it increases electrode stability, avoids damage to the nerve and can be performed years after the muscle transposition. Due to precise in tramuscular placement, contraction of a great part of the muscle is obtained and most often stimulation thresholds for good contraction are below 1 Volt. From the data published by Williams ${ }^{163}$ and Baeten ${ }^{197}$ the calculated efficiency does hardly differ, $11.75 \mathrm{mmHg} / \mathrm{mA}$ versus $11.93 \mathrm{mmHg} / \mathrm{mA}$.

Magnetic resonance imaging showed a decrease in muscle diameter of 33 percent during the first 6 weeks after transposition and before electrical stimulation was started. No correlation existed between degree of reduction in size and the functional outcome. ${ }^{198}$ Despite a certain degree of atrophy, enough force can be produced to close the anal canal. A period of 6 weeks was chosen to allow the muscle to recover and to allow the distal tendon to fix to the bone. Still, if earlier stimulation can prevent atrophy without being harmful to the muscle this could be performed. 
Indications for a dynamic graciloplasty are: an external anal sphincter that is damaged beyond repair, a sphincter with severe neurogenic damage and patients with a congenital disease like anal atresia or spina bifida. In general dynamic graciloplasty will be performed in patients in whom all previous treatment to restore sphincter function failed. Contra-indications are: inflammatory bowel disease, not motivated / physically or mentally incapable patients. The presence of a cardiac pacemaker is not a contra-indication. Because the gracilis pulse generator can interfere with the sensing functions of the cardiac pacemaker, especially with unipolar stimulation, careful evaluation needs to be performed. ${ }^{199}$ The average patient accepted for dynamic graciloplasty has a grade $\mathrm{V}$ incontinence, is incontinent for many years, has had maximal conservative treatment, biofeedbacktraining and one or more previous operations for restoration of continence. ${ }^{196}$

The method of the dynamic graciloplasty

\section{Transposition of the gracilis muscle}

Systemic antibiotics (metronidazole, gentamycin and flucloxacillin) are administered for 24 hours. In male parients a urinary catheter is introduced. The graciloplasty is performed according to Pickrell ${ }^{168}$ with several slight modifications. Instead of three small incisions, on a large incision is made at the upper thigh (figure 2). The gracilis muscle is identified, the peripheral arteries are ligated and the muscle is mobilized towards its insertion at the medial shaft of the tibia. A small incision is made under the knce and the distal tendon is cur. The gracilis muscle is then further mobilized up to the neurovascular bundle. During the perineal part of the operation two incisions are made lateral to the anus on either side. Three tunnels are made: posterior from the anal canal over the rima ani as high as the os coccygis, anterior from the anal canal in the retrovaginal wall (female) or behind the urethra (man), and the third tunnel from the perineum to the incision in the leg, passing the strong Scarpa's fascia. This last tunnel should be wide enough to easily accommodare the muscle in order to prevent entrapment, which would endanger muscular bloodflow. Than the muscle is wrapped around the anal canal. The configuration that can be performed is determined by the anatomical situation. Most often the gamma loop is used, making the first turn on the frontal side, a second turn on the dorsal side and a third turn on the frontal side again (figure 2). When there is a large muscle mass or much scar tissue in the recto-vaginal septum the first turn will be on the dorsal side (epsilon loop). When the muscle is not long enough to make one and a half turn the tendon is fixed on the ipsilateral side (alpha loop). In order to make a perfect circular loop the modified alpha or split-sling loop was developed. ${ }^{200}$ Therefore a hole is made in the mid part of the muscle and the distal part is pulled through. Uncertain is whether vascularity and / or innervation are endangered by this action. The chuice which configuration is applied is of course also a matter of 


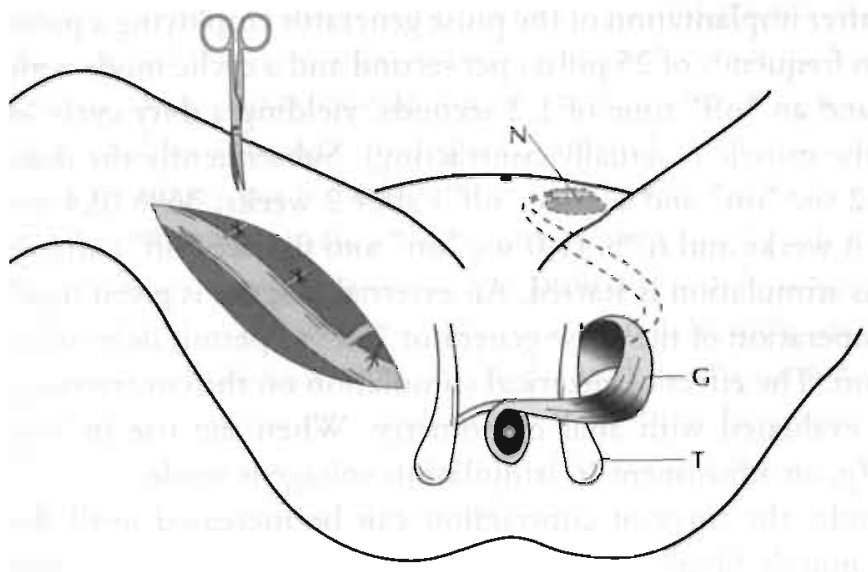

Figure 2. On the right side of the patient mobilisation of the gracilis muscle, by ligation of the minor vascular pedicles, is shown. Proximally the major vascular pedicle and the obturator nerve with its branches are located. On the left side of the patient the dynamic graciloplasty configuration is shown after transposition of the muscle and implantation of the stimulation devices. $\mathrm{N}=$ neurostimulator, $\mathrm{G}=$ gracilis nnuscle and $\mathrm{T}=$ ischial spine.

preference and experience of the surgeon. The distal tendon is sutured to the medial side of the ischial spine. Another possibility is fixation to the skin. ${ }^{195}$ No protective colostomy is created. Patients are encouraged to walk the next day and to wear an elastic stocking for several weeks.

\section{Implantation of the Stimulation Equipment}

Ar least 6 weeks after the rransposirion, the pacemaker and the leads are implanted (figure 2). All patients have systemic antibiotic prophylaxis as mentioned above for 24 hours. At the site of implantation the skin is covered with a iodine foil. An incision is made in the medial upper thigh on the site of lowest threshold (located under transcutaneous stimulation before the operation) and an intramuscular flexible coil wire of platinum iridium is introduced as an anode (model 4300 , Medtronic, Kerkrade, The Netherlands) about $4 \mathrm{~cm}$. distal to the obturator nerve (towards the anus). With the introductionneedle of a similar electrode the optimal position for the cathode is determined under electrical stimulation (as close as possible to the intramuscular branches of the nerve). Than the electrode is pulled crosswise through the muscle, perpendicular to the muscle fibers, and fixed to the epimysium. The length of the bare surface of the electrode can be adjusted to the diameter of the muscle. Subsequently, the leads are subcutaneously tunneled to a pocket in the lower abdominal wall and connected to an Itrel TM pulse generator (model 7424, Medtronic, Kerkrade, The Netherlands). All implanted devices are soaked in a gentamycin solution and local antibiotics are administered (Sulmycin Implant Fssex Pharma, Munich, Germany). 


\section{Training}

Stimulation is started 3 days after implantation of the pulse generator employing a pulse width of $210 \mu \mathrm{s}$, a stimulation frequency of 25 pulses per second and a cyclic mode with an "on" time of 0.1 second and an "off" time of 1.2 seconds, yielding a duty cycle of $8 \%$ (the time during which the muscle is actually contracting). Subsequently the dury cycle is increased to $14 \%$ ( $0.2 \mathrm{sec}$ "on" and $1.2 \mathrm{sec}$ "off") after 2 weeks, $36 \%(0.4 \mathrm{sec}$ "on" and $0.7 \mathrm{sec}$ "off") after 4 weeks and $67 \%$ (1.0 sec "on" and $0.5 \mathrm{sec}$ "off") after 6 weeks. At 8 weeks continuous stimulation is started. An external magnet is given to all patients to turn the mode of operation of the pulse generator "off" to permit defecation and "on" again after defecation. The effect of electrical stimulation on the contractions of the transposed muscle is evaluated with anal manometry. When the rise in anal pressure is less than $20 \mathrm{mmHg}$, an adjustment in stimulation voltage is made.

By increasing the amplitude, the force of contraction can be increased until the maximum shortening of the muscle fibers is reached. A furcher increase in amplitude therefore is useless. During the training often the amplitude has to be increased to maintain the same level of contraction. This is due to transformation of the muscle fibers from fast-twitch to slow-twitch fibers. Another reason is the formation of fibrosis around the electrodes, which is a normal tissue reaction to implanted material. After 26 weeks the amplitude is fairly stable, and stays below an average of 3.0 volts. 196

Ac the end of the 8 weeks of training, when there is a majority of type I, fatigue resistant, muscle fibers, a fused contraction can be achieved with a decreased stimulation frequency of 15 pulses per second.

\section{Double dynamic graciloplasty after an abdominoperineal resection}

After an abdominoperineal resection for low rectal cancer, normally a permanent colostomy is created. The presence of the stoma inevitably distorts the patients' body image $^{201}$ and can have a considerable effect on the quality of life. ${ }^{202,203}$ Furthermore, it is to be expected that one out of three patients will have moderate to severe complications with their stoma and 10 percent will need to be re-operated. ${ }^{204.205}$

Total anorectal reconstruction consists of a safe resection of the tumor 206,207 , a pull-through of the colon stump to the perineum and the creation of a new pelvic floor and anal sphincter ${ }^{208}$ Patients are candidate for a total anorectal reconstruction when the tumor is well resectable, their general health is good and regional spread or distant metastases are excluded.

Application of a smooth muscle neosphincter after APR was reported by Elias ${ }^{209}$ and Fedorov 210 but results were disappointing. In 1930 already, Chirtenden ${ }^{211}$ used the glutei muscles to construct a new anal sphincter by transposing one gluteus muscle behind and the other in front of the neorectum. Simonsen was the first to use the gracilis muscle and the neorectum was brought through an incision that was made in the 
muscle. ${ }^{212}$ Because not only the anal sphincter was removed but part of the pelvic floor as well, Cavina ${ }^{213}$ started in 1985 to use a second gracilis muscle to replace the puborectal sling (figure 3). The right muscle was passed behind the pulled-through colon and sutured to the controlateral side to recreate the anorectal angle. The left muscle was, superficial to the right, transposed around the neorectum and sutured to the skin. Postoperatively temporary electric stimulation was given with an external stimulator in order to prevent muscle atrophy and to improve muscle function. Mercati transposed both gracilis muscles around the pulled-through colon for re-creation of the anal sphincter. ${ }^{214}$ Williams only used one gracilis muscle and he started with continuous electrical stimulation with an implanted neurostimulator. ${ }^{215}$ Rosen used a single, electrically stimulated, graciloplasty as well but he remodulated the wrap into a splitsling configuration. ${ }^{200} \mathrm{~A}$ longitudinal incision is made in the muscle and the distal part is pulled through. The functional results achieved by the different authors are depicted in table 3 .

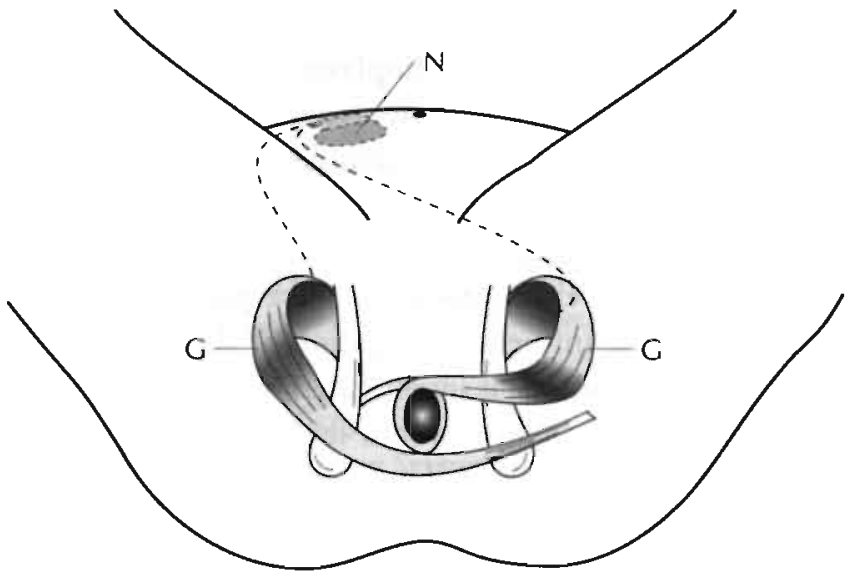

Figure 3. Double dynamic graciloplasty according to Cavina 213 . Depicted are the neurostimularor $(=\mathrm{N})$, the gracilis muscle $(=G)$ and the electrodes (dotted lines).

Outline of this thesis

The first results of dynamic graciloplasty for the treatment of patients suffering from intractable fecal incontinence were very promising. Longer follow-up in a larger group of patients is necessary to be able to assess the permanence of improvement and to evaluate the morbidity that accompanies this new technique. Is failure of rreatment the result of the technique used or do patients with a cerrain pathogeneses bencfit less than others? If pathogenesis determines final outcome, what are the causes of failure and can protective measure be taken? Can the gracilis muscle be safely used to construct a ncw anal sphincter after abdominoperineal resection for low rectal cancer? The goal of our 
Table 3. Graciloplasty after Miles resection.

\begin{tabular}{|c|c|c|c|c|c|c|c|c|}
\hline \multirow[t]{2}{*}{ Authors } & \multirow[t]{2}{*}{ Year } & \multirow[t]{2}{*}{$\mathrm{n}$} & \multirow{2}{*}{$\begin{array}{l}\text { Follow-up } \\
\text { (years) }\end{array}$} & \multicolumn{5}{|c|}{ Succes* } \\
\hline & & & & I & II & III & IV & V \\
\hline Simonsen 212 & 1976 & 22 & $0.1-9$ & & & 17 & 2 & 3 \\
\hline Wong 217 & $1984 \mathrm{r}$ & 1 & 0.5 & & 1 & & & \\
\hline Williams 215 & 1990 & 1 & 0.3 & & 1 & & & \\
\hline Mercati 214 & 1991 & 7 & & & & 7 & & \\
\hline Santoro 216 & 1994 & 11 & $0.2-2.5$ & & & 8 & 2 & 1 \\
\hline Seccia ${ }^{195}$ & 1994 & 52 & $0.1-10$ & & 40 & 11 & & 1 \\
\hline Rosen 200 & 1994 & 3 & $?$ & & 1 & 2 & & \\
\hline
\end{tabular}

* Continence was classified from I to V according to a standardized scoring

program is to further improve the outcome. The aim of this thesis is to investigate causes of failure and success and to formulate proposals for further improvement of the results. In a prospective, longitudinal, clinical study it is assessed whether patients can be given well-functioning neosphincters using the dynamic graciloplasty, and how this therapy affects their quality of life (chapter 2). In a second prospective, longitudinal, clinical study the results of total anorectal reconstruction with a double dynamic graciloplasty after abdominoperineal reconstruction (APR) for low rectal cancer (chapter 3.1) or after severe perineal trauma (chapter 3.2) are evaluated.

All complications that occurred over an cight-year period are presented and their management is discussed (Chapter 4). The influence of ligation of the minor vascular pedicles on blood flow in the distal gracilis muscle is investigated by visualization of the arterial anatomy within the muscle and by quantification, using laser Doppler flowmetry, of the potential acute ischaemia (Chapter 5.1). The protective effects of vascular delay and stimulation delay on function and histochemistry of the transposed and stimulated muscles are characterized in an experimental rabbit study (Chapter 5.2). Fecal incontinence can have a profound effect on the life of a child and the child's family. Views on pathogenesis, diagnosis and treatment of pediatric fecal incontinence are discussed (Chapter 6.1) To evaluate the possibility of the application of the dynamic graciloplasty in growing individuals the physiological and immunohistochemical properties of transposed and electrically stimulated skeletal muscle are assessed in an experimental study in puppies (Chapter 6.2). The results of simultaneous treatment of fecal and urinary incontinence in two children with spina bifida using a double dynamic graciloplasty are discussed (Chapter 6.3). Finally in chapter 7 a comprehensive discussion of the collective data is given and proposals for further improvement of results in the treatment of patients with intractable fecal incontinence are made. 


\section{References}

1. Thomas TM, Egan M, Walgrove A, Meade TW. The prevalence of faecal and double incontinence. Community Med 1984;6:216-20.

2. Mandelstam DA. Henry MM, Swash M, editors. Coloproctology and the pelvic floor: parhofysiology and management. London: Butterworths; 1985; Faecal Incontinence. p. 217-21.

3. Nelson R, Norton N, Cautley E. Prevalence of fecal incontinence in Wisconsin households. Dis Colon Rectum 1994;37:Suppl:P9

4. Leigh RJ, Turnberg LA. Faecal incontinence: the unvoiced symptom. Lancet 1982;1:1349-51 .

5. Resnick NM, Beckett LA, Branch LG, Scherr PA, Werle T. Short-term variability of self report of incontinence in older persons. J Am Geriatr Soc 1994;42:202-7.

6. Borrie MJ, Davidson HA. Incontinence in institutions: cost and contributory factors. Can Med Assoc J 1992;147:322-8.

7. Sangwan YP, Coller JA. Fecal incontinence. Surg Clin North Am 1994;74:1377-98.

8. Ouslander JG, Schnelle JF. Incontinence in the nursing home. Ann Intern Med 1995;122:438-49.

9. Madoff RD, Williams JG, Caushaj PF. Fecal incontinence. N Engl J Med 1992;326:1002-7.

10. Gray H. Gray H, editors.Anatomy Descriptive and Surgical. London: Parker and Son; 1858;

11. Wood BA, Kelly AJ. Henry MM, Swash M, edirors.Coloproctology and the pelvic floor. 2 th ed. Oxford: Butterworth-Heinemann Ltd; 1992; 1, Anatomy of the anal sphincters and pelvic floor. p. 3-19.

12. Sorensen M, Rasmussen OO, Tetzschner T, Christiansen J. Physiological variation in rectal compliance. $\mathrm{Br}$ J Surg 1992;79:1 106-8.

13. Madoff RD, Orrom WJ, Rorhenberger DA, Goldberg SM. Rectal compliance: a critical reappraisal. Int J Colorectal Dis 1990;5:37-40.

14. Rasmussen $\mathrm{O}$, Christensen $\mathrm{B}$, Sorensen M, Tetzschner $T$, Christiansen J. Rectal compliance in the assessment of patients with fecal incontinence. Dis Colon Rectum 1990;33:650-3.

15. Rao SSC, Read NW, Davison PA, Bannister JJ, Holdsworth CD. Anorectal sensitivity and responses to rectal distension in patients with ulcerative colitis. Gastroenterology 1987;93:1270-5.

16. Varma JS, Smith AN, Busuril A. Correlation of clinical and manometrical abnormalities of rectal function following chronic radiation injury. Br J Surg 1985;72:875-8.

17. Goligher JC, Hughes ESR. Sensibility of the rectum and the colon. Lancet 1951:543-7.

18. Akervall S, Fasth S, Nordgren S, Oresland T, Hulten L. Rectal reservoir and sensory function studied by graded isobaric distension in normal man. Gut 1989;30:496-502.

19. Durhie HL. Dynamies of the rectum and anus. Clin Gastroenterol 1975;4:467-77.

20. Nivarvongs S, Stern HS, Fryd DS. The length of the anal canal. Dis Colon Rectum 1981;24:600-1.

21. Milligan ETC, Morgan CN. Surgical anatomy of the anal canal. Lancet 1934;1150-6.

22. Onufrowicz. B. Notes on the arrangement and function of the cell groups in the sacral region of the spinal cord. J Nerv Mental Dis 1899;26:498-504.

23. Walls EW. Observations on the microscopic anatomy of the human anal canal. $\mathrm{Br} J$ Surg 1958;45:504-12.

24. Duthie HL, Gairns FW. Sensory nerve-endings and sensation in the anal region of man. Br J Surg 1960;47(206):585-95.

25. Papachrysostomou M, Pye SD, Wild SR, Smith AN. Significance of the thickness of the anal sphincters with age and its relevance in faecal incontinence. Scand J Gastroenterol 1994;29:710-4.

26. Bennett RC, Duthie HL. The functional importance of the internal sphincter. Br J Surg 1964;51(5):355-7.

27. Frenckner $B$, Thre $T$. Influence of autonomic nerves on the internal and sphincter in man. Gut 1976;17:306-12.

28. Meunier P, Mollard P. Control of the internal anal sphincter (manometric study with human subjects). Pflugers Arch 1977;370:233-9. 
29. Lubowski DZ, Nicholls RJ, Swash M, Jordan MJ. Neural control of internal anal sphincter function. Br J Surg 1987;74:668-70.

30. Speakman CT, Hoyle CH, Kamm MA, Henry MM, Nicholls RJ, Burnstock G. Neuropeptides in the internal anal sphincter in neurogenic faecal incontinence. Int J Colorectal Dis 1993;8:201-5.

31. Farouk R, Duthie GS, MacGregor AB, Bartolo DC. Evidence of electromechanical dissociation of the internal anal sphincter in idioparhic fecal incontinence. Dis Colon Rectum 1994;37:595-601.

32. Lubowski DZ, Nicholls RJ, Burleigh DE, Swash M. Internal anal sphincter in neurogenic fecal incontinence. Gastroenterology 1988;95:997-1002.

33. Speakman CT, Hoyle CH, Kamm MM, Henry MM, Nicholls RJ, Burnstock G. Abnormalities of innervation of internal anal sphincter in fecal incontinence. Dig Dis Sci 1993;38:1961-9.

34. Oh C, Kark AE. Anatomy of the external anal sphincter. Br J Surg 1972;59:717-23.

35. Laurberg $S$, Swash M. Effects of aging on the anorectal sphincters and their innervation. Dis Colon Rectum 1989;32:737-42.

36. Gagnard C, Godlewski G, Prat D, Lan O, Cousineau J, MakloufY. The nerve branches to the external anal sphincter: the macroscopic supply and microscopic structure. Surg Radiol Anat 1986;8:115-9.

37. Parks AG, Porter NH, Melzack J. Experimental study of the reflex mechanisin controlling the muscles of the pelvic floor. Dis Colon Rectum 1962;5:407-14.

38. Dubrovsky B. Effects of rectal distension on the sphincter ani externus and levator ani muscles in cats. Am J Physiol 1988;G100:254

39. Read NW, Haynes WG, Bartolo DC, Hall J, Read MG, Donnelly TC, Johnson AG. Use of anorectal manometry during rectal infusion of saline to investigate sphincter function in incontinent patients. Gastroenterology 1983;85:105-13.

40. Lawson JO. Pelvic Anatomy. I. Pelvic floor muscles. Ann R Coll Surg Engl 1974; 54:244-52.

41. Wall L.L. The muscles of the pelvic floor. Clin Obster Gynecol 1993;36:910-25.

42. Levi AC, Borghi F, Garavoglia M. Development of the anal canal muscles. Dis Colon Rectum 1991;34:262-6.

43. Matzel KE, Schmidt RA, Tanagho EA. Neuroanatomy of the striated muscular anal continence mechanism. Implications for the use of neurostimulation. Dis Colon Rectum 1990;33:666-73.

44. Bartolo DC, Roe AM, Locke Edmunds JC, Virjee J, Mortensen NJ. Flap-valve theory of anorectal continence. Br J Surg 1986;73:1012-4.

45. Hajivassiliou CA, Carter KB, Finlay IG. Anorectal angle enhances faecal continence. Brit J Surg 1996;83:53-6.

46. Lunniss PJ, Phillips RK. Anatomy and function of the anal longitudinal muscle [see comments]. $\mathrm{Br}$ J Surg 1992;79:882-4.

47. Ratran $S_{2}$ Sarkar $A$, Chakder $S$. Nitric oxide parthay in rectoanal inhibitory reflex of opossum internal anal sphincter. Gastroenterology 1992;103:43-50.

48. Miller R, Lewis GT, Bartolo DC, Cervero F, Mortensen NJ. Sensory discrimination and dynamic activity in the anorectum: evidence using a new ambulatory technique. Br J Surg 1988;75:1003-7.

49. Bannister JJ, Read NW, Donnelly TC, Sun WM. External and internal anal sphincter responses to rectal distension in normal subjects and in patients with idiopathic faecal incontinence. $\mathrm{B}_{\mathrm{r}} \mathrm{J}$ Surg 1989;76:617-21.

50. Sangwan YP, Coller JA, Schoetz DJ, Jr., Roberts PL, Murray JJ. Spectrum of abnormal rectoanal reflex patterns in patients with fecal incontinence. Dis Colon Recturn 1996:39:59-65.

51. Sun WM, Read NW, Miner PB. Relation between rectal sensation and anal function in normal subjects and patients with faecal incontinence. Gut 1990;31:1056-61.

52. Duthie HL, Bennetr RC. The relation of sensation in the anal canal to the functional anal sphincrer: a possible factor in anal continence. Gut 1963:4:179-82.

53. Miller R, Bartolo DC, Cervero F, Mortensen NJ. Anorectal temperature sensation: a comparison of normal and incontinent patients. Br J Surg 1987;74:511-5. 
54. Rogers J, Hayward MP, Henry MM, Misiewica JJ. Temperature gradient between the rectum and the anal canal: evidence against the role of temperature sensation as a sensory modality in the anal canal of normal subjects [see comments]. Br J Surg 1988;75:1083-5.

55. Wald A. Colonic and anorectal motility testing in clinical practice [see comments]. Am J Gastioenrerol 1994;89:2109-15.

56. Ambroze WL, Pemberton JH, Bell AM, Brown ML, Zinsmeister AR. The effect of stool consistency on rectal and neorectal emptying. Dis Colon Rectum 1991;34:1-7.

57. Scharli AF. Anorectal incontinence: diagnosis and rreatment. J Pediatr Surg 1987;22:693-701.

58. Hill J, Corson RJ, Brandon H, Redford J, Faragher EB, Kiff ES. History and examination in the assessment of patients with idiopathic fecal incontinence. Dis Colon Recrum 1994;37:473-7.

59. Hallan RI, Marzouk DEMM, Waldron DJ, Womack NR, Williams NS. Comparison of digital and manometric assessment of anal sphincter function. Br J Surg 1989;76:973

60. Wexner SD, Jorge JM. Colorectal physiological tests: use or abuse of technology? Eur J Surg 1994; 160:167-74.

61. Meunier PD, Gallavardin D. Anorectal manometry: the state of the art. Dig Dis 1993;11:252-64.

62. Penninckx FM, Lestar B, Kerremans RP. A new balloon-retaining test for evaluation of anorectal funcrion in incontinent patients. Dis Colon Rectum 1989;32:202-5.

63. Williams N, Barlow J, Hobson A, Scott N, Irving M. Manometric asymmetry in the anal canal in controls and patients with fecal incontinence. Dis Colon Rectum 1995;38:1275-80.

64. Enck P, Kuhlbusch R, Lubke H, Frieling T, Erckenbrecht JF. Age and sex and anorectal manometry in incontinence. Dis Colon Rectum 1989;32:1026-30.

65. Loening Baucke V, Pringle KC, Ekwo EE. Anorectal manometry for the exclusion of Hirschsprung's disease in neonates. J Pediatr Gastroenterol Nutr 1985;4:596-603.

66. Arhan P, Faverdin C, Devroede G, Dubois F, Coupris L, Pellerin D. Manometric assessment of continence after surgery for imperforate anus. J Pediatr Surg 1976;11:157-66.

67. Meunier P, Mollard P, Jaubert de Beaujeu M. Manometric studies of anorectal disorders in infancy and childhood: an investigation of the physiopathology of continence and defaecation. $\mathrm{Br} \mathrm{J}$ Surg 1976;63:402-7.

68. Delechenaut P, Leroi AM, Weber J, Touchais JY, Czernichow P, Denis P. Relarionship between clinical symptoms of anal incontinence and the results of anorectal manometry. Dis Colon Rectum 1992;35:847-9.

69. Doolin EJ, Black CT, Donaldson JS, Schwartz D, Raffensperger JG. Rectal manometry, compured tomography, and functional results of anal atresia surgery. J Pediatr Surg 1993;28:195-8.

70. Mahieu P, Pringot J, Bodart P. Defecography: II. Contribution to the diagnosis of defecation disorders. Gastrointest Radiol 1984:9:253-61.

71. Mahieu P, Pringor J, Bodart P. Defecography: 1 . Description of a new procedure and results in normal patients. Gastrointest Radiol 1984;9:247-51.

72. Goei R. Anorectal function in patients with defecation disorders and asymptomatic subjects: evaluation with defecography. Radiology 1990;174:121-3.

73. Law P], Bartram Cl. Anal endosonography: technique and normal anatomy. Gastrointest Radiol 1989;14:349-53.

74. Deen KI, Kumar D, Williams JG, Olliff J, Keighley MR. Anal sphincter defects. Correlation berween endoanal ultrasound and surgery. Ann Surg 1993;218:201-5.

75. Benninga MA, Wijers OB, van der Hoeven CW, Taminiau JA, Klopper PJ, Tytgat GN, Akkermans L.M. Manometry, profilomerry, and endosonography: normal physiology and anatomy of the anal canal in healthy children. J Pediatr Gastroenterol Nutr 1994; 18:68-77.

76. Law PJ, Kamm MA, Bartram Cl. Anal endosonography in the investigarion of faecal incontinence. Br J Surg 1991;78:312-4.

77. Sachs TM, Applebaum H, Touran T. Use of MRI in evaluation of anorectal anomalies. J Pediatr Surg 1990;25:817-21.

78. Pang D. Sacral agenesis and caudal spinal cord malformations. Neurosurgery 1993;32:755-78. 
79. Percy JP, Neill ME, Swash M, Parks AG. Electrophysiological study of motor nerve supply of pelvic floor. Lancet $198 \mathrm{i} ; 1: 16-7$.

80. Neill ME, Swash M. Increased motor unit fibre density in the external anal sphincter muscle in ano-rectal incontinence: a single fibre EMG study. J Neurol Neurosurg Psychiarry 1980;43:343-7.

81. Vernava AM, Longo WE, Daniel G.L. Pudendal neuropathy and the importance of EMG evaluation of fecal incontinence. Dis Colon Rectum 1993;36:23-7.

82. Jost WH, Schimrigk K. Magnetic stimulation of the pudendal nerve. Dis Colon Rectum 1994;37:697-9.

83. Freeman NV, Burge DM, Soar JS, Sedgwick EM. Anal Evoked Potentials. Z Kinderchir 1980;31:2230.

84. Roe AM, Bartolo DC, Mortensen NJ. New method for assessment of anal sensation in various anorectal disorders. Br J Surg 1986;73:310-2.

85. Rogers J, Laurberg S, Misiewicz J, Henry MM, Swash M. Anorectal physiology validated: a repeatability study of the moror and sensory tests of anorectal function. Br J Surg 1989;76:607-9.

86. Papadopoulou A, Clayden GS, Boorh IW. The clinical value of solid marker transit studies in childhood constipation and soiling. Eur J Pediatr 1994;153:560-4.

87. van der Putre SC. Normal and abnormal development of the anorectum. J Pediarr Surg 1986;21:43440 .

88. Lambrecht $\mathrm{W}$, Lierse $\mathrm{W}$. The internal sphincter in anorectal malformations: morphologic investigarions in neonatal pigs. J Pediatr Surg 1987;22:1160-8.

89. deVries PA, Pena A. Posterior sagittal anorectoplasty. J Pediatr Surg 1982;17:638-43.

90. Langemeijer RA, Molenaar JC. Concinence after posterior sagittal anorectoplasty [see comments]. J Pediatr Surg 1991:26:587-90.

91. Rintala RJ, Lindahl $\mathrm{H}$. Is normal bowel funcrion possible after repair of intermediate and high anorecral malformations? J Pediatr Surg 1995;30:491-4.

92. Nagashima M, Iwai N, Yanagihara J, Shimotake T. Motility and sensation of the rectosigmoid and the rectum in parients with anorectal malformations. J Pediatr Surg 1992;27:1273-7.

93. Khubchandani IT, Reed JF. Sequelae of internal sphincteroromy for chronic fissure in ano. $\mathrm{Br}$ J Surg 1989;76:431-4.

94. MacDonald A, Smith A, MoNeill AD, Finlay IG. Manual dilatation of the anus. Br J Surg 1992;79:1381-2.

95. Snooks S, Henry MM, Swash M. Faecal incontinence after anal dilatation. Br J Surg 1984;7 1:617-8.

96. van Tets WF, Kuijpers HC. Conrinence disorders after anal fistulotomy. Dis Colon Rectum 1994:37:1194-7.

97. Sultan $\mathrm{AH}$, Kamm MA, Hudson $\mathrm{CN}$. Thomas JM, Bartan CI. Anal-sphincter disruption during vaginal delivery [see comments]. N Engl ] Med 1993:329:1905-11.

98. Sorensen M, Tereschner T, Rasmussen OO, Bjarnesen J, Chrisriansen J. Sphincter rupture in childbirth. Br J Surg 1993:80:392-4k.

99. Bumen SJ, Spence Jones C, Speakman CT, Kamm MA, Hudson CN, Bartram CI. Unsuspected sphincrer damage following childbirch revealed by anal endosonography. Br J Radiol 1991;64:225-7.

100. Sultan AH, Kamm MA, Bartram CI, Hudson CN. Anal sphincter trauma during instrumental delivery. Int J Gynaecol Obster 1993:43:263-70.

101. Parks AG, Swash M, Urich H. Sphincter denervarion in anorectal inconcinence and recral prolapse. Guĩ 1977;18:656-65.

102. Kiff ES, Swash M. Slowed conduction in the pudendal nerves in idiopathic (neurogenic) faecal incontinence. Br J Surg 1984;71:614-6.

103. Keef KD, Du C, Ward SM, McGregor B, Sanders KM. Enteric inhibitory neural regulation of human colonic circular muscle: role of nitric oxide. Gastroenterology 1993:105:1009-16.

104. Snooks SJ, Swash M, Henry MM, Serchell M. Risk factors in childbirth causing damage to the pelvic floor innervation. Br I Surg 1985;72 Suppl:S15-7. 
105. Hill J, Mumtaz A, Kiff ES. Pudendal neuropathy in parients with idioparhic faecal incontinence progresses with time. Br J Surg 1994;81:1494-5.

106. Haadem K, Dahlstrom JA, Ling L. Anal sphincrer competence in healthy women: clinical implications of age and other factors. Obster Gynecol 1991;78:823-7.

107. Snooks SJ, Swash M, Mathers SE, Henry MM. Effect of vaginal delivery on the pelvic floor: a 5-year. follow-up. Br J Surg 1990;77:1358-60.

108. Womack NR, Morrison JF, Williams NS. The role of pelvic floor denervation in the aeriology of idioparhic faecal incontinence. Br J Surg 1986;73:404-7.

109. Whitehead WE, Parker L, Bosmajian L, Morrill Corbin ED, Middaugh S, Garwood M, Cataldo MF, Freeman J. Treatment of fecal incontinence in children with spina bifida: comparison of biofeedback. and behavior modification. Arch Phys Med Rehabil 1986;67:218-24.

110. Yamada S, lacono RP, Andrade T, Mandybur G, Yamada BS. Pathophysiology of tethered cord syndrome. Neurosurg Clin N Am 1995;6:311-23.

111. Agnarsson U, Warde C, McCarthy G, Clayden GS, Evans N. Anorectal function of children with neurological problems. I: Spina bifida. Dev Med Child Neurol 1993;35:893-902.

112. MacLeod JH. Management of anal incontinence by biofeedback. Gastroenterology 1987;93:291-4.

113. Wald A. Biofeedback for neurogenic fecal incontinence: rectal sensation is a dererminant of outcome. J Pediatr Gastroenterol Nutr 1983;2:302-6.

114. Cerulli MA, Nikoomanesh P, Schuster MM. Progress in biofeedback conditioning for fecal incontinence. Gastroenterology 1979;76:742-6.

115. Wald A, Tunuguntla AK. Anorectal sensorimotor dysfunction in fecal incontinence and diaberes mellitus. Modification with biofeedback therapy. N Engl J Med 1984;310:1282-7.

116. Loening Baucke V. Efficacy of biofeedback training in improving faecal incontinence and anorectal physiologic function. Gut 1990;31:1395-402.

117. Hopkinson BR, Lighrwood R. Electrical treatment of anal incontinence. Lancet 1966;1:297-8.

118. Caldwell KP. The treatment of incontinence by electronic implants. Hunterian Lecture delivered at the Royal College of Surgeons of England on 8th December 1966. Ann R Coll Surg Engl 1967; $41: 447-59$.

119. Pescatori M, Pavesio R, Anastasio G, Daini S. Transanal electrostimulation for fecal incontinence: clinical, psychologic, and manometric prospective study. Dis Colon Rectum 1991;34:540-5.

120. Scheuer M, Kuijpers HC, Bleijenberg G. Effect of electrostimulation on sphincter function in neurogenic fecal continence. Dis Colon Recrum 1994:37:590-3.

121. Fleshman JW, Perers WR, Shemesh EI, Fry RD, Kodner I]. Anal sphincter reconstrucrion: anterior overlapping muscle repair. Dis Colon Rectum 1991;34:739-43.

122. Fleshman JW, Dreznik Z, Fry RD, Kodner IJ. Anal sphincter repair for obstetric injury: manometric evaluation of funcrional results. Dis Colon Recrum 1991;34:1061-7.

123. Engel AF, Kamm MA, Sultan AH, Bartram CI, Nicholls RJ. Anterior anal sphincter repair in patients with obstetric trauma. Br J Surg 1994;81:1231-4.

124. Fang DT, Nivarvongs S, Vermeulen FD, Herman FN, Goldberg SM, Rothenberger DA. Overlapping sphincteroplasty for acquired anal incontinence. Dis Colon Rectum 1984;27:720-2.

125. Laurberg S, Swash M, Henry MM. Delayed external sphincter repair for obstetric tear. Br J Surg $1988 ; 75: 786-8$.

126. Wexner SD, Marchetti F, Jagelman DG. The role of sphincteroplasty for fecal incontinence reevaluated: at prospective physiologic and funcrional review. Dis Colon Rectum 1991;34:22-30.

127. Ctercteko GC, Fazio VW, Jagelman DG, Lavery IC, Weakley FL, Melia M. Anal sphincter repair: a report of 60 cases and review of the literature. Aust N Z J Surg 1988;58:703-10.

128. Miller R, Orrom WJ, Cornes H, Duthie G, Barrolo DC. Anterior sphincter plication and levatorplasty in the treatment of faecal incontinence. $\mathrm{Br}$ J Surg 1989;76:1058-60.

129. Christiansen J, Pedersen IK. Traumatic anal incontinence. Results of surgical repair. Dis Colon Recrum 1987:30:189-91.

130. Parks AG. Anorectal incontinence. Proc R Soc Med 1975;68:681-90. 
131. Womack NR, Morrison JF, Williams NS. Prospective study of the effects of postanal repair in neurogenic faecal incontinence. Br J Surg 1988;75:48-52.

132. Scheuer M, Kuijpers HC, Jacobs PP. Postanal repair restores anatomy rather than function. Dis Colon Rectum 1989;32:960-3.

133. Setti Carraro P, Kamm MA, Nicholls RJ. Long-term results of postanal repair for neurogenic faecal incontinence. Br J Surg 1994;81:140-4.

134. Engel AF, van Baal SJ, Brummelkamp WH. Late results of postanal repair for idiopathic faecal incontinence. Eur J Surg 1994;160:637-40.

135. Yoshioka K, Keighley MR. Critical assessment of the quality of continence after postanal repair for faecal incontinence [published erratum appears in Br J Surg 1990 Mar;77(3):356]. Br J Surg 1989;76:1054-7.

136. Rainey JB, Donaldson DR, Thomson JP. Postanal repair: which patients derive most benefit? J R Coll Surg Edinb 1990;35:101-5.

137. Deen KI, Oya M, Ortiz J, Keighley MR. Randomized trial comparing three forms of pelvic floor repair for neuropathic faecal incontinence. Br J Surg 1993;80:794-8.

138. Husemann B, Hager T. Experience with the Erlangen magnetic ring colostomy-closure system. Int Surg 1984;69:297-300.

139. Khubchandani IT, Trimpi HD, Sheets JA, Stasik JJ, Jr., Balcavage CA. The magnetic stoma device: a continent colostomy. Dis Colon Recrum 1981;24:344-50.

140. Christiansen J, Lorentzen M. Implantation of artificial sphincter for anal incontinence. Lancer 1987;2:244-5.

141. Wong WD, Bartolo DCC. An arrificial sphincter for anal inconrinence. Dis Colon Rectum 1992;35:P4(abstract)

142. Schmidt E. The continent colostomy. World J Surg 1982;6:805-9.

143. Schmidt E. [Surgical management of anus incontinence using free-transplanted aurologous, endogenous intestinal musculature]. Chirurg 1978;49:320-1.

144. Hofmann von Kap herr S, Koltai I. [New methods in the treatment of anorectal incontinence (author's transl)]. Z Kinderchir 1981:32:258-70.

145. Holschneider AM, Hecker WC. [Flapped and free muscle transplantation in the treatment of anal incontinence (aurhor's transl)]. Z Kinderchir 1981;32:244-58.

146. Hakelius L. Nystrom B. Stalberg E. Histochemical and neurophysiological studies of aurotransplanted cat muscle. Scand J Plast Reconstr Surg 1975;9:15-24.

147. Shono T, Nagasaki A, Goto $S$. Ikeda K. Experimental free muscle transplantation to the anus using microsurgical rechnique-a new treatment for anal incontinence. Z Kinderchir 1989;44:352-6.

148. Hakelius L, Gierup J. Grotre G. Jorulf H. A new treatment of anal incontinence in children: free autogenous muscle transplantation. J Pediatr Surg 1978:13:77-82.

149. Hakelius L, Olsen L. Free autogenous muscle transplantation in children. Long-term results. Eur J Pediatr Surg 1991:1:353-7.

150. Holle J, Freilinger G. [Functional reconstruction of the striated sphincter muscle in the inconcinent anus (aurhor's rransl)]. Langenbecks Arch Chir 1980:351:133-44.

151. Hallan RI. Williams NS, Hurton MR, Scorr M, Pilot MA, Swash M, Koeze TH, Watkins ES. Electrically stimulated sartorius neosphincter: canine model of activation and skeletal muscle transformation. Br J Surg 1990;77:208-13.

152. Marhes SJ. Nahai F. Classification of the vascular anatomy of muscles: experimental and clinical correlation. Plast Reconstr Surg 1981;67:177-87.

153. Romanes GJ. Romanes GJ, editors.Cunningham's Textbook of Anatomy. 12th ed. Oxford Medical Publications; 1981;p. 375-82.

154. Chetwood CH. Plastic operation for restoration of the sphincrer ani with report of a case. Med Rec 1902;61:529

155. Schoamaker J. Un nouveau procede operatoire pour la reconstruction du sphincter anal. Sem Med $1909 ; 29: 160$ 
156. Bistrom O. Plastischer Ersatz des M. Sphincter ani. Acta Chir Scand 1944;90:431-48.

157. Bruining HA, Bos KE, Colthoff EG, Tolhurst DE. Creation of an anal sphincter mechanism by bilateral proximally based gluteal muscle transposition. Plast Reconstr Surg 1981;67:70-3.

158. Prochiantz A, Gross P. Gluteal myoplasty for sphincter replacement: principles, results and prospects. J Pediatr Surg 1982;17:25-30.

159. Hentz VR. Construction of a rectal sphincter using the origin of the gluteus maximus muscle. Plast Reconstr Surg 1982;70:82-5.

160. Devesa JM, Vicente E, Enriquez JM, Nuno J, Bucheli P, de Blas G, Villanueva MG. Total fecal incontinence-a new method of gluteus maximus transposition: preliminary results and report of previous experience with similar procedures. Dis Colon Rectum 1992;35:339-49.

161. Pearl RK, Prasad ML, Nelson RL, Orsay CP, Abcarian H. Bilateral gluteus maximus transposition for anal incontinence. Dis Colon Rectum 1991;34:478-81.

162. Congilosi S, Johnson D, Madoff R, Wong WD, Rothenberger D. Canine model of a perineal wrap for fecal incontinence. Dis Colon Rectum 1994;37:P44

163. Williams NS, Patel J, George BD, Hallan RI, Watkins ES. Development of an electrically stimulated neoanal sphincter. Lancet 1991;338:1166-9.

164. Christiansen J, Hansen CR, Rasmussen O. Bilateral gluteus maximus transposition for anal incontinence. Br J Surg 1995;82:903-5.

165. Patel J, Shanahan D, Williams NS, Sinnatamby CS, George B, Watkins ES. The anatomy of the anterior division of the obturator nerve in relation to the electrically stimulated gracilis neoanal sphincter. Clinical Anatomy 1991;4:385(abstract)

166. Shanahan D, Riches DJ, Sinnatamby CS, Williams NS, Warkins ES. The arterial anatomy and surgical relevance of the human gracilis muscle. J Anat 1991;176:270-272(abstract).

167. Futrell JW. Kenneth L. Pickrell, M.D. Plast Reconstr Surg 1985;75:457-60.

168. Pickrell K, Georgiade N, Richard EF, Morris F. Gracilis muscle transplant for the correction of neurogenic rectal incontinence. Surgical clinics of North America 1959;39:1405-15.

169. Pickrell KL, Broadbent TR, Masters FW, Merzger JT. Construction of a rectal sphincter and restoration of continence by transplanting the gracilis muscle. Ann Surg 1952;135(6):853-62.

170. Stone HB. Plastic operation for anal incontinence. Arch Surg 1932;24:120

171. Stone HB, McLanahan S. Results with the fascia plastic operation for anal incontinence. Ann Surg 194I;114:73

172. Pickrell K, Georgiade N, Crawford H, Maguire C, Boone A. Gracilis muscle transplant for correction of urinary incontinence in male children. Ann Surg 1956;143(6):764-79.

173. Raffensperger J. The gracilis sling for fecal incontinence. J Pediatr Surg 1979;14:794-7.

174. Corman ML. Follow-up evaluation of gracilis muscle transposition for fecal incontinence. Dis Colon Rectum 1980:23:552-5.

175. Leguit P, Jr., van Baal JG, Brummelkamp WH. Gracilis muscle transposition in the treatment of fecal incontinence. Long-term follow-up and evaluation of anal pressure recordings. Dis Colon Rectum 1985:28:1-4.

176. Yoshioka K, Keighley MR. Clinical and manomerric assessment of gracilis muscle transplant for fecal incontinence. Dis Colon Rectum 1988;31:767-9.

177. Christiansen J, Sorensen M, Rasmussen OO. Gracilis muscle transposition for faecal incontinence. Br J Surg 1990;77:1039-40.

178. Sonnino RE, Reinberg O, Bensoussan AL, Laberge JM, Blanchard H. Gracilis muscle transposition for anal incontinence in children: long-term follow-up [see comments]. J Pediarr Surg 1991;26:121923.

179. Faucheron JL, Hannoun L, Thome C, Parc R. Is fecal continence improved by nonstimulated gracilis muscle transposition? Dis Colon Rectum 1994;37:979-83.

180. Kumar D, Hutchinson R, Grant E. Bilateral gracilis neosphincter construction for treatment of faecal incontinence. Br J Surg 1995;82:1645-7. 
181. Konsten J, Baeten CG, Havenith MG, Soeters PB. Morphology of dynamic graciloplasty compared with the anal sphincter. Dis Colon Rectum 1993;36:559-63.

1.82. Buller AJ, Eccles JC, Eccles RM. Interactions between motorneurons and muscles in respect of the characteristic speeds of their responses. J Physiol (London) 1960;150:417-39.

183. Salmons $\mathrm{S}, \mathrm{Vrbova} \mathrm{G}$. The influence of activity on some contractile characteristics of mammalian fast and slow muscles. J Physiol Lond 1969;201:535-49.

184. Pette D, Vrbova G. Adaptation of mammalian skeletal muscle fibers to chronic electrical stimulation. Rev Physiol Biochern Pharmacol 1992;120:115-202.

185. Caldwell KP. A new treatment for rectal prolapse. Proc R. Soc Med 1965;58:792-3.

186. Dickson AS, Nixon HH. Control by electronic stimulator of incontinence after operation for anorectal agenesis. J Pediatr Surg 1968;3:696-701.

187. Kantrowitz A, McKinnon W. The experimental use of the diaphragm a an auxiliary myocardium. Surg Forum 1959;9:266

188. Carpentier A, Chachques JC. Myocardial substitution with a stimulated skeletal muscle: first successful clinical case [letter]. Lancet 1985;1:1267

189. Carpentier A, Chachques JC, Acar C, Relland J, Mihaileanu S, Bensasson D, Kieffer JP, Guibourt P, Tournay D, Roussin I, et al. Dynamic cardiomyoplasty at seven years. J Thorac Cardiovasc Surg 1993; 106:42-52.

190. Chachques JC, Grandjean PA, Cabrera Fischer EI, Latremouille C, Jebara VA, Bourgeois I, Carpentier A. Dynamic aortomyoplasty to assist left ventricular failure. Ann Thorac Surg 1990;49:225-30.

191. Cernaianu AC, Vassilidze TV, Flum DR, Gallucci JG, Olah A, Cilley JH, Jr., Grosso MA, DelRossi AJ. Latissimus dorsi and serratus anterior dynamic descending aortomyoplasty for ischemic cardiac failure. Ann Thorac Surg 1995;59:639-43.

192. Baeten C, Spaans F, Fluks A. An implanted neuromuscular stimulator for fecal continence following previously implanted gracilis muscle. Report of a case. Dis Colon Rectum 1988;31:134-7.

193. George BD, Williams NS, Patel J, Swash M, Watkins ES. Physiological and histochemical adaptation of the electrically stimulated gracilis muscle to neoanal sphincter function. Br J Surg 1993;80:1342-6.

194. Konsten J, Baeten CG, Spaans F, Havenith MG, Soeters PB. Follow-up of anal dynamic graciloplasty for fecal continence. World J Surg 1993;17:404-8.

195. Seccia M, Menconi C, Balestri R, Cavina E. Study protocols and functional results in 86 electrostimulated graciloplasties. Dis Colon Rectum 1994;37:897-904.

196. Baeten CG, Geerdes BP, Adang EM, Heineman E, Konsten J, Engel GL, Kester AD, Spaans F, Soeters PB. Anal dynamic graciloplasity in the treatment of intractable fecal incontinence. $N$ Engl J Med 1995;332:1600-5.

197. Baeten CG, Konsten J, Spaans F, Visser R, Habets AM, Bourgeois IM, Wagenmakers AJ, Soeters PB. Dynamic graciloplasty for treatment of faccal incontinence. Lancet 1991;338:1163-5.

198. Konsten J, Baeten CG, Havenith MG, Oeil TK. Evaluation of gracilis muscle transposition for fecal incontinence with magnetic resonance imaging. Eur J Radiol 1993;16:190-4.

199. Konsten J, Baten CG, Den Dulk K. Spaans F. Demonstration of the feasibility of implantation of a skeletal muscle pulse generator for fecal incontinence in a patient with an implanted unipolar DDD pacemaker. PACE Pacing Clin Electrophysiol 1992;15:825-30.

200. Rosen HR, Feil W. Novi G, Zoch G, Dahlberg S, Schiessel R. The electrically stimulated (dynamic) graciloplasty for faecal incontinence-first experiences with a modified muscle sling. Int $]$ Colorectal Dis 1994;9:184-6.

201. Orbach C, Tallent N. Modification of perceived body and of body concepts. Arch Gen Psychiat 1965;12:126-35.

202. Sprangers MA, Taal BG, Aaronson NK, te Velde A. Quality of life in colorectal cancer. Stoma vs. nonsioma patients. Dis Colon Rectum 1995;38:361-9.

203. Williams NS, Johnston D. The quality of life affer rectal excision for low rectal cancer. Br J Surg 1983;70:460-2. 
204. Porter JA, Salvati EP, Rubin RJ, Eisenstat. TE. Complications of colostomies. Dis Colon Rectum 1989;32:299-303.

205. Londono Schimmer EE, Leong AP, Phillips RK. Life table analysis of stomal complications following colostomy. Dis Colon Rectum 1994;37:916-20.

206. Miles WE. A method of performing abdomino-perineal excision for carcinoma of the rectum and of the terminal portion of the pelvic colon. Lancer 1908;ii:1812-3.

207. Quirke P, Durdey P, Dixon MF, Williams NS. Local recurrence of rectal adenocarcinoma due to inadequate surgical resection. Histoparhological study of lateral tumour spread and surgical excision. Lancer 1986;2:996-9.

208. Abercrombie JE, Williams NS. Total anorectal reconstruction. Br J Surg 1995;82:438-42.

209. Elias D, Lasser P, Leroux A, Rougier P, Comandella MG, Deraco M. [Pseudo-continent perineal colostomies after amputation of the rectum for cancer] Colostomies perincales pseudo-continentes apres amputation rectale pour cancer. Gastroenterol Clin Biol 1993;17(3):181-6.

210. Fedorov VD, Odaryuk TS, Shelygin YA, Tsarkov PV, Frolov SA. Method of creation of a smoothmuscle cuff at the site of the perineal colostomy after extirpation of the rectum. Dis Colon Rectum 1989;32:562-6.

211. Chitrenden AS. Reconstruction of anal sphincter by muscles slips from the glurei. Ann Surg 1930;92:152

212. Simonsen OS, Stolf NA, Aun F, Raia A, Habr Gama A. Rectal sphincter reconstruction in perineal colostomics after abdominoperineal resection for cancer. Br J Surg 1976;63:389-91.

213. Cavina E, Seccia M, Evangelista G. Chiarugi M, Buccianti P, Chirico A, Lenzi M, Bortolotri P, Bellomini $G$, Arganini M, et al. Construction of a continent perineal colostomy by using electrostimulared gracilis muscles after abdominoperineal resection: personal technique and experience with 32 cases. Ital J Surg Sci 1987;17:305-14.

214. Mercati U, Trancanelli V, Castagnoli GP, Mariotti A, Ciaccarini R. Use of the gracilis muscles for sphincteric construction after abdominoperineal resection. Technique and preliminary results. Dis Colon Rectum 1991;34(12): 1085-9.

215. Williams NS, Hallan RI, Koeze TH, Warkins ES. Restoration of gastrointestinal continuity and continence after abdominoperineal excision of the rectum using an electrically stimulated neoanal sphincter. Dis Colon Rectum 1990:33:561-5.

210. Santoro E, Tirelli C, Scutari F, Garofalo A, Silecchia G, Scaccia M. Continent perineal colostomy by transposition of gracilis muscles. Technical remarks and results in 14 cases. Dis Colon Recrum 1994;37:S73-80.

217. Wong SK, Wee JT. Reconstruction of an orthoropic functional anus after abdominoperineal resection. Aust N Z ] Surg 1984;54:575-8. 

Chapter 2

\section{ANAL DYNAMIC GRACILOPLASTY IN THE TREATMENT OF INTRACTABLE FECAL INCONTINENCE}

Baeten CGMI, Geerdes BP, Adang EMM, Heineman E, Konsten J, Engel GL, Kester ADM, Spaans F and Soeters PB.

New Engl J Med 1995;332:1600-5. 


\section{Introduction}

Severe fecal incontinence is a problem that may substantially diminishes a person's quality of life. ${ }^{1,2}$ The prevalence of persistent fecal incontinence in the Unired States has been reported to be 2.3 percent. ${ }^{3}$ Trearment methods such as a change of diet, the use of constipating agents or daily enema's and training in biofeedback can often be effective. ${ }^{4}$ If conservative treatment fails, several surgical treatments, including the creation of a colostomy, have been used with varying success.

One surgical treatment is the construction of a neosphincter around the anal canal with the gracilis muscle. ${ }^{5}$ The results of this procedure have been disappointing, ${ }^{6}$ mainly because this muscle is dependent on volition, and thus a sustained contraction is not possible. Because of muscle fatigue due to preponderance of type II muscle fibers, this skeletal muscle can provide forceful contractions for only a short time. ${ }^{7}$ The reported success of conventional transposition of the gracilis muscle can probably be explained by a tightening of the anal canal that results in outlet obstruction. ${ }^{8,9}$ Studies in animals and clinical trials have shown that the clinical results of graciloplasty were improved by electrical stimulation administered after the implantation of electrodes and a pulse generator. ${ }^{10-12}$ The stimulator replaces voluntary contraction and exerts a sustained contraction ${ }^{13,14}$ that leads to the transformation of type II, fatigue-prone, muscle fibers into type I fatigue-resistant fibers. ${ }^{15,16}$ Electrical stimulation gives the transposed gracilis muscle the properties required to function as a sphincter. ${ }^{17,18}$

To assess the clinical and social effects of this new technique, we designed a prospective, longitudinal, clinical study to assess whether parients could be given well-functioning neosphincters and how this therapy affected their quality of life.

\section{Methods}

\section{Patients}

From November 1986 through January 1994, 52 patients (37 women, 15 men) were rreated by anal dynamic graciloplasty (transposition of the gracilis muscle to the anus with the implantation of stimulating electrodes).

Their median age was 44 years (range, 18 to 71 ), and the mean duration of incontinence was 15 years (range, 1 to 40 ). All the patients had previously received the maximal conservative treatment, and 39 patients had had one or more unsuccessful incontinence-related operations (Table 1).

The causes of fecal incontinence were anal atresia (12 patients), perineal trauma (24), cauda equina syndrome (2) and pudendal nerve lesions (14) (Table 1). Perineal trauma was due to vaginal delivery, sphincter surgery, or direct trauma.

All patients were interviewed, underwent a physical examination, and were evaluated by anal manomerry, electromyography, defecography and enema test. Patients were accep- 
Table 1. Characteristics of the parients with severe fecal incontinence before dynamic graciloplasty, according to the cause of incontinence. Plus - minus values are means \pm SD. Numbers in parentheses are percentages of the group.

\begin{tabular}{|c|c|c|c|c|c|}
\hline & Anal arresia & Trauma & Cauda lesion & Pudendopathy & Total \\
\hline No. of parients & $12(23.1)$ & $24(46.2)$ & $2(3.8)$ & $14(26.9)$ & $52(100)$ \\
\hline Age $(y r)$ & $27 \pm 7.6$ & $48 \pm 11.0$ & $44 \pm 30.4$ & $52 \pm 10.2$ & $44 \pm 14.0$ \\
\hline Male sex- No. $(\%)$ & $8(15.4)$ & $4(7.7)$ & $1(1.9)$ & $2(3.8)$ & $15(28.8)$ \\
\hline $\begin{array}{l}\text { Duration of } \\
\text { incontinence (yr) } \\
\text { No, with previous } \\
\text { procedure }\end{array}$ & $27 \pm 9.5$ & $11 \pm 11.6$ & $13 \pm 13.4$ & $14 \pm 11.7$ & $15 \pm 12.0$ \\
\hline Colostomy & 2 & 3 & 0 & 1 & 6 \\
\hline Graciloplasty & 4 & 1 & 0 & 1 & 6 \\
\hline Surgery & 12 & 16 & 0 & 11 & in \\
\hline Biofeedback & 6 & 7 & 0 & 5 & 18 \\
\hline Rectal sensibility ( $\mathrm{ml}$ ) & $50 \pm 17.8$ & $35 \pm 14.3$ & $100 \pm 70.7$ & $40 \pm 19.3$ & $40 \pm 18.5$ \\
\hline Rectal capacity (ml) & $175 \pm 72.1$ & $150 \pm 78.3$ & - & $130 \pm 46.8$ & $150 \pm 69.0$ \\
\hline
\end{tabular}

ted into the study if they had grade 5 incontinence as classified on a scale of 1 to 5 according to a standardizes scoring method ${ }^{14}$ (table 2) and if there was no other therapeutic option than the construction of a colostomy. Patients who already had a colostomy retained their stoma until the dynamic graciloplasty was successfully completed.

\section{Treatment and evaluation.}

The gracilis muscle was mobilized down to its insertion into the tibial tuberosity and the distal tendon was divided. Proximally, the neurovascular bundle was left intact, and the muscle was transposed around the anal canal and fixed to the ischial spine (according to the method of Pickrell et al., ${ }^{5}$ with slight modifications ${ }^{17}$ ). Six weeks later intramuscular electrodes (model SP 5566, Medtronic, Kerkrade, The Netherlands) were implanted at the site of nerve entry and connected through a subcutaneously tunnel to the neurostimulator (Itrel II ${ }^{\mathrm{TM}}$, model 7424 , Medtronic) which was placed in the abdominal wall (Figure 1).

With an external magnet the parient can switch the neurostimulator on (causing the transposed gracilis muscle to contracr) and off (causing the muscle to relax). The amplitude, rate, pulse width, polarity and duty cycle can be programmed telemetrically by the physician. Before continuous stimulation was applied, the transposed gracilis was trained for eight weeks according to a stimulation protocol. ${ }^{17}$ All 52 patients received systemic antibiotic prophylaxis for 24 hours at the time of transposition and the implantation. In the last 37 patients to be treated, local antibiotics (gentamycin, 
Table 2. Scoring system for fecal incontinence. Adapted from the classification system of Williams et al ${ }^{14}$

\section{Score Symptoms}

1 Continence with regard to solids, liquids and flatus

2 Continence with regard to solids and liquids, but not to flatus

3 Continence with regard to solids, but occasional incontincnce of liquids

4 Occasional episodes of incontinence of solids

5 Frequent episodes of incontinence of solids and liquids

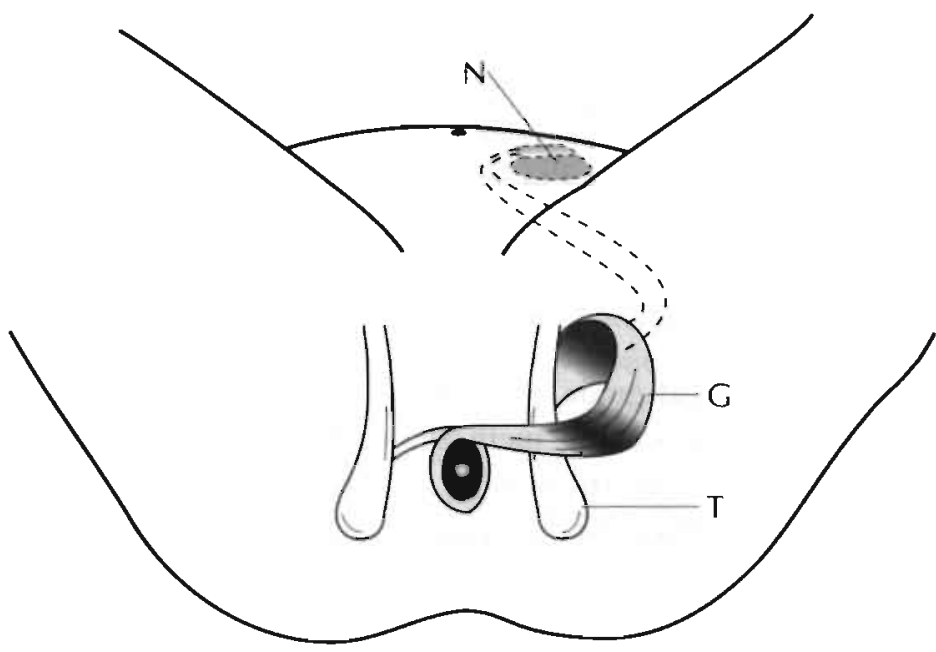

Figure 1. Configuration of the anal dynamic graciloplasty, showing the transposed gracilis muscle (G), the ischial spine (T), the electrodes (dotred line), and the neurostimulator (N).

Sulmycin Implant, Essex Pharma, München, Germany) were administered with the implant.

The number and characteristics of the episodes of incontinence, the frequency of bowel emptying, and the length of time to which defecation could be postponed were recorded. In the evaluation of continence, only patients with scores of 1 or 2 were considered to be continent ${ }^{14}$ (Table 2).

Anal manometry was performed before and after graciloplasty with a catheter (Konigsberg Instruments, Pasadena, Cal) that was connected to a computer-assisted polygraph (Synectics Medical, Stockholm, Sweden). The highest basal pressure and the constriction pressure were measured with a standardized stationary pull-through technique. With repeated inflation of a balloon intrarectil sensitivity and capacity were assessed in millimeters. ${ }^{19}$ Defecography was performed according to established methods. ${ }^{20}$ Electromyography of the external sphincter, the pelvic floor ${ }^{21}$ and both gracilis 
muscles was performed with a Nicolet Viking electromyography-apparatus (Nicolet, Madison, Wisconsin, USA).

The length of time during which a 250 - $\mathrm{ml}$ phosphate enema could be retained was assessed before and after the muscle transposition and again after eight weeks and one year of electrical stimulation. The enema was given with the patient in a left lateral position, and the time of first leakage was recorded.

\section{Quality-of-Life Evaluation}

The quality-of-life study started later in the study period and included 30 patients. This subgroup did not differ substantially from the overall group of 52 patients with respect to sex, age, duration and cause of incontinence. This study was performed prospectively, with the measurements obtained two months preoperatively compared with three postoperative measurements (at 3,6 and 12 months).

Four question naires were used to assess quality of life: parts 1 and 2 of the Nottingham Health Profile ${ }^{22}$, the State-Trait Anxiety Inventory, ${ }^{23,24}$ and the Self-rating Depression scale (Zung scale). 25,26 Part 1 of the Nottingham Health Profile is designed to measure perceived health in six specific areas, whereas part 2 is related to the following five areas of "task performance" that are most affected by health: effectiveness in one's occupation, ability to perform tasks around the home, personal relationship, sexual function, and social life. These questionnaires have been validated and translated into Dutch.

A disease-specific questionnaire was constructed for this study that included irems addressing the patient's problem with fecal incontinence in relation to sport, holidays, visiting, and eating. This questionnaire was tested in a pilot study. ${ }^{27}$ To determine the success or failure of the dynamic graciloplasty, the disease specific questionnaire was used together with the continence scale. ${ }^{1.4}$

In addition, patients were stratified according to whether their incontinence had lasted a long or a short time in relation to their age, in order to investigate a potential relation of this variable with their adaptation to their condition. Duration was considered to be long if years of incontinence divided by years of age equaled 0.9 or more. The group thus defined were compared on the basis of their preoperative scores un part 2 of the Nottingham Health Profile, which were used as proxies for their degree of adaptation; lower scores indicated berrer adaptation.

\section{Statistical Analysis}

Data on the patients were expressed as medians and ranges in the case of categurical measurements and otherwise as proportions. Since the duration of follow-up varied, we estimated the percentages of successful treatments with the product-limit method, much as the Kaplan-Meier method is use to study survival data. ${ }^{28}$ In these calculations, patients with stoma were considered to be incontinent at wetk 0 (after graciloplasty but before 
neurostimulation). In the case of quantitative data, the normality of the distributions was determined from histograms. When distributions were not normal and normality could not be obtained by transformation of the data, medians were presented, and Wilcoxon signed-rank tests were used to evaluate differences between groups. In case of normally distributed data, mean values were estimated by a repeated-measures procedure that allowed for missing data. ${ }^{29,30}$ In this analysis, we tested whether the changes from week 0 to weeks 26 and 52 were significant. To avoid multiple testing, data obtained at other times were not tested. To determine correlation, the Spearman rank-correlation coefficient was used.

The quality-of-life data were also tested nonparametrically; with the Wilcoxon signed-rank test used to compare groups of patients. These data were expressed as the median and interquartile ranges of the differences between preoperative and postoperative measurements. A P-value of 0.05 or less was considered to indicate statistical significance.

The studies were approved by the medical ethical committee of Maastricht University Hospital, and informed consent was obtained from all patients.

\section{Results}

\section{Clinical results}

After a median follow-up of 2.1 years (range, 12 weeks to 7.4 years) after the implantation of the electrical stimulator, 38 of the 52 parients ( 73 percent) were continent. In 14 patients ( 27 percent) only partial, if any, improvement in continence could be achieved; these patients had continence scores of 3, 4 or 5 after follow-up (Figure 2). The treatment failures were partly due to problems with the dynamic graciloplasty - i.e., inadequate contraction of the distal part of the gracilis muscle (in four patients) or infection around the neurostimulator and leads that necessitated their removal (four patients). Six patients had no improvement even though each had a well-functioning dynamic graciloplasty. In four this was due to very strong peristalsis, the presence of a non-distending rectum, a perforation of the anal canal by the graciloplasty, and overflow incontinence (one patient each). In the remaining two patients no objective reasons for the treatment failure could be found. Among the 12 patients with anal atresia, 6 (50 percent) were treated successfully, as were 22 out of 24 patients with trauma ( 92 percent), 9 of the 14 with pudendal-nerve lesions ( 64 percent), and 1 of the 2 with caudal lesions (50 percent).

The sensitivity of the rectum was influenced by the cause of inconcinence (Table 1). The median value for sensibility was $30 \mathrm{ml}$ for patients with a continence score of 1,40 $\mathrm{ml}$ for those with a score of 2 and $50 \mathrm{ml}$ for those with a score of 5 . At 26 weeks there was a significant association $(P=0.003)$ between sensitivity and the outcome of treatment. No significant correlation was found between capacity and the outcome of 


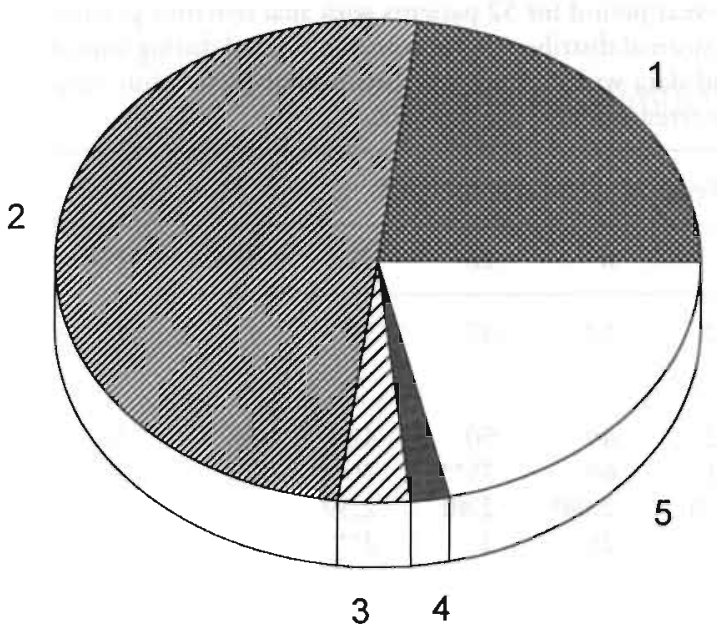

Figure 2. Ourcomes of treacment according to the patiens' continence scores at followup. Scores 1 and 2 were considered to indicare successful treatment, and scores 3,4, and 5 to indicate unsuccessful treatment.

treatment $(P=0.09)$ (Table 1). No correlation $(r=-0.07)$ was found between the outcome of treatment and the interval (range, 44 to 4734 days) that elapsed between the transposition of the gracilis muscle and the implantation of the stimulation device.

The median voltage needed for a good contraction (Table 3, Figure 3) increased from $1.26 \mathrm{~V}$ when stimulation was first used to $2.04 \mathrm{Volt}$ at 8 weeks (measured in 52 patients, $\mathrm{P}<0.001$ ) and $2.40 \mathrm{~V}$ at 26 weeks (in 47 patients, $\mathrm{P}$ not significant). Thereafter, it increased very little, and even after 156 weeks the median voltage needed was below 3 Volt. After eight weeks the frequency of stimulation could be lowered from 25 to 15 pulses per second in 70 percent of the patients who had preservation of smooth contraction.

The resting pressure of the anal sphincter increased from a mean of $38 \mathrm{mmHg}$ before the muscle transposition to $49 \mathrm{mmHg}$ after eight weeks of stimulation (P not significant) and remained constant thereafter (Table 3). After the muscle transposition, the mean constriction pressure improved significantly from 50 to $72 \mathrm{~mm} \mathrm{Hg}$. During stimulation this pressure was $69 \mathrm{~mm} \mathrm{Hg}$ after 8 weeks and $75 \mathrm{mmHg}$ after 26 weeks $(P=0.001)$. It then remained constant through week 156 weeks of stimulation (Table 3).

The median frequency of defecation decreased from five times per 24 hours (i.e., state of incontinence) before the muscle transposition to four times per 24 hours before stimulation and to two times per 24 hours $(\mathrm{P}<0.001)$ after eight weeks of stimulation. It then remained constant at two times per 24 hours through week 156 (Table 3). The median time defecation could be postponed increased from 9 seconds $(0.15$ minute) before stimulation to 11 minutes at 8 weeks (in 51 patients, $\mathrm{P}=0.016$ ) and to 19 minutes at 52 weeks (in 32 patients, $P=0.012$ ) (Table 3). Because patients with a stoma cannot postpone defecation, they were not included in this analysis. The median time the $250-\mathrm{ml}$ phosphate enema could be retained was 0 seconds before transposition, 60 
Table 3. Estimated clinical results overa three-year period for 52 patients with anal dynamic graciloplasty, based on data of the study patients. Data with normal distribution (pressure at rest and during stimulation, and voltage) are estimated clinical results, and data with nonnormal distribution (defecation frequency, ability to postpone defecation, and the enema retention test) are medians.

\begin{tabular}{|c|c|c|c|c|c|c|c|c|}
\hline \multirow{2}{*}{ Variable } & \multirow{2}{*}{$\begin{array}{l}\text { Before } \\
\text { Surgery }\end{array}$} & \multirow{2}{*}{$\begin{array}{l}\text { After } \\
\text { Surgery }\end{array}$} & \multicolumn{6}{|c|}{ Weeks of Neurostimulation } \\
\hline & & & 0 & 8 & 26 & 52 & 104 & 156 \\
\hline $\begin{array}{l}\text { No. studied } \\
\text { Sphincter pressure } \\
(\mathrm{mmHg})\end{array}$ & 52 & 52 & 52 & 52 & 47 & 39 & 18 & 11 \\
\hline At rest & 38 & 42 & 42 & 49 & 50 & 48 & 52 & 51 \\
\hline During stimulation & $50^{*}$ & $72^{*}$ & 61 & 69 & $75^{* * *}$ & $76^{* *}$ & 77 & 77 \\
\hline Voltage (V) & - & - & 1.26 & 2.045 & 2.40 & 2.59 & 2.91 & 2.96 \\
\hline $\begin{array}{l}\text { Defecation freq. } \\
\text { (times/day) }\end{array}$ & 5 & 4 & 4 & $2 \$$ & 2 & $2^{* * *}$ & 2 & 2 \\
\hline $\begin{array}{l}\text { Ability to postpone } \\
\text { defecarion (min) }\end{array}$ & 0.15 & 一 & 0.5 & $11^{\dagger}$ & - & $19^{t i}$ & - & 一 \\
\hline $\begin{array}{l}\text { Fnema retention } \\
\text { (sec) }\end{array}$ & 0 & 3 & 一 & $60^{\circ}$ & - & $180^{9}$ & - & - \\
\hline
\end{tabular}

* this is squecze pressure, ${ }^{* *} p=0.001, \dagger p=0.016, \dagger \dagger p=0.012, \$ p<0.001,9 n=11, p=0.005$

seconds at 8 weeks of stimulation (measure in 51 patients, $\mathrm{P}<0.001$ ) and 180 seconds at 52 weeks (measured in 11 parients, $\mathrm{P}=0.005)$ ( Table 3 ).

In seven patients infection around the neurostimulator and leads necessitated their removal, and four of these patients remained incontinent even after the implantation of a second neurostimulator. Five infections occurred among the first 15 patients who were treated, whereas there were only two infections among the next 37 patients. This varying infection rate may have been due to modifications in the perioperative regimen of antibiotics.

\section{Quality of Life}

The results of the quality-of-life evaluation of a sub-group of 30 patients are shown in Table 4. Treatment was successful in 22 patients and unsuccessful in 8 . These 30 patients did not differ significantly from the overall group with respect to outcome of the treatment. There was good correlation $(r=0.76, n=30, p<0.001)$ between the clinical results as scored by the patient's physician ${ }^{14}$ and the results obtained by the independent quality-of-life-researcher who scored the questionnaires the patients completed at home. The State-Trait Anxiety Inventory questionnaire administered at 52 weeks showed that the patients who were successfully treated were less anxious than the unsuccessfully treated patients $(P=0.002)$. Part 2 of the Nottingham Health Profile questionnaire revealed significant improvement in the successfully treated group at 52 weeks $(\mathrm{P}=$ 


\section{Estimated stimulation voltages}

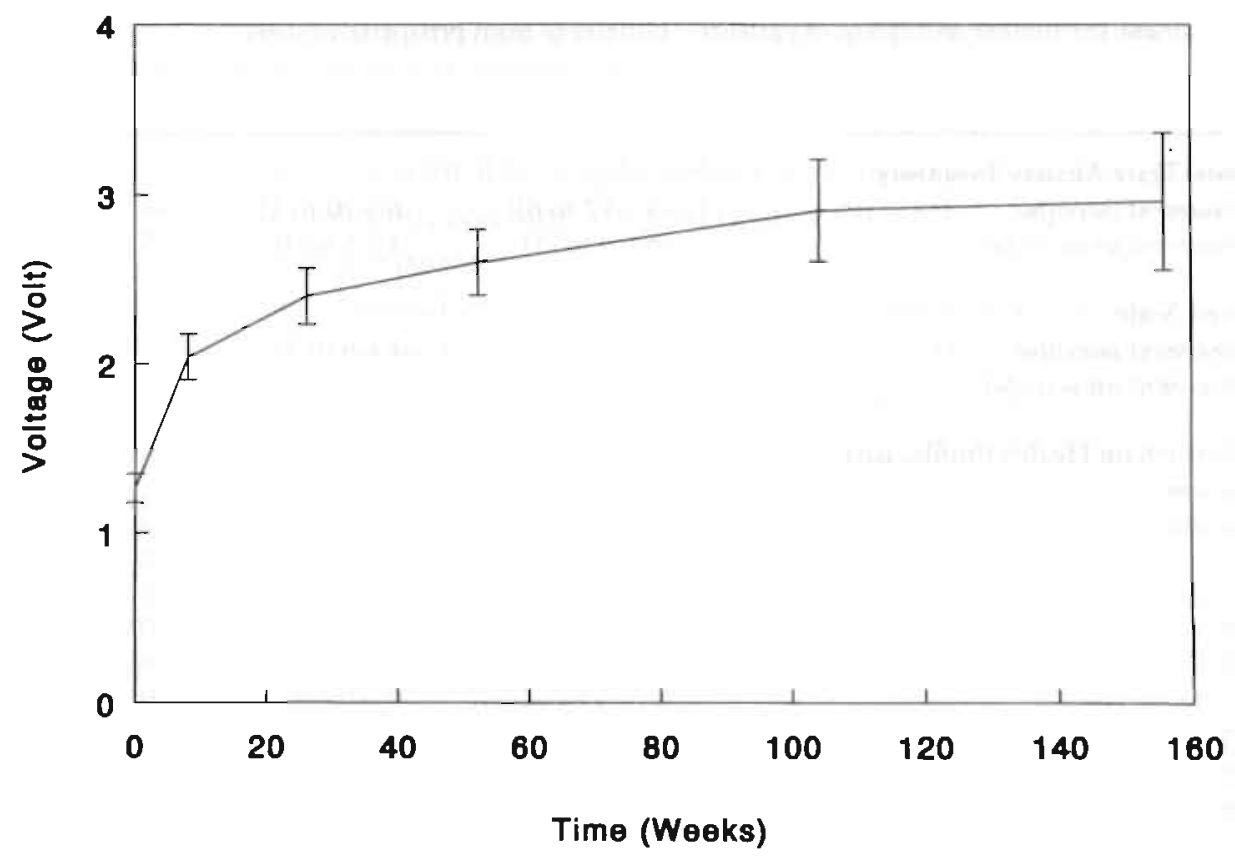

Figure 3. Estimated mean $( \pm S D)$ voltage needed to achieve continence in the 52 study patients at various periods after the implantation of the stimulation devices.

$0.01)$. These patients also had significant improvement at 26 weeks $(P=0.05)$ with regard to social isolation, a dimension analyzed in part 1 of the Notringham Health Profile that is of particular importance in this population. No significant changes were found in the other areas analyzed, except for mobility $(\mathrm{P}=0.016)$ (Table 4). No significant change were found in either group in the results of the Zung questionnaire. There were no significant changes in any area of any questionnaire in the unsuccessfully treated group. The relation between the duration of fecal incontinence and adaptability of the patients was investigated preoperatively in part 2 of the Nottingham Health Profile. Significant differences were found between the patients with a short duration of incontinence and those with a long duration (i.e., patients with anal atresia) $(P<0.01)$. Patients with anal atresia scored very well preoperatively on all questionnaires (with scores similar to those of healthy persons), unlike those who had a short history of incontinence. 
Table 4. Results of the Quality-of-Life evaluation in 30 patients who underwent anal dynamic graciloplasty, according to whether their treatment was successful or unsucccessful. Negative values indicate improvement, positive values deterioration, and 0 means no change. Treatment was successful in 22 parients and unșuccessful in 8.

Assessment Instrument and group of patients Difference from preoperative score

Ac 2 monchs At 6 months At 12 monchs

State-Trate Anxiety Inventory

Treatment successful

Treatment unsuccessful

$-4(-12$ ro 6$)$

$-6(-10$ to 1$)$

$-6(-8 \text { to } 1)^{*}$

$-5(-9$ to -1$)$

$-1(-5$ to 3$)$

$5(7$ to 8$)$

\section{Zung Scale}

Treatment successful

Treatment unsuccessful

$\begin{array}{llll}-1(-6 \text { to } 7) & -1(-6 \text { to } 2) & -2(-4 \text { to } 3) \\ 1(-6 \text { to } 7) & -2(-7 \text { to } 1) & 7(-3 \text { to } 9)\end{array}$

Nottingham Health Profile, part 1

Treament successful

mobility

$0(-9$ to 0$)$

$0(-11 \text { to } 0)^{* *}$

$0(-12$ to 5$)$

pain

$0(0$ to26)

$0(-1$ to 21$)$

$0(-11$ to 21$)$

energy

$0(0$ to 0$)$

$0(0$ to 0$)$

0 (0 to 19)

sleep

$0(0$ to 13$)$

$0(0$ to 2$)$

$0(-4$ to 6$)$

social isolation

$0(0$ to 0$)$

$0(-23 \text { to } 0)^{\dagger}$

$0(-21$ to 0$)$

emorional reaction

$0(-14$ to 12$)$

$0(-10$ to 0$)$

$0(-21$ to 1$)$

Treatment unsuccessfil

mobility

$0(-17$ to 0$)$

$0(0$ to 11$)$

$0(-27$ to 31$)$

$0(-10$ to 0$)$

$-2(-8$ to 0$)$

$0(-12$ to 7$)$

energy

$0(0$ to 2$)$

$0(-28$ to 0$)$

$0(-13$ to 24$)$

sleep

$0(-22$ to 0$)$

$0(-17$ to 0$)$

$0(0$ to 17$)$

social isolation

$0(-19$ to 19$)$

$0(-52$ to 0$)$

$0(-43$ to 22$)$

emotional reaction

$1(-9$ to 7$)$

$-6(-16$ to 0$)$

$0(-6$ ro 9$)$

Nottingham Health Profile, part 2

Treatment sucressful

Treatment unsucessful

$-2(-3 \text { to } 0)^{5}$

$-1(-4 \text { to } 0)^{\dagger \dagger}$

$-2(-6 \text { to }-1)^{\ddagger}$

1 (0 to 3$)$

$-2(-7$ ro 1$)$

$-1(-3$ to 4$)$

${ }^{*} \mathrm{P}=0.002,{ }^{*} \mathrm{P}=0.016, \uparrow \mathrm{P}=0.05, \$ \mathrm{P}=0.005+\uparrow \mathrm{P}=0.04 \neq \mathrm{P}=0.01$ These $\mathrm{P}$-values are for the comparison with the corresponding group unsuccessfully treated

\section{Discussion}

Since 1952 conventional graciloplasty has been performed to replace a dysfunctional or absent external anal sphincter, but contradictory results have been reported. $5,6,8,9,31-33$ The basic problem has been that the patient cannor achieve sustained contraction of the transposed muscle. This problem can be solved by stimulating the gracilis muscle electrically with implanted electrodes. ${ }^{17,18}$ Gradually increasing the dury cycle, gives the muscle the opportunity to adjust to its new function. The ongoing electrical stimulation 
causes fast-twitch, fatigue-prone type II fibers to be transformed into slow-twitch, fatigue-resistant type I fibers. ${ }^{34,35}$ In this process the histochemical composition of the gracilis muscle comes to resemble that of the external anal sphincter.

A normal anal sphincter achieves fecal continence with only a moderate degree of contraction, produced by the alternating activation of a limited number of motor units. Through electrical stimulation, however, continence is achieved by continuous activation of all motor units involved. The results show that in a majority of cases the transposed muscle can cope with this nonphysiologic level of activation. The increase in pressure during stimulation, reaching $75 \mathrm{mmHg}$ after 26 weeks, resulted in continence in the majority of the patients.

For good continence, several anatomical and physiologic entities are considered to be essential. These are the muscle wall of the anorectum, the internal and external anal sphincters, the transitional epithelium of the anal canal, and a rectum with sufficient capacity. Physiologically the bowel should have a normal pattern of motility, whereas the anorectum should be able to sense its contents, to relax on filling, and to distinguish among flatus, liquid stool, and solid stools. Restoring the anal sphincter alone is therefore no guarantee of continence. In patients with impaired sensibility (which is more common in patients with anal atresia, the cauda syndrome, or pudendopathy) good closure of the anal canal is achieved, but inability to sense extensive filling can lead to overflow incontinence.

We observed no difference in outcome between groups in which different intervals elapsed between the transposition of the gracilis muscle and the implantation of the electrical stimulator. Even when stimulation is begun years after the muscle transposition, there can still be improved function of the graciloplasty. This strategy can therefore benefic many parients who have had unsuccessful graciloplasty.

Because dynamic graciloplasty requires lifelong stimulation of the transposed muscle in order to maintain a tetanic contraction, the increasing voltage needed for stimulation remains a source of concern. Insufficient contraction that requires an increase in voltage may be due to the transformation of muscle fibers from type II to type I, progressive fibrosis around the electrodes, or displacement of the electrodes. An increase in the stimulation voltage was needed until 26 weeks after the start of stimulation, but the further increase up to a period of 2 years was minimal. At the present settings for stimulation, the expected longevity of the stimulator would be seven years.

The patients in whom the technique was successful became less anxious and improved in areas such as effectiveness in their occupations, ability to perform tasks around the home, personal relationships, sexual function, and social life. The patients became less socially isolated after 26 weeks of stimulation. Patients with long-standing incontinence (i.e., those with anal atresia) seemed before the operation to be very well adapted to their incontinence. Patients in whom the operation failed remained at their preoperative level with regard to quality of Life. 
We conclude that dynamic graciloplasty is an excellent technique for replacing the anal sphincter in patients of whom no other treatment is effective. Dynamic graciloplasty is safe and reliable and leads to a better quality of life.

\section{References}

1. Rintala R, Mildh L, Lindahl H. Fecal continence and quality of life in adult patients with an operated low anorectal malformation. J Pediatr Surg 1992;27:902-5.

2. Mandelstam DA. Faecal incontinence, social and economic factors. In: Coloproctology and the pelvic floor. Henry MM and Swash M. (eds) lst ed, Burterworths, Sevenoaks England, 1985:217-22.

3. Nelson R, Norton N, Cautley E. Prevalence of fecal incontinence in Wisconsin households. Dis Colon Rectum 1994;37:P9.

4. Madoff RD, Williams JG, Caushaj PF. Fecal incontinence. N Engl J Med 1992;326(15):1002-7.

5. Pickrell KL, Broadbent TR, Masters FW, Metzger JT. Construction of a rectal sphincter and restorarion of anal incontinence by transplanting the gracilis muscle: report of four cases in children. Ann Surg 1952;135:853-62.

6. Yoshioka K, Keighly MRB. Clinical and manometric assessment of gracilis muscle transplant for fecal incontinence. Dis Colon Rectum 1988;31:767-9.

7. Konsten J, Baeten CG, Havenith MG, Soeters PB. Morphology of dynamic graciloplasty compared to the anal sphincter. Dis Colon Rectum 1993;36:559-63.

8. Leguit P, Baal van JG, Brummelkamp WH. Gracilis muscle transposition for fecal continence. Long term follow-up and evaluation of anal pressure recordings. Dis Colon Rectum 1985;28:1-4.

9. Raffensperger J. The gracilis sling for fecal incontinence. J Pediatr Surg 1979;6:794-7.

10. Baeten C, Spaans F, Fluks A. An implanted neuromuscular stimulator for fecal incontinence following previously implanted gracilis muscle. Dis Colon Rectum 1988;31;134-7.

11. Cavina $E_{n}$ Seccia $M$, Evangelista $G$ et al. Perineal colostomy and electrostimulated gracilis "neosphincter" after abdomino-perineal resection of the colon and anorectum: a surgical experience and follow-up study in 47 cases. Int. J. Colorectal Dis 1990; 5:6-11.

12. Hallan RI, Williams NS, Hutton MRE et al. Electrically stimulated sartorius neosphincter: canine model of activation and skeletal muscle transformation. Bric J Surg 1990; 77:208-13.

13. Baeten CGMI, Konsten J, Spaans F et al. Dynamic graciloplasty for treatment of fecal incontinence. Lancet 1991;338:1163-5.

14. Williams NS, Parel J, George BD, Hallan RI, Watkins ES. Development of an electrically stimulated neoanal sphincter. Lancer 1991;338:1166-9.

15. Salmons $\$$, Vrbova $G$. The influence of activity on some contractile characteristics of mammalian fast and slow muscle. J Physiol London 1969;201:535

16. Chacques JC, Grandjean PA, Carpentier A. Dynamic Cardiomyoplasty: experimental cardiac wall replacement with a stimulated skeleral muscle. In: Cardiomyoplasty and Muscle-powered Devices. RCJ Chiu (ed). Futura Publishing, New York; 1986:59-84.

17. Konsten J, Baeten CG, Spaans F, Havenith MG, Soeters PB. Follow-up of anal dynamic graciloplasty for fecal incontinence. World J Surg 1993;17:404-9.

18. Gcorge BD, Williams NS, Parel J, Swash M, Warkins ES. Physiological and histochemical adaptation of the electrically stimulated gracilis muscle to neoanal sphincter function. Brit J Surg 1993;80:1342-6

19. Meunier PD, Gallavardin D. Anorectal manometry: the state of the art. Digest Dis 1993;11:252-64.

20. Goei R. Anorectal function in patients with defecation disorders and asymptomaric subjects. Radiology 1990;74:121-3.

21. Swash $M$ and Snooks S]. Electromyography in pelvic floor disorders. In: coloproctology and the pelvic floor. Henry MM and Swash M. (eds) 2nd ed, Butterworths, Sevenoaks England 1992:196 
22. Hunt SM, McEwen J, McKenna SP Measuring Health Status: A new tool for clinicians and epidemiologists. J Roy Coll General Practitioners 1985;35:185-188-206.

23. Ploeg HM van der, Defares PB, Spielberger CD. Een Nederlandsalige bewerking van de Spielberger Stare-Trait Anxiety Inventory: de Zelfbeoordelings Vragenlijst. De Psycholoog 1980; 15:460-467

24. Spielberger CD, Gorsuch RL, Lushene RE (eds). STAI manual for the state-trait anxiety inventory. Consulting Psychologists Press Inc. Palo Alto, California 1970.

25. Dijkstra P. The self-rating depression scale of Zung (in Dutch), In: Praag HM van, Rooymans HGM (eds) Stemming en ontstemming. Erven Bohn, Amsterdam, 1974;56-67

26. Zung WWK. A self-rating depression scale. Arch Gen Psychiatry 1965;13:63-70.

27. Adang EMM, Engel GL, Konsten J. Baeten CGMI. Quality of life after dynamic graciloplasty, first results. Theor Surg 1993;8:122-4.

28. Little RJA and Rubin DB. Statistical Analysis with Missing Data. Wiley, New York, 1987;p.174

29. Dixon WJ, chief editor: Brown MB Engelman L and Jenrich RI. BMDP Staristical soltware manual: to accompany the 1990 software release. University of California Press, Berkeley, 1990.

30. Jenrich RI and Schluchter MD. Unbalanced repeared-measures models with structured covariance matrices. Biometrics 1986;42:805-20.

31. Corman ML. Follow up evaluation of gracilis muscle transposition for fecal incontinence. Dis Colon Rectum 1980;8:552-5.

32. Chrisriansen J, Sørenson M, Ramussen $\varnothing \varnothing$. Gracilis muscle transposition for faccal incontinence. Brit J Surg 1990;77:1039-40.

33. Sonnino RE, Reinberg O, Bensoussan AL, Laberge JM, Blanchard H. Gracilis muscle rransposition for anal incontinence in children: long-term follow up. J Pediatr Surg 1991;10:1219-23.

34. Pette D, Vrbova G. Adaptation of mammalian skeletal muscle fibers to chronic electrical stimulation. Rev Biochem Pharmacol 1992;120:115-202.

35. Dickson AS, Nixon HH. Control by electronic stimulator of incontinence after operation for anorecral agenesis. J Pediarr Surg 1968;3:696-701. 
Chapter 3

DOUBLE DYNAMIC GRACILOPLASTY FOR TOTAL ANORECTAL RECONSTRUCTION 


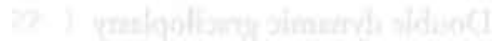


Chapter 3.1

\section{TOTAL ANORECTAL RECONSTRUCTION WITH A DOUBLE DYNAMIC GRACILOPLASTY AFTER ABDOMINOPERINEAL RECONSTRUCTION FOR LOW RECTAL CANCER.}

Parts of this chapter were or will be published under the titles:

Double Dynamic Graciloplasty and colo-perineal pull-through after abdominoperineal resection. Geerdes BP, Zoetmulder FAN, Baeten CGMI. Eur J Canc 1995;31A:1248-52.

Dubbele dynamische $\mathrm{M}$. gracilis-plastiek: alternatief voor een colostoma na een volledig verlies van het anorectum. Geerdes BP, Heineman E, Zoetmulder FAN, Adang EMM, Vos E en Baeten CGMI. NTVG 1996;140(14):773-7

Total Anorectal Reconstruction with a double dynamic graciloplasty after abdominoperineal reconstruction for low rectal cancer. Geerdes BP, Zoermulder FAN, Heineman E, Vos EJ, Rongen M-J and Baeten CGMI. Dis Colon Rectum (in press) 


\section{Introduction}

In 1839 Jean Amussat performed the first successful extraperitoneal creation of a colostomy for obstructing rectal cancer. Kraske, in 1885, performed the first resection of the rectum with preservation of the anus and the sphincters. Due to complications this operation fell into disrepute. In 1908 Miles introduced his modification of Czerny's abdominoperineal resection which improved strongly the outcome of the surgery ${ }^{1}$. The introduction of the stapling techniques and the better understanding of rectal cancer pathology nowadays allow preservation of the sphincter without compromise to oncological safety.

Still, standard treatment for patients with a rectal tumor at less than 5 cencimeters from the anal verge is a Miles resection and the creation of a permanent colostomy. The presence of the stoma inevitably distorts the parients' body image ${ }^{2}$ and can have a considerable effect on the quality of life ${ }^{3,4}$. Furthermore, it is to be expected that one out of three parients will have moderate to severe complications with their stoma and 10 percent will need to be re-operated 5.6

Total anorectal reconstruction consists of a Miles resection of the anorectum ${ }^{1,7}$, a pull-through of the colon stump to the perineum and the creation of a new pelvic floor and anal sphincter ${ }^{8}$. The electrically stimulated gracilis muscle, or dynamic graciloplasty, has proven to act as a well functioning new sphincter in patients with intractable fecal incontinence?. To replace the resected pelvic floor a second gracilis muscle is added. Several configurations have been described, with or without electrical stimulation, claiming moderate to very good results ${ }^{10-17}$.

After resection of the anal canal and the rectum, sensibility, storage capacity of feces and coordination of defecation are lost as well. Construction of a pouch aims to increase the distensibility of the neorectum and decreases its propulsive drive ${ }^{18}$. Because autonomic colon contractions proved to be a problem in some patients a pouch was constructed in 4 of the 20 patients in order to overcome this problem.

The aim of this study is to evaluate the technique and the overall results with the double dynamic graciloplasty as well as the preliminary results of the patients in whom a pouch was added.

\section{Patients and Methods}

Berween May 1991 and May 199620 patients were treated with a mean age of 52 years (range 25-71) (Table 1). Eight were male and twelve female. Prerequisites to be selected for this procedure were: a histologically proven adenocarcinoma of the last $5 \mathrm{~cm}$ of the rectum that had to be well resectable, no proof of regional spread or signs of distant metastases, good general condition and good function of the gracilis muscles. All parients with a primary reconstruction were pre-operatively screened with a physical examina- 
Table 1. Patient dara. Sex, age, stage according to Astler-Coller classification, primary or secundairy procedure eventually with pouch (P), possible complications and final result are depicted.

\begin{tabular}{|c|c|c|c|c|c|c|}
\hline & $\mathrm{M} / \mathrm{F}$ & Age & Stage & Prim/Sec & Complication & Result \\
\hline 1. & $\mathrm{~F}$ & 46 & $\mathrm{~B} 2$ & prim & necrosis colon stump & stoma \\
\hline 2 . & $M$ & 56 & $\mathrm{~B} 2$ & $\sec$ & $\begin{array}{l}\text { presacral bleeding, infection } \\
\text { pacemaker, stenosis }\end{array}$ & continent, enemat \\
\hline 3. & $\mathrm{~F}$ & 53 & B1 & prim & & continent, enema \\
\hline 4. & I: & 67 & A & prim & stenosis & sroma \\
\hline 5. & $M$ & 52 & $\mathrm{BI}$ & prim & $\begin{array}{l}\text { necrosis colon stump, } \\
\text { liver metastases }\end{array}$ & stoma \\
\hline G. & $\mathrm{F}$ & 65 & $\mathrm{~B} 2$ & prim & & continent \\
\hline 7. & $M$ & 64 & A & prim & & incontinent \\
\hline 8. & $\mathrm{l}:$ & 46 & $\mathrm{~B} 2$ & prim & & continent \\
\hline 9. & I: & 28 & $\mathrm{C} 2$ & $\sec$ & stenosis, lung metastasis & continent, enema, \\
\hline 10 & $\mathrm{~F}$ & 68 & $\mathrm{~B} 2$ & prim & & stoma \\
\hline 11. & $\mathrm{~F}$ & 71 & B2 & prim & brain metastasis, hemiplegic & continent, enema \\
\hline 12. & $\mathrm{M} \dagger$ & 53 & B2 & prim & lung metastasis & continent, enema, died \\
\hline 13. & $\mathrm{~F}$ & 34 & B1 & prim $+P$ & & stomát \\
\hline 14 & $\mathrm{~F}$ & 25 & $\mathrm{Cl}$ & prim + P & & continent, enema \\
\hline 15. & $\mathrm{M}$ & 40 & $\mathrm{C} 2$ & prim $+\mathrm{P}$ & & incontinent, will start enemas \\
\hline 16. & $\mathrm{~F}$ & 45 & B2 & prim $+P$ & & in training \\
\hline 17. & M & 51 & A & sec & & in training; \\
\hline 18. & $\mathrm{~F}$ & 71 & Bl & $\sec$ & & to be implanted \\
\hline 19. & M & 63 & $\mathrm{~B} 2$ & $\sec$ & & to be implanted \\
\hline 20. & M & 43 & $\mathrm{C}$ & $\sec$ & & to be implanted \\
\hline
\end{tabular}

$\dagger=$ disease related death.

tion, CEA-level, colonoscopy, rectal endosonography, abdominal CT-scan, sonography of liver and chest-Xray.

The mean distance from the anal verge to the lowest edge of the tumor was detarmined before operation on colonoscopy and this was $3.0 \mathrm{~cm}$ (range 0 to $5 \mathrm{~cm}$ ). The mean tumor diameter was $4.6 \mathrm{~cm}$ (range 2 to $8 \mathrm{~cm}$ ). Patients were classified according to the modified Astler-Coller system (Table 1). In 14 patients the abdomino-perineal resection, the pull-through and the double dynamic graciloplasty were performed in one session. Six parients recived preoperative radiotherapy in a dose of 45 Gray over 5 weeks according to the protocol applied in one of the centers (Netherlands Cancer Institute).

In 6 patients the pull-through with the graciloplasty was done at an average of 4.1 year $(1.1$ - 8.8) after the APR. Prerequisites to be selected for this procedure were: major physical and psychological difficulties with the colostomy, free from local recurrence or distant metastases for at least 2 years (only in patient no. 2 this was less), good general condition and good function of the gracilis muscles. These patients underwent the same pre-operative work up, except for anal endosonography. 
Beforc the operation all patients were well informed about the procedure, the possible complications, the fact that a temporary ileostomy would be created, and the possible advantages and disadvantages compared with other treatment modalities.

\section{The procedure was undertaken in 3 stages:}

Stage 1: Preoperatively the patient was prepared with mechanical colon preparation and all patients had preoperative systemic antibiotic prophylaxis for 24-hours (gentamycin, metronidazole, flucloxacillin). A standard Miles procedure was performed and the specimen was sent to the pathology lab, and after confirmation of removal of the complete tumor with a free lateral margin of at least $1.0 \mathrm{~mm}^{7}$ the operation was continued. The remaining left colon, the splenic flexure and part of the transverse colon were mobilized paying attention not to damage the arcade of Riolan. When there was adequare blood supply and enough length to reach the perineal skin the graciloplasties were performed. Both gracilis muscles were identified and mobilized, leaving the proximal neurovascular bundle intact ${ }^{19}$. In the first 5 patients the double graciloplasty was performed as described by Cavina et al ${ }^{12}$ (A configuration). One gracilis muscle was transposed behind the neorectum and fixed to the ischial tuberosity, serving as a new puborectal muscle. The other muscle is transposed around the neoanal canal and fixed to the pubic bone, serving as a neosphincter.

In the last 15 patients both gracilis muscles without distal tendons were used to re-create the pelvic floor and the anal sphincter simultaneously (B configuration). Both muscles were first passed dorsal to the new anal canal (Figure 1, 2a and $2 \mathrm{~b}$ ). In the mesentery a small opening was made next to the bowel wall at $3-4 \mathrm{~cm}$. of the end of the stump and both gracilis muscles were passed through this opening and fixed to each other. In this way, bloodflow to the end of the colon stump could not be endangered by compression of the mesentery by the double gracilis wrap. Furthermore, the graciloplasty in this way was anchored to the bowel without the use of surures. In all patients a temporary, protecting ileostomy was created.

In 4 patients a pouch was constructed. Just proximal to the intended gracilis wrap the colon was opened anti-mesenterically over a length of $15 \mathrm{~cm}$. In the defect an isolated segment of distal ileum, opened as a parch, was sutured. In this way a pouch was created without compromising the perineal colostomy.

To ensure that the gracilis muscles remained in good condition, the contractility was evaluated after 4 weeks by transcutaneous electrical stimulation and the sites of lowest threshold were marked. Voluntary contractions of the transposed gracilis muscles were tested by anal manometry.

Stage 2. Three months later, implantation of the stimulator and the leads was performed. An incision was made on the site of lowest threshold and an intramuscular flexible coil wire of platinum iridium was introduced as an anode $(4300$, Medtronic, Kerkrade, The Netherlands). At the site of the lowest threshold the electrode was pulled crosswise through the muscle and fixed. The length of the bare surface of the electrode 


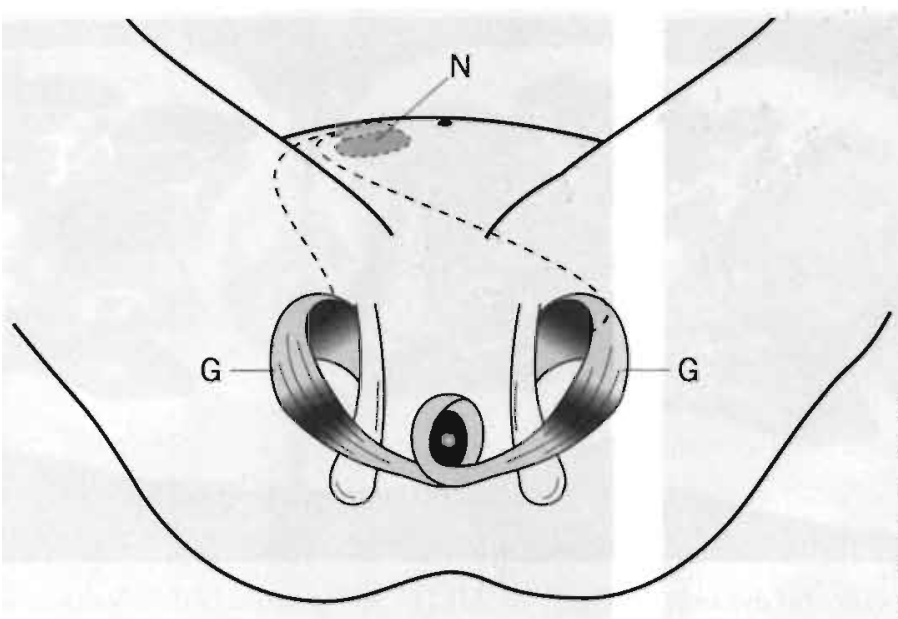

Figure 1. B configuration of the double dynamic graciloplasty, showing the gracilis musles $(G)$, the neurostimulator $(\mathrm{N})$, the electrodes (= dotred line) and the temporary ileostomy (S)

could be adjusted to the diameters of the muscle. The same procedure was performed on the other side. Subsequently, the leads were subcuraneously tunneled to a pocket in the lower abdominal wall contralateral to the protecting ileostomy and connected to an Itrel ${ }^{\mathrm{TM}}$ pulse generator (model 7424, Medtronic, Kerkrade, The Netherlands). Both leads were programmed as cathode while the stimulator case functioned as anode.

Electrical stimulation of the graciloplasty. Stimulation was started 3 days after implantation according to a previously described protocol ${ }^{19}$, consisting of 8 weeks of training with an increasing duty cycle before continuous stimulation was started. An external magnet was given to all patients to turn the mode of operation of the pulse generator "off" to permit defecation and "on" again after defecation.

Stage 3. When good funcrion was confirmed by defecography after 4 weeks of continuous stimulation (figure 3 ), the ileostomy was closed.

Then the final adaptation started for the parient, integrating (i) the use of the dynamic graciloplasty, (ii) the acquirement of a new defecation sensation, (iii) having a normal consistency of the feces. This would normally take about 3 to 4 months.

\section{Clinical evaluation}

All patients had regular follow up for their carcinoma. The number and nature of events of incontinence, the frequency of bowel emprying and the time to postpone defecation were recorded. Continence was classified from I to $\mathrm{V}$ according to a standardized scoring method. 2) The treatment was regarded as successful if the patient was continent to formed and liquid stools, while occasional soiling was accepted.

Anal manometry was performed using a Konigsberg catheter (Konigsberg Instruments Inc, Pasadena, CA), which was connected to a computer-assisted polygraph (Synecrics Medical, Stockholm, Sweden). Highest basal pressure, squeeze pressure and the pressure during electrical stimulation were measured by means of a standardized 


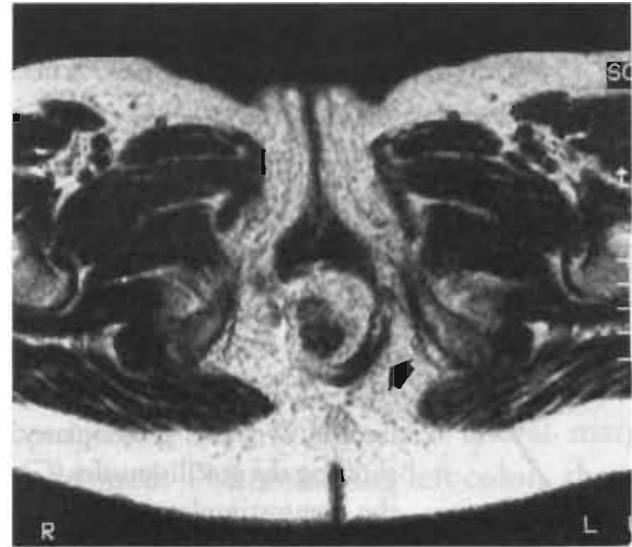

Figure 2a. MRI of configuration of double dynamic graciloplasty as applied in last 16 parients. The left gracilis muscle is indicated.(arrow)

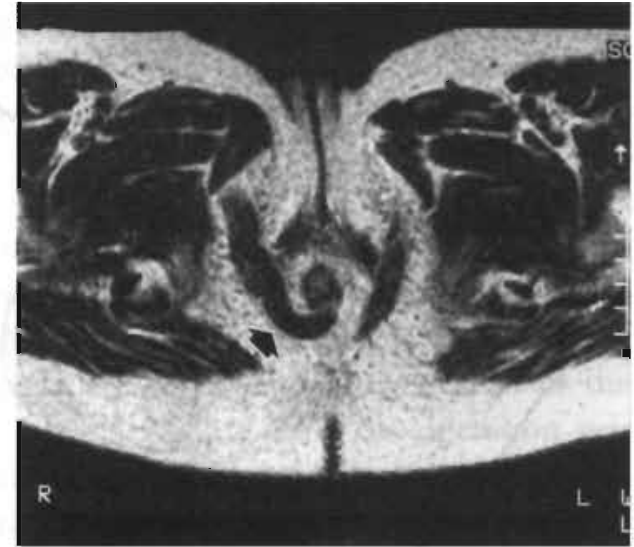

Figure 2b. MRI of configuration of double dynamic graciloplasty as applied in last 16 parients. The right gracilis muscle is indicated.(arrow)

stationary pull-through technique. Defecography was performed according to Goei. ${ }^{21}$ with the stimulator turned "on" and "off".

Patient data are expressed as mean and the range or the standard deviation. The studies were approved by the medical ethical committee of both hospitals. Informed consent was obtained from all patients.

\section{Results}

After a mean follow up of 24 months (range, 1 - 60) after APR the following disease-related, morbidity / mortality occurred. None of the patients developed local recurrence, while 4 patients developed distant metastasis. Patient no. 5 developed liver metastases and underwent a hemi-hepatectomy. Patient 9 who had been free of recurrence for 4 years when the dynamic graciloplasty was performed, developed a lung metastasis and she underwent radiotherapy. Patient no. 11 became hemi-plegic after surgical removal of the brain metastases she developed 18 months after APR. Patient no. 12 died of lung metastases he developed 10 months after APR.

Fifreen out of 20 patients were available for evaluation because 5 patients were still in training. Of these 15 patients 8 patients were continent ( 53 percent), 2 patients were incontinent and in 5 patients the perineal stoma was converted to an abdominal stoma (Table 1). Failures were due to necrosis of the colon stump $(n=2)$ and incontinence $(n=3)$. Patient no. 4 was continent for over a year but never regained continence after a severe GI-tract infection. Patients with a pouch did not better than parients without a pouch. 


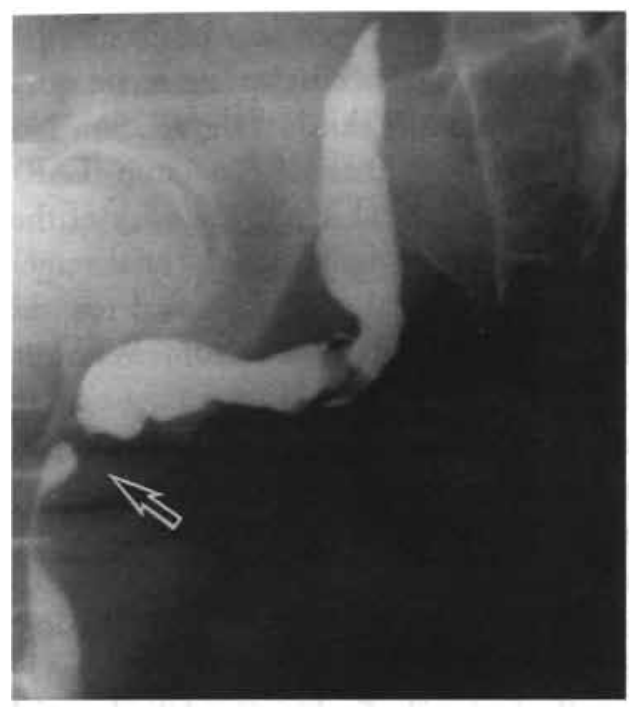

Figuie 3a. Defecography, the site of the double graciloplasty is indicated.(arrow) The neurostimulator is switched "on".

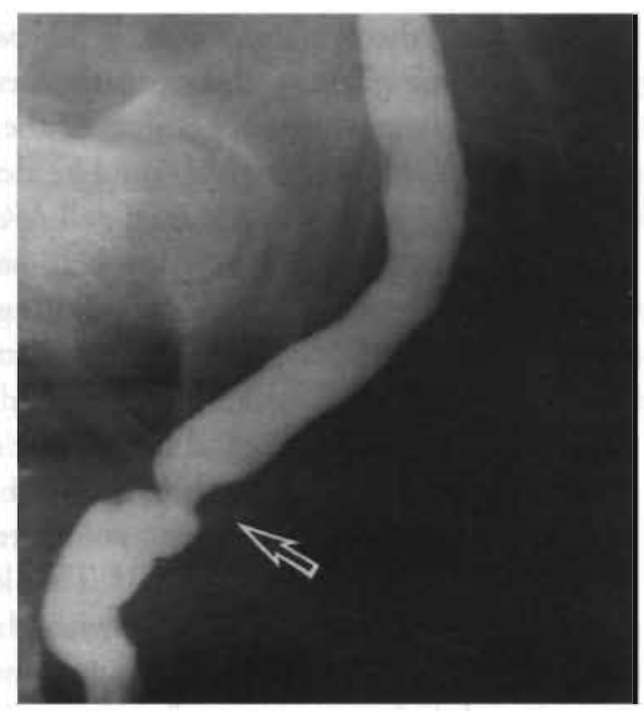

Figure 3b. Defecography, the site of the double graciloplasty is indicated.(arrow) Evacuation while neurostimulator is switched "off".

Manometry data are not complete because in some patients with configuration B the anal canal was pulled into an S-shape after several months of electrical stimulation making introduction of the probe impossible. After transposition, the overall mean resting pressure was 40 (S.D. 22) $\mathrm{mmHg}$ and the mean squeeze pressure, as measured while pressing the knees against each other, was $138 \mathrm{mmHg}$ (S.D. 114, $\mathrm{n}=20$ ). Ar 26 weeks the pressure during electrical stimulation was $90.7 \mathrm{mmHg}$ (S.D. 46) and at 52 weeks $92.2 \mathrm{mmHg}$ (S.D. 33, $\mathrm{n}=14$ ).

The stimulation voltage needed for a good contraction was 1.0 Volt (S.D. 0.5) at 0 weeks and mounted to 1.9 Volts (S.D. 0.7) at 8 weeks, 3.5 Volts (S.D. 1.2) at 26 weeks and 3.7 Volts (S.D. 0.6) at 52 weeks. There were no differences between configuration $A$ and $B$.

At 26 weeks the mean defecation frequency was 3 times per day (range 1 to 5). Of the 8 patients who were continent 6 used daily enemas. The mean time to postpone defecation was 11 minutes (range 0 to 30 ).

\section{Discussion}

The first goal in the treatment of rectal cancer is the prevention of local recurrence and distant metastasis. The outcome of surgery is strongly dependent upon the skills of the 
surgeon $^{22}$ and the technique used ${ }^{23,24}$. New insights into the importance of the distal ${ }^{25}$ and lateral ${ }^{7}$ margins together with the development of advanced stapling techniques allowed sphincter saving operations of the lower and middle third of the rectum. No differences in local recurrence could be detected after Low Anterior Resection (LAR) and $A P R^{26,27}$. Within one year after LAR, function is normal in the majority of the patients ${ }^{28}$. However, after very low colo-anal anastomosis $(<4 \mathrm{~cm}$ from the anal verge) functional outcome is often disappointing ${ }^{29}$. For oncological and functional reasons APR therefore is still the standard treatment in the lower third of the rectum. With the introduction of a new technique like the double dynamic graciloplasty, no concession should be made to oncological safety. The outcome of this study confirms the safety of the procedure which is in accordance with previous data ${ }^{30}$.

Patients treated by sphincter saving resection appeared to have a quality of life superior to patients treated by APR 4 . Thanks to the introduction of new stoma materials most people can cope very well with their stoma and live a life with acceptable limitations. Nevertheless receiving a stoma is experienced as a violation of the body image $^{2}$ and for some it can have a serious effect on physical, mental and social well-being ${ }^{3}$. Several attempts have been made to create a continent abdominal stoma such as the Kock pouch, the smooth muscle sphincter, the artificial sphincter and the Erlangen magnetic ring but no successful technique has been found ${ }^{31-33}$.

Attempts to create a continent perineal stoma have not been more successful. Experimental work on the use of an artificial sphincter was accompanied by many complications ${ }^{34}$. Application of the smooth muscle neosphincter was reported by Elias et $\mathrm{al}^{35}$ and Fedorov and colleagues ${ }^{36}$ but results were moderate. It is highly unlikely that continence can be achieved with a new internal sphincter alone. Fedorov and Shelygin ${ }^{37}$ also described the creation of a neosphincter with the use of the adductor longus femoris muscle.

In 1930 Chittenden ${ }^{38}$ used the glutei muscles to construct a new anal sphincter by transposing one gluteus muscle behind and the other in front of the neorectum. Simonsen ${ }^{10}$ et al were the first to use the gracilis muscle for anal sphincter reconstruction after APR. They brought the neorectum through an incision in the gracilis muscle. Wong and Wee ${ }^{11}$ performed an alpha-loop with fixation of the tendon to the ipsilateral pubic bone. Cavina et $\mathrm{al}^{39}$ used the same configuration but added a second gracilis muscle to replace the puborectal sling. The right muscle was passed behind the pulled-through colon and sutured to the controlateral ischial tuberosity to re-create the anorectal angle. The left muscle was, superficial to the right, transposed around the neorectum and surured to the skin. Postoperatively temporary electrical stimulation was given with an external stimulator in order to prevent muscle atrophy and to improve muscle function ${ }^{39}$. In our series we had a failure in two patients because of necrosis of the distal colon stump, therefore we remodeled the double graciloplasty into a configuration in which both gracilis muscles were transposed around the neorectum without the use of the tendons.(figure 1) This had the advantage that only muscular tissue 
surrounded the vulnerable pulled-through bowel, giving less impairment of circulation in the terminal colon while having a better potential for contraction. By first transposing the muscles posterior to the bowel the anorectal angle was restored at the same time. (figure $3 \mathrm{a}$ en b) Interesting experimental work in which the transposed skeletal muscle neosphincters are cross-innervated by intact pudendal nerves might add a new dimension to the "dynamic" graciloplasty and its function may even be superior ${ }^{40}$.

Total anorectal reconstruction performed years after the actual APR (secondary procedure) is a far more complicated operation than the performance of both procedures in one session. Adhesions formed over the years, possibly increased by post-operative radiotherapy make surgery difficult, especially in the narrow male pelvis.

Continence after graciloplasty performed for intractable fecal incontinence is compared with the situation of complete continence. In patients with a double graciloplasty after APR this is not realistic, continence will never be as it was before. All patients suffer from minor soiling. The 3 to 4 centimeters between the muscle wrap and the colo-cutaneous anastomosis consist of normal bowel which produces mucous which causes minor soiling. During the final adaptation the patient has to try to achieve an optimal regime, often with the use of daily enemas or loperamide. While in other series enemas had to be used for rectal voiding, ${ }^{41}$ in our study enemas were used to wash the neorectal ampulla in order to be clean for the resc of the day. Possible factors are the consistency of the feces, the length of the bowel removed and the tightness of the muscle wrap. Further complicating factors are the loss of sensibility, rectal capacity and coordination of defecation.

After an abdomino-perineal resection all receptors, necessary for sensation and discrimination of impending evacuation, situated in the anal canal ${ }^{42}$ and the rectum ${ }^{43,44}$ have been removed. Functional testing of the sensibility of the new anorectum revealed complete sensory loss in parients after total anorectal reconstruction ${ }^{45}$. However, clinical data showed that many patients develop an alternative form of perception after several months ${ }^{10,17,39,46}$. The type of perception can vary from a periumbilical sensation, a hypogastric murmur, tension on the gracilis muscles to a feeling described as almost similar to normal perception. In the future, development of artificial anorectal sensation using sensors measuring changes in electrical impedance or magnetic field strength across the anal canal may improve function ${ }^{47}$.

Analogous to the situation of a very low colorectal or coloanal anastomososis ${ }^{29}$, some patients after toral anorectal reconstruction experience a high bowel frequency and urgency. The normal function of the rectum as a reservoir organ and the role it plays in sensibility and coordination of anorectal motility and defecation is $\operatorname{lost}^{48}$. Some parients can have difficulties in voiding and have to be assisted by retrograde $e^{41}$ or antegrade irrigation ${ }^{49}$. Experimental work is exploring whether the construction of a J pouch in combination with electrically stimulated evacuation might improve function ${ }^{50}$. Other patients may experience occasional strong peristaltic waves, surpassing the holding forces of the gracilis neosphincter and thereby causing incontinence. Construction of a pouch 
constructed after LAR improved stool frequency and maximum tolerable volume but had no significant effect upon urgency, tenesmus, resting pressure or maximum squeezing pressure ${ }^{51}$. Unfortunately, preliminary results of the patients with a pouch in this series do not show clear improvement compared to the other patients. Despite an increased tolerable volume they all need daily irrigation.

In patients with a stoma constructed after APR for rectal cancer, who come with the request for total anorectal reconstruction, it can be very hard to evaluate whether the patient has an unmanageable stoma (for physical or psychological reasons) or not. We make use of an extensive quality of life questionnaire that has to be filled out by the patient twice (at home) with an interval of several weeks. Patients with a high quality of life (according to the questionnaire) are persuaded not to undergo the procedure. We realize that the effect of a stoma on a persons' quality of life is highly determined by his individual, and also cultural, situation. Therefore, the outcome of total anorectal reconstruction should not only be evaluated by clinical data but by a quality of life study as well.

\section{Conclusions}

Based on the results of this study we come to the conclusion that, in experienced hands, the double dynamic graciloplasty is an oncologically safe procedure which can have an acceptable functional outcome in a well selected group of patients. However, to improve the outcome further modifications will be necessary. So far, the addition of a pouch has not resulted in improvement in outcome.

\section{References}

1. Miles WE. A method of performing abdomino-perineal excision for carcinoma of the rectum and of the terminal portion of the pelvic colon. Lancet 1908;1812-3.

2. Orbach C, Tallent N. Modification of perceived body and of body concepts. Arch Gen Pswchiarry 1965; 12:126-35.

3. Sprangers MA, Taal BG, Aaronson NK, re Velde A. Quality of life in colorectal cancer: Stoma versus nonstoma patients. Dis Colon Rectum 1995;38:361-9.

4. Williams NS, Johnston D. The quality of life after rectal excision for low rectal cancer. Br J Surg 1983;70:460-2.

5. Porter JA, Salvati EP, Rubin RJ, Eisenstat TE. Complications of colostomies. Dis Colon Rectum 1989;32:299-303.

6. Londono-Schimmer EE, Leong AP, Phillips RK. Life table analysis of stomal complications following colostomy. Dis Colon Rectum 1994;37:916-20.

7. Quirke P, Durdey P, Dixon MF, Williams NS. Local recurrence of rectal adenocarcinoma due to inadequate surgical resection. Histopathological study of lateral tumour spread and surgical excision. Lancet 1986;2:996-9.

8. Abercrombie JE, Williams NS. Total anorectal reconstruction. $\mathrm{B}_{\mathrm{r}} \mathrm{J}$ Surg 1995;82:438-42. 
9. Baeten CG, Geerdes BP, Adang EMM et al. Anal dynamic graciloplasty in the treatment of intractable fecal incontinence. N Engl J Med 1995;332:1600-5.

10. Simonsen OS, Stolf NA, Aun F, Raia A, Habr Gama A. Rectal sphincter reconstruction in perineal colostomies after abdominoperineal resection for cancer. Br J Surg 1976;63:389-91.

11. Wong SK, Wee JT. Reconsrruction of an orthotopic functional anus after abdominoperineal resection. Aust N Z J Surg 1984;54:575-8.

12. Cavina E, Seccia M, Evangelista G et al. Perineal colostomy and electrostimulated gracil is "neosphincter" after abdomino-perineal resection of the colon and anorectum: a surgical experience and follow-up study in 47 cases [see comments]. Int J Colorectal Dis 1990;5:6-11.

13. Mercati U, Trancanelli V, Castagnoli GP, Mariotri A, Ciaccarini R. Use of the gracilis muscles for sphincteric construction after abdominoperineal resection. Technique and preliminary results. Dis Colon Rectum 1991;34:1085-9.

14. Williams NS, Hallan RI, Koeze TH, Warkins ES. Restoration of gastrointestinal continuity and continence after abdominoperineal excision of the rectum using an electrically stimulared neoanal sphincter. Dis Colon Rectum 1990;33:561-5.

15. Rosen HR, Feil W, Novi G, Zoch G, Dahlberg S, Schiessel R. The electrically stimulated (dynamic) graciloplasty for faecal incontinence-first experiences with a modified muscle sling. Int I Colorectal Dis 1994;9:184-6.

16. Santoro E, Tirelli C, Scutari F et al. Continent perineal colostomy by transposition of gracilis muscles. Technical remarks and results in 14 cases. Dis Colon Recrum 1994;37(suppl):S73-80.

17. Geerdes BP, Zoetmulder FA, Baeten CG. Double dynamic graciloplasty and coloperineal pullthrough after abdominoperineal resection. Eur J Cancer 1995;31A:1248-52.

18. Taylor BM, Cranley B, Kelly KA, Phillips SF, Beart RW, Jr., Dozois RR. A clinico-physiological comparison of ileal pouch-anal and straight ileoanal anastomoses. Ann Surg 1983;198:462-8.

19. Konsten J, Baeten CG, Spaans F, Havenith MG, Soeters PB. Follow-up of anal dynamic graciloplasty for fecal continence. World J Surg 1993;17:404-8.

20. Williams NS, Parel J, George BD, Hallan RI, Watkins ES. Development of an electrically stimulated neoanal sphincter. Lancet 1991;338:1166-9.

21. Goei R. Anorectal funcrion in patients with defecation disorders and asymptomatic subjects: evaluation with defecography. Radiology 1990;174:121-3.

22. McArdle CS, Hole D. Impact of variability among surgeons on postoperative morbidity and mortality and ultimate survival [see comments]. BM] 1991;302:1501-5.

23. Heald RJ, Ryall RD. Recurrence and survival after total mesorectal excision for rectal cancer. Lancet 1986; 1:1479-82.

24. Enker WE. Potency, cure, and local control in the operative treatment of rectal cancer. Arch Surg 1992;127:1396-401.

25. Williams NS, Dixon MF, Johnston D. Reappraisal of the 5 centimetre rule of distal excision for carcinoma of the rectum: a study of distal intramural spread and of patients' survival. Br J Surg 1983;70:150-4.

26. Nymann T, Jess $P$, Christiansen J. Rate and treatment of pelvic recurrence after abdominoperineal resection and low anterior resection for recral cancer. Dis Colon Rectum 1995;38:799-802.

27. Fick TE, Baeten CG, von Meyenfeldr MF, Obertop H. Recurrence and survival after abdominoperineal and low anterior resection for rectal cancer, without adjunctive therapy. Eur J Surg Oncol $1990 ; 16(2): 105-8$.

28. Garcia D, Hira G, Mompean B, Hernandez A, Pellicer E, Morales G, Parrilla P. Colonic motility: electric and manometric description of mass movement. Dis Colon Rectum 1991;34:577-84.

29. Lewis WG, Holdsworth PJ, Stephenson BM, Finan PJ, Johnston D. Role of the rectum in the physiological and clinical results of coloanal and colorectal anastomosis after anterior resection for recral carcinoma. Br J Surg 1992;79:1082-6.

30. Cavina $\mathrm{E}$. Outcome of restorative perineal graciloplasty with simultaneous excision of the anus and rectum for cancer: a ten-year experience with 81 patients. Dis Colon Rectum 1996;39:182-90. 
31. Kock NG, Myrvold HE, Philipson BM, Svaninger G, Ojerskog B. Continent cecostomy: an account of 30 patients. Dis Colon Rectum 1985;28:705-8.

32. Schmidt E. The continent colostomy. World J Surg 1982;6:805-9.

33. Husemann B, Hager T. Experience with the Erlangen magneticering colostomy-closure system. Int Surg 1984;69:297-300.

34. Satava RM, King GE. An artificial anal sphincter. Phase 2: Implantable sphincter with a perineal colostomy. J Surg Res 1989;46:207-11.

35. Elias D, Lasser P, Leroux A, Rougier P, Comandella MG, Deraco M. Colostomies perineales pseudo-continentes apres amputation rectale pour cancer. Gastroenterol Clin Biol 1993;17:181-6.

36. Fedorov VD, Odaryuk TS, Shelygin YA, Tsarkov PV, Frolov SA. Method of creation of a smoothmuscle cuff at the site of the perineal colostomy after excirpation of the rectum. Dis Colon Rectum $1989 ; 32: 562-6$.

37. Fedorov VD, Shelygin YA. Treatment of patients with rectal cancer. Dis Colon Rectum $1989 ; 32(2): 138-45$.

38. Chitrenden AS. Reconstruction of anal sphincter by muscles slips from the glutei. Ann Surg $1930 ; 92: 152$

39. Cavina E, Seccia M, Evangelista $G$ et al. Construction of a continent perineal colostomy by using electrostimulated gracilis muscles after abdominoperineal resection: personal technique and experience with 32 cases. Ital J Surg Sci 1987;17:305-14.

40. Congilosi SM, Johnson DR, Medor $M$ er al. Pudendal nerve innervarion of a skeletal muscle neosphincter for fecal incontinence: a canine model. Dis Colon Recrum 1995:38:PI 8-9.

41. Seccia M, Menconi C, Balestri R, Cavina E. Scudy protocols and functional results in 86 electrostimulated graciloplasties. Dis Colon Recrum 1994;37:897-904.

42. Duthie HL, Gairms FW. Sensory nerve-endings and sensation in the anal region of man. Br J Surg $1960 ; 47: 585-95$.

43. Goligher JC, Hughes ESR. Sensibiliry of the rectum and the colon. Lancer 1951;5:543-7.

44. Kamm MA, Lennard Jones JE. Rectal mucosal electrosensory testing-evidence for a rectal sensory neuropathy in idiopathic constipation. Dis Colon Rectum 1990:33:419-23.

45. Abercrombie JF, Rogers J, Williams NS. Toral anorectal reconstruction results in complete anorectal sensory loss. Brit J Surg 1996;83:57-9.

46. Barretr DM, Parulkar BG. The artificial sphincter (AS-800). Experience in children and young adults. Urol Clin North Am 1989;16:1 19-32.

47. Johnson D, Buie WD, Paterson R, Wong WD, Rothenberger DA, Madoff RD. Artificial anorectal sensation. Dis Colon Rectum 1994;37:P44

48. Akervall S, Fasth S, Nordgren S, Oresland T, Hulten L. Rectal reservoir and sensory function studied by graded isobaric distension in normal man. Gut 1989;30:496-502.

49. Hughes SF, Williams NS. Continent colonic conduit for the treatment of faecal incontinence associated with disordered evacuation. Br J Surg 1995;82:1318-20.

50. Hughes SF, Scotr SM, Pilot MA, Williams NS. Electrically stimulated colonic reservoir for total anorectal reconstruction. Br J Surg 1995;82:1321-6.

51. Orriz H, De Miguel M, Armendariz P, Rodriguez J, Chocarro C. Coloanal anastomosis: are functional results betrer with a pouch? Dis Colon Rectum 1995;38:375-7. 
Chapter 3.2

DOUBLE DYNAMIC GRACILOPLASTY AFTER TRAUMATIC DESTRUCTION OF THE RECTUM AND SPHINCTERS.

Dynamic graciloplasty for restoration of continence after traumatic destruction of the rectum and sphincters. Report of a case. Konsten J, Geerdes BP, Versluis P, Heineman E, Baeten CGMI.

J Trauma 38(1):11-3; 1995 


\section{Introduction}

Complex trauma of the anorectum with destruction of the sphincters usually requires the construction of a permanent colostomy. Gracilis muscle transposition around the anal canal has been used as sphincter reconstruction procedure. ${ }^{1}$ However, the clinical outcome may be disappointing because such a graciloplasty needs to be contracted voluntarily during a sustained period of time. ${ }^{2}$ Recently, good results have been achieved by using an electrically stimulated gracilis muscle neosphincter (dynamic graciloplasty) for treatment of fecal incontinence. ${ }^{3-5}$ In this procedure, gracilis muscle transposition is followed by the implantation of intramuscular electrodes and an electrical stimulator, 8 weeks later. The stimulator can be turned "off" with an external magnet to allow defecation. Such a dynamic graciloplasty was used in combination with rectal reconstruction in a girl who suffered from traumatic destruction of the anorectum.

\section{Case Report}

During summer 1992, a 13 year old girl was crossed over by a speedboat during her holidays in southern France. The screw propeller destroyed the complete perineum. The os coccyges, the distal sacrum, the posterior part of the rectum and the anal sphincters had disappeared. The accident also caused a disrupted pelvis and a fracture of the sacroiliac joint. The right sciatic nerve was damaged which resulted in a partial paralysis of the right leg. Initially, she was operated on in France where her fractures were stabilized and a colostomy was constructed. Afterwards, she was taken to the Maastricht University Hospital and anorectal reconstruction was proposed. Her coccyx and distal sacrum had disappeared and the rectum was open posteriorly, but the rectovaginal septum was intact and had kept a normal sensibility. Preoperative electromyographic investigation revealed that both gracilis muscles might be suited for anal sphincter reconstruction.

\section{Procedures}

\section{Reconstruction of the rectum and anal sphincters}

In January 1993, the rectum was reconstructed by using a modified Duhamel procedure, in which the previously constructed stoma was closed, and the distal colon mobilized, incised longitudinally and sutured to the anterior part of the rectum. ${ }^{6}$ The original anal sphincter musculature was absent. Consequently, a sphincter replacement procedure was indicared during the same procedure. Both gracilis muscles were dissected with their neurovascular supply left intact in this almost full-grown girl. The right gracilis was positioned around the rectum as a puborectal sling and sutured to the fascia of the 
opposite adductor muscles. The left gracilis was wrapped around the anal cinal in a circular fashion and sutured to the opposite ischial spine as described by Cavinit et al. ${ }^{7}$ Finally, a divided protective colostomy more proximal in the descending: colon wis made.

\section{Implantation of the stimulation device}

In the second operation (April 1993), a model SP 5528 intranuscular electrode (Medtronic, Kerkrade, The Netherlands) was sutured in each transposed gracilis muscle tunneled to a subcutaneous pocket in the lower abdominal wall, and then connected to an Itrel pulse generator (Model 7472, Medtronic, Kerkrade, The Netherlands). Subsequently, the dynamic graciloplasties were intermittently stimulated during the eight weeks before starting continuous stimulation. ${ }^{5}$ The sigmoid colostomy was closed in June 1993.

\section{Evaluation}

The neorectum was inspected endoscopically. The new anorectal physiology was tested by turning the stimulator " on " and "off " using: (1) anal manometry at regular intervals, (2) radiographs of the neorectum and neosphincter, and (3) retention time measurement of a $250 \mathrm{cc}$ enema that was installed in the neorectum.

\section{Results}

Postoperarive recovery was withour complications. Initially, after closure of the dividing colostomy the parient had problems with extreme liquid stools for two months. Six months later, she is now continent for formed stools. The patient considers call to stool similar to perception before the accident. Normal defecation is possible by turning off the stimulator with a magnet. Endoscopy revealed a normal neorectum withour any signs of inflammation. Anal manometry demonstrated that the pressure in the neoanal canal increased (table 1) with the stimulator on. The radiographs of the neorectum demonstrated the function of the neosphincter with the stimulator turned on while loss of contrast was shown without stimulation. In addition, she could retain $250 \mathrm{cc}$ of water for 2 minutes with the stimulator on, but there was immediate loss of enema if the stimulator was turned off. The patient did not have any complaints about her legs after gracilis muscle mobilization. 
Table 1

\begin{tabular}{llllll}
\hline time (weeks) after implantation & 0 & 2 & 4 & 6 & 8 \\
\hline resting pressure (mm Hg) * & 25 & 34 & 53 & 50 & 46 \\
pressure with stimulator "on" (mm Hg) ** & 27 & 42 & 86 & 90 & 63 \\
stimulation voltage (Volts) *** $^{* \cdots *}$ & 2.0 & 2.4 & 2.4 & 2.4 & 2.6 \\
\hline
\end{tabular}

* resting pressure is the maximal anal canal pressure with the stimulator "off"; ${ }^{* *}$ pressure wich stimulator "on" is the maximal anal canal pressure with the stimulator "on"; ${ }^{* * *}$ stimulation voltage is the amplitude which was necessary to achieve the anal canal pressure increase

\section{Discussion}

The combination of dynamic graciloplasty and reconstruction of the rectum has not been reported previously, to the best of our knowledge. Although perineal injuries in children are not rare, surgical procedures describe either rectal reconstruction or sphincter reconstruction. ${ }^{8,9}$ We decided to use both dynamic graciloplasty and rectal reconstruction and found a good clinical outcome. Continence might have been achieved in this patient because she had a normal anorectal sensibility which was due to the intact rectovaginal seprum. Stelzner ${ }^{9}$ reported that secondary sphincter reconstruction after trauma was never successful in his series. All patients who had a gracilis muscle transposition required construction of a permanent colostomy, which he attributed to extensive scar formation around the anal canal. However, not only scar formation after trauma but also the inability of a patient to concentrate 24 hours a day on voluntarily and sustained gracilis muscle contraction may contribute to the disappointing results of a conventional graciloplasty. Electrical stimulation of such a conventional graciloplasty induces a sustained contraction independent of volition and as a consequence restoration of sphincter function. ${ }^{10}$

Simonsen et al. ${ }^{11}$ used the gracilis muscle for reconstruction of the anal sphincter after abdominoperineal resection without electrical stimulation. Seventeen of 22 patients were continent for soft and solid stools. However, their study was not supported by objective data such as anal manometry, radiographs and retention times. Nevertheless, a prospective randomized study is indicated to compare an electrically stimulated gracilis muscle neopshincter with a conventional graciloplasty because data from previous studies are inharmonious. ${ }^{1-5,7,11}$ Although, Baeten et al. demonstrated in a case control study that a graciloplasty without electrical stimulation could not ensure continence. $^{3}$ 


\section{Conclusion}

We conclude that anorectal reconstruction in combination with dynamic graciloplasty avoided the construction of a permanent colostomy after trauma in this patient. Meticulous follow-up is indicated.

\section{References}

1. Pickrell KR, Broadbent TR, Masters FW, Merzger JT. Construction of a rectal sphincter and restoration of anal continence by transplanting the gracilis muscle: reporr of four cases in children. Ann Surg 135: 853-62, 1952

2. Christiansen J, Sørenson $M$, Rasmussen $\emptyset$. Gracilis muscle transposition for faecal incontinence. Br J Surg 77: 1039-40, 1990

3. Baeten CGMI, Konsten J, Spaans F, et al: Dynamic graciloplasty for treatment of faecal incontinence. Lancet 338: 1163-65, 1991

4. Williams NS, Parel J, George BD, et al: Development of electrically stimulated neoanal sphincter. Lancer 338: 1166-69, 1991

5. Konsten J, Baeten CGMI, Spaans F, Havenith MG, Soeters PB. Follow-up of anal dynamic graciloplasty for faecal continence. W J Surg 17: 404-9, 1993

6. Duhamel B. Retrorectal and transanal pull-through procedure for the treatment of Hirschsprung's disease. Dis Colon Rectum 7: 1964; 455-8

7. Cavina E, Menconi G, Ghiselli M, Seccia M. Static Dynamic Graciloplasty: a reconstructive technique of the anal sphincrers after abdominoperineal resection of the rectum. Dis Colon Recrum 36: P29, 1993

8. Birolini D, Steinman E, Utiyama EM, Arroyo AA. Open pelviperineal trauma. J Trauma 30:492-495, 1990

9. Stelzner F. Complex injuries of the perineum, especially of the anorectal sphincter. Langenbecks Arch Chir 375: 55-63, 1990

10. Konsten J, Baeren CGMI, Havenith MG, Soerers PB. Morphology of dynamic graciloplasty compared with the anal sphincrer. Dis Colon Rectum 36: 559-63, 1993 ,

11. Simonsen OS, Stolf NAG, Aun F, Raia A, Habr-Gama A. Rectal sphincter reconstruction in perineal colostomies after abdominoperineal resection for cancer. $\mathrm{Br}_{\mathrm{J}} \mathrm{J}$ Surg 63: 389-91, 1976 


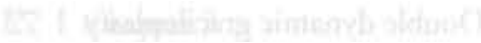


Chapter 4

\section{DYNAMIC GRACILOPLASTY: \\ Complications and management.}

Dynamic graciloplasty: Complications and Management. Geerdes BP, Heineman E, Konsten J, Soeters PB and Baeten CGMI.

Dis Colon Rectum 1996;39:912-17. 


\section{Introduction}

When a permanent colostomy is the only option that remains in treatment of intractable fecal incontinence, the patient could be treated by dynamic graciloplasty; however, the results of conventional graciloplasty are disappointing. ${ }^{1}$ Dynamic graciloplasty entails the implantation of leads and a pulse generator to give continuous electrical stimulation to a gracilis muscle, which is wrapped around the anal canal according to Pickrell et al. ${ }^{2}$ Continuous stimulation improves the function of the graciloplasty because it enables a prolonged contraction, something which is impossible to perform by voluntary action and because stimulation induces a transformation of Type II, fatigue-prone, muscle fibers into Type I, fatigue-resistant, muscle fibers. ${ }^{3}$

Results have been encouraging; $4-6$ however, applicarion of the technique involves specific problems. In this study, complications during an eight-year period are analyzed.

\section{Patients and methods}

Berween November 1986 and April 1995, 67 parients (48 female, 19 male) were treated with anal dynamic graciloplasty for fecal incontinence. Etiology of the disabling incontinence was anal atresia $(n=13)$, trauma $(n=34)$, and pudendopathy $(n=20)$. Median age was 44 (range 18-71) years, and median duration of incontinence was 13.1 (range, $1-40$ ) years.

All patients underwent preoperative anorectal manometry, defecography, and an electromyography. Anorecta! manometry was performed using a Konigsberg ${ }^{T M}$ catheter (Konigsberg Instruments Inc, Pasadena, CA), which was connected to a compurer-assisted polygraph (Synectics Medical, Stockholm, Sweden). By repeated inflation of a rectal balloon, sensation, urge capacity, and rectoanal inhibitory reflex were measured. Electromyography was performed of the external sphincter, pelvic floor, and both gracilis muscles. Both pudendo-anal reflex and pudendal nerve terminal motor latency were determined using a Nicolet Viking I IM electromyography apparatus (Nicoler, Madison, Wisconsin, USA). Patients were selected for this treatment modality when electromyography showed moderate to severe damage to the pudendal nerve.

The gracilis muscle was transposed around the anal canal, leaving the neurovascular bundle intacr (figure 1), and six weeks later the neurostimulator (Itre ${ }^{\circledR} \mathrm{II}$, model 7424, Medtronic, Kerkrade, The Netherlands) and the intramuscular electrodes (model 4300-35, Medtronic, Kerkrade, The Netherlands) were implanted. ${ }^{7}$ Stimulation was started three days later employing a pulse width of $210 \mathrm{~ms}$, a stimulation frequency of 25 pulses, and a cyclic mode with an "on" time of 0.1 second and an "off" time of 1.2 seconds, yielding a duty cycle of 8 percent (the time during which the muscle is actually contracting). Subsequently, the duty cycle was increased over the next six weeks to 14 percent $(0.2$ seconds on and $1.2 \mathrm{sec}$ off) after two weeks, 36 percent $(0.4$ seconds on 

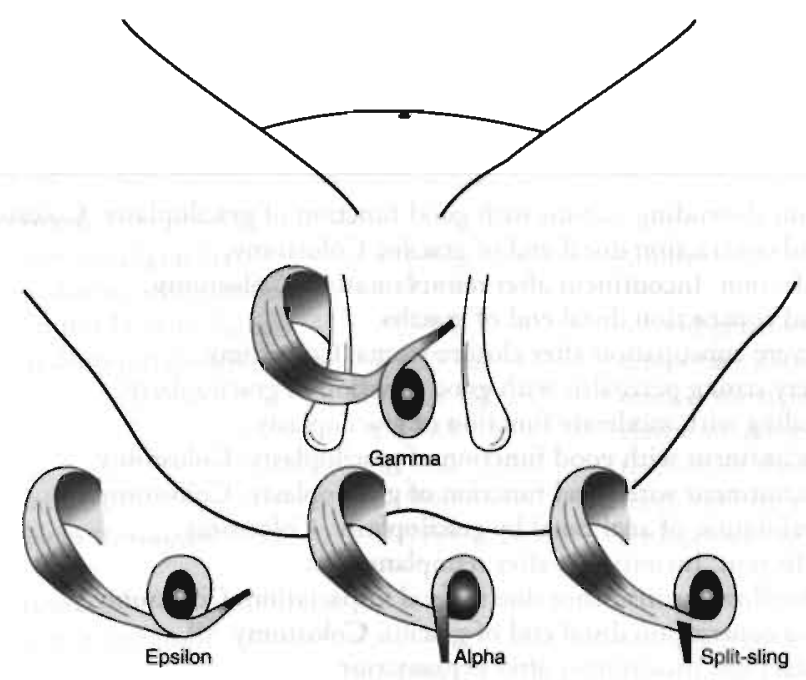

Figure I. Configurarion of the graciloplasty. The gracilis muscle is transposed from the right leg, wrapped around the anal canal and fixed to the ischial spine. The $\gamma-$, $\alpha-\varepsilon$-loop and the split-sling are depicted.

and 0.7 seconds off) after four weeks, and 67 percent ( 1 second on and 0.5 seconds off) after six weeks. At eight weeks, continuous stimulation was started. Continence was defined as being continent to solid and liquid stools and eventually to flatus. ${ }^{5}$

Postoperatively, all patients were monitored closely at fixed intervals $(2,4,6,8,16$, 26, 52 weeks, 1.5, 2, 3 years etc.). Physical examination, anal manomerry and defecography were repeated. All complications were noted and treated.

Patient data are expressed as median and the range; correlation was tested with the Spearman's correlation coefficient. Results were considered significant if $\mathrm{P}<0.05$. Studies were approved by the medical ethical committee of Mastricht University Hospital. Informed consent was obtained from all patients.

\section{Results}

With a mean follow-up of 2.7 years after the implantation of the neurostimulator (range, 14 weeks- 8.7 years), 52 patients ( 78 percent) were continent. No patient was continent after graciloplasty alone. Mean preoperative resting pressure $(n=67)$ was $36 \mathrm{mmHg}$ (standard deviation $(S D)=22$ ), and mean squeeze pressure was $55 \mathrm{mmHg}(S D=32$ ). Resting and squeeze pressures one year after implantation of the stimulator $(n=53)$ are $57 \mathrm{mmHg}(\mathrm{SD}=23)$ and $90 \mathrm{mmHg}(\mathrm{SD}=37)$ and remain stable thereafter. 
Table 1. Patients in whom the dynamic graciloplasty failed with the parhogenesis of fecal incontinence ( 1 = anal atresia, 2 = trauma, 3 = pudendoparhy) and the cause of failure.

\begin{tabular}{lll} 
Pat & Group & Cause \\
\hline 1. & 1 & Non-distending rectum with good funcrion of graciloplasty. Colostomy. \\
2. & 1 & Bad contraction distal end of gracilis. Colostomy. \\
3. & 1 & Infection. Incontinent after reimplantation. Colostomy. \\
4. & 1 & Bad contraction distal end of gracilis. \\
5. & 1 & Severe constipation after closure stoma. Colostomy. \\
6. & 1 & Very strong peristalsis with good function of graciloplasty. \\
7. & 2 & Soiling with moderate function of graciloplasty. \\
8. & 2 & Incontinent with good function of graciloplasty. Colostomy. \\
9. & 2 & Incontinent with good function of graciloplasty. Colostomy. \\
10. & 3 & Perforation of anal canal by graciloplasty. Colostomy. \\
11. & 3 & Infecrion. Incontinent after reimplantation. \\
12. & 3 & Overflow incontinence due ro fecal impactation. Colostomy. \\
13. & 3 & Bad contraction distal end of gracilis. Colostomy. \\
14. & 3 & Infecrion. Incontinent after explantation. \\
15. & 3 & Bad contraction distal end of gracilis.
\end{tabular}

In 15 patients, results are regarded as unsuccessful (Table 1). Of these, 11 were among the first 30 patients treated whereas in next 37 patients only 4 failures occurred. Complications resulted from technical problems, problems with infection, and problems attributable to an abnormal physiology of the muscle or an anorectal functional imbalance. In total, 53 complications were identified in 36 patients. Complications, actions taken, and outcome are summarized in Table 2.

Technical problems were encountered 25 times in 21 patients. In five patients, this led to eventual failure of the procedure. In four patients, insufficient contraction of the distal part of the gracilis muscle caused a failure of the graciloplasty ( 6 percent). In one patient, perforation of the anal canal during stimulation required the creation of a permanent colostomy.

Two transposed gracilis muscles could not be stimulated afterwards ( 3 percent), and a second graciloplasty had to be performed. The anal canal was perforated during transposition in one patient, requiring creation of a temporary ileostomy. In three patients, the tendon had to be shortened because the wrap was performed roo loosely (4 percent). In two patients there was transient edema of the leg after transposition of the muscle.

Revision of a lead had to be performed in five patients (7 percent), twice for a bad connection to the stimulator and three times because of dislocation. Because of displacement, the stimulator had to be repositioned in six patients $(9$ percent). In one patient, there was spontaneous off-switching of the stimulator; after replacement of the stimu- 
Table 2. Complications that occurred with the dynamic graciloplasty, divided in technical, infectious and physiological complications.

Incidence

Technical complications:

Insufficient contraction distal gracilis

Perforation anal canal during stimulation

Transposed muscle cannot be stimulated

Perforation anal canal during transposition

Anal wrap too loose

Transient edema leg

Lead problems

Displacement stimulator

"Off"-switching problem stimulator

Infectious complications:

Infecrion neurostimulator and leads

Perianal infection

Inficcion lead

Physiological complications:

Overflow incontinence

Soiling

Non distending rectum

Strong peristalsis

Severe constipation

Moderate constipation

No clear reason found

$4(6 \%)$
$1(1.5 \%)$
$2(3 \%)$
$1(1.5 \%)$
$3(4.5 \%)$
$2(3 \%)$
$5(7 \%)$
$6(9 \%)$
$1(1.5 \%)$

$8(12 \%)$

$2(3 \%)$

$1(1.5 \%)$
$1(1.5 \%)$

$1(1.5 \%)$

$1(1.5 \%)$

$1(1.5 \%)$

l $(1.5 \%)$

$12(18 \%)$

$2(3 \%)$
Result / therapy

failure

failure

second graciloplasty

temporary ileostomy

tendon shortened

elastic stockings

revision of the lead

repositioning stimulator

replacement stimulator

reimplantation ( $n=6)$, failure $(n=3)$

removal of suture

exchange lead failure

failure

failure

failure

failure

biofeedback, laxatives, enemas

failure

lator, the parient did well. Apart from this, no hardware problems (concerning stimulator or leads) occurred.

Complications by infection were encountered 11 times in ten patients. In three patients, this led to eventual failure of the technique. Infection of the implanted neurostimulator and leads occurred in eight patients (12 percent). Two patients remained continent without reimplantation; the other six patients had a reimplantation of a neurostimulator and leads. Three of these patients did not regain continence.

In two patients, a perianal infection occurred after transposition of the muscle. Instead of the usual prolene sutures, silk sutures were used to anchor the gracilis tendon. Both patients recovered well after removal of the suture. One patient had an infection of one of the leads, which was successfully replaced.

Finally, complications related to physiological imbalance occurred 17 times in 17 patients. The technique failed in 5 patients because of overflow incontinence, soiling, 
nondistending rectum, strong peristalsis and severe constipation. Twelve patients complained of constipation (18 percent) of a mild nature.

Analyses of the success rate in connection with the pathogenesis of incontinence reveal that in the anal atresia group only 7 of 13 patients ( 54 percent) were treated successfully, whereas in the trauma group 31 of 34 ( 91 percent) were continent after treatment. In the pudendopathy group, this was 14 of 20 (70 percent).

Assessment of the threshold for sensation in the anal canal revealed a median of 50 $\mathrm{ml}$ in the anal atresia group ( $\mathrm{n}=7$; range, $10-100), 30 \mathrm{ml}$ in the trauma group ( $\mathrm{n}=29$; range, $8-70)$, and $40 \mathrm{ml}$ in the pudendopathy group $(n=18$; range, 12-180). Sensation associated well with the outcome of treatment $(p=0.003)$. Capacity of the rectum appeared to be similar in all three groups, $150 \mathrm{ml}$ on average.

Two patients ( 3 percent) remained incontinent despite a well-functioning graciloplasty. No obvious cause for this failure was found.

\section{Discussion}

A steep learning curve was experienced with the application of the dynamic graciloplasty, and these data confirm a previous report. ${ }^{8}$ Dealing with the reported complications requires a profound understanding of all three categories involved (technical, infecrious and physiologic).

In understanding the technical problems, both the background of muscle transposirion and muscle stimulation should be considered. Afrer the gracilis muscle is transposed around the anal canal, the whole muscle should be well vascularized in order to guarantee viable, contracting muscle tissue. Minor or no contraction of the distal part of the gracilis with a good contraction of the proximal part can be attributed to several reasons. Ligation of the peripheral arteries may cause insufficient blood supply to the distal part of the muscle, inducing necrosis or fibrosis. No evidence of necrosis was observed, but fibrosis has been demonstrated in one occasional patient and may, therefore, have occurred in more parients with a failure. Division of the distal vascular pedicles four to six weeks before transposition of the muscle (vascular delay) is suggested ${ }^{5}$ to improve outcome by allowing formation of sufficient collaterals, but further investigation is needed.

An additional reason may be an inadequate construction of the anal wrap. A transposed muscle will adapt to the new situation by optimizing sarcomere number and length to develop optimal tension. ${ }^{9}$ Sometimes the wrap is still too loose requiring shortening of the tendon. A transposed gracilis muscle should allow at least $270^{\circ}$ of muscle tissue surrounding the anal canal. Continence is achieved by contraction of the muscle and not by tightness of the wrap. Too much tendon reduces the active part of the turn and can damage the bowel. In a patient with spina bifida with minor sensation 
in the perianal region and short muscular parts of the gracilis, the wrap was too tight and partly tendinous, resulting in late perforation of the anal canal.

So far, no randomized study has been performed to explore whether the final result depends upon the type of the loop. Good results have been reported with the gamma loop $^{6}$, the epsilon loop ${ }^{5}$, the alpha loop ${ }^{10}$ and the modified epsilon loop or splitsling ${ }^{11}$ (Figure 1). We previously used the gamma loop but switched to an epsilon loop (large muscle mass or much scar tissue in the rectovaginal septum) or an alpha loop (short muscle) when the operative situation demanded this. Certainly the choice is also a matter of preference and experience of the surgeon.

During the first months of stimulation a gradual increase of the amplitude is mandatory to preserve good muscle contraction. Type I muscle fibers become abundant after stimulation and contract less forceful than type II muscle fiber, which diminish in quantity. To develop the same force of contraction, a higher amplitude is required (that is, more motor units are recruited to yield the same effect). Also, as is customary with implanted devices, fibrosis is formed around the leads, and this is activated even more so by electrical stimulation. If the stimulation amplitude has to be strongly increased or if it exceeds $5 \mathrm{~V}$ and voluntary muscle contraction is good, dislocation or fracture of the lead may have occurred. Dislocation of the cathodal lead increases the electrode nerve distance requiring an elevation of the stimulation amplitude. This occurred in three parients: twice because of a trauma and once in a patient with osteogenesis imperfecta attributable to very weak muscle tissue. To optimize stability, leads have to be implanted perpendicular to the muscle fibers and need to be securely fixed to the epimysium.

In the course of the treatment, patients can experience pain in the transposed and stimulated gracilis muscle, the knee, around the anal canal, and over the neurostimulator or lead. Muscular pain can be caused by muscle fatigue, this can be reduced by decreasing the stimulation amplitude or frequency, restarting intermittent stimulation to retrain the muscle, choosing an alternative electrode selections ( $+/$-) or using unipolar stimulation. An inadequately low frequency can also cause pain because of insufficient pulses to induce a fused (tetanic) contraction. If pain is only experienced when the stimulator is switched on, stimulation of sensory nerves through an open circuit is possible. In one patient, an infection near the anus caused a pain sensation in the knee, probably mediated by still intact sensoric nerves. Pain over the stimulator pocket or the lead often is the result of infection or local tissue/skin irritation. Irritation over the pocket is treated by repositioning the stimulator in a deeper pocket (under the fascia of the rectus muscle) away from bony structures. During tunneling of the leads, care should be taken to place them far enough away from the pubic bone as not to cause pain through pressure when sitring on them, e.g. when biking.

Severe technical complications leading to failure of the rechnique occurred mainly in the beginning; manageable problems of dislocation and displacement still occur. In obese patients, neurostimulators are nowadays always fixed to the fascia of the $\mathrm{M}$. rectus abdominis because they tended to move or to twist. 
When foreign bodies are implanted, infection can be a serious cause of failure, especially in this easily contaminated area. Infection normally starts at the site of implantation of the leads and continues towards the stimulator. If infection occurs, antibiotic therapy is rarely efficacious, and removal of implanted devices is requested. The majority of infections occurred in the first 15 patients. The infection rate decreased sharply after antibiotic prophylaxis had been changed into application of systemic antibiotics (24 hours of metronidazole, gentamicin, flucloxacillin intravenously) and local antibiotics (Sulmycin Implant ${ }^{\circledR}$, Essex Pharma, Munich, Germany) and immersion of the neurostimulator and leads in a gentamicin solution before implantation. One-half of infections occurred after repositioning of a stimulator or a lead; therefore, optimal initial application is essential.

Sensory function of the anorectum is an important factor in the preservation of continence. ${ }^{12-14}$ Patients with an impaired sensation and /or an altered peristalsis of the bowel, therefore may benefit less from a restoration of the anal sphincter. In both groups of patients with long-standing pudendal neuropathy and anal atresia the threshold for sensation appeared to be higher than for patients in the trauma group, and this may account for the decreased success rate. According to current opinions in pediatric surgery, an infant with anal atresia is treated with the creation of a stoma directly after birth. Six months larer the colon stump is exteriorized and the anorectum is reconstructed. Apart from a hypotrophic external anal sphincter, sensation and motor function may be impaired as well. Whether this is congenital or induced by six months of bowel inactivity is uncertain. In three of these patients, the technique failed because of an abnormal rectal compliance or peristalsis. These deficits can probably be prevented by immediate repair after birth ${ }^{15}$ and not by the construction of a dynamic graciloplasty afterwards.

In none of the patients with constipation was an obstruction of the anal canal attributable to a very high resting pressure found. Three patients developed a lumpy, bag-shaped rectum, ${ }^{16}$ and they need to use enemas occasionally. Ten patients had a poor technique of straining, unable to produce enough propulsive force $(n=5)$ or simultaneously straining and contracting the graciloplasty $(n=5)$. Two patients improved without therapy, three patients regularly use enemas, and four patients were successfully treated with biofeedback training. One patient, incontinent because of a congenital origin, bciame severcly obstipated after closure of her stoma; when all further therapy failed, a new colostomy was created. It was remarkable that of the seven patients who underwent biofeedback training only patients who were incontinent because of trauma responded well, where:as both patients with long-standing pudendopachy and the patient with anal atresia did not.

Three of five physiological complications leading to failure of the technique are found in patients with anal atresia, although this group only represents 20 percent of the whole group. The other four failures in the anal atresia group are atrriburable to infections $(n=2)$ and technical problems $(n=2)$. Nine anal atresia patients were among the first 25 
patients treated. Failures in this group, therefore not only have their origins in an abnormal anorectal physiology but also suffer from the steep learning curve.

It should be noted that most patients treated so far were among the most difficule cases to deal with. Almost all had had multiple previous surgery and/or adjuvant therapies. It is to be expected that the complication rate will decrease if patients can be treated at an earlier stage.

\section{Conclusion}

Complications associated with the technique of the dynamic graciloplasty such as loss of contraction, infection, bad contraction in the distal part of the muscle, and constipation can often be prevented or treated. Difficulties related to an impaired sensation and/or motility, because of a congenital cause or degeneration, are impossible to treat, and this signifies that a good selection of the patients is essential to prevent disappointment.

\section{References}

1. Yoshioka K, Keighley MR. Clinical and manometric assessment of gracilis muscle transplant for fecal incontinence. Dis Colon Recum 1988;31:767-9.

2. Pickrel KL, Broadbent TR, Masters FW, Merzger JT. Construction of a rectal sphincter and restoration of continence by rransplanting the gracilis muscle. Ann Surg 1952;135(6):853-62.

3. Pette D, Vrbova $G$. Adaptation of mam malian skeletal muscle fibers to chronic electrical stimulation. Rev Physiol Biochem Pharmicol 1992;120:115-202.

4. Baeten CG, Konsten J, Spaans F et a!. Dynamic graciloplasty for treatment of faecal incontinence. Lancet 1991;338:1163-5.

5. Williams NS, Patel J, George BD, Hallan RI, Watkins ES. Development of an electrically stimulated neoanal sphincter. Lancet 1991;338:1166-9.

6. Baeten CG, Geerdes BP, Adang EM et al Anal dynamic graciloplasty in the treatment of intractable fecal incontinence. New Engl J Med 1995; 332:1600-5.

7. Konsten J, Baeten CG, Spaans F. Havenith MG, Soeters PB. Follow-up of anal dynamic graciloplasty for fecal continence. World J Surg 1993;17:404-8.

8. Gonzalez AP, Teoh TA, Wexner SD et al The stimulated gracilis neosphincter operation: initial experience, pitfalls and complications. [meeting abstract] Dis Colon Rectum 1995:38:P19

9. Williams PE, Goldspink G. Changes in sarcomere length and physiological properties in immobilized muscle. J Anat 1978;127:459-68.

10. Cavina E, Seccia M, Evangelista Getal. Perineal colostomy and electrostimulated gracilis "neosphincter $^{n}$ after abdomino-perineal resection of the colon and anorectum: a surgical experience and follow-up study in 47 cases [see comments]. Int ] Colorectal Dis 1990;5:6-11.

11. Rosen HR, Feil W, Novi G, Zoch G, Dahlberg S, Schiessel R. The electrically stimulared (dynamic) graciloplasty for faecal incontinence - first experiences with a modified muscle sling. Int J Colorectal Dis 1994;9:184-6.

12. Goligher JC, Hughes ESR. Sensibility of the rectum and the colon. Lancet 1951;1:543-8. 
13. Bielefeldt K, Enck P, Erckenbrecht JF. Sensory and motor function in the maintenance of anal continence. Dis Colon Rectum 1990;33:674-8.

14. Rogers J, Henry MM, Misiewce JJ. Combined sensory and motor deficit in primary neuroparhic faecal incontinence. Gut 1988;29:5-9.

15. Moore TC. Advantages of performing the saggital anoplasty operation for imperforate anus at birth. J Pediatr Surgery 1990;25:276-77.

16. Versluis PJ, Konsten J, Geerdes B, Baeten CG, Oei KT. Defecographic evaluation of dynamic graciloplasty for fecal incontinence. Dis Colon Rectum 1995;38:468-73. 
Chapter 5

MUSCLE PRESERVATION 

Chapter 5.1

\section{ASSESSMENT OF ISCHAEMIA OF THE DISTAL PART OF THE GRACILIS MUSCLE DURING TRANSPOSITION FOR ANAL DYNAMIC GRACILOPLASTY}

Assessment of ischaemia of the distal part of the gracilis muscle during transposition for anal dynamic graciloplasty. Geerdes BP, Kurvers HAJM, Konsten J, Heineman E, Baeten CGMI.

$\mathrm{Br} J$ Surg (in press) 


\section{Introduction}

Nowadays, anal dynamic graciloplasty proves to be a successful treatment modality for patients with intractable fecal incontinence. ${ }^{1,2}$ In this technique, the gracilis muscle is mobilized from the upper leg and wrapped around the anal canal with intact proximal neurovascular supply. In a second procedure, intramuscular electrodes and a pulse generator are implanted to activate the graciloplasty independent of volition. In about 25 percent of patients this treatment fails. Complications with the technique ${ }^{1}$, infection and constipation ${ }^{3}$ are the main reasons for failure. In 6 percent there is insufficient contraction of the distal part of the gracilis muscle, the part essential for closure of the anal canal.

Bloodsupply of the gracilis muscle is from the major vascular pedicle, descending from the profunda fumoris perforator artery, and by 1 to 4 minor pedicles, descending from the superficial femoral artery (Figure 1). Gracilis muscle mobilization may induce ischaemia of the distal parr of the muscle because it requires ligation of the minor vascular pedicles. Other possible causes of a compromised blood flow are muscle transposition and continuous electrical stimulation. Ischaemia can interfere with the clinical results because it provokes fibrosis or even necrosis of the distal gracilis muscle. An additional

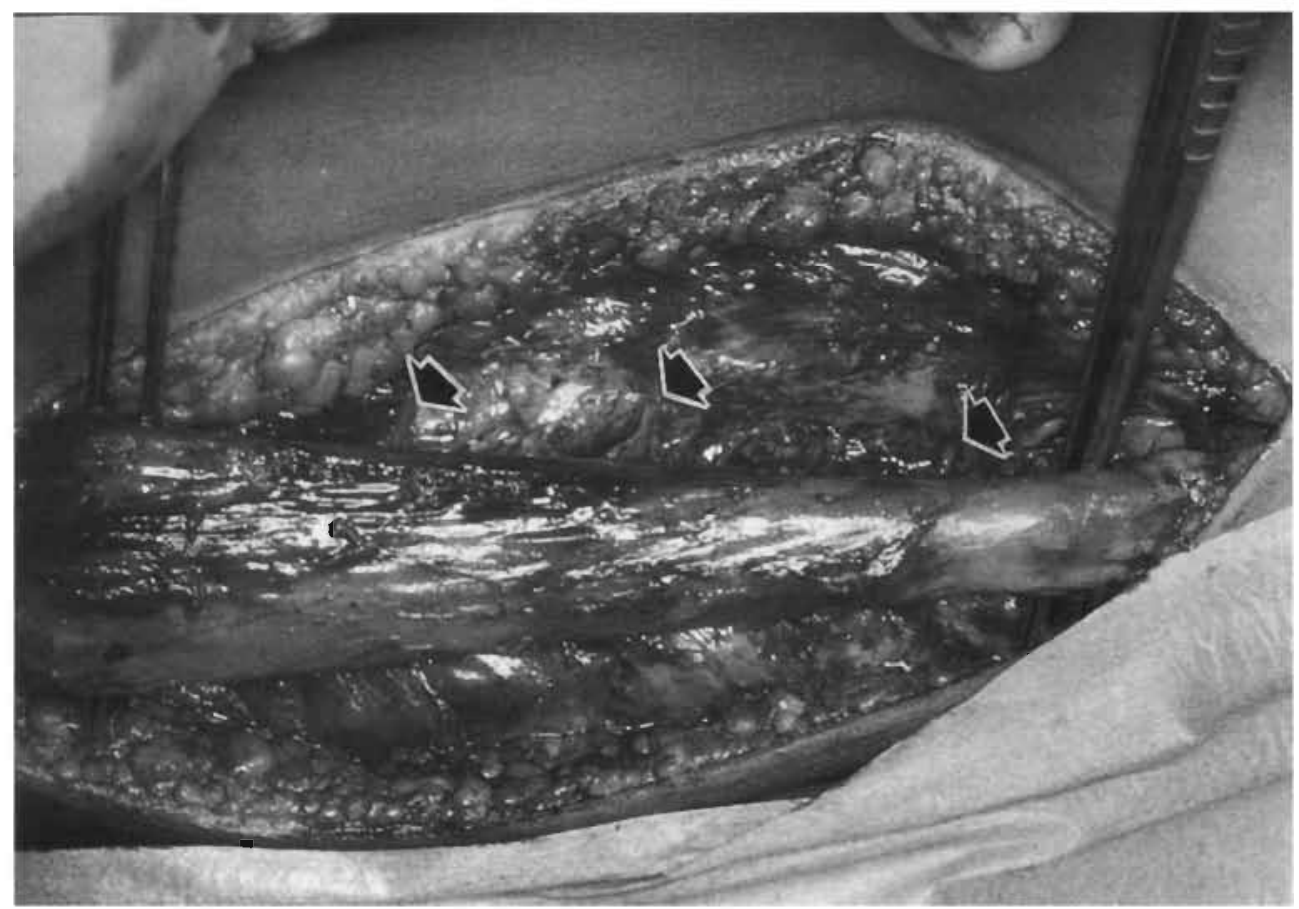

Figure 1. Photograph taken during the operation, showing the right gracilis muscle with 3 minor vascular pedicles (arrows) 
vascular delay procedure (ligation of the minor vascular pedicles several weeks before transposition) may be indicated to allow development of collateral vessels. ${ }^{4}$

Therefore we investigated the influence of ligation of the minor vascular pedicles on blood flow in the distal gracilis muscle. The arterial anatomy within the muscle was visualized. To quantify potential acute ischaemia capillary flow before and after ligation was assessed by peroperative measurement with laser Doppler flowmetry (LDF). Finally, we correlated changes in muscle blood flow with the functional outcome approximately 2 years after transposition.

\section{Patients and methods}

Eleven post-mortem gracilis specimens from 6 patients with a mean age of 69 years (range, 30-89) were dissected free from the surrounding tissue. The major vascular pedicle and all minor pedicles were cannulated. The muscles were placed on an imaging table and radiocontrast (Isopaque 350, Nycomed Imaging, Oslo, Norway) was injected into the main pedicle under continuous imaging (Diasonic 9600, OEC Medical Systems Inc, Salt Lake City, Utah, USA). Then, after real-time subtraction, radiocontrast was injected into the minor pedicle(s).

In ten consecutive patients (mean age of 40 years, range 18 - 62) undergoing a graciloplasty for fecal incontinence, we assessed blood flow in the distal part of the gracilis muscle, by means of laser Doppler flowmetry (LDF), before and after clamping of all minor vascular pedicles. All 10 patients had a normal EMG of the gracilis muscle. The LDF instrument has proven to be a useful tool to assess muscle blood flow. ${ }^{5}$ Its use, which has been described in detail before ${ }^{6}$, is based on the principle of Doppler shift of laser light, backscattered by moving blood cells. Measurements were performed with a commercially available system (Periflux PF3 monitor with a PF 302 needle probe, Perimed, Stockholm, Sweden). An output of 1 Volt was calibrated against 100 Perfusion Units (P.U.). The analog output from the LDF device was digitized by an analog to digital converter and subsequently stored on hard disk. Off-line analysis was performed employing a software program developed in our Institute. Following introduction of the needle probe $5 \mathrm{~cm}$ proximal from the distal tendon of the gracilis muscle, basal blood flow was measured ( 5 minutes recording) after stabilization of blood flow during at least 5 minutes. Subsequently all minor vascular pedicles were clamped after which muscle blood flow was allowed to stabilize during at least 5 minutes. Then, muscle blood flow was again assessed during 5 minutes. This procedure was repeated 3 times for each muscle. From these laser Doppler flow readings we calculated the mean basal blood flow before and after clamping.

As alluded to before, we correlated changes in muscle blood flow with the functional outcome. The functional outcome was judged by both anal manometry and clinical results. Anal manometry was performed using a Konigsberg catheter (Konigsberg 
Instruments Inc, Pasadena, CA), which was connected to a computer-assisted polygraph (Synectics Medical, Stockholm, Sweden). Continence was classified from I to V according to a standardized scoring method as described by Williams et al. ${ }^{4}$ Score I means continence to solids, liquids and flatus, score II: continence to solids and liquids but not to flatus, score III: continence to solids but occasional episodes of liquid incontinence, score IV: occasional episodes of incontinence of solids and score V: frequent episodes of incontinence of solids and liquids. Only patients with score I and II were considered as continent and thus successful.

Data are presented as means with standard deviation. Statistical analysis was performed with the Wilcoxon matched-pairs signed-ranks test and correlation was tested with the Spearman correlation coefficient. A p-value of less than 0.05 was considered statistically significant. The studies were approved by the medical ethical committee of the Maastricht University Hospital.

\section{Results}

The mean number of minor pedicles in the post-mortem specimen was 2 (range, 1-3). In several muscles the smallest minor pedicle, often located at the transition from muscle to tendon, was too small to be cannulated and even after successful cannulation the contribution of this pedicle to muscular bloodsupply was negligible. After radiocontrast injection of the major pedicle, a mean of 2 ascending (smaller) and 3 descending branches ( 2 large, 1 small) became visible parallel to the muscle fibers and giving off smaller branches that traversed the muscle. The largest descending branch connected all minor pedicles and upon injection all cannulae filled with contrast, suggesting the existence of one large arterial system. This was confirmed when radiocontrast was injecred at the site of a minor pedicle, in which case the whole system was filled as well. (Figure $2 \mathrm{a}$ and $2 \mathrm{~b}$ )

The mean number of minor pedicles in the patients operated upon was 2 (range, 1-4). Blood flow in the distal part of the gracilis muscle as assessed after clamping of the minor vascular pedicles (mean 25.8 p.u., range 6.5-74.3) did not differ from values obtained before clamping (mean 25.4 p.u., range 7.5-68.7) (table 1). Change (in percent) in muscle blood flow following clamping was also not significant $(p=0.33)$. There were considerable individual differences in basal blood flow and in change of flow after clamping.

After a mean of 1.8 years (S.D. 0.2) all muscles were vital and none of the patients suffered from post-operative complications such as perineal sepsis. After training by electrical stimulation the mean pressures were: $54 \mathrm{mmHg}$ (S.D. 20.6) at rest, $180 \mathrm{~mm} \mathrm{Hg}$ (S.D. 61.6) during active contraction and $110 \mathrm{mmHg}$ (S.D. 31.5) during electrical stimulation. No correlation existed between the change in muscle blood flow and either squeeze pressure $(r=-0.2)$ or functional outcome $(r=0.31)$. 

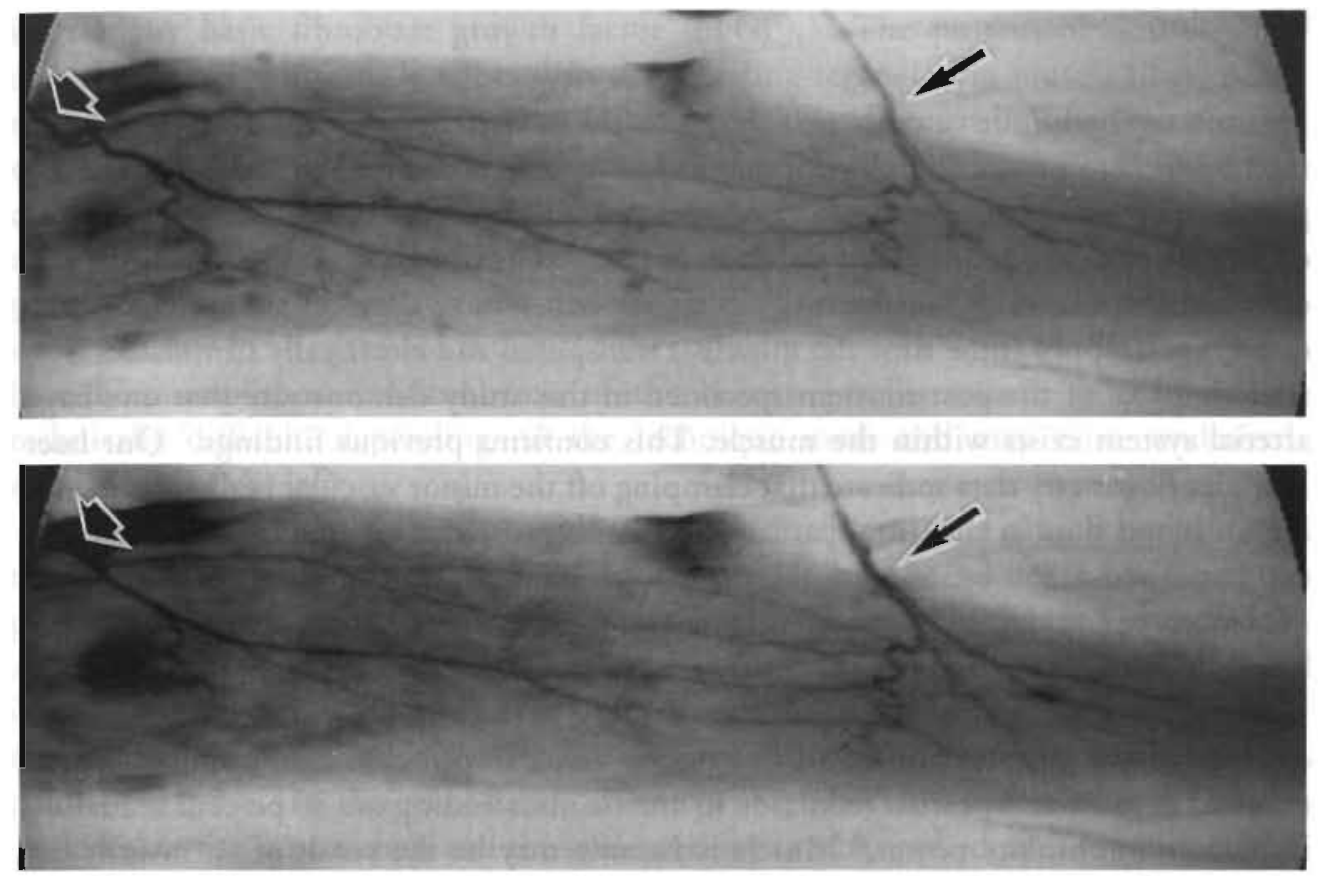

Figure $2 \mathrm{a}$ and $2 \mathrm{~b}$. Angiographies of the gracilis muscle. $a$. Radiocontrast is injected in the main vascular pedicle (broad arrow) and the arterial system within the muscle, including the minor vascular pedicle (small arrow), is filled. $b$. After real time subtraction radiocontrast is injected in the minor vascular pedicle (small arrow) and the same system, including the main vascular pedicle (broad arrow), is filled again

Table 1. Number of minor vascular pedicles, mean bloodflow data (s.d.) as measured by laser Doppler flowmetry before and after clamping of all minor vascular pedicles in perfusion units (s.d.), the change (in percent) and the final outcome of graciloplasty (according to the Williams incontinence classification) for all 10 patients.

\begin{tabular}{llllll}
\hline Parient & No & $\begin{array}{l}\text { Before } \\
\text { (p.u.) }\end{array}$ & $\begin{array}{l}\text { After } \\
\text { (p.u.) }\end{array}$ & $\begin{array}{l}\text { Percentage } \\
(\%)\end{array}$ & Outcome \\
\hline 1 & 1 & $7.5(0.1)$ & $6.5(0.2)$ & 13.3 & 2 \\
2 & 2 & $26.9(5.2)$ & $30.2(17.3)$ & -12.3 & 2 \\
3 & 2 & $46.2(23.8)$ & $36.8(20.2)$ & 20.4 & 2 \\
4 & 1 & $28.9(5.8)$ & $30.1(5.5)$ & -4.2 & 1 \\
5 & 1 & $19.4(2.7)$ & $18.6(3.2)$ & 4.1 & 2 \\
6 & 4 & $16.4(5.6)$ & $6.9(1.9)$ & 57.9 & 2 \\
7 & 2 & $19.0(9.6)$ & $29.5(24.7)$ & -54.7 & 2 \\
8 & 3 & $34.2(0.0)$ & $36.8(3.4)$ & -7.6 & 1 \\
9 & 1 & $68.7(6.0)$ & $74.3(12.8)$ & -8.2 & $5 *$ \\
10 & 3 & $12.6(9.4)$ & $9.1(2.5)$ & 27.8 & 2 \\
\hline
\end{tabular}

* Failure of the technique due to an unrelated cause. 


\section{Discussion}

Ligation of the minor vascular pedicles, 5 weeks before the muscle is transposed, is a method used to prevent the development of fibrosis or necrosis of the distal part of the gracilis muscle. Pre-supposition is that this procedure causes (mild) ischaemia in the distal part of the muscle even if the muscle remains in situ and is not yet subjected to electrical stimulation. Consequently collateral vessels may develop guaranteeing adequate bloodsupply at the time the muscle is transposed and electrically stimulated. The angiographies of the post-mortem specimen in this study demonstrate that one large arterial system exists within the muscle. This confirms previous findings. ${ }^{7}$ Our laser Doppler flowmetry data indicate that clamping off the minor vascular pedicles does not impair blood flow in the distal part of the gracilis muscle. This finding argues against the hypothesis that ligation of these pedicles is responsible for ischemic changes. Moreover, our study demonstrated that no correlation exists between changes in muscle blood flow following clamping and either contraction force or functional outcome.

Various factors may be responsible for damage of the muscle. Mobilization requires division of the distal tendon and the minor vascular pedicles. Tenotomy has been reported to cause a 33 percent reduction in muscle mass leading to a 30 percent reduction in maximum absolute power. ${ }^{8}$ Muscle ischaemia may be the result of an insufficient microcirculation after ligation of the minor pedicles but it may be caused as well by the transposition of the muscle around the anal canal under too much tension or by chronic electrical stimulation. When the muscle is transposed around the anal canal the loss of normal resting tension may induce an increase in the connective tissue component of the muscle.? This was found to be the single most damaging intervention. ${ }^{10}$ When stretch is applied to the muscle, connective tissue accumulation can be prevented and protein synthesis is induced to prevent atrophy. ${ }^{11}$ Too much stress however can give compression of the vascular pedicle and thereby impair muscle blood flow. Little is known about problems that can arise from an impaired venous or lymph drainage. Mobilization of the muscle certainly damages smaller lymph vessels necessitating the use of tight stockings for several weeks in order to prevent edema in the leg. An impaired lymph drainage within the transposed muscle may cause swelling and complicate normal blood flow.

After transposition the muscle is allowed to recover and to form a strong attachment to the pubic bone. Six weeks after gracilis muscle transposition there is a 33 percentage decrease in muscle diameter. ${ }^{12}$ Apart from atrophy, disuse is known to affect the microvascular structure and the resting state blood flow but nevertheless the vascular responsiveness to a metabolic challenge is maintained. ${ }^{13}$ Despite atrophy the muscle remains forceful enough to close the anal canal.

Long-term mild electrical stimulation improves the perfusion pressure, increases the capillary-ro-fiber ratio, restores dilatation of terminal arterioles and improves blood flow and muscle fatigue. ${ }^{14}$ Angiogenesis within the stimulated skeletal muscle might be 
induced by basic fibroblast growth factor (bFGF). ${ }^{15}$ The protein bFGF, a direct endothelial cell mitogen, is released in degenerating-regenerating muscle fiber. After muscle transposition alone no increase in bFGF could be detected. ${ }^{16}$ When muscles are stimulated in situ before transposition they tend to be affected less by ligation of the collateral blood supply. They also show an increased resistance to fatigue ${ }^{17}$ and have adequate function. ${ }^{18} \mathrm{~A}$ possible explanation for this phenomenon is the increased percentage of type I, fatigue resistant, muscle fiber which would be less sensitive to ischaemia due to an increased intramuscular capillary network ${ }^{19}$ but conflicting results have been published. ${ }^{20}$ Stimulation of the human gracilis muscle in situ can be technically difficult, depending on the technique used, and may cause undesired movements of the leg.

It is clear that many factors are involved in the development of muscle damage and they all exert an additive effect upon each orher. It may be advisable to give extra protection at the moment most damage is inflicted on the muscle. Since animal models are seldom alike and therefore give contradictory results, it is hard to tell which factor is the main responsible. The different effect of stimulation upon comparable muscles in the same model and the great variability between individuals ${ }^{21}$ make it even harder to predict outcome. On the other hand, we accept the fact that not everybody is equally equipped to run a marathon and the same analogy can be applied to chronic electrical stimulation.

Laser Doppler flow provides an accurate measure of muscle blood flow. The LDF data indicate that ligation of the distal vascular pedicles does not compromise blood flow within the distal part of the gracilis muscle. This finding is in line with the long term functional outcome. Given these data, it is questionable whether ligation of the minor vascular pedicles is the bottle neck in human dynamic graciloplasty. The possible value of vascular delay may be increased if the muscle is challenged by electrical stimulation, but this can be rechnically difficult. The experimental data from this study question the value of a vascular delay procedure. To investigate the clinical effect of the procedure, a prospective randomized trial to compare the outcome in patients with and withour a vascular delay is necessary. Given the anatomical and physiological differences berween parients, a group of patients that does benefit from a vascular delay might then be selected for this procedure.

\section{References}

1. Baeten CG, Geerdes BP, Adang EM, Heineman E, Konsten J, Engel GL, Kester AD, Spaans F, Soeters $\mathrm{PB}$. Anal dynamic graciloplasty in the treatment of intractable fecal incontinence. N Engl J Med 1995:332:1600-5.

2. George BD, Williams NS, Patel J, Swash M, Watkins ES. Physiological and histochemical adaptation of the electrically stimulated gracilis muscle to neoanal sphincter function. Bי J Surg 1993;80:1342-6. 
3. Korsgen S, Keighley MRB. Stimulated Gracilis Neosphincter- Not as Good as Previously Thought. Report of Four Cases. Dis Colon Rectum 1995;38:1331-3.

4. Williams NS, Patel J, George BD, Hallan RI, Watkins ES. Development of an electrically stimulated neoanal sphincter. Lancet 1991;338:1166-9.

5. Lombard JH, Roman RJ. Assessment of muscle blood flow by laser-Doppler flowmetry during hemorrhage in SHR. Am J Physiol 1990;259:H860-5.

6. Nilsson GE, Tenland T, Obert PA. A new instrument for continuous measurement of tissue blood flow by light beating spectroscopy. IEEE Trans Biomed Eng 1980;27:12-9.

7. Shanahan D, Riches DJ, Sinnatamby CS, Williams NS, Watkins ES. The arterial anatomy and surgical relevance of the human gracilis muscle. J Anat 1991;176:270-272(abstract).

8. Kadhiresan VA, Guelinckx PJ, Faulkner JA. Tenotomy and repair of latissimus dorsi muscles in rats: implications for transposed muscle grafts. J Appl Physiol 1993;75:1294-9.

9. Williams PE, Goldspink G. Connective tissue changes in immobilised muscle. J Anat 1984;138:343-50.

10. el Oakley RM, Jarvis JC, Barman D, Greenhalgh DL, Currie J, Downham DY, Salmons S, Hooper TL. Factors affecting the integrity of latissimus dorsi muscle grafts: implications for cardiac assistance from skeletal muscle. J Heart Lung Transplant 1995; 14:359-65.

11. Williams PE, Catanese T, Lucey EG, Goldspink $G$. The importance of stretch and contractile activity in the prevention of connective tissue accumulation in muscle. J Anat 1988;158:109-14.

12. Konsten J, Baeten CG, Havenich MG, Oei TK. Evaluation of gracilis muscle transposition for fecal incontinence with magnetic resonance imaging. Eur J Radiol 1993;16:190-4.

13. Tyml K, Mathieu Costello O, Noble E. Microvascular response to ischemia, and endothelial ultrastructure, in disused skeletal muscle. Microvase Res 1995;49:17-32.

14. Hudlicka O, Brown MD, Egginton S, Dawson JM. Effect of long-term electrical stimulation on vascular supply and fatigue in chronically ischemic muscles. J Appl Physiol 1994;77:1317-24.

15. Morrow NG, Kraus WE, Moore JW, Williams RS, Swain JL. Increased expression of fibroblast growth factors in a rabbit skeletal muscle model of exercise conditioning. J Clin Invest 1990;85:1816-20.

16. Blood VF, Magno MG, Bailey WF, Shi Y, Yurgenev L, DiMeo F, Edie RN, Mannion JD. Basic fibroblast growth factor identified in chronically stimulated cardiomyoplasties. Ann Thorac Surg 1994;58:1320-5.

17. Mannion JD, Velchik M, Hammond R, Alavi A, Mackler T, Ducketr S, Staum M, Hurwiz S, Brown W, Stephenson LW. Effects of collateral blood vessel ligation and electrical conditioning on blood flow in dog latissimus dorsi muscle. J Surg Res 1989;47:332-40.

18. Shatari T, Sugiyama Y, Teramoto T, Kitajima M. Minamitani H. Reconstruction of anal function by transposed gracilis muscle with electrical stimulation: rabbit model. Int J Artif Organs $1994: 17: 240-4$.

19. Hilton SM, Jeffries MG, Vrbova G. Functional specializations of the vascular bed of soleus. J Physial Lond 1970;206:543-62.

20. Sternbergh WC, Adelman B. Skeletal muscle fiber type does not predict sensicivity to postischemic damage. J Surg Res 1992;53:535-41.

21. Lexell J, Jarvis J, Downham D, Salmons S. Quantitative morphology of stimulation-induced damage in rabbir fast-rwirch skeleral muscles. Cell Tissue Res 1992;269:195-204. 
Chapter 5.2

\section{VASCULAR AND STIMULATION DELAYS IN DYNAMIC MUSCULOPLASTY: an experimental study in rabbits}

Vascular and stimulation delays in dynamic musculoplasty. Geerdes BP, Heineman E, Freling G, Keizer HA, Woloszko J, Baeten CGMI.

Surgery (in press) 


\section{Introduction}

The anal sphincter complex is a highly complicated mechanism consisting of an internal and an external sphincter. The internal sphincter is a continuation of the smooth muscle of the bowel wall and is under both sympathic as parasympathic influence. ${ }^{1}$ The external anal sphincter is a voluntary muscle with a predominance of rype I muscle fibers ${ }^{2}$ and is innervated by the pudendal nerve. ${ }^{3}$ The results of surgical repair of the anal sphincters are poor when the innervation is damaged. Creation of a new anal sphincter using a skeletal muscle (gracilis or gluteus muscle) has proven to be a feasible option. ${ }^{4}$ Electrical stimulation with an implanted neurostimulator greatly improved the results of this technique. Low frequent electrical stimulation of a skeletal muscle induces a transformation of type II, fast-twitch, muscle fibers into type I, slow twitch, muscle fibers. ${ }^{5,6}$ This allows a long-lasting contraction needed for sphincter function. It also makes contraction independent of volition.

In order to be able to transpose the gracilis muscle around the anal canal, the distal part of the muscle has to be mobilized. This includes ligation of the minor vascular pedicles and tenotomy of the distal tendon. After transposition, the muscle is allowed six weeks to recover and for the tendon to fix to the bone. MRI srudies demonstrated a decrease in diameter of the transposed muscle during these weeks of inacrivity. An immediate start of the stimulation might prevent atrophy but it is uncertain whether this would be harmful to the muscle.

Although intramuscular arterio-arrerial anastomosis were shown in the human gracilis muscle under radiocontrast injection ${ }^{8}$, part of the failures of the dynamic graciloplasty are atrributed to ischemia that would develop due to ligation of the minor vascular pedicles. Therefore a vascular delay procedure was introduced ${ }^{9}$, including ligation of the minor vascular pedicles, five weeks before transposition of the muscle. This would allow formation of (more) collateral vessels, thereby preventing ischaemia.

The distal part of the muscle that is transposed around the anal canal is the most vulnerable part of the muscle for ischemic damage. At the same time, it is most essential for a good sphincter function. Because surgeons have been reluctant to take muscle biopsies of this part of the muscle, discussions about function and malfunction of the graciloplasty were always funded on biopsies from the proximal part of the muscle. Currently, limited information exists about the correlation between the condition of the proximal and the distal parts of the gracilis muscle.

The goal of this study, therefore, was to characterize both the functional and the histochemical properties of the transposed and stimulated muscles when either immediate stimulation was applied, or when six weeks of rest were allowed, or when the vascular delay procedure was performed. Since these investigations cannot be performed in humans, an animal model was developed in rabbits. Histochemical data were correlated with the biochemical data. Furthermore, the results in the proximal and distal parts of the muscle were compared. Our hypotheses were that immediate stimulation 
Table 1. Rabbits were randomized in 3 groups of 6 rabbits. The right muscles were stimulated, the left muscles served as controls.

\begin{tabular}{llll}
\hline Group & $\mathrm{n}$ & Muscle & Procedure \\
\hline 1a. & 6 & Left & Transposition, no stimulation. \\
1b. & 6 & Right & Transposition, immediate stimulation (3 days). \\
2a. & 6 & Left & In situ. \\
2b. & 6 & Right & Transposition, delayed stimulation (6 weeks). \\
3a. & 6 & Left & Vascular delay, transposition, no stimulation. \\
3b. & 6 & Right & Vascular delay, transposition, immediate stimulation (3 days) \\
\hline
\end{tabular}

would be harmful to the muscle, that the vascular delay procedure would add little to muscle function and that the condition of the proximal and distal parts of the muscle would correlate well. Functional assessment included manometry for resting and stimulation pressures, fusion frequency and fatigue index. Histochemistry was performed for general muscle condition, number of type I muscle fibers and fiber diameter, the amount of collagen, and the number of proliferating cells. For biochemical analysis, activities were measured of mitochondrial, glycolytic, $\beta$-oxidative and oxidative enzymes.

\section{Methods}

Experiments were performed on 18 adult crossbred Flemish giant rabbits $(3-4 \mathrm{~kg})$ of either sex. The experiments and operative procedures were carried out in accordance with the Ethical Committee on Animal Research of the University of Limburg, Dutch legislation and EEC regulations. All rabbits were individually housed and were provided with food and water ad libitum.

The rabbits were divided into three groups, the right muscles were electrically stimulated and the left muscles were used as controls (table 1). Group 1: Immediate stimulation $(n=6)$. The left muscle was transposed only (group la) and the right muscle was transposed and stimulated (group 1b). Electrical stimulation was started 3 days after transposition. Group 2: Postponed stimulation $(n=6)$. The left muscle was left in situ (group 2a) and the right muscle was transposed and stimulated (group 2b). Electrical stimulation was started 6 weeks after transposition. Group 3: Vascular delay ( $n=6)$. A vascular delay was performed 5 weeks before transposition of the muscles. The left muscle was transposed only (group 3a) and the right muscle was transposed and stimulared (group 3b). Electrical stimulation was started 3 days after transposition. At the end of the final experiment the rabbir was sacrificed by injection with Euthesate, pentobarbital sodium $200 \mathrm{mg} / \mathrm{ml}$ (Aparmo, Holland) for $1 \mathrm{ml} / \mathrm{kg}$ body weight. 


\section{Operative procedures}

Each operation was performed under aseptic conditions. Rabbits were anesthetized by intramuscular injections of Ketamine $\mathrm{HCl}(0.5 \mathrm{mg} / \mathrm{kg}$, Nimatek, AUV, The Nethèrlands) and Xylazine $\mathrm{HCl}$ i.v. (0.5 mg/kg, Sedamun, AUV, The Netherlands) and each rabbit received Ampicillin i.m. pre-operatively $(0.1 \mathrm{mg} / \mathrm{kg}$, Pentrexil, Bristol-MeyersSquibb, The Netherlands). Supplementary doses were administered i.v. as required.

In the medial thigh of both legs the skin was incised and the gracilis muscles were separated from the surrounding connective tissue by blunt dissecrion. Both peripheral vessels were ligated and the distal ligament was dissected. In the right gracilis muscle two intramuscular leads (SP 5577-20, Medtronic, The Netherlands) were implanted, perpendicular to the muscle fibers. The cathode was positioned as close to the obrurator nerve as possible and the anode $2 \mathrm{~cm}$ more distally. Because in the rabbit the anal canal is positioned in the narrow pelvis, making gracilis transposition around the anal canal impossible, the muscle was then wrapped around a double, flexible polyurethane tube. The distal ligament of the gracilis muscle was fixed to the inguinal ligament. The outer polyurethane tube had a diameter of $2.9 \mathrm{~mm}$ and the inner tube a diameter of $2.2 \mathrm{~mm}$. The inner tube gave enough resistance to allow normal training and could be taken out, to allow prissure measurement. Threshold for a good contraction of the gracilis muscle was determined using a temporary pacing analyzer (PSA 5300, Medtronic, Minneapolis, $\mathrm{MN}$ ). Both leads were subcutaneously tunneled to the abdomen and connected to a neurostimulator (Model 7420, Medtronic, Minneapolis, MN) which was fixed to the abdominal wall. The double polyurethane tube, both leads and the neurostimulator were soaked in Gentamycin solution ( $80 \mathrm{mg} / 100 \mathrm{ml}$ ) before implantation. The leg and the abdomen were closed in 2 layers with Vicryl 3.0 (Ethicon, Norderstedt, Germany). Post-operatively the rabbit received Cisapride p.o. (Prepulsid, $1 \mathrm{mg} / \mathrm{ml}$, Janssen Pharmaceurica, Belgium) and Buprenorphine $\mathrm{HCl}$ i.m. $(0.06 \mathrm{mg} / \mathrm{ml}$, Temgesic, Reckitt $\&$ Colman, UK).

\section{Previous ligation of collateral blood vessels (vascular delay)}

The gracilis muscle in the rabbit, like the human, receives its dominant blood supply from the profunda lemoral artery. However, it also receives an abundant collateral supply from branches of the superficial femoral artery. Five weeks before transposition, the vascular delay procedure was performed in group 3. A small incision in the medial thigh was made, the peripheral arteries of the gracilis muscle were located and ligated and the skin was then closed.

\section{Stimulation protocol}

The amplitude, rate, pulse width and duty cycle could be programmed using telemetry. Electrical stimulation was started with a frequency of $25 \mathrm{~Hz}$, a pulse width of 210 microseconds and the stimulation amplitude (Volt) was assessed on palpation. During 
the first 8 weeks the duty cycle was increased every 2 weeks $(6,11,25$ and $80 \%$ duty cycle). The "on" and "off" times of the electrical stimulation were: $0.125 \mathrm{sec}$ and 2.0 $\sec (0-2$ weeks), $0.125 \mathrm{sec}$ and $1.0 \mathrm{sec}(2-4$ weeks), $0.125 \mathrm{sec}$ and $0.375 \mathrm{sec}$ (4-6 weeks) and $1.5 \mathrm{sec}$ and $0.375 \mathrm{sec}(6-8$ weeks) respectively. From 8 to 11 weeks, electrical stimulation was continuous and the frequency that gave a fused contraction could be lowered to 20 or even $15 \mathrm{~Hz}$. This stimulation protocol is identical to the one used in humans, for dynamic graciloplasty.

\section{Evaluation of contractile properties}

The force of contraction was measured twice: during the operation following transposition and implantation of the stimulation devices $(\mathrm{t}=0)$ and after 11 weeks of stimulation ( $t=11)$. Manometry was performed using a Millar Mikro-tip catheter pressure transducer (Millar Instruments Inc., Houston, Texas, USA) connected to a recorder pen writer. After the inner polyurethane tube was removed, the catheter could be introduced into the outer, thin-walled, polyurethane tube. The resting pressure, the pressure during electrical stimulation and the amplitude which gave the most forceful contraction were measured. Subsequently, the fusion frequency was assessed by continuous stimulation and increasing frequencies of $5,10,15,20$ and $25 \mathrm{~Hz}$. Fusion frequency was defined as less than 10\% ripple. After 30 minutes of rest, fatigue index was measured. An index of fatigue resistance was defined as the time elapsing from the moment the neurostimulator was switched on, until 50 percent of the initial contraction force was lost.

\section{Tissue removal}

Muscle biopsies were taken from the proximal and the distal parts of the muscle during the operation $(t=0, n=18)$ and after completion of the stimulation program $(t=11$, $\mathrm{n}=18$ ). Biopsies were fixed in formalin and paraffin embedded. To determine muscle enzyme activities in the last 9 rabbits, biopsies from the mid portion of the muscle were taken and quickly frozen in liquid nitrogen and stored at $-80^{\circ} \mathrm{C}$ until assayed $(\mathrm{t}=11, \mathrm{n}$ $=9)$.

\section{Histochemical analysis}

Histology was performed on the paraffin embedded biopsies. Serial sections $5 \mu \mathrm{m}$ thick were cur in the microtome (Leica J1130, Rijswijk, The Netherlands). Muscle integrity was judged double-blind by the pathologist on biopsies stained with hematoxylin and eosin. Change in the muscular tissue (intracellular nuclei, fat, fibrosis and incoherent structure) was scored. No change was category 1, up to $25 \%$ change was category 2 , $25-75 \%$ was category 3 and more than $75 \%$ of change was category 4 . The percentage and lesser diameter of type I and type II muscle fibers were assessed, using the monoclonal antibody R11D10 directed against the myosin heavy chain of type I muscle fibers. ") The percentage of endomysial collagen was measured after staining with Sirius 
Red ${ }^{11}$, using the Picrosirius Red-Polarization merhod and a computer assisted image analyzer (CAS 200, Becton Dickinson Inc, Lombard, Illinois, USA). The number of proliferating cells (satellite cells) per 100 cells was measured using the monoclonal antibody MIB-1 (Immunotech S.A., Marseille, France), which reacts with the Ki-67 nuclear antigen associated with cell proliferation found throughout the cell cycle $\left(\mathrm{G}_{1}\right.$, $S, G_{2}, M$ phases) and absent in resting $\left(G_{0}\right)$ cells.

\section{Biochemical analysis}

Activities of metabolic enzymes were measured by spectrophotometric methods. Cytochrome-C oxidase $(\mathrm{CytC})$ was measured at $25^{\circ} \mathrm{C}$ in homogenates treated with digitonin (final concentration $1 \mathrm{mg} / \mathrm{ml}$ ), applying the method described by Gohil et al. ${ }^{12}$ Activities of other metabolic enzymes were measured at $37^{\circ} \mathrm{C}$ in $10,000 \mathrm{~g}$ supernatants of homogenates that had been subjected to 4 cycles of freezing and thawing and to sonication. Fructose-6-phosphate kinase (PFK) was assayed as described by Ling et al ${ }^{13}$ with $0.3 \mathrm{mM} \mathrm{KCN}$ added to the medium to suppress endogenous $\mathrm{NAD}^{+}$formation. 3-Hydroxyacyl-CoA dehydrogenase (HAD) activity was assessed according to Bergmeyer et al ${ }^{14}$, using $0.16 \mathrm{mM} \mathrm{S}$-acetoacetyl-CoA as substrate. Citrate synthase (CS) activity was measured by the method of Shepard \& Garland. ${ }^{15}$ Enzyme activities are expressed in units $(\mu \mathrm{mol} / \mathrm{min})$ per gram wet weight of tissue. The above enzyme activities were interpreted as relative measures of the metabolic capacities of the tricarboxylic acid cycle (CS), glycolysis (PFK), respiratory chain $(\mathrm{CytC})$ and $\beta$-oxidation $(\mathrm{HAD})$ respectively. All enzyme assays were performed in duplicate and samples from all animals were assayed in the same run to reduce interassay variation.

\section{Statistical analysis}

Data were analyzed with paired students'-t-test for changes in the whole group and the Wilcoxon matched-pairs signed-ranks test for comparison between groups. For correlation Spearman test was used. A p-value of less than 0.05 was considered statistically significant.

\section{Results}

All animals tolerated the procedures well. No wound infections were seen and all rabbits thrived well. Electrical muscle stimulation did not seem to cause any inconvenience to the rabbits.

\section{Functional aspects (table 2)}

Table 2 contains the following data: the amplitude needed for a good palpable contraction at the start and after 11 weeks of electrical stimulation, the increase in amplitude 
Table 2. Functional results of the stimulated right muscles for all rabbits and divided by group.

\begin{tabular}{|c|c|c|c|c|c|c|c|c|c|c|}
\hline Group & $\mathrm{n}$ & $\begin{array}{l}\text { Amplst } \\
\text { (V) }\end{array}$ & $\begin{array}{l}\text { Ample } \\
(V)\end{array}$ & $\begin{array}{l}\text { Amplinc } \\
\text { (V) }\end{array}$ & $\begin{array}{l}\text { Ampl/Max } \\
\text { (V) }\end{array}$ & $\begin{array}{l}\text { Ff } \\
\text { (pps) }\end{array}$ & $\begin{array}{l}\text { PrenE } \\
(\text { mmitg) }\end{array}$ & $\begin{array}{l}\text { Primk } \\
(\mathrm{mmH} H \mathrm{~g})\end{array}$ & $\begin{array}{l}\mathrm{P}_{\max } \\
\left(\mathrm{mmH} \mathrm{H}_{\mathrm{g}}\right)\end{array}$ & $\begin{array}{l}\text { FI } \\
(\mathrm{sec})\end{array}$ \\
\hline All rabbiss & 18 & $0.93(0.09)$ & $1.14(0.1)$ & $0.21(0.07)$ & $1.88(0.18)$ & $17.6(0.5)$ & $36.0(6.4)$ & $68.9(9.3)$ & $107.4(10.8)$ & $372(66)$ \\
\hline Group 1b & 6 & $0.88(0.15)$ & $1.25(0.11)$ & $0.38(0.13)^{*}$ & $2.04(0.29)$ & $18.8(1.0)^{*}$ & $39.2(7.9)$ & $64.3(8.3)$ & $107.5(23.0)$ & $259(130)^{*}$ \\
\hline Group 2b & 6 & $1.0(0.24)$ & $1.04(0.24)$ & $0.04(0.09)^{*}$ & $1.75(0.49)$ & $15.8(0.6)^{2}$ & $31.8(14.7)$ & $73.0(20.4)$ & $107.2(20.0)$ & $515(102)^{*}$ \\
\hline Group $3 b$ & 6 & $0.92(0.1)$ & $1.13(0.22)$ & $0.21(0.18)$ & $1.83(0.32)$ & $18.3(1.0)$ & $37.0(15.9)$ & $69.3(25.11)$ & $107.5(24.5)$ & $341.7(139)$ \\
\hline
\end{tabular}

Values are means $\pm \mathrm{SE}$. The amplitude needed for a good palpable contraction at the start $\left(\mathrm{Ampl}_{\mathrm{St}}\right)$ and

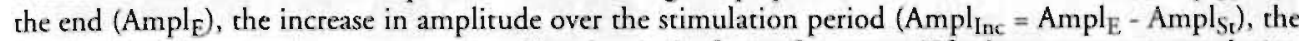
amplitude giving a maximum contraction $\left(\mathrm{Ampl}_{\mathrm{Max}}\right.$ ), the fusion frequency (FF), the pressures at rest, during electrical stimulation and the maximum pressure $\left(\mathrm{P}_{\text {Rest }}, \mathrm{P}_{\text {Stim }}, \mathrm{P}_{\mathrm{Max}}\right)$ and the fatigue index (FI) are depicted. ${ }^{*}=$ significant differences between groups 1 and $2, p<0.05$

over the stimulation period, the amplitude giving a maximum contraction, the fusion frequency, the pressure at rest, the pressure during electrical stimularion, the maximum pressure and the fatigue index. No significant differences were seen between the groups with regard to the amplitude at the start, the amplitude after 11 weeks of training, or the amplitude needed for maximum contraction. In group 1 the increase in amplitude (Amplitude -Amplitude $_{S_{t}}$ ) needed for a good palpable contraction was significantly higher than in group $2(p=0.038)$. The overall fusion frequency decreased from $25 \mathrm{~Hz}$ before electrical stimulation to $17.6(\mathrm{SE} 0.6) \mathrm{Hz}$ after stimulation $(\mathrm{p}=0.001)$. In group 2 the overall fusion frequency was significantly lower than in group $1(\mathrm{p}=0.026)$ and group 3 ( $p=0.041)$. The fatigue index for the whole group $(n=18)$ before electrical stimulation of 20.8 (SE 3.2) seconds, was significantly increased after 11 weeks of training to 372 (SE 66) seconds $(\mathrm{p}=0.027)$. The increase in fatigue index in group 1 was significantly lower than in group $2(p=0.049)$. No significant differences existed in the resting pressure, the pressure during stimulation or the maximum pressure.

\section{Histochemical analysis (table $3 a$ and 36 )}

In the whole group, no significant changes were seen before and after the period of stimulation in muscle integrity $(\mathrm{HE})$ of the non-stimulated muscle, whereas both in the proximal ( $\mathrm{p}=0.008)$ as well as in the distal $(\mathrm{p}=0.001)$ part of the stimulated muscle this was significant (figure $1 \mathrm{a}, \mathrm{lb}$ and 2 ). Compared to group 2 , changes in group 1 were significantly higher $(p=0.047)$ in the distal part of the stimulated muscle. The overall change in type I muscle fibers (figure $3 \mathrm{a}$ and $3 \mathrm{~b}$ ) was from 4.6 (SE 1.3) percent before transposition to 3.8 (SE 1.4) percent in the non-srimulated muscle $(\mathrm{p}=0.365)$ and 41.9 (SE 6.3) percent in the stimulated muscle $(\mathrm{p}<0.0001$ ) (distal parts, $\mathrm{n}=18$ ). No significant changes were seen between different groups. There was a small decrease in diameter of type I muscle fibers after transposition and after stimulation, although not significant. The increase in the percentage of collagen was significant after transposition from 1.5 (SE 0.1) percent to 4.2 (SE 0.9) percent in the non-stimulated muscles ( $p=$ 
Table 3a. Histochemical data of the control muscles at $\mathrm{r}=11$ weeks.

\begin{tabular}{llllllll}
\hline Group & $\mathrm{n}$ & $\mathrm{HE}$ & $\begin{array}{l}\text { Type I } \\
(\%)\end{array}$ & $\begin{array}{l}\text { Diam } \\
(\mu \mathrm{m})\end{array}$ & $\begin{array}{l}\text { Diam } \\
(\mu \mathrm{m})\end{array}$ & $\begin{array}{l}\text { Collagen } \\
(\%)\end{array}$ & $\begin{array}{l}\text { Sat.cells. } \\
(\%)\end{array}$ \\
\hline Group 1a prox & 6 & $1.2(0.2)$ & $1.0(0.6)$ & $46.2(6.2)$ & $49.4(6.0)$ & $2.6(0.4)$ & $0.6(0.3)$ \\
Group 1a dist & 6 & $1.3(0.4)$ & $3.2(2.0)$ & $39.8(6.5)$ & $60.1(4.8)$ & $4.1(1.8)$ & $4.4(4.3)$ \\
Group 2a prox & 6 & $1.0(0.0)$ & $1.3(0.5)$ & $46.5(3.1)$ & $54.7(2.6)$ & $1.9(0.3)^{*}$ & $0.5(0.4)$ \\
Group 2a dist & 6 & $1.0(0.0)$ & $2.5(1.0)$ & $48.6(5.2)$ & $61.5(4.9)$ & $2.8(0.5)$ & $0.2(0.2)$ \\
Group 3a prox & 6 & $1.0(0.0)$ & $1.2(0.7)$ & $42.5(4.7)$ & $54.6(3.6)$ & $4.1(0.6)^{*}$ & $0.2(0.2)$ \\
Group 3a dist & 6 & $1.5(0.3)$ & $5.7(4.2)$ & $55.0(2.6)$ & $62.3(4.4)$ & $5.6(2.5)$ & $0.4(0.3)$ \\
\hline
\end{tabular}

Values are means $\pm S E$. * significance

Table 3b. Histochemical dara of the stimulated muscles at $t=11$ weeks.

\begin{tabular}{llllllll}
\hline Group & $\mathrm{n}$ & $\mathrm{HE}$ & $\begin{array}{l}\text { Type I } \\
(\%)\end{array}$ & $\begin{array}{l}\text { Diam } \\
(\mu \mathrm{m})\end{array}$ & $\begin{array}{l}\text { Diam } \\
(\mu \mathrm{m})\end{array}$ & $\begin{array}{l}\text { Collagen } \\
(\%)\end{array}$ & $\begin{array}{l}\text { Sat.cells } \\
(\%)\end{array}$ \\
\hline Group 1b prox & 6 & $1.5(0.4)$ & $30.3(15.5)$ & $44.3(4.8)$ & $60.3(1.2)$ & $6.0(3.2)$ & $3.0(0.9)$ \\
Group 1b dist & 6 & $3.2(0.4)^{*}$ & $42.2(14.5)$ & $43.9(3.7)$ & $62.0(3.7)$ & $14.1(3.6)$ & $8.4(5.9)$ \\
Group 2b prox & 6 & $1.3(0.4)$ & $38.3(10.0)$ & $36.8(1.9)$ & $56.0(5.7)$ & $8.7(4.9)$ & $2.2(0.4)$ \\
Group 2b dist & 6 & $2.2(0.4)^{*}$ & $39.0(10.2)$ & $42.4(6.3)$ & $60.2(4.6)$ & $10.0(5.7)$ & $3.0(1.0)$ \\
Group 3b prox & 6 & $2.2(0.5)$ & $42.7(14.2)$ & $44.0(2.5)$ & $56.6(3.6)$ & $5.2(1.5)$ & $7.0(3.9)$ \\
Group 3b dist & 6 & $2.7(0.7)$ & $44.7(14.1)$ & $40.2(4.5)$ & $56.6(2.8)$ & $12.2(3.3)$ & $7.8(4.1)$ \\
\hline
\end{tabular}

Values are means \pm SE. * = significance

0.0002 ) and to 11.9 (SE 2.1) percent in the stimulated muscles $(\mathrm{p}<0.0001)$ (distal parts, $n=18$ ). Apart from a significant difference between groups 2 and 3 in the proximal part of the non-stimulated muscle $(p=0.02)$, no significant differences between groups were detected. The increase in the number of satellite cells per 100 cells (figure 4) from 0.6 (SE 0.2) to 1.6 (SE 1.2) in the non-stimulated muscles was not significant ( $\mathrm{p}=0.16$ ), and to 6.2 (SE 2.0) in the stimulated muscles $(\mathrm{p}=0.0001)$ (distal parts).

Correlation between muscle integrity $(\mathrm{HE})$, as judged by the parhologist, and percentage of collagen $(p=0.03)$, percentage of type I muscle fibers $(p=0.002)$ and number of satellite cells $(\mathrm{p}=0.04)$ were all significant. Correlation between the proximal and the distal parts of the stimulated muscle concerning muscle integrity $(\mathrm{HE})(\mathrm{p}=0.02)$ and percentage of collagen $(\mathrm{p}=0.04)$ were significant, but for percentage of type I muscle fibers or for number of satellite cells, it was not significant.

\section{Biochemical analysis (table 4)}

Citrate synthase levels changed from 3.0 U (SE 0.2) at the start to 2.1 U (SE 0.2) in the non-stimulated legs and to $5.6 \mathrm{U}(\mathrm{SE} 1.0)$ in the stimulated legs $(\mathrm{p}=0.03)$. Fructose-6- 


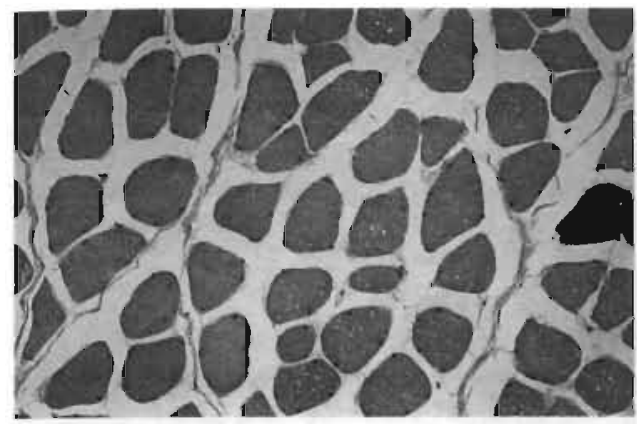

Figure la. Muscle tissue (hematoxylin and eosin stained) after electrical stimulation, classified as category 1 (= no change, or normal muscle tissue). $200 \mathrm{x}$

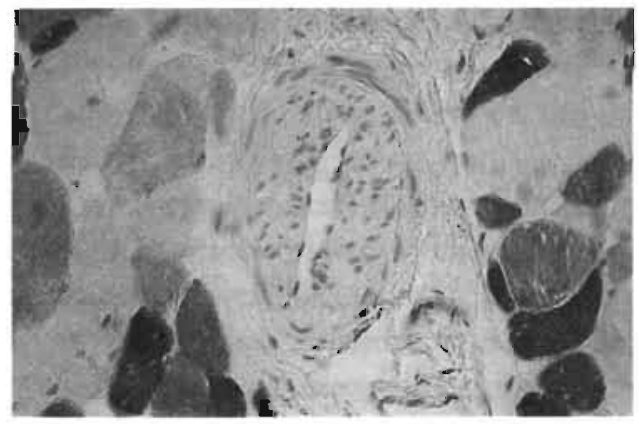

Figure 2. In muscle rissue classified as category 4, incima hyperplasia of the intramuscular arteries can sometimes be found. $400 \mathrm{x}$

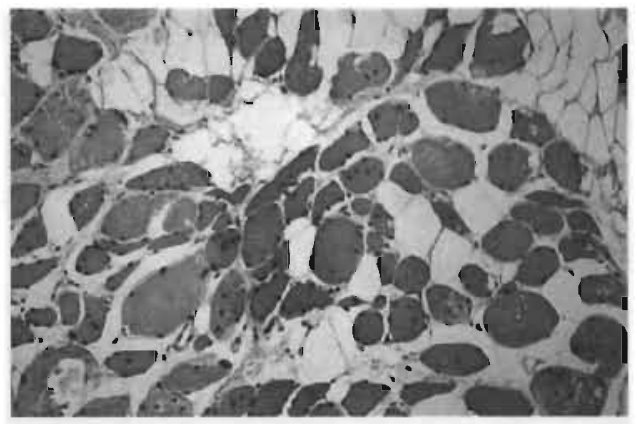

Figure 1b. Muscle tissue (hematoxylin and eosin stained) after electrical stimulation, classified as category 4 (= more than $75 \%$ of change). Note the intracellular nuclei, far, fibrosis and incoherent strucrure. $200 \mathrm{x}$

phosphate kinase levels changed from 3.3 (SE 0.4) at the start to 3.0 (SE 0.4) in the non-stimulated legs and to 1.1 (SE 1.0) in the stimulated legs $(p=0.02)$. 3-HydroxyacylCoA dehydrogenase levels changed from 0.92 (SE 0.09) at the start to 0.74 (SE 0.05) in the non-stimulated legs and to 1.89 (SE 0.29) in the stimulated legs $(p=0.02)$. Cytochrome-c oxidase levels changed from 0.04 (SE 0.01) at the start to 0.06 (SE 0.02) in the non-stimulated legs and to 0.09 (SE 0.02) in the stimulated legs $(p=0.12)$.

Compared to groups 2 and 3 , the data from group 1 showed a trend of a less favorable adaptation to stimulation, but this is not significant due to small numbers. In the stimulated legs correlation with fatigue index was significant for $\mathrm{CS}$ and $\mathrm{Cyt} C$ $(\mathrm{p}<0.05)$ but nor for HAD and PFK. 


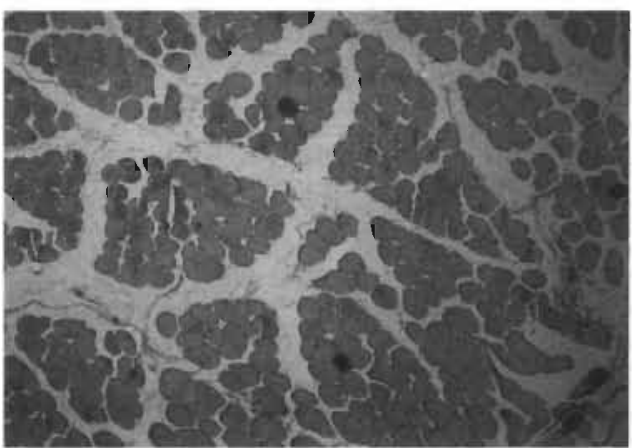

Figure 3a. Muscle tissue (R11D10 stained) before electrical stimulation. The dark fibers represent type I, slow-twitch, muscle fibers. $50 \mathrm{x}$

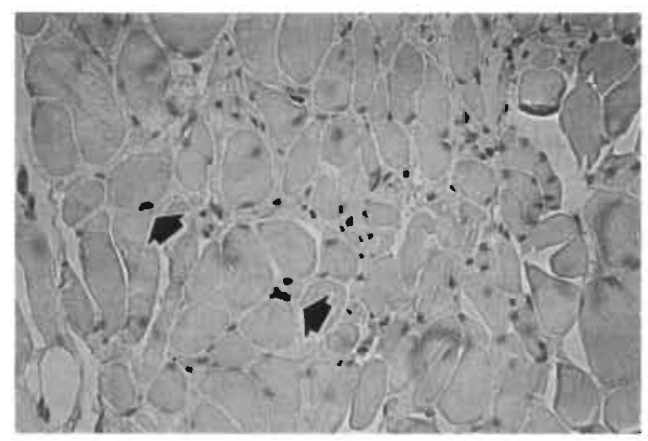

Figure 4. Staining of the proliferating or satellite cells (arrows) with the monoclonal antibody MIB-1. $200 \mathrm{x}$

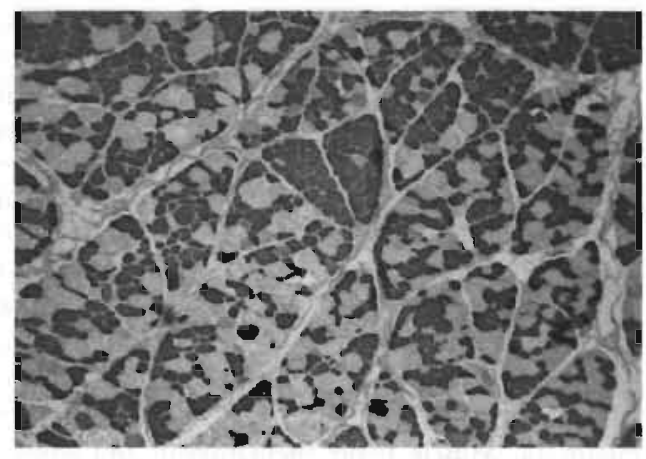

Figure 3b. Muscle tissue (R11D10 stained) after electrical stimularion. Note the increased amount of type I, slow-twitch, muscle fibers. 50x

\section{Discussion}

Skeletal muscles are increasingly used to correct functional disabilities like creation of a new anal sphincter in intractable fecal incontinence. ${ }^{4}$ During transposition and chronic electrical stimulation of a muscle, various factors may contribute to muscle damage. Mobilization of the muscle includes division of the collateral vessels, transection of the distil tendon and loss of normal resting tension. During transposition, the muscle has to make several curves in order to be brought into its new position. This may affect blood flow as well. Because chronic electrical stimulation induces a repeated contraction, it may impose excessive metabolic and physiologic demands upon an untrained muscle. 
Table 4. Biochemical data of the mid part of the muscles before and after electrical stimulation for the last 9 rabbirs, and after stimulation by group.

\begin{tabular}{llllll}
\hline Group & $\mathrm{n}$ & $\begin{array}{l}\text { CS } \\
(\mathrm{u})\end{array}$ & $\begin{array}{l}\text { PFK } \\
(\mathrm{u})\end{array}$ & $\begin{array}{l}\text { HAD } \\
(\mathrm{u})\end{array}$ & $\begin{array}{l}\text { CytC } \\
(\mathrm{u})\end{array}$ \\
\hline Before stimulation & 9 & $3.0(0.2)$ & $3.3(0.4)$ & $0.92(0.09)$ & $0.04(0.01)$ \\
After stimulation & 9 & $5.6(1.0)^{*}$ & $1.13(0.2)^{*}$ & $1.89(0.29)^{*}$ & $0.09(0.02)^{*}$ \\
Group 1a & 3 & $2.2(0.2)$ & $2.1(0.2)$ & $0.80(0.01)$ & $0.02(0.01)$ \\
Group 2a & 3 & $2.2(0.4)$ & $4.1(1.2)$ & $0.64(0.09)$ & $0.02(0.01)$ \\
Group 3a & 3 & $2.0(0.4)$ & $2.4(0.1)$ & $0.85(0.15)$ & $0.02(0.01)$ \\
Group 1b & 3 & $3.1(0.3)$ & $1.5(0.6)$ & $1.11(0.25)$ & $0.05(0.02)$ \\
Group 2b & 3 & $7.4(2.7)$ & $1.3(0.3)$ & $2.13(0.38)$ & $0.09(0.04)$ \\
Group 3b & 3 & $5.6(1.8)$ & $0.8(0.3)$ & $2.17(0.86)$ & $0.10(0.06)$ \\
\hline
\end{tabular}

Values are means $\pm \mathrm{SE} .{ }^{*}=$ significance

Numerous protective measures have been developed at different stages during transposition and training in order to allow optimal adaptation of the muscle to its new function. The present study was designed to evaluate the influence of immediate stimulation and vascular and stimulation delays on the structural integrity and function of the gracilis muscle in rabbits.

Tenotomy has been found to be responsible for a 33 percent reduction in muscle mass, a 26 percent decrease in single fiber cross sectional area and a 30 percent loss of maximum power. ${ }^{16}$ Guelinckx et al. found that in neurovascular repaired grafts tenotomy and repair is a major factor responsible for functional deficits. ${ }^{17}$ When muscle is immobilized in a shortened position there is an increase in the proportion of connective tissue, an increased muscle stiffness and a loss of serial sarcomeres. ${ }^{18}$ By using passive stretch or active stimulation, an increase in the proportion of connective rissue could be prevented but not the loss of serial sarcomeres. ${ }^{19}$ Changes in sarcomere number result in an adjustment of sarcomere length to one which gives an optimum overlap of myosin and actin filaments, hence enabling the muscle to develop maximum tension in the immobilized position. ${ }^{20}$ Collateral blood vessel ligation showed impaired muscular blood flow during electrical stimulation in the distal part of the muscle, and even after 3 weeks of recovery this was inferior to controls. ${ }^{21}$ During rest, no significant differences in flow were measurable, which questions the effect of a vascular delay procedure as performed in dynamic graciloplasty. Tenoromy, loss of resting pressure and ligation of collateral vessels all have their effect on muscle viability and they may adversely affect each other. This study shows improved results in the vascular delay group compared to the group with immediate stimulation, but the results are poorer compared to the group with delayed stimulation. Apparently, vascular delay allows for recovery from ligation of the collateral vessels, while allowing no recovery for tenotomy and loss of resting 
pressure after transposition, resulting in diminished function in group 3 compared to group 2 .

The beneficial effect of rest after transposition can be counteracted by the effects of disuse of the muscle over this period. Disuse is accompanied by atrophy of the muscle fibers and a deterioration of microvascular function and structure. ${ }^{22}$ Two weeks did prove to be insufficient for recovery of the muscle from transposition ${ }^{23}$, while 6 weeks resulted in a 33 percent decrease in muscle diameter. ${ }^{7}$ Faulkner et $\mathrm{al}^{24}$ found that transposed, non stimulated, muscle developed sufficient force and power to function effectively to maintain posture and patent sphincters. After 90 days the muscle mass was stable at 75 percent of the control value and he noted a decrease in maximal force to 60 percent of the control value which was 75 percent if normalized for total muscle cross sectional area. After 11 weeks of electrical stimulation, we did not find differences in maximum force between group 1 and group 2 . Whether immediate stimulation has a deleterious effect on development of force in group 1 , or whether electrical stimulation makes up for the atrophy sustained during disuse in group 2, is nor clear. Because dynamic graciloplasty does not need maximum force, all groups in this paper could develop adequate force to close the lumen of the polyurethane tube. What is therefore important in muscle conditioning for dynamic graciloplasty is that there is no damage to the muscle.

The damage that does result from electrical stimulation varics considerably berween muscles and between individual animals, as well as within a muscle cross section and along the length of the muscle. ${ }^{25}$ Damage is not a prerequisite for fiber type transformation $^{25}$ and can take place within the existing muscle fibers. ${ }^{26}$ Muscles stimulated intermittently show significantly less damage than those stimulated continuously. ${ }^{25}$ During electrical stimulation, strenuous stimulation increases atrophy, fails to restore blood flow and worsens fatigue, while mild stimulation improves blood flow and fatigue. ${ }^{27}$ Discernible damage is present in all stimulated muscles regardless of the frequency used, but the mean volume percentage of degenerating muscle fibers declines with declining frequency. ${ }^{28}$ On the other hand, lowering the stimulation frequency produces a less complete conversion. ${ }^{29}$ In the data presented here, all muscles were stimulated according to a standard stimulation protocol ${ }^{4}$ with an increasing duty cycle followed by continuous stimulation after 8 weeks. Significantly more damage was found after immediate stimulation compared to delayed stimulation. If immediate stimulation was performed afrer a vascular delay procedure (group 3) the amount of damage could strongly be decreased although functional and histological data were still less favorable compared to delayed stimulation. To use immediate stimulation for muscle preservation, it would be advisable to employ a much lower frequency $(2.5,5$ or $10 \mathrm{~Hz})$. To stimulate conversion to type I muscle fibers, the frequency could be increased after several weeks. Note that muscle fiber type conversion is not a pre-requisite for fatigue resistance and is therefore not necessary for successful dynamic graciloplasty. 
Changes in metabolic enzyme activities are in accordance with previous literature ${ }^{30}$, i.e. a two-fold increase in aerobic enzyme activicy was observed, whereas PFK decreased accordingly. As was reported before ${ }^{31}$, metabolic data seem to be more in agreement with the functional data than the histochemical data, as $\mathrm{CS}$ and $\mathrm{CytC}$ had a significant correlation with fatigue index. Therefore, more emphasis should be put on improvement of the metabolic capacity of the muscle instead of maximum increase of type I muscle fibers. Metabolic enzyme activity proves to be a better indicator of functional capacity than histochemical data.

The fact that there was a significant correlation between the proximal and the distal parts of the stimulated muscles concerning muscle integrity and percentage of collagen justifies judgment on the state of muscle condition by biopsies of the proximal part of the muscle. This however can never guarantee good function of the graciloplasty.

New methods to reduce the effect of ischemia on the muscle are currently being developed. Interesting results are achieved by application of electrical stimulation before ligation of the collateral vessels (conditioning). While intramuscular bloodflow was greater in unconditioned muscles when they were subjected to chronic electrical stimulation, conditioned muscles were less affected by ligation of collateral vessels ${ }^{21}$ and damage was reduced after chronic electrical stimulation ${ }^{32}$. The basis of protection is unknown, but may be the early adaptive changes in blood supply and oxidative capacity or the fact that there is an increased amount of type I muscle fibers. Whether slow-twitch muscle fibers are less sensitive to ischaemia still remains under debate ${ }^{33,34}$. Although peak tension is reduced in conditioned muscle ${ }^{21}$, function remains good and closure of the anal canal is achieved. ${ }^{35}$ Ischemic pre-conditioning (IP) is a another promising new concept to increase the tissue resistance against ischaemia. IP is the phenomenon that one or more brief periods of ischaemia render an organ more resistant to the effects of a subsequent sustained ischemic period. The effect of IP on post-ischemic myocardium has been documented in various experimental ${ }^{36}$ and, most recently in clinical studies. ${ }^{37}$ Several mechanisms mediating the effect of IP in the heart are currently under discussion, like the role of Adenosine- $A_{1}$-receptors, carbohydrate metabolism, myocardial stunning, free radicals, neurrophils, anti-oxidants, heat stress proteins and nitric oxide.

In conclusion, immediate stimulation using the same stimulation protocol leads to more damage of muscle tissue, demands a higher increase in amplitude to achieve sufficient contraction, while fatigue index is impaired. Vascular delay seems to protect against ischaemia caused by ligation of the collateral vessels but muscle funcrion is still inferior to delayed stimulation. Therefore, delayed stimulation is the best approach in muscle conditioning in dynamic graciloplasty. Development of better techniques of muscle preservation and further refinement of stimulation protocols are necessary to further improve outcome. 


\section{REFERENCES}

1. Speakman CT, Hoyle CH, Kamm MM, Henry MM, Nicholls RJ, Burnstock G. Abnormalities of innervation of internal anal sphincter in fecal incontinence. Dig Dis Sci 1993;38:1961-9.

2. Schroder HD, Reske Nielsen E. Fiber types in the striated urethral and anal sphincters. Acta Neuropathol Berl 1983;60:278-82.

3. Percy JP, Neill ME, Swash M, Parks AG. Electrophysiological study of motor nerve supply of pelvic floor. Lancet $1981 ; 1: 16-7$.

4. Baeten CG, Geerdes BP, Adang EM, Heineman E, Konsten J, Engel GL, Kester AD, Spaans F, Soeters $\mathrm{PB}$. Anal dynamic graciloplasty in the treatment of intractable fecal incontinence. $\mathrm{N}$ Engl J Med 1995;332: 1600-5.

5. Salmons S, Vrbova G. The influence of activity on some contractile characteristics of mammalian fast and slow muscles. J Physiol Lond 1969;201:535-49.

6. Pette D, Vrbova G. Adaptation of mammalian skeletal muscle fibers to chronic electrical stimulation. Rev Physiol Biochem Pharmacol 1992;120:115-202.

7. Konsten J, Baeten CG, Havenith MG, Oei TK. Evaluation of gracilis muscle transposition for fecal incontinence with magnetic resonance imaging. Eur J Radiol 1993;16:190-4.

8. Shanahan D, Riches DJ, Sinnatamby CS, Williams NS, Watkins ES. The arterial anatomy and surgical relevance of the human gracilis muscle. J Anat 1991;176:270-272(abstract).

9. Williams NS, Patel J, George BD, Hallan RI, Watkins ES. Development of an electrically stimulated neoanal sphincter. Lancet 1991;338:1166-9.

10. Havenith MG, Visser R, Schrijvers van Schendel JM, Bosman FT. Muscle fiber typing in routinely processed skeletal muscle with monoclonal antibodies. Histochemistry 1990;93:497-9.

11. Dolber PC, Spach MS. Picrosirius red staining of cardiac muscle following phosphomolybdic acid treatment. Stain Technol 1987;62:23-6.

12. Gohil K, Jones DA, Edwards RHT. Analysis of muscle mitochondrial function with techniques applicable to needle biopsy samples. Clin Physiol 1981;1:195-207.

13. Ling KH, Paetkau V, Marcus F, Lardy HA. Merh Enzymol 1966;9:425-9.

14. Bergmeyer HU. Mechods of Enzymatic Analysis. New York: Academic Press; 1974;p. 474-6.

15. Shepherd D, Garland PB. Citrate synthase from the rat liver. Meth Enzymol 1969;13:11-6.

16. Kadhiresan VA, Guelinckx PJ, Faulkner JA. Tenotomy and repair of latissimus dorsi muscles in rats: implicarions for transposed muscle grafts. J Appl Physiol 1993;75:1294-9.

17. Güelinckx PJ, Faulkner JA, Essig DA. Neurovascular-anastomosed muscle grafts in rabbits: functional deficits result from tendon repair. Muscle Nerve 1988;11:745-51.

18. Williams PE, Goldspink G. Connective tissue changes in immobilised muscle. J Anat 1984;138:343-50.

19. Williams PE, Catanese T. Lucey EG, Goldspink G. The importance of stretch and contractile activity in the prevention of connective tissue accumulation in muscle. J Anat 1988;158:109-14.

20. Williams PE, Goldspink $G$. Changes in sarcomere length and physiological properties in immobilized muscle. J Anat 1978; 127:459-68.

21. Mannion JD, Velchik M, Hammond R, Alavi A, Mackler T, Duckett S, Staum M, Hurwizz S, Brown W, Stephenson LW. Effects of collateral blood vessel ligation and electrical conditioning on blood flow in dog Jatissimus dorsi muscle. J Surg Res 1989;47:332-40.

22. Tyml K, Machieu Costello O, Budreau CH. Microvascular response to ischemia, and tissue structure, in normal and arrophied skeleral muscle. Microvase Res 1990;39(2):223-39.

23. el Oakley RM, Jarvis JC, Barman D, Greenhalgh DL, Currie J, Downham DY, Salmons S, Hooper TL. Factors affecting the integricy of latissimus dorsi muscle grafts: implications for cardiac assistance from skeletal muscle. J Heart Lung Transplant 1995; 14:359-65.

24. Faulkner JA, Carlson BM, Kadhiresan VA. Review: Whole skeleral muscle transplantation: mechanisms responsible for functional defecits. Biotechnology and Bioengeneering 1994;43:757-63. 
25. Lexell J. Jarvis J, Downham D, Salmons S. Quantitative morphology of stimulation-induced damage in rabbir fast-rwitch skeletal muscles. Cell Tissue Res 1992;269:195-204.

26. Salmons S, Henriksson J. The adaptive response of skeletal muscle to increased use. Muscle Nerve 1981;4:94i-105.

27. Hudlicka O, Brown MD, Egginton S, Dawson JM. Effect of long-term electrical stimulation on vascular supply and fatigue in chronically ischemic muscles. J Appl Physiol 1994;77:1317-24.

28. Lexell J, Jarvis J, Downham D, Salmons S. Stimulation-induced damage in rabbit fast-twitch sikeletal muscles: a quantitative morphological study of the influence of pattern and frequency. Cell Tissue: Res 1993:273:357-62.

29. Mayne CN, Sutherland H, Jarvis JC, Gilroy S., Craven SJ, Salmons S. Induction of a fast-oxidative phenorype by chronic muscle stimulation: histochemical and metabolic studies. Am J Physiol 1996;270:C313-20.

30. Reichmann H, Wasl R, Simoneau JA, Petre D. Enzyme activities of fatry acid oxidation and the respiratory chain in chronically stimulated fast-twitch muscle of the rabbit. Pflugers Arch $1991: 418(6): 572-4$

31. Rouanet P, Bacou F. Changes in fibre type, metabolic character and acetylcholinesterase forms in rabbir skeletal muscle following stretch and electrical stimulation. Neuromuscul Disord 1993:3:401-5.

32. Jones J, Emmanuel J, Sutherland H, Jackson MJ, Jarvis JC, Salmons S. Stimulation-induced skeleral muscle damage: cytoprorective effect of prestimulation. BAM 1996;

33. Sternbergh WC, Adelman B. Skeletal muscle fiber type does not predict sensitivity to postischemic damage. J Surg Res 1992;53:535-41.

34. Perrasek PF, Homer Vanniasinkam S, Walker PM. Determinants of ischemic injury to skeletal muscle. J Vasc Surg 1994; 19:623-31.

35. Shatari T, Sugiyama Y, Teramoto T, Kitajima M, Minamitani H. Reconstruction of anal function by transposed gracilis muscle with electrical stimulation: rabbir model. Int J Arrif Organs $1994 ; 17: 240-4$.

36. Lawson CS, Downey JM. Preconditioning: state of the art myocardial protection. Cardiovase Res 1993;27:542-50.

37. Alkhulaifi AM, Yellon DM, Pugsley WB. Precondirioning the human heart during aorto-coronary bypass surgery. Eur J Cardiorhorac Surg 1994;8(5):270-5. 


\section{Chapter 6}

\section{PEDIATRIC INCONTINENCE AND THE DYNAMIC GRACILOPLASTY}

Nature is nowhere accustomed more openly to display ber secret mysteries than in cases where she shows traces of her workings apart from the beaten path; nor is there any better way to advance the proper practice of medicine than to give our minds to the discovery of the usual law of nature, by careful investigation of cases of rarer forms of disease. For it has been found in almost all things, that what they contain of useful or of applicable, is hardly perceived unless we are deprived of them, or they become deranged in some way.

William Harvey to John Vlackveld

London 24 April 1657. 

Chapter 6.1

\section{RECENT DEVELOPMENTS IN THE TREATMENT OF PEDIATRIC INCONTINENCE}

Recent Developments in Treatment of Pediatric Incontinence. Geerdes BP, Heineman E. and Baeten CGMI.

(submitted) 


\section{Introduction}

Most children in the Western society are expected to achieve fecal continence at the age of 3 years. ${ }^{1}$ If fecal incontinence persists it can have a profound effect on the life of the family and the child. It can strongly affect school placement ${ }^{2}$ and even at a cooperative school many children experience periods of loneliness or even social isolation. ${ }^{3}$ Children and adolescents suffering from fecal incontinence have a higher prevalence of clinically significant emotional problems in relation to normative populations, with a high proportion of internalizing problems and depressive symptoms. ${ }^{4}$ It has potentially scverely disruptive implications for the overall development of the child, whose coping strategies such as overt denial, secretiveness and acceptance strongly depend on age, sex and parental facrors. ${ }^{3}$

Continence is dependent upon several anatomical, physiological and psychological entities. The internal sphincter consists of smooth muscle fiber, which is capable of continuous tonic contraction and therefore mainly responsible for continence in rest. ${ }^{5}$ The external anal sphincter consists of a majority of type I, fatigue-resistant muscle fibers, dependent upon active contraction and preventing passage of a motion at an inconvenient time. ${ }^{6}$ The puborectalis muscle, the most important muscle of the pelvic floor, is responsible for creation of the anorectal angle ${ }^{7}$, which provides an anatomical barrier for the passage of rectal stool, and possesses nerve-endings important for sensibility. To be able to postpone defecation, the rectal volume and the compliance of the rectal wall have to be large enough in order to store stool until defecation can take place. Sensibility, dependent upon the receptors in the anorectal mucosa and the pelvic floor is extremely important for the call to stool and discrimination between solid, liquid and gas. Colonic motility is responsible for the volume, consistency and the speed at which stool is delivered at the anorecrum. Rectal filling results in a reflex relaxation of the internal anal sphincter, the recto-anal inhibitory reflex, which has an important role both in anorectal sampling and defecation. Apart from the importance of each of these enticies, they only achieve maximal efficacy by working together in a highly coordinated way.

Types of incontinence

\section{The different causes of incontinence are summarized in table 1.}

\section{Encopresis and Constipation with fecal soiling}

The commonest cause of inconcinence in children is constipation due to an enlarged rectum with ineffective contraction. Encopresis can be defined as the persistent voluntary or involuntary passage of formed morions of normal or near normal consistency 
Table 1. The different causes of incontinence and the anatomical or physiological entities affected.

\begin{tabular}{|c|c|c|c|c|c|c|c|}
\hline $\begin{array}{l}\text { Pathogenesis } \Rightarrow \\
\text { Entities affected } \Downarrow\end{array}$ & $\begin{array}{l}\text { Encopresis } \\
\text { Constipation }\end{array}$ & Trauma & $\begin{array}{l}\text { Sacral } \\
\text { Agenesis }\end{array}$ & $\begin{array}{l}\text { MMC } \\
\text { (high) }\end{array}$ & $\begin{array}{l}\text { MMC } \\
\text { (low) }\end{array}$ & $\begin{array}{l}\text { Anal atresia } \\
\text { (high) }\end{array}$ & $\begin{array}{l}\text { Anal airesia } \\
\text { (low) }\end{array}$ \\
\hline Internal sphincter & - & \pm & + & + & \pm & + & \pm \\
\hline External sphincter & \pm & + & + & + & + & + & \pm \\
\hline Puborectalis muscle & \pm & \pm & + & + & \pm & + & \pm \\
\hline Recral volume & \pm & - & - & - & - & \pm & - \\
\hline Compliance wall & \pm & - & - & - & - & \pm & - \\
\hline Sensibilicy & \pm & \pm & \pm & + & \pm & + & - \\
\hline Motility & - & - & + & + & \pm & \pm & - \\
\hline Psychologyy & + & - & - & - & - & - & - \\
\hline
\end{tabular}

$-=$ no role, $\pm=$ possible role, and $+=$ role .

into places not intended for that purpose and without any organic cause. It is only called encopresis when it occurs after the age of four and on a regular basis. ${ }^{8}$ Often encopresis and soiling are used in the same context. Classification can be into primary when the child has never developed bowel control, or secondary when it occurs after completion of the toilet training. Another classification is into retentive encopresis, when there is clear evidence of constipation, and non-retentive encopresis, when there is no evidence of constipation which is then often associated with psychosocial stress." The group of affected children is extremely heterogeneous in terms of symptomatology, psychosocial background and treatment response. The etiology is probably a combination of social, psychogenic and physical symptoms. Over-rigid or over-permissive attitudes result in a holding back syndrome with a progress from chronic constipation to rectal inertia or even overflow incontinence. ${ }^{10}$ On the other hand an abnormal physical defecation pattern may exist, consisting of increased thresholds of sensation of the rectal distension $^{11}$, weakness of the internal sphincter ${ }^{12}$ and a poor coordination of defecation. ${ }^{13}$ Treatment methods for encopresis that have been described are verbal treatment, biofeedback treatment, behavioral treatment and mixed treatments. ${ }^{1 / 4}$ Contrary to a high incidence of social competency and behavior problems, the inability to defecare and the inability to relax the external sphincter during defecation were related to treatment failure. ${ }^{15}$ Nearly always encopresis resolves spontaneously by adolescence. ${ }^{16}$

\section{Traumatic}

Traumatic injuries to the anal sphincter due to surgery for e.g., Hirschsprungs disease or sacrococcygeal teratomata, or direct trauma at home or in the traffic may cause incontinence. ${ }^{17}$ Special attention should be paid to injuries caused by child abuse or sexual abuse by parents or caretakers. ${ }^{18}$ 


\section{Neurological}

This group consist of the congenital anomalies of the lower vertebral column like sacral agenesis (SA) and myelomeningocele (MMC). These anomalies are commonly associated with neurological, orthopedical, anorectal and urological malformations. In SA lumbosacral sensation is better preserved than the motor functions and the level of the vertebral aplasia is correlated with the motor but not with the sensory level. ${ }^{19}$ In MMC the neural tube defect involves the nerve tracts descending from the lower spinal cord. Anorectal function in MMC patients is determined by the degree of striated muscle paralysis in the pelvic floor and the effect of spinal nerve loss on the autonomic innervation of the intestinal smooth muscles. ${ }^{20}$ Internal anal sphincter function and pressure are more reduced in patients with damage high in the spinal cord than in patients with low spinal lesions, probably due to a more affected excitatory sympatheric nerve supply provided via the hypogastric nerve plexus (L5). ${ }^{20}$ External anal sphincrer function is severely affected in all children due to sacral root dysfunction. When the lesion is below L2 the cauda equina is mostly affected. Agnarsson et $\mathrm{al}^{21}$ found that some of these children can have high anal pressures. Anorectal sensibility was almost only affected in children with a high lesion. Due to the low pressure zone of the anal canal almost all children were able to defecate a rectal balloon from the inert and distended rectum. Weak abdominal muscles or a relatively high anal sphincter pressure causing ineffective straining could hinder defecarion.

\section{Anorectal anomalies}

Embryologically, anal atresia can be viewed as an agenesis of the dorsal part of the cloacal membrane which blocks the normal shift of this part and the adjacent gut to the body surface of the tail groove. ${ }^{22}$ There is a close relationship between the extent of the cloacal plate defect and the type of the anorectal malformation. The puborectal and external sphincter muscles develop independently at their normal sites although they are often malformed, in seriousness depending on the degree of the anal orifice ectopia. Even the internal sphincter muscle can be present and is then spread out as a wide disc surrounding the proximal part of the fistula. ${ }^{23}$ Most patients with low anorectal anal atresia will achieve continence. Patients with high anal atresia are often given a colostomy at birch and at the age of 6 months - 1 year the anorectum and the pelvic floor are reconstructed by a posterior saggital anorectoplasty (PSARP). ${ }^{24}$ Despite this perfect anatomical reconstruction patients seldom become continent. ${ }^{25}$ Even when the internal sphincter can be saved, 30 percent of the patients remain incontinent. ${ }^{26}$ Poor anorectal sensibility and abnormal bowel motility are probably responsible for poor outcome. A possible reason for this may be the lack of stimuli to the bowel during the first 6 to 12 months of life due to the presence of a colostomy. The first months of life are known to be essential for the final development of the central and autonomic nervous system. This includes the enteric nervous system and the brain-defecation neurocircuitry, both important entities for a good coordination of defecation, depending on sensibility and 
motility. Immediate anorectal repair appears to be feasible and achieves continence in a higher percentage of the patients. ${ }^{27-29}$ As it is known that the first operation is the most important, the surgeon, the type of operation and the timing should be carefully chosen to achieve an optimal outcome.

\section{Evaluation}

\section{Clinical history and examination}

The clinical history and a physical examination form the must important tools to properly diagnose the patients' disease. A detailed history should contain information about the general health condition, physical and mental development, diet, drugs, possible contributing factors, discrimination, onset of incontinence, defecation frequency, stool consistency, amount and frequency of loss of stool, use of protection material such as diapers, urge to defecate.

Inspection of the general condition and the anal region and digital examination of the anorectum will yield information about the existence of a patolous anus or stenosis, the elasticity of the anal introitus, the intactness and the strength of the anal sphincters, the function of the pelvic floor i.e. the puborectal muscle, and the sensitivity of the anorectum. ${ }^{30}$

\section{Anal manometry}

Anal manometry is the most appropriate tool to study anorectal physiology. It is absolutely harmless and becomes more accurate when the the child becomes older. ${ }^{31}$ Using perfused or solid-state multi-channel catheters, it can provide information about the maximal resting pressure (internal anal sphincter), the maximal squeeze pressure (external sphincter), the length of the high pressure zone, the presence or absence of the rectoanal inhibitory reflex. Intrarectal inflation of a latex balloon and the balloon retaining test ${ }^{32}$ evaluate the rectal capacity and sensitivity. Manometry is useful in the diagnosis of morbus Hirschsprung ${ }^{33}$, anal atresia ${ }^{34}$, congenital megacolon, constipation, incontinence, and spina bifida. ${ }^{35}$ Although manometry is highly objective, it was unable to predict continence in children with anorectal anomalies. ${ }^{36}$ Profilomerry (rapid pull-through, three dimensional, eight-channel radial manomerry) showed a significant correlation between age and sphincrer length. ${ }^{37}$

\section{Defecography}

After introduction of barium contrast in the recrum the patient strains in order to expel the contrast. Simultaneous radiological imaging (defecography) provides information concerning the physiology of defecation by showing: the anorectal angle, the function 
and possible descendence of the pelvic floor, the capability to void completely and the occurrence of rectal wall abnormalities such as prolapse, cele, and intussusceprion. ${ }^{38}$

\section{Anal endosonography}

In patients who have an accessible anal canal anal endosonography is an elegant imaging technique, without the disadvantage of radiation exposure. It allows visualization of the thickness and intactness of the internal and external anal sphincter, the pelvic floor and adjacent structures. ${ }^{39}$ The thickness of the external anal sphincter, the puborectal muscle and the levator ani complex exhibit a significant correlation with the age of the child. ${ }^{37}$

\section{Magnetic resonance imaging}

This rechnique shows the position and extent of pelvic and anal musculature. ${ }^{40}$ It is unable to visualize the internal anal sphincter. In patients with characteristic fearures or $x$-ray evidence of sacral agenesis, anorectal, and genitourinary anomalies or other complex malformations of the caudal region it allows further evaluation. ${ }^{19}$

\section{Electromyography (EMG)}

EMG provides useful clinical information about the funcrion of the pelvic floor muscularure, especially the external anal sphincter and the puborectalis muscle, in rest and during squeezing and straining. ${ }^{41}$ Using the single fiber EMG technique, quantification of the fiber density is a useful parameter for assessing reinnervation of previously damaged pudendal nerve. ${ }^{42}$ Because of the painful insertion of needles, EMG recordings in children are usually integrated in manometry recordings with the use of surface electrodes attached to the perianal skin.

\section{Solid Marker Studies}

Ten small radio-opaque Silastic tubing fragments are given orally on 3 subsequent days and a plain abdominal film is taken on day 5 . Then the number of markers is counted in the right colon, left colon and rectosigmoid. It is a well-tolerated and useful technique in establishing the diagnosis of constipation in children. ${ }^{4.3}$

\section{Conservative treatment}

\section{Diet and Drugs}

Most parienrs with constipation and soiling can be rreated successfully with the use of a special diet and drugs but it requires a strong morivation from borh the child (and family) and the physician. First a rapid success should be achieved by careful cleansing of the bowel: this may need frequent enemas (outpatient) or even an intestinal lavage 
in the hospital. During this phase only low residue diets should be used. Then during the next weeks laxatives, artificial bulking agents and sufficient fluids should be prescribed. At the same time, training of defecation at fixed times should be started and when needed small enemas should be used. Finally one should aim at modifying the life style by the use of high fiber diets and fluids, regularizing bowel movements with very low doses of laxatives and fixed hours. Good bowel training, a diet containing bulking agents, and regular toilering by evacuation with the help of digital stimulation, laxatives or enemas was able to achieve continence in 79 percent of compliant patients. ${ }^{44}$ The start at an early age and the presence of an anocutaneous reflex were the predictors of compliance and success.

\section{Behavioral therapy}

The strategies that have been developed can be divided into the ones that encouragc behavior such as defecation into the toilet by giving rewards for appropriate elimination, those that actively discourage behavior such as soiling by punishment for inappropriate elimination, and others that use positive reinforcement for passage of continent as well as incontinent stools. ${ }^{14,45}$ Often behavioral therapy is given in combination with enemas, high fiber diets, bulking agents or a combination of all. ${ }^{46}$ In patients with resistant symptoms the paradoxical approach method can be used, which is based on the principle that a person is expected to change by using the symptom itself as an effective prescription. ${ }^{47}$ Behavioral therapy has been reported to be successful in the treatment of encopretic children ${ }^{48}$, children with learning disabilities ${ }^{45.49}$ and children with spina bifida. ${ }^{44,50}$ Unfortunately prospective, randomized studies are lacking, often sample sizes are very small and seldom control groups are used.

\section{Biofeedback}

Biofeedback has proven to be successful in increasing the voluntary contraction amplitude of the external anal sphincter ${ }^{51}$, the coordination of the internal and external anal sphincter responses to rectal distension and recto-anal sensitivity. 52 Prerequisites are an intact anal sfincter, intact innervation, a strong motivation, and maturity. Children with constipation and/or fecal incontinence have successfully been treated. ${ }^{53,54}$ Patients with high anal atresia are responding moderately ${ }^{55}$ to good ${ }^{56}$ to the therapy. Wald reported good results with biofeedback in a selected group of patients with spina bifida and good rectal sensation. ${ }^{52}$ Whitehead however found little effect by biofeedback if it was not combined with behavior modification. ${ }^{57}$ Successful outcome was even described in a patient with sacral agenesis. ${ }^{58}$ One of the advantages of biofeedback training is the possibility of active participation by the patient at home, doing exercises and applying transcutaneous electrostimulation of the pelvic floor using specially designed devices $^{59,60}$, something which can work very well in children. 


\section{Bowel washout programs}

Highly motivated patients may benefit from the enema continence catheter, a latex catheter with a balloon used for fixation in the rectum. ${ }^{61-63}$ Unfortunately the drop out rate in the long run can be high because of too great demands placed on the child and its family, pain, abdominal discomfort, inability to retain the balloon and allergic reactions to the latex. ${ }^{64}$

\section{Surgical treatment}

\section{Antegrade enema tube}

Because of the great demands daily retrograde bowel washouts place on the child and its family, Malone constructed a continent catheterizable colonic stoma using the appendix. ${ }^{65}$ The stoma is easy accessible and by performing an antegrade bowel washout, the patient can empty the whole colon and is continent and confident the rest of the day. If patients have undergone an appendectomy in the past also a caecal flap ${ }^{66}$ or a pedicled gastric tube ${ }^{67}$ can be used to create a continent stoma. Although many patients have become continent and independent by using this technique, the complication rate seems to be rather high in the long run. ${ }^{68}$ Recently, good short time results were presented using a percutaneous cecostomy. ${ }^{69}$ An operation would then be redundant.

\section{Anal repair}

In children with a traumatic lesion of the external anal sphincter the anal repair as performed in adults has an excellent outcome. ${ }^{70}$

\section{Creation of an anal neosphincter}

\section{Smooth muscle sphincter}

The creation of a new anal sphincter with the use of a free smooth muscle collar is an attractive idea. In contrast to skeleral muscle, smoorh muscle is able to maintain a continuous state of contraction for long periods of time. About $10 \mathrm{~cm}$. of free, denervated and pre-stretched large bowel are folded around the colon-stump as a cuff. Good results were reported ${ }^{7-72}$, although it is difficult to understand that continence would completely rely upon internal sphincter funcrion. Furthermore, due to deprivation from circulation this cuff tends to scar. ${ }^{73}$ 


\section{Free autogenous muscle transplantation}

Since long it has been tried to construct a neosphincter with the help of another skeletal muscle. Precondition is that this muscle should not be essential for locomotion and/or posture. Transplantation of a denervated and de-vascularized palmaris longus muscle around the anus showed good results. ${ }^{74-75}$ There appeared to be revascularisation and reinnervation from the surrounding muscles.

It is more common to use a vital muscle that remains innervated and vascularized. Therefore it is necessary that site, muscle mass and the position of the neuro-vascular bundle should allow easy mobilization and transposition of the muscle to its new place. For construction of an anal neosphincter in man the gluteus maximus or the gracilis muscle are suited.

\section{Gluteoplasty}

The choice for the gluteus maximus to recreate an anal sphincter is a logical one because it is a powerful muscle that often is used as an accessory muscle to continence. The gluteus muscle is not important for posture or ordinary walking, but running, walking stairs and rising from a seated position depend upon its activity. Using the inferior fibers of bilateral gluteus maximus muscles, the distal part of one muscle is split, wrapped around the anal canal and fixed to the other mobilized muscle. ${ }^{76}$ Compared to the graciloplasty the gluteoplasty is technically a more complicated procedure, especially due to difficult identification of the nerve. Contrary to the gracilis muscle the gluteus maximus muscle is an important muscle in daily use, therefore, if muscle function is impaired or painful this may pose problems to the patient. So far, the technique has not been used in children.

\section{Graciloplasty}

The gracilis muscle, the most supcrficial adductor on the medial side of the thigh, was first used for neosphincter construcrion in 1952 by Pickrell in the treatment of children with fecal incontinence due to a neurogenic cause (spina bifida). ${ }^{77}$ Because of its superficial position, the gracilis muscle can easily be identified, the peripheral arteries are ligated and the distal tendon is cut, and the muscle is mobilized towards the neurovascular bundle. Than the muscle is wrapped around the anal canal and fixed to the contralateral ischial spine. By adducting the leg (bringing the knees together) the patient can actively contract the gracilis muscle and thereby close the anal canal. Since 1952, this technique has been applied on a wide scale with mixed results. ${ }^{78-79}$

Although active contraction of the muscle is forceful enough to hold up stool, long-standing adduction of the leg is an uncomfortable procedure making it impossible to reach the toilet. After a while patients may be able to have a voluntary, isolated, contraction of the gracilis muscle (instead of the whole adductor group), still all day continence is seldom achieved. This is also due to the fact that the gracilis, like all skeletal 
muscles, has a majority of type II, fast twitch, non fatigue resistant muscle fibers. These fibers are unable to have a sustained contraction.

\section{Dynamic Graciloplasty}

The first electrical stimulation of a transposed gracilis muscle was reported by the pediatric surgeons Dickson and Nixon in 1968 and their goal was to achieve a sustained contraction when stool arrived. ${ }^{80}$ Unfortunately, only preliminary data were published. In 1986 Baeten implanted the first neurostimulator in an anal atresia patient who had been treated with a conventional graciloplasty 10 years before. ${ }^{81}$ She had a good active contraction of the gracilis muscle but was still incontinent. However, after implantation of the neurostimulator she regained her continence. Electrical stimulation induces a change from fast-twitch, fatiguable (type II) muscle fibers into slow-twitch, fatigue-resistant (type I) muscle fibers. Active contraction is changed into stimulation induced contraction. An external magnet is given to all patients to turn the mode of operation of the pulse generator "off" to permit defecation and "on" again after defecation.

Indications for a dynamic graciloplasty are: an external anal sphincter that is damaged beyond repair, a sphincter with severe neurogenic damage and parients with a congenital disease like anal atresia or spina bifida. Contra-indications are: inflammatory bowel disease, not motivated / physically or mentally incapable patients.

In the group of patients with intractable fecal incontinence, dynamic graciloplasty has shown to be successful in the majority of the patients. ${ }^{82}$ The defecation frequency decreased, the time to postpone defecation increased and the possibility to withhold an enema improved. A quality of life study showed significant improvement in these patients as well. ${ }^{83}$

In a group of 52 patients with a mean follow-up of 2.1 years, patients incontinent due to a trauma had a success percentage of over 90 percent, while patients incontinent due to long-standing pudendopathy (64 percent) or anal atresia ( 50 percent) did less good. ${ }^{82}$ Apart from their poor sphincter function, both in patients with long-standing pudendal neuropathy and anal atresia the threshold for sensation appeared to be higher than for patients in the trauma group. Patients with an impaired sensation and /or an altered peristilsis of the bowel therefore may benefit less from restoration of the anal sphincter. To date, anal atresia patients have only been treated as an adult, many years after their initial operation for anorectal malformation. ${ }^{84}$ Experimental data showed that electrical stimularion of a gracilis muscle in a growing individual was well accepted by the muscular tissue, resulting in normal morphological changes and an excellent function. ${ }^{85}$ Implantation of the neurostimulator, which was relatively large for these small dogs, resulted though in necrosis and/or infection of the surrounding tissue in several dogs. In one of the dogs a fracture of one of the electrodes was found. Therefore it was advised that stimulation devices for fecal incontinence should be implanted only after the growing spurt. ${ }^{85}$ Good functional outcome was achieved with the construction of a dynamic graciloplasty in a thirteen year old girl who had suffered from a severe 
trauma, and the construction of a permanent colostomy could be prevented. ${ }^{17}$ Future research has to eluminate the most appropriate age at: which reconstructive surgery should be performed in this group of young patients with no other treatment option.

\section{References}

1. Fritz GK, Armbrust J. Enuresis and encopresis. Psychiarr Clinic N Am 1982;5:283-96.

2. Wasson CM, Bannister CM, Ward GS. Factors affecting the school placement of children with spina bifida. Eur J Pediatr Surg 1992;2 Suppl 1:29-34.

3. Ludman L, Spirz L. Coping strategies of children with faecal incontinence. J Pediatr Surg 1996;31(4):563-7.

4. Ludman L, Spirz L, Kiely EM. Social and emotional impact of faecal incontinence after surgery for anorectal abnormaliries. Arch Dis Child 1994;71:194-200.

5. Bennert RC, Duthie HL. The functional importance of the internal sphincter. Br J Surg 1964:51(5):355-7.

6. Read NW, Haynes WG, Bartolo DC, Hall J, Read MG, Donnelly TC, Johnson AG. Use of anorectal manometry during rectal infusion of saline to investigate sphincter function in incontinent parients. Gastroenterology 1983;85:105-13.

7. Bartolo DC, Miller R, Mortensen NJ. Sphincteric mechanism of anorectal continence during Valsalva manoeuvres. Coloproctology 1987;9:103-7.

8. Levine MD. Children with encopresis: A descriptive analysis. Pediatrics 1975;56:412-6.

9. Levine MD. Levine MD, Carey WB, Crocker AC, editors.Developmental behavioui pediatrics. Philadelphia: W.B.Saunders; 1983;Encopresis. p. 586-95.

10. Kock NG, Myrvold HE, Philipson BM, Svaninger G, Ojerskog B. Continent cecostomy. An account of 30 patients. Dis Colon Rectum 1985;28:705-8.

11. Molnar D, Tairz LS, Urwin OM, Wales JKH. Anorectal manomerry results in defecarion disorders. Arch Dis Child 1983;58:257-61.

12. Loening Baucke VA, Younoszia MK. Abnormal and sphincter response in chronically constipated children. J Pediatr 1982;100:213-8.

13. Wald A. Chandra R, Chiponis D. Gabel S. Anorectal funcrion and continence mechanisms in childhood encopresis. J Pediatr Gastroenterol Nutr 1986;5:346-51.

14. Thapar A, Davies G, Jones T, Rivett M. Treatment of childhood encopresis - a review. Child Care Healch Dev 1992;18:343-53.

15. Loening Baucke V, Cruikshank B. Savage C. Defecation dynamics and behavior profiles in encopreric children. Pediarrics 1987;80:672-9.

16. Bellman M. Studies on encopresis. Acta Paediacr Scand 1966:Suppl:170

17. Konsten J, Geerdes B, Versluis P, Heineman E, Bacten GM. Dynamic graciloplasry for testoration of continence after traumatic destruction of the rectum and sphincters: report of a case. J Trauma 1995:38:11-3.

18. Black CT, Pokorny W], McGill CW, Harberg FM. Anorectal trauma in children. J Pediatr Surg 1982;17:501-4.

19. Pang D. Sacral agenesis and caudal spinal cord malformations. Neurosurgery 1993:32:755-78.

20. Frenckner $B$, Ihre $T$. Influence of autonomic nerves on the internal and sphincter in man. Gut 1976;17:306-12.

21. Agnarsson U, Warde C. McCarthy G, Clayden GS, Exans N. Anorectal function of children with neurological problems. I: Spina bifida. Dev Med Child Neurol 1993:35:893-902.

22. van der Putre SC. Normal and abnormal development of the anorectum. J Pediatr Surg 1986;21:43440. 
23. Lambrecht W, Lierse W. The internal sphincter in anorectal malformations: morphologic investigations in neonatal pigs. J Pediatr Surg 1987;22:1160-8.

24. deVries PA, Pena A. Posterior sagittal anorectoplasty. I Pediatr Surg 1982;17:638-43.

25. Langemeijer RA, Molenaar JC. Continence after posterior sagittal anorectoplasty [see comments].'] Pediatr Surg 1991;26:587-90.

26. Rintala RJ, Lindahl $\mathrm{H}$. Is normal bowel function possible after repair of intermediace and high anorectal malformarions? J Pediatr Surg 1995:30:491-4.

27. Moore TC. Advantages of performing the sagittal anoplasty operation for imperforate anus at birth [sce comments]. J Pediarr Surg 1990;25:276-7.

28. Aluwihare AP. Primary perineal recrovaginoanoplasty for supralevaror imperforate anus in female neonates. J Pediatr Surg 1990;25:278-81.

29. Kooi Goon H. Repair of anorectal anomalies in the neonatal period. Pediatr Surg Int 1990;5:246-9.

30. Scharli AF. Anorectal incontinence: diagnosis and trearment. J Pediatr Surg 1987;22:693-701.

31. Meunier P, Marechal JM, Mollard P. Accuracy of the manometric diagnosis of Hirschsprung's disease. J Pediarr Surg 1978;13:411-5.

32. Penninckx FM, Lestar B, Kerremans RP. A new balloon-retaining test for evaluation of anorectal function in incontinent patients. Dis Colon Rectum 1989;32:202-5.

33. Loening Baucke V, Pringle KC, Ekwo EE. Anorectal manometry for the exclusion of Hirschsprung's disease in neonates. J Pediatr Gastroenterol Nutr 1985;4:596-603.

34. Arhan P, Faverdin C, Devroede G, Dubois F, Coupris L, Pellerin D. Manometric assessment of continence after surgery for imperforace anus. J Pediatr Surg 1976;11:157-66.

35. Meunier P, Mollard P, Jauberr de Beaujeu M. Manometric studies of anorectal disorders in infancy and childhood: an investigation of the physiopathology of continence and defaecation. $\mathrm{Br} \mathrm{J}$ Surg 1976;63:402-7.

36. Doolin EJ, Black CT, Donaldson JS, Schwartz D, Raffensperger JG. Rectal manometry, computed tomography, and functional results of anal atresia surgery. J Pediatr Surg 1993:28:195-8.

37. Benninga MA, Wijers OB, van der Hoeven CW, Taminiau JA, Klopper PJ, Tytgat GN, Akkermans L.M. Manometry, profilometry, and endosonography: normal physiology and anatomy of the anal canal in healthy children. J Pediatr Gastroenterol Nurr 1994; 18:68-77.

38. Goei R. Anorectal function in patients with defecarion disorders and asymptomatic subjects: evaluation with defecography. Radiology 1990;174:121-3.

39. Law PJ, Bartram CI. Anal endosonography: Technique and normal anatomy. Gastrointest Radiol 1989; 14:349-53.

40. Sachs TM, Applebaum H, Touran T. Use of MRI in evaluation of anorectal anomalies. J Pediatr Surg 1990;25:817-21.

41. Percy JP, Neill ME, Swash M, Parks AG. Electrophysiological study of motor nerve supply of pelvic floor. Lancet 1981;1:16-7.

42. Neill ME, Swash M. Increased motor unit fibre density in the external anal sphincter muscle in ano-rectal incontinence: a single fibre EMG study. J Neurol Neurosurg Psychiatry 1980;43:343-7.

43. Papadopoulou A, Clayden GS, Booth IW. The clinical value of solid marker transit studies in childhood constipation and soiling. Eur J Pediatr 1994;153:560-4.

44. King JC, Currie DM, Wright E. Bowel training in spina bifida: importance of education, patient compliance, age, and anal reflexes. Arch Phys Med Rehabil 1994;75:243-7.

45. Smith LJ, Franchetti B, McCoull K, Patrison D, Pickstock J. A behavioural approach to retraining bowel function after long-standing constipation and faecal impaction in people with learning disabilities [see comments]. Dev Med Child Neurol 1994:36:41-9.

46. Stark L, Spirito A, Lewis AV, Hart KJ. Encopresis:behavioural parameters associated with children who fail medical management. Child Psychiat Hum D 1990;20:181-90.

47. Knights B, Pandey SK. Paradoxical approach to the management of faecal incontinence in normal children. Arch Dis Child 1990;65:598-600. 
48. Lowery SP, Srour JW, Whitehead WE, Schuster MM. Habit training as treatment of encopresis secondary to chronic constipation. J Pediatr Gastroenterol Nutr 1985;4:397-401.

49. Piazza CC, Fisher W, Chinn S, Bowman L. Reinforcement of incontinent stools in the treatment of encopresis. Clin Pediatr Phila 1991;30:28-32.

50. Leibold S. A systematic approach to bowel continence for children with spina bifida. Eur J Pediatr Surg 1991;1 Suppl 1:23-4.

51. MacLeod JH. Management of anal incontinence by biofeedback. Gastroenterology 1987;93:291-4.

52. Wald A. Biofeedback for neurogenic fecal incontinence: rectal sensation is a determinant of outcome. J Pediatr Gastroenterol Nutr 1983;2:302-6.

53. Weber J, Ducrorte P, Touchais JY, Roussignol C, Denis P. Biofeedback training for constipation in adults and children. Dis Colon Rectum 1987;30:844-6.

54. Arhan P, Faverdin C, Devroede G, Besancon Lecointe I, Fekete C, Goupil G, Black R, Jan D, Martelli $\mathrm{H}$, Pellerin D. Biofeedback re-education of faecal continence in children. Int J Colorectal Dis 1994;9:128-33.

55. Iwai $N$, Nagashima M, Shimorake T, Iwara G. Biofeedback therapy for fecal incontinence after surgery for anorectal malformations: preliminary results. J Pediatr Surg 1993;28:863-6.

56. Arnbjornsson E, Kullendorff CM, Mikaelsson C, Okmian L, Rosen I. The value of physiorherapy for faecal continence after correction of high anal atresia. A clinical and electromyographic study. Acta Chir Scand 1988;154:467-70.

57. Whitehead WE, Parker L, Bosmajian L, Morrill Corbin ED, Middaugh S, Garwood M, Cataldo MF, Freeman J. Treatment of fecal incontinence in children with spina bifida: comparison of biofeedback and behavior modification. Arch Phys Med Rehabil 1986;67:218-24.

58. Benninga MA, van der Hoeven CW, Wijers OB, Buller HA, Tytgar GN, Akkermans LM, Taminiau JA. Treatment of faecal incontinence in a child with sacral agenesis: the use of biofeedback training. Dev Med Child Neurol 1994;36:518-27.

59. Herold A, Bruch HP, Hocht B, Dorsing C. [Improving anal continence performance by intensive continence training]. Z Kinderchir 1989;44:318-20.

60. Kirsch SE, Shandling B, Warson SL, Gilmour RG, Pape KE. Continence following electrical stimularion and EMG biofeedback in a teenager with imperforate anus. J Ped Surg 1993;28(10):140810.

61. Walker J, Webster P. Successful management of faecal incontinence using the enema continence cacheter. Z Kinderchir 1989;44 Suppl 1:44-5.

62. Blair GK, Djonlic K, Fraser GC, Arnold WD, Murphy JJ, Irwin B. The bowel management tube: an. effective means for controlling fecal incontinence. J Pediatr Surg 1992;27:1269-72.

63. Willis RA. Faecal incontinence-Willis Home Bowel Washout Programme. Z Kinderchir 1989;44 Suppl 1:46-7.

64. Liptak GS, Revell GM. Management of bowel dysfunction in children with spinal cord disease or injury by means of the enema continence catheter. J Pediatr 1992;120:190-4.

65. Malone PS, Ransley PG, Kiely EM. Preliminary report: the antegrade continence enema. Lancet 1990;336:1217-8.

66. Kiely EM, Ade Ajayi N. Wheeler RA. Caecal flap conduir for antegrade continence enemas. Br J Surg 1994;81:1215

67. Borzi P, Gough DC. Pedicled gastric tube as a catheterising conduit. Eur Urol 1993;24:103-5.

68. Griffiths DM, Malone PS. The Malone antegrade continence enema. J Pediatr Surg 1995;30:68-7 1.

69. Shandling B, Chait PG, Forrest-Richards H. Percutaneous cecostomy: a new rechnique in the management of fecal incontinence. J Pediatr Surg 1996;31:534-7.

70. Browning GG, Motson RW. Results of Parks operation for faccal incontinence after anal sphincter injury. Br Med J Clin Res Ed 1983;286:1873-5.

71. Schmidt E. [Surgical management of anus incontinence using free-transplanted autologous, endogenous intestinal musculature]. Chirurg 1985;56:305-10.

72. Schmidt E. [Late results following smooth muscle sphincter replacement]. Chirurg 1985;56:305-10. 
73. Holschneider AM, Hecker WC. [Flapped and free muscle transplantation in the treatment of anal incontinence (author's transl)]. Z Kinderchir 1981;32:244-58.

74. Hakelius L, Gierup J, Grotte G, Jorulf H. A new treatment of anal incontinence in children: free autogenous muscle transplantation. J Pediatr Surg 1978;13:77-82.

75. Hakelius L, Olsen L. Free autogenous muscle transplantation in children. Long-term results. Eur J Pediatr Surg 1991;1:353-7.

76. Devesa JM, Vicente E, Enriquez JM, Nuno J, Bucheli P, de Blas G, Villanueva MG. Total fecal incontinence- a new method of gluteus maximus transposition: preliminary results and report of previous experience with similar procedures. Dis Colon Rectum 1992;35:339-49.

77. Pickrell KL, Broadbent TR, Masters FW, Merzger JT. Construction of a rectal sphincter and restoration of continence by transplanting the gracilis muscle. Ann Surg 1952;135(6):853-62.

78. Raffensperger J. The gracilis sling for fecal incontinence. J Pediatr Surg 1979;14:794-7.

79. Yoshioka K, Keighley MR. Clinical and manometric assessment of gracilis muscle transplant for fecal incontinence. Dis Colon Rectum 1988;31:767-9.

80. Dickson AS, Nixon HH. Control by electronic stimulator of incontinence after operation for anorecral agenesis. J Pediatr Surg 1968;3:696-701.

81. Baeten C, Spaans F, Fluks A. An implanted neuromuscular stimulator for fecal concinence following previously implanted gracilis muscle. Report of a case. Dis Colon Rectum 1988:31:134-7.

82. Baeten CG, Geerdes BP, Adang EM, Heineman E, Konsten J, Engel GL, Kester AD, Spaans F, Soeters PB. Anal dynamic graciloplasty in the treatment of intractable fecal incontinence. $N$ Engl J Med 1995;332:1600-5.

83. Adang EMM, Engel GL, Konsten J, Baeten CGMI. Quality of life after dynamic graciloplasty for fecal incontinence: first results. Theor Surg 1993:8:122-4.

84. Baeten CGMI, Konsten J, Heineman E, Soeters PB. Dynamic graciloplasty for anal atresia. J Ped Surg 1994;29(4):922-5.

85. Konsten J, Geerdes B, Baeten CG, Heineman E, Arends JW, Pette D, Soeters PB. Dynamic myoplasty in growing dogs as a feasibility study for treatment of fecal incontinence. J Pediatr Surg 1995;30:580-4. 
Chapter 6.2

\section{DYNAMIC MYOPLASTY FOR TREATMENT OF INCONTINENCE IN GROWING INDIVIDUALS}

Dynamic Myoplasty in growing dogs as a feasibility study for treatment of fecal incontinence.

Konsten J, Geerdes BP, Baeten CGMI, Heineman E, Arends JW, Perte D, Soeters PB.

J of Pediatric Surgery 1995; 30(4):580-4 


\section{Introduction}

Recently, encouraging results have been reported with an electrically activated gracilis muscle neosphincter (dynamic graciloplasty) for fecal incontinence in adults in whom other treatment modalities failed. ${ }^{1,2}$ The procedure consists of a conventional graciloplasty that is stimulated with an implanted pulse generator to achieve a continuous contraction independent of volition. In addition, electrical stimulation induces a transition from type II fatigue-prone into type I fatigue-resistant fibers, which enables prolonged contraction of skeletal muscle. 3,4

The application of dynamic graciloplasty in children who are incontinent after surgery for anal atresia might be an attractive perspective, but transposition and electrical stimularion of a skeletal muscle in a growing individual may have undesirable effects on muscle structure and function. ${ }^{5}$ Williams and Goldspink suggested that immobilization of a skeletal muscle in a shortened position in a growing mouse results in lengthening of the tendon instead of muscle growth. In addition, they reported that immobilization of a muscle (which might happen in a conventional graciloplasty) results in increased muscle stiffness. ${ }^{6}$ These changes in muscular structure may influence the funcrion of a myoplasty for fecal incontinence. Therefore, we investigated the physiological and immunohistochemical properties of transposed and electrically stimulated skeletal muscle in growing dogs.

\section{Material and methods}

Five puppies with a mean weight of $7 \mathrm{~kg}$ (range, 5-8) were operated on, and in one dog (weight $7 \mathrm{~kg}$ ) the muscles were left in situ to serve as a control for normal growth and only biopsies were taken. Premedication consisted of Domitor (Farmos group Ltd, Turku, Finland). Anesthesia was induced with a nitrous oxide, oxygen (1:2) Halothane $(0.8 \%)$ (Trofields Surgical A.G., Zug Swirzerland) mixrure. Domitor was antagonized with Antisedan (Farmos) to avoid alterations in skeletal muscle tone during pressure measurements. Standard aseptic surgical procedures were used.

\section{Surgical procedures}

The superior belly of the canine sartorius muscle was dissected in borh legs of the animal, and the neurovascular pedicle was identified and saved. In the righr sarrorius muscle, we inserted a model SP 5548 intramuscular electrode as cathode in the vicinity of the nerve entry; a similar electrode was used as anode, $2 \mathrm{~cm}$ distal of this point. These electrodes were tunneled subcutaneously and connected with a model 7424 pulse generator (Medtronic, Kerkrade, The Netherlands) which was positioned preperitoneally. The left sartorius muscle was transposed only and served as a control nonstimulated neosphincter. Subsequently, a midline laparotomy was performed and a 


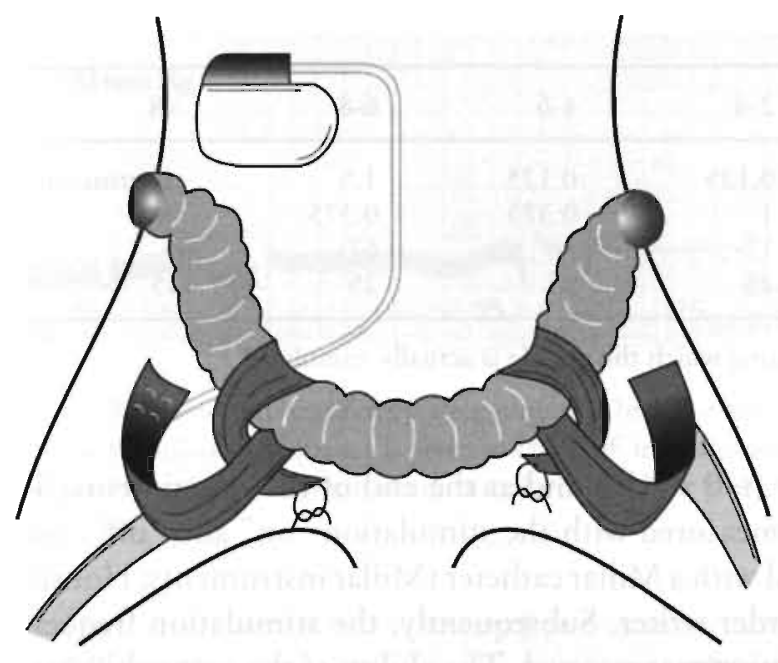

Figure 1. ' $\mathrm{S}$ ' = transposed sartorius muscle $-1+$ are respectively indicating the negative and positive lead and ' $E S$ ' = the implanted pulse generator and ' $L$ ' = Thiry-Vella loop

Thiry Vella loop was constructed. The continuity of the gut was restored, using a single-layer hand-sewn anastomosis. The dissected sartorius muscles were wrapped around the Thiry-Vella loop in each animal and sutured to the anterior iliac spine as a neosphincter (figure 1). During surgery, Flagyl (Rhône-Poulenc, Amstelveen, The Netherlands), Gentamicin (AUV, Cuyck, The Netherlands) and saline (Sodium chloride $[\mathrm{NaCl}] 0.9 \%)$ were administrated intravenously. The animals were allowed to recover from surgery for 6 weeks. The feasibility of sartorius muscle transposition and subsequent stimulation in adult dogs has already been described by Hallan. ${ }^{7}$ The experiments were approved by the ethical committee of the University of Limburg and the animals were treated according to Dutch legislation.

\section{Stimulation}

The right sartorius muscles were intermittently stimulated (table 1) for 8 weeks to induce a transformation from type II fatigue-prone into type I fatigue-resistant muscle fibers. Subsequently, continuous stimulation was applied for a mean period of 11 weeks (range 8-14 weeks). The adequacy of the stimulation voltage level was judged by manometry of the new sphincter at the beginning and at the end of the experiments. During the intermittent stimulation program, the contractions of the transposed sartorius muscle were judged by palparion of the transposed muscles. The load impedance was determined by using a model 7432 console programmer (Medtronic, Minnesota, USA) immediately after surgery and at the end of the experiments.

\section{Function}

Anesthesia (as has been described for the surgical procedures) was used during the functional test to avoid moving artifacts. Manometry of the right stimulated neosphinc- 
Table 1. Stimulation protocol

\begin{tabular}{llllll}
\hline time (weeks) & $0-2$ & $2-4$ & $4-6$ & $6-8$ & $>8$ \\
\hline "on" time (sec) & 0.125 & 0.125 & 0.125 & 1.5 & continuous \\
"off" time (sec) & 2 & 1 & 0.375 & 0.375 & \\
duty cycle (\%) & 8 & 17 & 36 & 67 & 15 \\
frequency & 25 & 25 & 25 & 25 & 15 \\
\hline
\end{tabular}

* duty cycle is the percentage of time during which the muscle is actually stimulated

ter was performed during surgery ( $\mathrm{t}=0$ weeks) and at the end of the experiments. The pressure of the neosphincter was measured with the stimulation "on" and "off", using the stationary pull through method with a Millar catheter (Millar instruments, Houston, Texas, USA) connected to a recorder writer. Subsequently, the stimulation frequency that caused a fused tetanic contraction was assessed. The ability of the new sphincter to inhibit the inflow of saline ( $0.9 \%$ saline) from a height of $85 \mathrm{~cm} \mathrm{H}_{2} \mathrm{O}$ was evaluated for the right stimulated and left nonstimulated neosphincters at the end of the experiments.

\section{Muscle biopsies}

Muscle biopsies were obtained from the proximal part of the sartorius during surgery and at the end of the experiments in (i) transposed and stimulated, (ii) transposed non stimulated, and (iii) nontransposed non stimulated muscles. The percentage and diameter of type I, fatigue-resistant and type II, and fatigue-prone muscle and the percentage of endomysial collagen was assessed as described previously (4,8-10).

Crude myosin extracts were prepared on ice as described by Termin et al. ${ }^{11}$ Myosin heavy chain isoforms were electrophoretically separated in 5-8\% gradient polyacrylamide slab gels in the presence of sodium dodecyl sulfate. ${ }^{11}$ Gels were silverstained ${ }^{12}$ and the percentage distribution of the various isoforms was densitometrically evaluated (LKB 2202. Ultroscan densitometer).

Additionally, the length of the sartorius muscle was measured from origin to insertion before dissection. This was repeated at the end of the experiments after dissection of the neosphincter. In addition, the sartorius length measurements were compared with length measurements of the femur, which were obtained from radiographs (and corrected for magnification) to obtain information about maximal sartorius muscle length. All data were expressed as mean and range. 


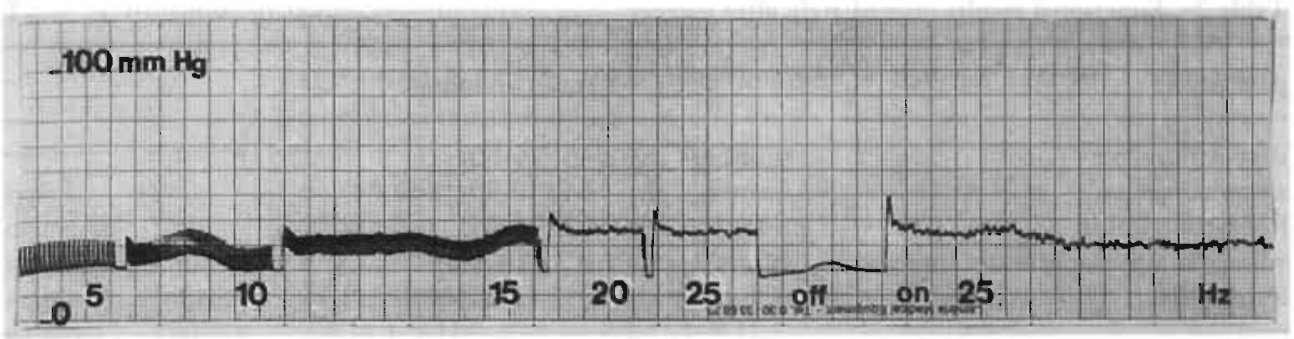

Figure 2. Manometry immediately after surgery. On the $y$-axis the pressure is given in $\mathrm{mmHg}$. On the $\mathrm{x}$-axis the stimulation frequency is given in $\mathrm{Hz}$. 'Off indicates when the pulse generator is turned 'off' and subsequently 'on'. The sartorius is stimulated with $0.7 \mathrm{Volt}$ and pulse width $210 \mathrm{msec}$. The recording speed is $5 \mathrm{~mm} / \mathrm{sec}$.

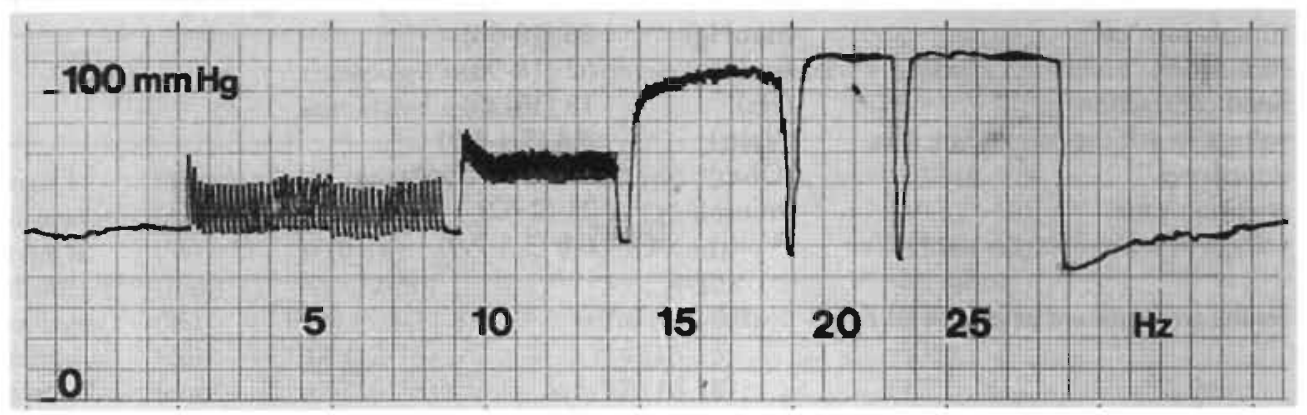

Figure 3. Manometry at the end of the experiments. On the $y$-axis the pressure is given in $\mathrm{mmHg}$. On the $\mathrm{x}$-axis the stimulation frequency is given in $\mathrm{Hz}$. The sartorius is stimulated with 3.4 Volt and pulse width $210 \mathrm{msec}$. The recording speed is $5 \mathrm{~mm} / \mathrm{sec}$.

\section{Results}

\section{Surgery}

Surgical recovery was normal in five dogs, but one puppy died 1 week after surgery as a result of a postoperative wound infection. The weight of the puppies in experiments increased from $7 \mathrm{~kg}$ (range, 5 to $8 \mathrm{~kg}$ ) before surgery to $18 \mathrm{~kg}$ (range, 16 to $21 \mathrm{~kg}$ ) at the end of the experiments (mean follow-up 27 weeks (range, 24 to 31 weeks). The control puppy weight (which had nontransposed, nonstimulated muscles) increased from 7 to $23 \mathrm{~kg}$ (follow-up, 22 weeks). In the remaining 4 puppies, the pulse generator caused necrosis of the overlying rectus fascia and skin which necessitated implantation of the stimulator into the abdominal cavity after 9 weeks (range 7 to 11 weeks) In one puppy the pulse generator eroded through the abdominal wall and was reimplanted successfully. 
Table 2a. Functional results immediately after surgery

\begin{tabular}{lll}
\hline parameters & & mean and range \\
\hline stimulation "off" & $(\mathrm{mmHg})$ & $45(20-60)$ \\
stimulation "on" & $(\mathrm{mmHg})$ & $64(30-90)$ \\
fused contraction & $(\mathrm{Hz})$ & $23(20-25)$ \\
voltage to achieve pressure increase & $(\mathrm{Volts})$ & $0.7(0.4-1.0)$ \\
impedance & $(\mathrm{Ohm})$ & $393(242-500)$ \\
\hline
\end{tabular}

Table 2b. Functional results at the end of the experiments

\begin{tabular}{lll}
\hline parameters & & mean and range \\
\hline stimulation "off" & $(\mathrm{mmHg})$ & $26(10-50)$ \\
stimularion "on" & $(\mathrm{mmHg})$ & $62(18-90)$ \\
fused contraction & $(\mathrm{Hz})$ & $18(15-20)$ \\
voltage to achieve pressure increase & $(\mathrm{Volts})$ & $3.6(3.4-3.9)$ \\
impedance & $(\mathrm{Ohm})$ & $471(211-756)$ \\
retention times & $(\mathrm{min})$ & $21(2-62)$ \\
voltage to achieve retention of saline & $($ Volts) & $6.8(3.5-7.0)$ \\
\hline
\end{tabular}

results are expressed as mean and range

\section{Stimulation}

The stimulation program was performed withour difficulties for the right neosphincrers, and the puppies had a normal kennel life. Ar the end of the experiments, lead fracture was noticed in one puppy which was confirmed with radiographs. Apparently, the transposed sartorius muscle in this dog was stimulated in an unipolar mode. The voltage to achieve a good contraction of the transposed and stimulated muscle increased from 0.7 to $3.6 \mathrm{~V}$ and the impedance increased from 391 to $471 \Omega$ during the program.

\section{Function}

The mean pressure of the right transposed and stimulated neosphincters with the pulse generator off measured $45 \mathrm{mmHg}$ (range, 20 to $60 \mathrm{~mm} \mathrm{Hg}$ ) before stimulation and amounted to $64 \mathrm{mmHg}$ (range, 30 to $90 \mathrm{~mm} \mathrm{Hg}$ ) with the pulse generator on before the stimulation program. At the end of the experiments, these values were 26 (range, 10 to 50 ) and 62 (range, 18 to 90$) \mathrm{mmHg}$ respectively. The frequency that caused a fused contraction decreased from 23 (range 20 to 25 ) immediately after surgery (figure 2, table 2a) to 18 (range 15 to 20 ) $\mathrm{Hz}$ at the end of the experiments (figure 3, table 2b). The mean time to inhibit saline flow amounted to 21 min (range 2 to 62) at the end of the experiments (table $2 \mathrm{~b}$ ) bur the stimulation voltage had to be increased to a mean of 5.0 
Table 3a. Morphology before experiments

\begin{tabular}{lllll}
\hline & & $\begin{array}{l}\text { transposed and } \\
\text { stimulated muscles }\end{array}$ & transposed muscles & control muscles \\
\hline type I & $(\%)$ & $61(54-68)$ & $57(54-58)$ & $54(53-55)$ \\
diameter & $(\mathrm{mm})$ & $22(18-23)$ & $20(17-23)$ & $22(21-22)$ \\
type II & $(\%)$ & $40(32-46)$ & $44(42-46)$ & $46(45-47)$ \\
diameter & $(\mathrm{mm})$ & $21(17-24)$ & $19(16-24)$ & $22(20-23)$ \\
collagen & $(\%)$ & $7.8(6.1-9.1)$ & $8.6(7.6-9.1)$ & $7.8(6.8-8.7)$ \\
sartorius & $(\mathrm{cm})$ & $10(10-11)$ & $10(10-11)$ & 10 \\
femur & $(\mathrm{cm})$ & $10(10-11)$ & $10(10-11)$ & 10 \\
\hline
\end{tabular}

Table 3b. morphology after experiments

\begin{tabular}{lllll}
\hline & & $\begin{array}{l}\text { transposed and } \\
\text { stimulated muscles }\end{array}$ & transposed muscles & control muscles \\
\hline type I & $(\%)$ & $94(86-100)$ & $67(60-71)$ & $52(48-56)$ \\
diameter & $(\mathrm{mm})$ & $30(24-38)$ & $31(29-34)$ & $39(37-40)$ \\
type II & $(\%)$ & $6(0-14)$ & $33(29-40)$ & $48(44-52)$ \\
diameter & $(\mathrm{mm})$ & $41(32-50)$ & $39(34-50)$ & $42(40-43)$ \\
collagen & $(\%)$ & $8.8(5.8-11.9)$ & $7.6(6.1-9.0)$ & $3.9(3.6-4.1)$ \\
sartorius & $(\mathrm{cm})$ & $14(12-16)$ & $14(13-15)$ & 17 \\
femur ${ }^{*}$ & $(\mathrm{~cm})$ & $17(16-18)$ & $17(16-18)$ & 17 \\
\hline
\end{tabular}

results are expressed as mean and range; * femur length was measured from $\mathrm{X}$-rays and corrected for magnification

$V$ to inhibit flow. On the other hand, the stimulated right muscles with the stimulator off and the transposed nonstimulated left muscle slings were unable to inhibit flow.

\section{Muscle Biopsies.}

The percentage of type I fibers increased in stimulated and transpused sartorius fium 61 to 94 . However, the percentage of type I fibers also increased in transposed and nonstimulated muscles (from 57 to 67). In contrast, no changes were observed in the percentage of type I fibers in nontransposed nonstimulated muscles (table $3 \mathrm{a}$ and $\mathrm{b}$ ). The diameter of these type I muscle fibers increased from 22 to $30 \mathrm{~mm}$ in transposed and stimulated sartorius muscles ( $36 \%$ increase) and from 20 to $31 \mathrm{~mm}$ ( $55 \%$ increase) in transposed and nonstimulated muscles. The diameter of type I fibers in nontransposed nonstimulated muscles increased from 22 to $39 \mathrm{~mm}$ ( $77 \%$ increase). The diameter of type II fibers increased similarly in the three described groups (with 95\% for transposcd and stimulated muscles, $105 \%$ for transposed nonstimulated muscles 
Table 4a. Percentage distribution (\%) of myosin heavy chain isoforms in muscles (right hindlimb) before and after completion of low-frequency stimulation.

\begin{tabular}{|c|c|c|c|c|c|}
\hline & Control & $\operatorname{Dog} 1$ & $\operatorname{Dog} 2$ & $\operatorname{Dog} 3$ & Dog 4 \\
\hline \multicolumn{6}{|c|}{ Unstimulated } \\
\hline HCIIa & 51 & 57 & 54 & 53 & 51 \\
\hline HCIId & 11 & 0 & 0 & 0 & 0 \\
\hline $\mathrm{HCI}$ & 38 & 43 & 46 & 47 & 49 \\
\hline \multicolumn{6}{|c|}{$\begin{array}{l}\text { Stimulated } \\
\text { proximal }\end{array}$} \\
\hline HCIIa & 60 & 24 & 0 & - & 15 \\
\hline HCIId & 8 & 11 & 0 & - & 0 \\
\hline $\begin{array}{l}\mathrm{HCl} \\
\text { distal }\end{array}$ & 32 & 65 & 100 & - & 85 \\
\hline HCIIa & 53 & 24 & 0 & 33 & 2 \\
\hline HCIId & 21 & 0 & 0 & 0 & 0 \\
\hline $\mathrm{HCI}$ & 26 & 76 & 100 & 67 & 98 \\
\hline
\end{tabular}

Table 4b. Percentage distribution (\%) of myosin heavy chain isoforms in controlateral muscles (left hindlimb) before and after completion of low-frequency stimulation.

\begin{tabular}{llllll}
\hline & Control & Dog 1 & $\operatorname{Dog} 2$ & $\operatorname{Dog} 3$ & $\operatorname{Dog} 4$ \\
\hline $\begin{array}{l}\text { Unstimulated } \\
\text { HCIIa }\end{array}$ & 56 & 59 & 51 & 58 & 62 \\
HCIId & 12 & 0 & 0 & 5 & 0 \\
HCI & 32 & 41 & 49 & 37 & 38 \\
Stimulated & & & & & \\
proximal & 59 & 48 & 52 & 63 & 53 \\
HCIIa & 8 & 6 & 8 & 0 & 0 \\
HCIId & 33 & 46 & 40 & 37 & 47 \\
HCI & 54 & 43 & 45 & 64 & 56 \\
distal & 13 & 0 & 8 & 0 & 14 \\
HCIIa & 32 & 57 & 47 & 36 & 30 \\
HCIId & & & & & \\
HCI & & & & & \\
\hline
\end{tabular}

only and $900_{0}^{\circ}$ for nontransposed nonstimulated muscles). In contrast, the percentage of endomysial collagen in the two groups with transposed muscles (stinulated and nonstimulated) was double the value of the nontransposed nonstimulated muscles (table 3).

Histochemistry shows a strong increase in $\mathrm{HCI}$ myosin isoform (slow fiber) in the stimulated muscle (table 4a) compared to the control muscle (table 4b) Myosin isoform 


\section{UNSTIMULATED}

\section{$\begin{array}{llllll}\text { Dog } & C & 1 & 2 & 3 & 4\end{array}$}

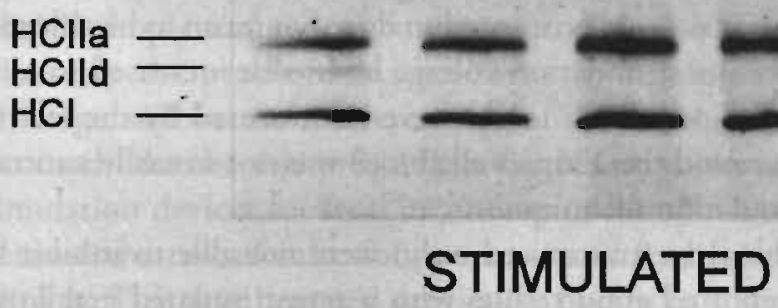

\section{HClla HClld $\mathrm{HCl}$}

Figure 4. Electrophoretically separated myosin heavy chain isoforms of unstimulated and electrically stimulated dog sartorius muscle. Stimulated are the dogs 1 through $4, \mathrm{C}$ is the control. HCIla and HCIId, fast myosin heavy chain isoforms; $\mathrm{HCI}$ slow myosin heavy chain.

rransformation goes from the fastest fiber $\mathrm{HCIIa}$, to the $\mathrm{HCIId}$ fiber, and finally to $\mathrm{HCI}$ the slowest fiber.(fig 4) The isoform HCllb could not be detected.

The length of the dissected sartorius muscle increased from 10 to $17 \mathrm{~cm}$ in nontransposed, nonstimulated muscles but the increase was from 10 to $14 \mathrm{~cm}$ in all transposed muscles. If these data were expressed as percentage of femur length, the increase in transposed (stimulated and nonstimulated) muscles and nontransposed, nonstimulated muscles was respectively 82 and $100 \%$, at the end of the experiments (table 3).

\section{Discussion}

The functional results in these series such as a mean retention time of saline of 21 minutes and the increased pressures of the right neosphincters with the pulse generator on suggest that a dynamic myoplasty in a growing dog is feasible although, the small number of animals did not allow statistical analysis. The transposed and stimulated muscles did 
not cause obstruction of the Thiry-Vella loop because saline flow into the loop was not inhibited (with the stimulation off) after a mean of 27 weeks. In addition, the pressure in the neosphincter with stimulation off decreased from $45 \mathrm{mmHg}$ at the beginning of the experiments to $26 \mathrm{mmHg}, 27$ weeks after surgery (table 2). On the other hand, the stimulation voltage to achieve a good contraction had to be increased by $2.9 \mathrm{~V}$ and the impedance increased from 393 to $471 \Omega$ which is probably caused by fibrosis around the electrodes. ${ }^{13}$ Having a good palpable contraction does not mean to be able to inhibit the flow of saline. Therefore the stimulation voltage had to be increased to a mean of $5.0 \mathrm{~V}$ to inhibit the flow of saline, which might have been caused by the fact that the distal part of the sartorius (around the Thiry-Vella loop) was not so easily contracted by using an intramuscular stimulation technique.

The non stimulated sphincters (transposed only) were not able to inhibit flow. In contrast, Sonnino et al $^{14}$ reported good results with a nonstimulated graciloplasty in pediatric patients. Nevertheless, our experimental study assessed continence for saline, which is different from formed stools. We did not measure the pressure into the Third-Vella at the end of the nonstimulated muscles slings because in this animal study voluntary contractions could not be measured.

The morphological results in these puppies showed an increase in the percentage of type I fibers in both the transposed nonstimulated and the transposed and stimulated muscles (table 3 ) which implies that not only stimulation but also transposition causes an alteration in fiber composition. Histochemistry clearly showed an effect of electrical stimulation with a strong increase in the myosin isoform $\mathrm{HCI}$, the slowest fiber. Transformation is identical to transformation found in adult individuals. The fact that no HCIlb isoform could be detected has been described before in dogs. ${ }^{15}$

However, both morphology and physiology (fusion frequency) changed in the stimulated and transposed muscles, which might explain the increased retention times for the dynamic myoplasties after the stimulation program. The type I fiber diameter in both neosphincters was small if compared with the nontransposed, nonstimulated sartorius muscles, which can be a result of transposition because similar findings have recently been reported for transposed gracilis muscle in adult parients. ${ }^{15}$ The sartorius length increased with $82 \%$ (ratio muscles, femur length) in transposed sartorius muscles. Muscle stretch during growth is apparently reduced in transposed sartorius muscle because extension is known to increase the number of sarcomeres and fibers, and therefore muscle length, and also induces fiber growth in girth. ${ }^{16,17}$ Growth showed to be no problem for conventional graciloplasty in children. ${ }^{14,18}$ Therefore, we can expect that a stimulated graciloplasty would not cause a stenosis after growth. The percentage of endomysial collagen is difficult to compare during growth because it is expressed as the ratio between the area collagen and area muscle fiber. Consequently, an increased fiber area implies a reduced percentage colligen.

Notwithstanding, a comparison between transposed and non transposed muscles (at the end of the experiments) showed that transposition doubled the percentage collagen. 
The latter might also offer an explanation for the increased stimulation voltages because the increased percentage of collagen might influence muscle stiffness.

We showed that a dynamic myoplasty for fecal incontinence in a growing individual is feasible. Transposition and stimulation induces an increase in fatigue-resistant type I fibers; transposition alone causes alterations in muscle fiber diameter and endomysial collagen. Necrosis of the overlying rectus muscle and skin during growth (which was caused by the implanted pulse generators) and the lead fracture are serious complications. Probably the problems in these very young dogs, in which the stimulator is relatively large, will be more severe than in 7-year-old children (the age at which you can expect a child to be able to handle a magnet for turning on and off the stimulator). Still, stimulation devices for fecal incontinence should be implanted after the growing spurt because the risk of infection, necrosis and lead fracture is unacceptable during rapid growth. This was reported previously by Dickson and Nixon ${ }^{18}$ and Nixon and Puri ${ }^{19}$ for pediatric patients who were treated with electrical devices after operations for anorectal agenesis. However, dynamic myoplasty may be indicated for children who have poor results after surgery for anorectal anomalies at the end of the growing spurt.

\section{References}

1. Williams NS, Patel J, George BD, Hallan RI, Watkins ES. Development of electrically stimulated neoanal sphincter. Lancet 338:1166-69,1991

2. Baeten CGMI, Konsten J, Spaans F, Visser R, Habets AMMC, Bourgeois IM, Wagenmakers AJM, Soeters PB. Dynamic graciloplasty for treatment of faecal incontinence. Lancet 338: 1163-65, 1991

3. George BD, Patel J, Mginah P, Swash M, Warkins ES. Histological changes in the gracilis neosphincter muscle following long-term electrical stimulation. Br J Surg 79:466,1992 (abstract)

4. Konsten J, Baeten CGMI, Havenith MG, Soeters PB. Morphology of dynamic graciloplasty compared with the anal sphincter. Dis Colon Rectum 36:559-64, 1993

5. Baeren CGMI, Konsten J, Heineman E, Soeters PB. Dynamic graciloplasty for anal atresia. J Pediarr Surg 1994; 29(4) 922-5

6. Williams PE, Goldspink G. Changes in sarcomere length and physiological properties in immobilized muscle. J Anat 127:459-68,1978

7. Hallan RI, Williams NS, Hutton MRE, Scot M, Pilor MA, Swash M, Koeze TH, Warkins ES, Electrically stimulared sartorius neosphincter: canine model of activation and skeletal muscle transformation. Br J Surg 77:208-13,1990

8. Havenith MG, Visser R, Schrijwers van Schendel JMC, Bosman FT. Muscle fiber typing in routinely processed skelecal muscle with monoclonal antibodies. Histochemistry 93: 497-99, 1990

9. Junquira LCU, Montes GS, Sanchez EM. The influence of tissue section thickness on the study of collagen by the picrosirius-Polarization merhod. Histochemistry 74:153-56,1982

10. Dolber PC, Spach MS. Picrosirius red staining of cardiac muscle following phosphomolybdic acid treatment. Stain Technol 62:23-26,1987

11. Termin A, Staron RS, Pette D. Myosin heavy chain isoforms in histochemically defined fiber types of rat muscle. Histochemistry 92:453-57, 1989

12. Oakley BR, Kirsch DR, Morris NR. A simplified ultrasensirive stain for derecting proteins in polyacrylamyde gels. Anal Biochem 105:361-3, 1980 
13. Lucas CMHB. Long term follow-up after dynamic cardiomyoplasty in goats. In: the use of the latissimus dorsi muscle for cardiac assist (thesis). Maastricht Universitaire pers 99-121,1992

14. Sonnino RE, Reinberg O, Bensoussan AL, et al: Gracilis muscle transposition for anal incontinence in children: Long term follow-up. J Pediatric Surg 26: 1219-1223, 1991.

15. Snow DH, Billeter R, Mascarello F, Carpene E, Rowlerson A, Jenny E. No classical type IIB fibers in dog skeletal muscle. Histochemistry 75:53-65 1982

16. Konsten J, Baeten CGMI, Havenirh MG, Oei TK. Evaluation of gracilis muscle transposition for fecal incontinence with magnetic resonance imaging. Eur J Radiol 3:190-5,1993

16. Montgomery RD. Growth of human striated muscle. Nature 195:194-5,1962

17. Goldspink G. Malleability of the motor system: a comparative approach. J Exp Biol 115:375-91, 1985

18. Dickson JAS, Nixon HH. Control by electronic stimulator of incontinence after operation for anorectal agenesis. J Pediatr Surg 3:696-701,1968

19. Nixon HH, Puri P. The results of treatment of anorectal anomalies: a thirteen to twenty year follow-up. J Pediatr Surg 12:27-37,1977 
Chapter 6.3

\section{SIMULTANEOUS TREATMENT OF FECAL AND URINARY INCONTINENCE IN CHILDREN WITH SPINA BIFIDA USING A DOUBLE DYNAMIC GRACILOPLASTY}

Simultaneous treatment of faecal and urinary incontinence in children with spina bifida using a double dynamic graciloplasty. Geerdes BP, Heesakkers JPFA, Heineman E, Spaans F, Janknegt RA, Baeten CGMI. $B r J$ Surg (in press) 


\section{Introduction}

Patients with spina bifida have impaired control over anorectal and bladder functions, keading to fecal and urinary incontinence. A wide range of conservarive and surgical treatment exist. However, 53 percent of patients have fecal soiling and long rerm results show only 24 percent become fully continent to feces and urine. ${ }^{1}$

In patients with intractable fecal or urinary incontinence, good results have been described by the creation of a new anal or urinary sphincter using a dynamic graciloplasty. ${ }^{2-4}$

Parients with spina bifida, who do not respond to other treatments, and are severely socially handicapped but seem to have good anorectal sensation and/or motility, could be treated using a combination of both techniques. In this study the results in the first two patients are discussed.

\section{Patients and Methods}

Parient data are depicted in table 1.

Patient $A$, a 17 years old man, was born with a spina bifida. He had a low spinal cord lesion and a cauda equina syndrome requiring an early operation. Several orthopedic correcrions of borh hips and legs were necessary. He now can walk with crurches but regularly uses a wheelchair. He was wearing diapers for continuous loss of both urine and feces. Catheterisation and rectal suppositories did not provide continence.

Cystoscopy showed a normal bladder and a wide open bladderneck. Although he had had reflux grade II of the left renal system in the past, no ureteral reflux was found during our work up. Urodynamic investigation was performed with a microtip transducer (Gaeltec, UK) and specially designed software (MMS, The Netherlands). Urethral Pressure Profilometry was performed with a puller speed of $30 \mathrm{~mm} / \mathrm{min}$. During filling cystometry major bladder instabilities werc observed. The bladder capacity was $254 \mathrm{ml}$. Low, hardly measurable ureteral pressures were recorded. In conclusion, a patient with a severe neurogenic bladder and a lacking sphincteric function.

Anal manometry showed a resting pressure of $83 \mathrm{mmHg}$ and a squeeze pressure of $8 . i \mathrm{~mm} \mathrm{Hg}$ with a high pressure zone of $3.0 \mathrm{~cm}$. Afrer inflation of an intra-rectal balloon sensibility appeared ar $20 \mathrm{ml}$. and the urge capacity at $80 \mathrm{ml}$. The recro-anal inhibitory reflex was present. Electromyography of the anal sphincter showed no vital muscle tissue; both gracilis muscles showed no abnormalities. Defecography showed incontinence, poor function of the pelvic floor with a blunt anorectal angle and incomplete rectal emprying.

Patient $B$, a 13 years old boy, who was born with a cauda equina syndrome and a spinal cord fistula requiring surgery. He had minor motor dysfunction of both lower extremi- 
Table 1. Patients characteriscics before and after double dynamic graciloplasty.

\begin{tabular}{|c|c|c|c|c|c|c|c|c|c|c|c|}
\hline \multirow{2}{*}{ Patient } & \multirow{2}{*}{$\begin{array}{l}\text { Age } \\
(y x)\end{array}$} & \multirow{2}{*}{$\begin{array}{l}\text { Follow-Up } \\
\text { (months) }\end{array}$} & \multicolumn{3}{|l|}{ Bladder } & \multicolumn{6}{|c|}{ Anal Canal } \\
\hline & & & $\begin{array}{l}\text { Capacity } \\
\text { (mi) }\end{array}$ & $\begin{array}{l}\text { UPP } \\
(\mathrm{mm} / \mathrm{min})\end{array}$ & $\begin{array}{l}\text { UPP }_{5 t} \\
(\mathrm{~mm} / \mathrm{min})\end{array}$ & $\mathrm{P}_{(\mathrm{mmH})}$ & $\begin{array}{l}P_{x} \\
(\mathrm{mmHg})\end{array}$ & $\begin{array}{l}\mathrm{P}_{\mathrm{u}} \\
(\mathrm{mmHg})\end{array}$ & $\begin{array}{l}\text { Sensation } \\
(\mathrm{ml})\end{array}$ & $\begin{array}{l}\text { Urge } \\
(\mathrm{ml})\end{array}$ & RAIR \\
\hline \multicolumn{12}{|l|}{ Before Sungery } \\
\hline 1 & 17 & & 254 & & & 83 & 83 & & 20 & 80 & + \\
\hline 2 & 13 & & 250 & & & 59 & 69 & & 20 & 70 & + \\
\hline \multicolumn{12}{|c|}{ Afier Sungery } \\
\hline i & & 12 & 450 & 40 & 50 & 66 & 159 & 130 & & & \\
\hline 2 & & 6 & 268 & 30 & 52 & 58 & 193 & 110 & & & \\
\hline
\end{tabular}

UPP $=$ Urethral Pressure Profile, $U P_{S_{t}}=$ Urechral Pressure Profile during electrical stimulation, $P_{5}=$ resting pressure, $P_{s}=$ voluntary squeeze pressure, $P_{S t}=$ pressure during electrical stimulation, $R A I R=$ recto-anal inhibitory reflex.

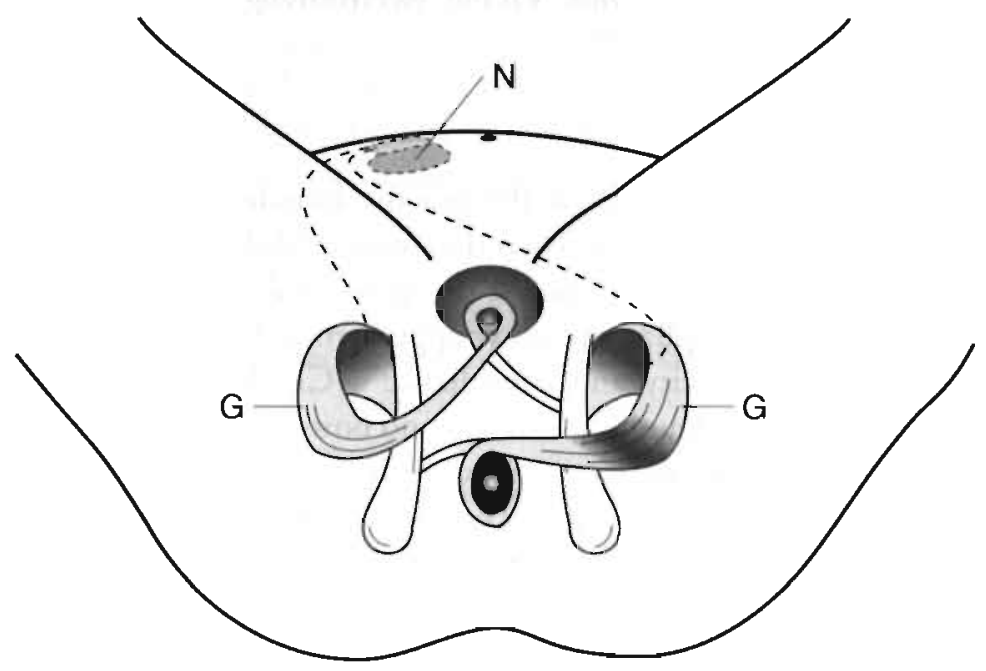

Figure 1. Configuration of the double dynamic graciloplasty for spina bifida patients with urinary and fecal incontinence. $\mathrm{Gu}=$ graciloplasty for recreation of a urinary sphincter, $\mathrm{Ga}=$ graciloplasty for recreation of an anal sphincter, $\mathrm{N}=$ neurostimulator.

ties. Urinary urge incontinence with a megacystis did not respond to physical therapy. Post-anal repair elsewhere was not successful in treating the fecal stress and urgency incontinence.

Cystoscopy showed a normal bladder and a wide open bladderneck. Urodynamic investigation showed motor urge with instable contractions, a normal compliance and a bladder capacity of $250 \mathrm{ml}$. The ureteral pressure profile was flat with a maximal 
ureteral closing pressure (MUCP) of $29 \mathrm{~cm}$. water. In conclusion, a patient with a neurogenic bladder and an atonic urethra.

Anal manometry showed a resting pressure of $59 \mathrm{mmHg}$ and a squeeze pressure of $69 \mathrm{mmHg}$ with a high pressure zone of $3.2 \mathrm{~cm}$. After inflation of an intra-rectal balloon sensibility appeared at $20 \mathrm{ml}$. and the urge capacity at $70 \mathrm{ml}$. The recto-anal inhibitory reflex was present as well as the cutaneo-anal reflex. Electromyography of the anal sphincter showed almost no vital muscle tissue; both gracilis muscles showed no abnormalities. Defecography showed incontinence, poor function of the pelvic floor and incomplete rectal emptying.

Anal manometry was performed using a Konigsberg catheter (Konigsberg Instruments Inc, Pasadena, CA), which was connected to a computer-assisted polygraph (Synecrics Medical, Srockholm, Sweden). Defecography was performed according to established merhods. 5 Electromyography was performed of the external sphincter and borh gracilis muscles using a Nicolet Viking electromyography-apparacus (Nicoler, Madison, Wisconsin, (ISA).

\section{Surgical procedure}

Stage 1: The neurovascular bundle of the gracilis muscle was isolated proximally. Therefore the muscles remained vital when they were mobilized and detached distally. One gracilis muscle was transposed around the anal canal ${ }^{2}$ and the other was passed through the genitourinary diaphragm and wrapped around the bladder neck. "Figure 1) To improve bladder capacity and compliance a CLAM-ileocystoplasty was performed. A $15 \mathrm{~cm}$ segment of ileum was isolated and bowel continuity was restored. The bladder was opened from one ureteral orifice to the other and bladder augmentation achieved with the ileal segment, which was opened on its antimesenteric border.

Stage 2: Six weeks later intramuscular electrodes (model 4300, Medtronic) were implanted in the vicinity of the obturator nerve branches in both gracilis muscles. Both leads were tunncled subcutaneously and connected to a single neurostimulator (Itrel $\mathrm{II}^{\mathrm{TM}}$, model 7424, Medtronic, Kerkrade, The Netherlands) which was implanted in the abdominal wall (Figure 1). Both electrodes were programmed as cathode (negative pole) while the neurostimulator served as the anode (positive pole).

Training: Amplitude, rate, pulse width, polarity and duty cycle were telemetrically programmed by a physician. With an external magnet the patient could switch the neurostimulator "on" and "off". Before continuous stimulation was applied the graciloplasty was trained for 8 weeks according to a srimularion-prorocol. ${ }^{2}$ Electrical stimulation caused the transformation of fast-twirch, fatigue-prone, type II fibers into slow-twitch, fatigue-resistant, type I fibers. ${ }^{6}$ 


\section{Results}

Both patients had an uncomplicated recovery after both operations.

Patient $A$ was given an indwelling catheter for several weeks because of urinary retention. He was temporarily continent for urine and feces and then became incontinent again. Rectal examination revealed severe coprostasis, therefore the patient suffered from overflow incontinence. Defecography revealed an extended rectum. Biofeedbacktraining to improve straining did not have a beneficial effect and the patient was advised to empty the rectum with regular enemas. Because of repeared urinary retention the patient was taught to perform clean intermittent catheterisation. This caused problems because the gracilis muscle indented the urethra.

One year after implantation of the stimulator, cystoscopy revealed a contracting gracilis which closed the urethra at the bladderneck. The bladder capacity was $450 \mathrm{ml}$, MUCP was $40 \mathrm{~cm}$ water without and $50 \mathrm{~cm}$ water with electrical stimulation although it was hardly possible to have long-lasting contractions. Anal manometry showed a resting pressure of $66 \mathrm{mmHg}$, a squeeze pressure of $159 \mathrm{mmHg}$ and a pressure of 130 $\mathrm{mmHg}$ during electrical stimulation (Table 1). Subjectively the patient was still incontinent to urine and had to evacuate the rectum with enemas.

At 2 years follow up the patient is continent for urine all day long if he performs self-catheterisation in the morning while the stimulator is switched off. He can than void with abdominal press during the rest of the day. He is continent for feces as well, although defecition has to be assisted by regular enemas, because otherwise overflow incontinence will occur.

In patient $B$ urodynamic investigation three months after implantation revealed a bladder capacity of $268 \mathrm{ml}$, an MUCP of $30 \mathrm{~cm}$ water without and of $52 \mathrm{~cm}$ water with electrical stimulation. Anal manometry showed a resting pressure of $5,8 \mathrm{mmHg}$, a squeeze pressure of $193 \mathrm{mmHg}$ and a pressure of $110 \mathrm{mmHg}$ during electrical stimulation (Table 1). Defecography showed a complete closure of the anal canal during stimulation. The patient did not use diapers anymore in time, however he had several wet periods every week. He was continent for feces and could reach the toilet in time.

At 6 months the patient was able to empty the bladder completely by abdominall press with a moderate flow of $8.3 \mathrm{ml} / \mathrm{second}$. By applying a toiler regime of going to the toiler twice a day to defecate he was continent for feces.

\section{Discussion}

In this paper we report for the first time a procedure which restores simultaneously both the urinary and the external anal sphincter function with a double dynamic graciloplasty in two spina bifida patients with debilitating urinary and fecal incontinence. In the first 
patient, the graciloplasty produces normal resting pressures (stimulation switched "off"), nevertheless he requires enemas for rectal emprying. He is continent of urine. The second patient is continent of both urine and feces.

In myelomeningocele the neural tube defect involves the micturation center in S2-S4. The bladder parasympatheric innervation as well as the somatic motor innervation of the external urethral sphincter originate in this level. Afferents from the bladder activate the sacral center by coordinated control of detrusor contraction, bladderneck opening and sphincter relaxation during micturation. During storage sphincteric contraction and detrusor relaxation derive from this center. In myelodysplasia, as in our two patients, a failure in organization of the anterior horn at the sacral level exists. Lesions at this level are mostly incomplete. The result is a diminished sphinteric function and a bladder function which is a mixture of spastic behavior and weak detrusor contractility.

Bladder augmentation and procedures to increase bladder outlet resistance are performed in patients with a neurogenic bladder and an incompetent sphincter. For bladder augmentation the use of small bowel is advocated because it would allow construction of a larger pouch than the colonic bowel. Possibly due to the smaller pouch and the thicker muscular wall colonic pouches are more prone to produce periodic dampness. ${ }^{7}$ Urinary incontinence can be prevented by intermittent catheterisation but is not successful in all children. When the outlet resistance is too low an increased outlet resistance should be created. Application of a neuroprosthesis ${ }^{8}$ cannot be considered when no sphincter function can be found. Good results have been reported with the artificial sphincter but frequent reoperations ${ }^{9}$ and complications like infection, malfunction or erosion ${ }^{10}$ make it less applicable in children. Construction of a fascial sling, using a free graft of rectus fascia, can produce enough outlet resistance ${ }^{11}$ but is a static construction resulting in incontinence if too little tension is applied or in obstruction, urethral atrophy or erosion if applied too tight. The advantages of the dynamic graciloplasty are that autologous material is used and a dynamic neosphincter created, consisting of contracting muscle. ${ }^{12}$ It allows normal closure and opening of the anus and the bladder neck. If not enough muscle can be mobilized however, tendon is surrounding the bladder neck as well, causing obstruction and making catheterisation difficult as happened in patient 1 . Fortunately the siruation improved over time and the patient is continent now.

Anorectal function in spina bifida patients is discussed in detail in chapter 6.1. Good bowel training, a diet containing bulking agents, and regular toileting by evacuation with the help of digital stimulation, laxatives or enemas was able to achieve continence in 79 percent of compliant patients. ${ }^{13}$ The start at an early age and the presence of an anocutaneous reflex were the predictors of compliance and success. Wald reported good results with biofeedback in a selected group of patients with good rectal sensation. ${ }^{14}$ Whitehead however found little effect by biofeedback if it was not combined with behavior modification. ${ }^{15}$ Highly motivated patients may benefit from the enema continence catheter, a latex catheter with a balloon used for fixation in the rectum. ${ }^{16,17}$ 
Unfortunately the drop out rate is high because of too great demands placed on the child and its family, pain, abdominal discomfort, inability to retain the balloon and allergic reactions to the latex. Although most studies dealing with conservative treatment claim good results, only 24 percent of the patients appears to become reliably dry and clean while 30 percent is double incontinent. ${ }^{1}$

Roberts et al described synchronous bladder reconstruction and the Malone antegrade continence enema (ACE) procedure in patients with double incontinence. ${ }^{18}$ Apart from bladder augmentation, the bladderneck was reconstructed or a continent urostomy was created with the Mitrofanoff procedure. A continent colostomy was created with the appendix or a tubularized flap of coecum, allowing antegrade colonic washouts. Complete continence was achieved in 5 out of 8 patients by 3 hourly clean intermittent catheterisation for urine and an ACE regimen (requiring approximately 1 hour) once daily. Unfortunately most patients required revision surgery which is explained by the complexity of the surgery. The effect of two abdominal stomas at such an early age is not known.

Fecal and urinary control in patients with spina bifida is an extremely complex matter. Because the situation is unique in every patient there is not a single solution to the problem. Every patient should be carefully diagnosed and treatment should be custom tailored. Prerequisite for a good outcome in any trearment is a highly motivated patient, family and doctor.

The double dynamic graciloplasty proves to be a feasible option. The operation was well tolerated by both patients and no revision surgery was required. It remains hard to predict whether patients who have been incontinent all their lives will become constipated once an outlet barrier is created. Patients expected to develop constipation should not undergo dynamic graciloplasty. This new treatment can provide a solution in well selected paticnts who are severely socially handicapped, have good anorectal sensation and for whom no other possibilities are available.

\section{References}

1. Malone PS, Wheeler RA, Williams JE. Continence in patients with spina bifida: Jong term results, Arch Dis Child 1994;70:107-10.

2. Baeten CG, Geerdes BP, Adang EM, Heineman E, Konsten J, Engel GL, Kester AD, Spaans F, Soeters PB. Anal dynamic graciloplasty in the treatment of intractable fecal incontinence. N Engl J Med 1995;332:1600-5.

3. Williams NS, Parel J, George BD, Hallan RI, Warkins ES. Development of an electrically stimulared neoanal sphincter. Lancer 1991:338:1166-9.

4. Janknegt RA, Baeten CG, Wcil EH, Spaans F. Electrically stimulated gracilis sphincter for treatment of bladder sphincter incontinence [see comments]. Lancet 1992;340:1 129-30.

5. Goei R. Anorectal funcrion in parients with defecarion disorders and asympromatic subjects: evaluation with defecography. Radiology 1990;174:121-3.

6. Petre D, Vrbova G. Adaptation of mammalian skeletal muscle fibers to chronic electrical stimularion. Rev Physiol Biochem Pharmacol 1992;120:115-202. 
7. Keating MA, Rink RC, Adams MC. Appendicovesicostomy: a useful adjunct to continent reconstruction of the bladder. J Urol 1993;149:1091-4.

8. Schmidt RA, Kogan BA, Tanagho EA. Neuroprostheses in the management of incontinence in myelomeningocele patients. J Urol 1990;143:779-82.

9. Barrett DM, Parulkar BG. The artificial sphincter (AS-800). Experience in children and young adults. Urol Clin North Am 1989;16:119-32.

10. Light JK, Scott FB. Complications of the artificial urinary sphincter in pediatric patients. Urol Clin North Am 1983;10:551-5.

11. Kakizaki H, Shibata T, Shinno $Y$, Kobayashi S, Matsumura K, Koyanagi T. Fascial sling for the management of urinary incontinence due to sphincter incompetence [see comments]. J Urol 1995; 153:644-7.

12. Janknegt RA, Heesakkers JP, Weil EH, Baeten CG. Electrically stimulated gracilis sphincter (dynamic graciloplasty) for treatment of intrinsic sphincter deficiency: a pilot study on feasibility and side effects. J Urol 1995;154:1830-3.

13. King JC, Currie DM, Wright E. Bowel training in spina bifida: importance of education, patient compliance, age, and anal reflexes. Arch Phys Med Rehabil 1994;75:243-7.

14. Wald A. Biofeedback for neurogenic fecal incontinence: rectal sensation is a determinant of outcome. J Pediatr Gastroenterol Nutr 1983;2:302-6.

15. Whitehead WE, Parker L, Bosmajian L, Morrill Corbin ED, Middaugh S, Garwood M, Cataldo MF, Freeman J. Treatment of fecal incontinence in children with spina bifida: comparison of biofeedback and behavior modification. Arch Phys Med Rehabil 1986;67:218-24.

16. Walker J, Webster P. Successful management of faecal incontinence using the enema continence catheter. Z Kinderchir 1989;44 Suppl I:44-5.

17. Liptak GS, Revell GM. Management of bowel dysfuncrion in children with spinal cord disease or injury by means of the enema continence catheter. J Pediatr 1992;120:190-4.

18. Roberts JP, Moon S, Malone PS. Treatment of neuropathic urinary and faecal incontinence with synchronous bladder reconstruction and the antegrade continence enema procedure. Br J Urol 1995:75:386-9. 
Chapter 7

GENERAL DISCUSSION AND SUMMARY 


\section{Cieneral discussion}

In this thesis dynamic graciloplasty proves to be a good treatment option for patients with intractable fecal incontinence. Of these patients, who received maximal conservative and surgical treatment before, 73 percent became continent. Outcome of treatment was related to the pathogenesis of the incontinence. Patients suffering from incontinence due to trauma did better than anal atresia patients. Patients who had a successful clinical outcome had an improvement of their quality of life, they became less anxious and improved with regard to effectiveness in their occupations, ability to perform tasks around the home, personal relationships, sexual function, and social life. Creation of a new anal sphincter and pelvic floor as part of a total anorectal reconstruction after abdomino-perineal resection for low rectal cancer proved to be feasible and oncologically safe. Outcome was less good than in patients treated with a dynamic graciloplasty for fecal incontinence. Difficulties were the lack of sensation, the changed motility of the bowel and the liquid to soft consistency of the stool.

Complications during graciloplasty were partly technical, partly related to the pathogenesis of incontinence. Complications related to the technique of transposition and electrical stimulation, and problems with infection most often can be prevented or treated. Problems due to abnormal anatomy and/or physiology, like poor sensation, rectal capacity and abnormal motility, are more difficult to treat and therefore careful patient selection is mandatory.

In post-mortem gracilis specimens it was shown that the main vascular pedicle, supplying blood to the gracilis muscle and all minor pedicles drain in one and the same arterial system within the muscle. In patients blood flow in the distal gracilis muscle was measured with laser Doppler flowmetry during mobilisation of the muscle and was not significantly diminished after clamping of the minor vascular pedicles. Animal experiments showed that vascular delay (ligation of the minor vascular pedicles which is performed in order to protect muscle from ischemia) did not improve functional outcome. When electrical stimulation was started immediately after transposition of the muscle this resulted more often in muscle damage and demanded a higher amplitude to achieve sufficient contraction.

Electrical stimulation of growing muscle did not harm the muscle tissue and resulted in normal fiber transformation and good improvement of function. However, it was also complicated by infection and necrosis around the implanied stimulators. Therefore the technique is unacceptable during rapid growth because of the risks of infection and dislocation of the implanted device. 
A new treatment modality was described in which new urinary and anal sphincters were created in two patients with spina bifida suffering from debilitating urinary and fecal incontinence. This technique can provide a solution in well selected patients.

From our experience a number of future avenues can be envisioned. We recognize that fecal (in)continence has multifactorial aspects and as a consequence the treatment with a new sphincter is a limited approach of the problem. As major determinant of success and failure the role of sensibility and motility can not be overemphasized. Here are important ways of thinking available where we have to differentiate berween the patients with congenital causes of incontinence and patients with acquired incontinence.

Concerning patients with congenital anorectal malformations and as such vulnerable to stay incontinent, attention should be given to Thomas Moore's statement that "the crux rather clearly is that major attention and consideration should be paid to developmental neurophysiological matters affecting the establishment of activity-driven brain-anus neurocircuitry and reflexes at birth when it matters most importantly, rather than upon the fine points of one anatomical repair versus another". ${ }^{1}$ Moore's and others' ${ }^{2}$ observation that the use it or loose it principle in the postnatal development of function is of utmost importance for the management of these patients. In experimental models the effects of immediate versus delayed repair procedures should be evaluated. The hyporhesis is that immediate repair of anorectal malformation will decrease the incidence of debilitating incontinence in later life and as such make later surgical intervention superfluous. A global initiative has been developed to evaluate in large groups of patients the results of immediate versus delayed repair approaches. Furthermore, a very challenging idea is to use modern technology like the positron emission tomography, or PET-scan, to evaluate in (adult) anal atresia patients and control patients the representation of motor and sensibility functions on the central nervous system esp. the brain. $^{3}$

A special condirion exists in the spina bifida patient group where the brain-anus neurocircuirry is blocked. Here early reconstruction obviously is not an issue and later application of the dynamic graciloplasty is by definition only solving part of the cause of incontinence. However patients with lower myelomeningocele lesions could possibly benefit from the surgical approach even if sensibility and driving force are uncertain. A clinical trial is required and mandatory before larger scale application is propagated. In patients with high lesions and incontinence problems a reluctant attitude should be takin and a colostomy is possibly preferable.

In conclusion, one of the avenues to be proposed for future research in fecal incontinence is the study of neurodevelopmental aspects of the (patho)physiology of (in)continence. Patients with acquired incontinence due to trauma or after the resection of the anal sphincters for low rectal cancer, would possibly benefit from current research aimed at the development of artificial sensation and electrically stimulared evacuation of stool. Interesting experimental work in which the transposed skeletal muscle neosphincters are 
cross-innervated by intact pudendal nerves might add a new dimension to the "dynamic" graciloplasty and improve its function.

A (randomized) clinical study is required to explore the place of the double dynamic graciloplasty as an immediate repair procedure after a curative abdomino-perineal resection (APR) for low rectal carcinoma. Another promising technique which needs further elaboration and long-term clinical study is the artificial sphincter for use in the treatment of fecal incontinence and after APR.

New methods have to be developed to further optimize muscle preservation after transposition and electrical stimulation. Interesting results are achieved by application of electrical stimulation before ligation of the collateral vessels (conditioning). Ischemic pre-conditioning, the phenomenon that one or more brief periods of ischemia (applied before ligation of the minor vascular pedicles) render an organ more resistant to the effects of a subsequent sustained ischemic period, is another promising new concept. Other methods may be pharmacological protection of the muscle. New stimulation protocols have to be designed, aiming at improvement of the capillary blood supply of the muscle resulting in acquisition of optimal fatigue resistance, more than to focus on fiber type transformation. Because graciloplasty demands continuous contraction, training probably has to be given under continuous electrical stimulation at the lowest possible frequency (e.g. $2 \mathrm{~Hz}$ ) rather than training in an intermittent mode at a stimulation frequency of $25 \mathrm{~Hz}$.

The aim of this thesis was to investigate causes of failure and success and to formulate proposals for further improvement of the results. Some questions have been answered and this has resulted into a better understanding of the problems and to improvement of the therapy. But more questions have come up making research necessary to even betrer understand the pathophysiology of fecal incontinence and to optimize the technique of dynamic graciloplasty.

1. Moore TC. Moore TC editors. Challenges in pediatric surgery. $1^{\text {st }}$ edition. Austin: Landes Company; 1994; 1, Imperforate anus. P. 1-16.

2. Wiesel TN, Hubel DH. Extent of recovery from the effects of visual deprivation in kittens. J Comp Neurol 1965;1060-72

3. Maquet P, Pecers J-M, Aerts J. et al Functional neuroanatomy of human rapid-eye -movement sleep and dreaming. Nature 1996;383:163-166. 


\section{Summary}

In chapter 1 a detailed overview of the aspects of anatomy and physiology of the anorectum in relation to fecal continence is given. The pathophysiology of fecal incontinence, its conventional treatment and classical surgical treatment are discussed. The use of smooth muscle, free muscle transplantation, gluteus muscle, gracilis muscle and electrically stimulated (dynamic) gracilis muscle for the construction of a new anal sphincter in the treatment of intractable fecal incontinence and in total anorectal reconstruction after abdomino-perineal resection for low rectal cancer are reviewed. In addition, the technique of dynamic graciloplasty is described in detail.

In chapter 2 the clinical results and the effects on the quality of life of the dynamic graciloplasty (transposition of the gracilis muscle to the anus with the implantation of stimulating electrodes) were evaluated in parients treated for intractable fecal incontinence.

We treated 52 patients with dynamic graciloplasty. The clinical results of treatment were evaluated in an interview, by anal manometry, and by an enema testing. The degree of continence was scored. To assess quality of life, four questionnaires were administered (parts 1 and 2 of the Nottingham Health Profile, the State Trait Anxiety Inventory, and the Self-raring Depression scale).

Ainong the 52 patients, 38 patients ( 73 percent) were continent after a median follow-up of 2.1 years. At 52 weeks the patients' condition had improved with respect to the median frequency of defecation (from five to two times per 24 hours, $\mathrm{P}<0.001$ ), the median time defecation could be postponed (from 9 seconds to 19 minutes, $\mathrm{P}=0.012$ ), and the median time an enema could be retained (from 0 to 180 seconds. $P=0.005$ ). Patients in whom the technique was successful became less anxious than those in whom it failed ( $\mathrm{P}=0.002$ ) and improved with regard to effectiveness in their occupations, ability to perform tasks around the home, personal relationships, sexual function, and social life $(\mathrm{P}=0.01)$. They also hecame less isolated socially $(\mathrm{P}=0.05)$.

Dynamic graciloplasty proves to be a safe and reliable technique in patients with severe incontinence and may result in a better quality of life.

In chapter 3.1 rotal anorectal reconstruction with a double dynamic graciloplasty was performed after abdomino-perineal reconstruction (APR) for low rectal cancer. In 4 patients an additional pouch was constructed to improve neorectal motility and capacity. The aim of this study was to evaluate the results in the first 20 patients and to report on the preliminary results of the patients with an additional pouch. 
Twenty patients were treated with a mean age of 52 years (range 25-71) and a rectal tumor at a mean of $3.0 \mathrm{~cm}(0-5)$ from the anal verge. In 14 patients the Miles resection, colon pull-through and construction of a neosphincter were performed in one session. Six patients had the double graciloplasty at an average of 4.1 year $(1.1-8.8)$ after the APR. In 4 patients a pouch was constructed with an isolated segment of distal ileum. After a mean follow up of 24 months (range 1 - 60) after APR none of the patients developed local recurrence, while 4 patients developed distant metastasis. Fifteen out of 20 patients were available for evaluation because 5 patients were still in training. Of these 15 patients 8 patients were continent (53 percent), 2 patients were incontinent and in 5 patients the perineal stoma was converted to an abdominal stoma Failures were due to necrosis of the colon stump $(n=2)$ and incontinence $(n=3)$. At 26 weeks the mean resting pressure was $44 \mathrm{mmHg}$ (S.D. 28) and the mean pressure during scimulation was $90 \mathrm{mmHg}$ (S.D. 46) at a mean of 3.5 volts (S.D.1.2) at 52 weeks. The mean defecation frequency was 3 times per day (range 1 to 5). Of the 8 patients who were continent 6 used daily enemas. The mean time to postpone defecation was 11 minutes (range 0 to 30).

In experienced hands, the double dynamic graciloplasty is an oncologically safe procedure which can have an acceptable functional outcome in a well selected group of patients. However, to improve the outcome further modifications will be necessary. So far, the addition of a pouch has not resulted in improved outcome.

In chapter 3.2 the case report of a thirteen year old girl is discussed who was involved in a speedboat accident which resulted in traumatic destruction of the rectum and anal sphincters. She was treated by using a modified Duhamel procedure for rectal reconstruction and a double gracilis muscle transposition as sphincter replacement procedure. Eight weeks after the first operation, intramuscular electrodes were implanted in both gracilis muscles and connected with an implanted electrical stimulator. This electrically stimulated gracilis muscle neosphincter restored sphincter function while anorectal sensation was preserved as a result of an intact rectovaginal septum. After closure of the temporary colostomy, the parient had good concinence.

In chapter 4 all specific problems that occurred during trearment with dynamic graciloplasty over an eight-year period are presented and their management is discussed. Dynamic graciloplasty was performed in 67 patients with a mean follow-up of 2.7 years. All patients were monitored by physical examination, anal manometry, defecography, and electromyography at fixed intervals. All complications were noted and treated. Continence was defined as being continent to solid and liquid stools.

The technique was successful in 52 pationts (78 percent), whereas failures occurred in 15 patients ( 22 percent). Complications resulted from technical problems, problems with infection and problems attributable to an abnormal physiology of the muscle or an anorectal funcrional imbalance. In roral 53 complications wire identified in 36 
patients. Most technical problems, concerning the transposition and stimulation of the gracilis muscle, could be treated. Failures were attributable to a bad contraction of the distal part of the muscle $(n=4)$ and perforation of the anal canal during stimulation $(n=1)$. In eight patients, infection of the stimulator and leads required explantation. Three patients did not regain continence after reimplantation. Apart from moderate constipation, physiological complications were very hard to treat and resulted in failures in five patients, because of overflow incontinence, soiling, a nondistending rectum, strong peristalsis, and strong constipation. In two patients, the technique failed despite a well-contracting graciloplasty, no clear reason for the failure was found.

Complications associated with the technique of the dynamic graciloplasty such as loss of contraction, infection, bad contraction in the distal part of the muscle, and constipation can often be prevented or treated. Difficulties related to an impaired sensation and/or motility, attributable to a congenital cause or degeneration, are impossible to treat, and this signifies that a good selection of patients is essential to prevent disappointment.

In chapter 5.1 the arterial anatomy within the gracilis muscle was visualized and capillary flow before and after ligation of the minor vascular pedicles was assessed by peroperative measurement with laser Doppler flowmetry to quantify potential acute ischemia during graciloplasty.

Angiographies of eleven post-mortem specimen showed that the main vascular pedicle and all minor pedicles drain in one and the same arterial system. In ten patients blood flow in the distal gracilis muscle was measured with laser Doppler flowmetry during mobilisation of the muscle. After clamping of the minor vascular pedicles blood flow (mean 25.8 p.u., range 6.5-74.3) did not differ from values obtained before clamping (mean 25.4 p.u., range 7.5-68.7). After a mean of 1.8 years all muscles were vital. No correlation existed between the change in muscle blood flow and either squeeze pressure $(r=-0.2)$ or functional outcome $(r=0.31)$. It is therefore questionable whether ligation of the minor vascular pedicles is the bottle neck in human dynamic graciloplasty. An additional operation for vascular delay may be redundant. Therefore a prospective, randomized clinical study should be performed to compare the functional outcome in patients with and without a delay procedure.

In chapter 5.2 the optimal timing to start electrical stimulation and the beneficial effect of a vascular delay are studied.

In rabbits $(n=3 \times 6)$ both gracilis muscles were wrapped around a double polyurethane tube and leads were implanted together with a neurostimulator. Right muscles were electrically stimulated for 11 weeks, left muscles served as controls. In group 1 the muscle was stimulated immediarely after transposition, in group 2 after 6 weeks of rest, and in group 3 a vascular delay was performed with transposition of the muscle 5 weeks later with an immediate start of stimulation,. 
During stimulation, the percentage of type 1 muscle fibers increased from a mean of 4.6 $\%$ to $41.9 \%$. In group 1 there was significantly more change of muscle tissue. There were no significant differences in recorded pressures between groups. In group 1, the increase in amplitude during stimulation was significantly elevated $(\mathrm{p}<0.05)$. The fatigue index in group 1, 259 (S.E. 130) seconds, was significantly lower than in group 2, 515 (S.E. 102) seconds $(p<0.05)$.

Compared to groups 2 and 3, immediate stimulation (group 1) gives more change in muscle tissue, demanding a higher increase in amplitude to achieve sufficient contraction. Fatigue index is impaired as well. Vascular delay as applied presently, does not improve muscle function.

In chapter 6.1 a detailed overview of pathogenesis, diagnosis and treatment of fecal incontinence in the pediatric patient is given.

In chapter 6.2 the feasibility of skeletal muscle transposition and electrical stimulation in young individuals is assessed. Therefore, the influence of growth on skeletal muscle transposition and stimulation was studied in five puppies. In each dog, two neosphincters were constructed around a Thiry-Vella loop by using a dissected sartorius muscle with the neurovascular supply intact. In each of these five puppies, one of these muscles was electrically stimulated during a mean of 19 weeks (one puppy died during the first postoperative week). Muscle biopsies showed an increase in the percentage type 1, fatigue-resistant muscle fibers from 61 to 94 in electrically stimulated sartorius neosphincters, but also an increase from 57 to 67 percent in transposed nonstimulated sartorius muscles. The diameter of these type I fibers during growth increased with $36 \%$ in electrically stimulated sartorius neosphincters and $55 \%$ in nonstimulated sphincters. Function of the neosphincters was tested with the inflow of saline in the Thiry-Vella loop. It was shown that the stimulated neosphincters were capable of inhibiting flow (which corresponded to manometric pressure registrations), but the nonstimulated sphincters were unable to inhibit flow. The experiments were complicated by infection and necrosis around the implanted stimulators in four puppies (which required reimplantation). We conclude that a dynamic myoplasty for fecal incontinence is feasible in growing puppies but that the technique is unacceptable during rapid growth because of the risks of infection and dislocation of the implanted device.

In chapter 6.3 a new treatment modality is described in which new urinary and anal sphincters are created in two patients with spina bifida suffering from debilitating urinary and fecal incontinence. Both patients had a neurogenic bladder, absent urinary sphincter function, a severely impaired anal sphincter, good anorectal sensibility and moderate bowel motility. One gracilis muscle was transposed around the anal canal and the orher was passed through the genitourinary diaphragm and wrapped around the bladder neck. To improve bladder capacity and compliance a CLAM-ileocystoplasty was 
performed. Six weeks later a neurostimulator was implanted to enable a prolonged muscle contraction independent of volition. Both patients achieved urinary and fecal continence. One patient later developed overflow incontinence due to serious constipation and now has to use enemas for voiding. Double dynamic graciloplasty can provide a solution in well selected patients when no other treatment modalities are available 


\section{Samenvatting}

In hoofdstuk 1 wordt een uitgebreid overzicht gegeven van de anatomische en fysiologische aspecten van het anorectum in relatie tot faecale continentie. De pathofysiologie van faecale incontinentie, haar conventionele behandeling en de klassieke chirurgische behandeling worden besproken. Een overzicht van het gebruik van glad spierweefsel, vrij spier transplantaat, de gluteus spier, de gracilis spier en de elektrisch gestimuleerde (dynamische) gracilis spier voor de constructie van een nieuwe anale sfincter in de behandeling van ernstige faecale incontinentie en in de totale anorectale reconstructie na een abdomino-perineale resectie voor een laag rectum carcinoom wordt gegeven. Tevens wordt de techniek van de dynamische gracilis-plastiek gedetailleerd beschreven.

In hoofdstuk 2 worden de klinische resultaten en de effecten op de kwaliteit van leven van de dynamische gracilis plastiek (transpositie van de M. gracilis naar de anus met de implantatie van elektrisch gestimuleerde elektroden) geëvalueerd bij patiënten behandeld voor onhandelbare faecale incontinentie.

Er werden 52 patiënten behandeld met een dynamische gracilis-plastiek. De klinische resultaten van de behandeling werden geëvalueerd door middel van een anamnese, anale manometrie en een klysma test. De mate van incontinentie werd beoordeeld. Om de kwaliteit van leven te beoordelen werden 4 vragenlijsten toegepast (deel 1 en 2 van de Nottingham Health Profile, de State Trait Anxiety Inventory, en de Self-rating Depression scale).

Van de 52 patiënten werden 38 patiënten ( 73 procent) continent na een mediane follow-up duur van 2.1 jaar. Na 52 weken was de conditie van de patiënt verbeterd met betrekking tor de mediane defecarie frequentie (van vijf tor twee maal per 24 uur, P.001), de mediane tijdsduur om defecatie uir te stellen (van 9 seconden tot 19 minuten, $\mathrm{P}=0.012$ ), en de mediane tijd dar een klysma kon worden opgehouden (van 0 tot 180 seconden, $\mathrm{P}=0.005)$. Patiënten bij wie de techniek succesvol was werden minder angstig dan de patiënten bij wie de techniek faalde ( $\mathrm{P}=0.002)$. Bovendien voelden zij zich beter met betrekking tor de doeltreffendheid van hun functioneren, het vermogen thuis taken uit te voeren, persoonlijke relaties, seksueel functioneren, en hun sociale leven $(\mathrm{P}=0.01)$. Tevens werden zij sociaal minder geisoleerd $(\mathrm{P}=0.05)$.

Geconcludeerd wordt dat de dynamische gracilis-plastiek bewijst een veilige en betrouwbare techniek te zijn voor patiënten met ernstige incontinentie en kan resulteren in een betere kwaliteit van leven. 
In hoofdstuk 3.1 werd totale anale reconstructie met een dubbele dynamische gracilisplastiek uitgevoerd na een abdomino-perineale resectie (APR) voor een laag rectaal carcinoom. Bij vier patiënten werd aanvullend een pouch aangelegd teneinde de motiliteit en capaciteit van het neorectum te verbeteren. Het doel van deze studie was de resultaten van de eerste 20 patiënten te evalueren en de voorlopige resultaten van de pariënten met een toegevoegde pouch te melden.

Twintig patiënten werden behandeld met een gemiddelde leeftijd van 52 jaar (uitersten: 25-71) met een rectale tumor op een gemiddelde afstand van $3.0 \mathrm{~cm}$ (uitersten: 0-5) van de anaal ring. Bij 14 patiënten worden de Miles resectie, de doorhaal procedure van het colon en de constructie van een neosfincter uitgevoerd in een enkele zitring. Zes patiënten kregen de dubbele gracilis-plastiek op gemiddeld 4.1 jaar (uitersten: 1.1 - 8.8) na de APR. Bij 4 patiënten werd tevens een pouch geconstrueerd met een geïsoleerd segment van het distale ileum.

Na een gemiddelde follow up duur van 24 maanden (uitersten: 1 - 60) na APR ontwikkelde geen van de patiënten een lokaal recidief. $\mathrm{Bij} 4$ patiënten ontstond een metastase op afstand. Vijftien van de 20 patiënten waren beschikbaar voor evaluatie. Vijf patiënten waren nog in training. Van deze 15 patiënten waren 8 patiënten continent (53 procent), 2 patiënten waren incontinent en bij 5 patiënten was het perineale stoma geconverteerd tot een abdominaal stoma. Mislukkingen waren het gevolg van necrose van de colonstomp $(n=2)$ en incontinentie $(n=3)$. Na 26 weken was de gemiddelde druk in rust $44 \mathrm{mmHg}$ (S.D. 28) en de gemiddelde druk tijdens stimulatie $90 \mathrm{mmHg}$ (S.D. 46) met een gemiddeld voltage van 3.5 Volt (S.D.1.2) na 52 weeks. De gemiddelde defecatie frequentie was 3 maal per dag (uitersten: 1 to 5). Van de 8 patiënten die continent waren, gebruikten 6 dagelijks klysma's. De gemiddelde tijd dat defecatie uitgesteld kon worden was 11 minuten (uitersten: 0 - 30).

In ervaren handen is de dubbele dynamische gracilis-plastiek een oncologisch veilige procedure die een acceptabel functioneel resultaat kan hebben bij een goed geselecteerde groep patiënten. Echter, teneinde het resultaat te verbeteren zijn verdere aanpassingen noodzakelijk. De toevoeging van een pouch heeft rot nu toe nog nier geresulteerd in een verbetering van het resultaat.

In hoofdstuk 3.2 wordt de ziektegeschiedenis van een dertienjarig meisje besproken die betrokken was bij een motorboot ongeluk, wat resulteerde in een traumarische destructie van het rectum en de anale sfincters. Ze werd behandeld met een gemodificeerde Duhamel procedure voor het beschadigde rectum en een dubbele gracilis-plastiek als vervanging van de anale sfincters. Acht weken na de eerste operatie werden intramusculaire elektroden in beide gracilis spieren geïmplanteerd en verbonden met een geïmplanteerde neurostimulator. Deze elektrisch gestimuleerde gracilis neosfincter herstelde de sfincter functie terwijl de anorectale sensibiliteit behouden bleef als gevolg van een intact rectovaginaal septum. Na sluiting van het tijdelijke stoma heeft de patiënte een goede continentie. 
In hoofdstuk 4 worden alle specifieke problemen die optraden tijdens de behandeling met een dynamische gracilis-plastiek gedurende een periode van acht jaar gepresenteerd en wordt hun behandeling besproken. De dynamische gracilis-plastiek was uitgevoerd bij 67 patiënten met een gemiddelde follow up duur van 2.7 jaar. Alle patiënten werden geëvalueerd door middel van een lichamelijk onderzoek, anale manometry, defecografie en elektromyografie op vaste intervallen. Alle complicaties werden genoteerd en indien mogelijk behandeld. Continentie werd gedefinieerd als het continent zijn voor vaste en vloeibare ontlasting.

De techniek was succesvol bij 52 patiënten ( 78 procent), terwijl bij 15 patiënten een mislukking optrad (22 procent). Complicaties waren het resultaat van technische problemen, problemen met infectie en problemen die het gevolg waren van een abnormale functie van de spier of een verstoring van de anorectale functie. Er werden in totaal 53 complicaties gevonden bij 36 patiënten. De meeste technische problemen, betreffende de transpositie en stimulatie van de gracilis spier, konden worden behandeld. Mislukking was het gevolg van slechte contractie van het distale gedeelte van de spier $(n=4)$ en perforatie van het anale kanaal gedurende stimulatie $(n=1)$. Bij acht patienten dienden de stimulator en de elektroden geëxplanteerd te worden als een gevolg van infectie. Drie pariënten werden niet opnieuw continent na reïmplantatie. Op matige obstipatie na, waren de fysiologische complicaties moeilijk te behandelen en resulteerden in mislukkingen bij 5 patiënten, ten gevolgen van overloop incontinentie, soiling, een star rectum, sterke peristaltiek en ernstige obstipatic. Bij twee patiënten faalde de techniek ondanks een goed contraherende gracilis-plastiek, zonder dat een oorzaak voor de mislukking werd gevonden.

Complicaties die samenhangen mer de rechniek van de dynamische gracilis-plastiek zoals verlies van contractie, infectie, slechre contractie van her distale gedeelte van de spier en matige obstipatie, kunnen meestal worden voorkomen of behandeld. Moeilijkheden die samenhangen met een verminderde sensibiliteit en/of moriliteir en die een gevolg zijn van een congenitale afwijking of degenerarie, kunnen nier worden behandeld en dit betekent dat een goede selectie van de patiënten essentieel is om teleurstelling te voorkomen.

In hoofdstuk 5.1 werd de arteriële anatomie binnen de gracilis spier in beeld gebracht en werd de capillaire doorstroming voor en na doornemen van de perifere arteriën bepaald met behulp van per-operatieve laser Doppler flowmeting teneinde porentiële acure ischemie gedurende een gracilis-plastiek te kwantificeren.

Angiografiën van elf post-mortem spieren toonden dat de hoofd arteric en alle perifere arteriën in hetzelfde arteriële systeem draineerden. Bij tien patiënten werd de arteriële doorstroming gemeten in het distale gedeelte van de gracilis spier met behulp van laser Doppler flowmeting gedurende de mobilisatie van de spier. $\mathrm{Na}$ afklemming van de perifere arteriën verschilde de bloed doorstroming (gemiddeld 25.8 p.u., uitersten: 6.5-74.3) niet van de waarden die werden gemeten voor afklemming (gemiddeld 25.4 
p.u., uitersten: 7.5-68.7). Na gemiddeld 1.8 jaar waren alle spieren vitaal. Er bestond geen correlatie tussen de verandering in doorbloeding van de spier en noch de contractie kracht $(r=-0.2)$ noch het funcrioneel resultaat $(r=0.31)$. Het is derhalve rwijfelachtig of doornemen van de perifere arterièn de bottleneck is bij de humane dynamische gracilisplastiek. Een extra operatie voor vervroegde doorneming van de perifere arteriën zou dan ook overbodig zijn. Daarom zal er een prospectieve, gerandomiseerde klinische studie uitgevoerd moeten worden om het functioneel resultaat te vergelijken tussen patiënten met en zonder een vervroegde ligatie procedure.

In hoofdstuk 5.2 worden het optimale tijdstip om met elektrische stimulatie te starten en het positieve effect van een vervroegde ligatie procedure bestudeerd.

Bij konijnen $(n=3 \times 6)$ werden beide gracilis spieren rond een dubbel polyurethaan buisje getransponeerd en werden elektroden en een neurostimulator geïmplanteerd. De rechter spieren werden gestimuleerd gedurende 11 weken, de linker spieren vormden de controle groep. In groep 1 werd de spier direct na transpositie gestimuleerd, in groep 2 na zes weken rust, in groep 3 werd de perifere arteriën geligeerd 5 weken voor de spier werd getransponeerd en direct gestimuleerd.

Gedurende stimulatie nam het percentage type 1 spiervezels toe van $4.6 \%$ tot 41.9 $\%$. In groep 1 bestond significant meer verandering van spierweefsel. Er bestond geen significant verschil in gemeten drukken tussen de groepen. In groep 1 was de toename van het voltage gedurende stimulatie significant toegenomen $(\mathrm{P}<.05)$. De vermoeibaarheid in groep 1, 259 (S.E. 130) seconden, was significant lager dan in groep 2, 515 (S.E. 102) seconden (P.05).

Vergeleken met groep 2 en 3 geeft directe stimulatie (groep 1) meer verandering van spierweefsel en behoeft het een grotere toename van her stimulatie voltage om voldoende contractie kracht te ontwikkelen. Tevens is de vermoeibaarheid vergroot. Vervroegd ligeren een verbetering van de spierfunctie.

In hoofdstuk 6.1 wordt een gedetailleerd overzicht gegeven van de pathogenese, diagnose en behandeling van faecale incontinentie bij het kind.

In hoofdstuk 6.2 wordt de mogelijkheid van transpositie en elektrische stimulatie van een skeletspier in het jonge individu bepaald. Derhalve werd de invloed van groei op de transpositie en stimulatie van de skeletspier bestudeerd bij vijf jonge hondjes. In elk hondje werden twee neosfincters geconstrueerd en getransponeerd rondom een ThiryVella loop met behulp van de vrij-geprepareerde sartorius spieren met een intacte neurovasculaire voorziening. In elk van deze vijf hondjes werd een van de spieren elektrisch gestimuleerd gedurende gemiddeld 19 weken ( 1 hondje overleed tijdens de eerste week postoperarief). Spier biopsiën toonden een toename in het percentage type 1, minder vermoeibare, spiervezel van 61 tot 94 in de elektrisch gestimuleerde sartorius neosfincters, maar ook een toename van 57 tor 67 procent in de getransponeerde 
niet-gestimuleerde sartorius spieren. De diameter van deze type I vezels tijdens de groei namen toe met $36 \%$ in de elektrisch gestimuleerde sartorius neosfincters en met $55 \%$ in de niet-gestimuleerde sfincters. De functie van de neosfincters werd getest met de instroom van fysiologisch zout in de Thiry-Vella loop. Het bleek dat de gestimuleerde neosfincters in staat waren het fysiologisch zout tegen te houden (dit correspondeerde met de manometrische druk registratie), maar de niet-gestimuleerde sfincters waren niet in staat het fysiologisch zout tegen te houden. De experimenten werden bemoeilijkt door infectie en necrose rond de geïmplanteerde stimulatoren bij vier hondjes (wat noodzaakte tot reïmplantatie). Wij concluderen dat een dynamische spierplastiek voor faecale incontinentie mogelijk is in de groeiende hond, maar dat de rechniek niet acceptabel is gedurende snelle groei vanwege de risico's van infectie en dislocatie van het geïmplanteerde materiaal.

In hoofdstuk 6.3 wordt een nieuwe behandelingsmerhode beschreven waarbij nieuwe urinaire en anale sfincters worden gecreëerd in twee pariënten met spina bifida die lijden aan ernstige incontinentie voor urine en faeces. Beide pariënten hadden een neurogene blaas, afwezige urinaire sfincrer functie, een ernstig verminderde anale sfincter functie, goede anorectale sensibiliteir en redelijke darm motiliteit. Een gracilisspier werd getransponeerd rond het anale kanaal en de andere werd getransponeerd door het urogenetale septum en rond de blaashals geslagen. Om de capaciteit en de compliantie van de blaas re verbereren werd een CLAM-ileocystoplastiek uitgevoerd. Zes weken later werd een neurostimula tor geïmplanteerd om langdurige contractie van de spier, onafhankelijk van de wil, mogelijk te maken. Beide patiënten werden continent voor urine en faeces. Een patiënt ontwikkelde later overloop incontinentie als gevolg van ernstige obstipatie en gebruikt derhalve nu klysma's voor recrale evacuatie. De dubbele dynamische gracilisplastiek kan een uitkomst bieden voor goed geselecteerde patiënten wanneer geen andere mogelijkheid tor behandeling resteert. 


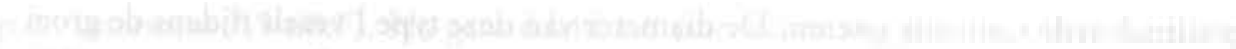

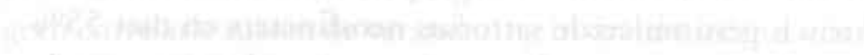

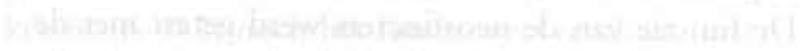

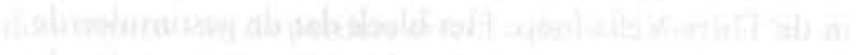

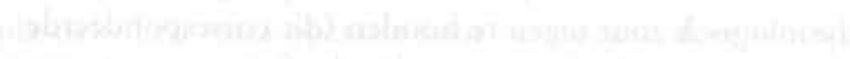

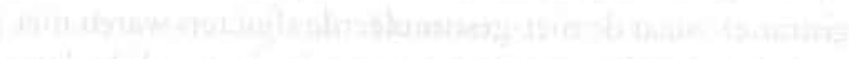

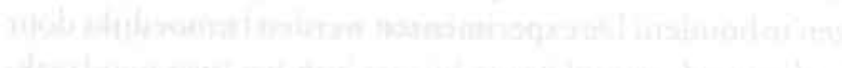

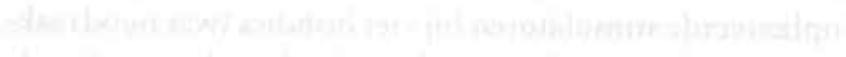

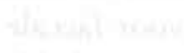

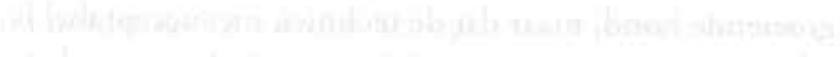

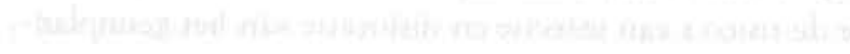




\section{Dankwoord}

Nu ik toekom aan het schrijven van het dankwoord valt het meteen op hoe ontzettend veel mensen bij het tot stand komen van dit proefschrift betrokken zijn geweest. Zovelen die hun deel hieraan hebben bijgedragen en zonder wiens hulp dit proefschrift niet binnen 3 jaar voltooid zou zijn geweest.

Beste Cor, heel veel dank dat ik de afgelopen jaren aan jouw zijde heb mogen vertoeven. Ik kan je verzekeren: het was een geweldige ervaring. Ik heb het als een enorm voorrecht ervaren om mee te mogen helpen met het grootbrengen van jouw "vierde kind". De vrijheid van werken die je bood, de altijd positieve benadering en je optimisme creëerden een werkklimaat waarin ik me ten volle kon ontplooien. De gezellige reisjes samen en de vele buitenlandse contacten zijn een ervaring voor het leven. Ik verheug me op onze samenwerking in de nabije toekomst.

Erik, toen ik jou nakwam vanuit Rotterdam was dat omdat ik onze prettige samenwerking zeer waardeerde. Voor je brede kennis en belangstelling, je stimulerende manier van werken en de manier waarop je altijd tijd weet vrij te maken heb ik grote bewondering. Ik hoop dat onze gezamenlijke "mission" nog lang niet "complered" is. Onze vriendschap zal dat zeker niet zijn!

Perer, bedankt voor het als promotor willen optreden bij dit proefschrift en voor het op' de achtergrond begeleiden van de eerste artikelen.

Professor Kootstra, bedankt voor de mogelijkheid om het onderzoek zoals beschreven in dit proefschrift op uw afdeling te kunnen uitvoeren. Uw belangstelling voor m.n. de kinderchirurgische aspecten hebben me zeker gestimuleerd.

Joop, van jou leerde ik de manometrie en kon ik het klinisch lopende onderzoek zonder problemen overnemen. Gedurende de afgelopen jaren bleef je vanuit Venlo meedenken en natuurlijk ook meepubliceren.

Wim, bedankt voor je gastvrijheid waardoor ik gedurende drie jaar in jouw nabijheid mocht huizen. Onze discussies over de klinische en experimentele studies waarmee ik bezig was, en waar jij vanuit je brede wetenschappelijke kennis zo'n waardevolle bijdrage aan leverde, hebben mij altijd bijzonder geholpen.

Eddy Adang bedankt voor het uitvoeren van de Quality of Life studie en het prettige contact dat we mochten hebben.

Graham Ramsay bedankr voor het als "native speaker" corrigeren van de door ons verzonden tekst.

Ivo en Carlo bedankt voor het samen delen van onderzoeks lief en leed en de vele geanimeerde discussies die we mochten voeren. Monique, Gaby, Trudy, Mieke, Mick, Hans, Dennis en Gabrie bedankt voor het gezellige verblijf op het lab. 
Marjan, Yvonne en Nicole bedankt voor de secretariële ondersteuning. Wilma In de Braekt: bedankt voor de voortreffelijke wijze van begeleiden van 'onze' patiënten met een stoma en het gezellige gezamenlijke congresbezoek.

Professor Spaans en de hele afdeling Neurofysiologie bedankt voor de ondersteuning bij de klinische en experimentele studies.

Professor Arends, Gerard Freling en de analisten van de afdeling pathologie, in het bijzonder John, Jan, Annick en Margriet, bedankt voor de ondersteuning bij het verwerken van mijn coupes. John, mijn bewondering voor jouw geduld als ik weer eens na weken van stilie aan kwam dragen met een paar biopten.

De afdeling radiologie, m.n. Pim Versluis en Marlous Mommers, bedankt voor de ondersteuning bij de klinische en experimentele studies.

Alle verpleegkundigen van de polikliniek Heelkunde bedankt voor de prettige samenwerking. Ik verheug me al op een voortzetring over drie jaar.

Het personeel van het CPV, te weten: Brigitte, Peter, Frans, Joyce, Mai, Frans en Huub, bedankt voor de professionele en gezellige ondersteuning bij de dierexperimenten. Ton, speciale dank aan jou. Niet alleen voor de onmisbare deskundige ondersteuning bij dag en ontij, maar misschien nog meer voor de interesse en het enthousiasme waarmee je ons werk volgde. Ik heb hier enorm van genoten en het heeft in belangrijke mate bijgedragen aan het slagen van dit proefschrift.

Henk van Mameren en Arno Lataster van de afdeling Anatomie bedankt voor ondersteuning bij de anatomische studie.

Iedereen van Medtronic, bedankt m.n. Rob, Lee, Ralf, Diederik, Matthias, Anne Barbara, Julietre, Jean, Martin, Laura, en in het bijzonder Fons, die altijd klaar stonden om me met raad en daad bij te staan. De vele gezellige momenten, o.a. het discotheek bezoek in Barcelona en de trip naar Minneapolis, zal ik niet snel vergeten. Fons, mijn verontschuldigingen dat je me vaak aan de case-report forms moest herinneren omdat $i k$ weer eens hopeloos achrer was met het invullen van de gegevens. Van onze gesprekken over werk, hobby of privé heb ik alrijd erg genoten.. Speciale dank aan Jan de Jonge die verantwoordelijk is voor her ontwerp van de figuren in dit proefschrift.

De audiovisuele dienst, foto en video, bedankt voor de professionele en snelle service bij de (meestal) te laat ingeleverde opdrachren.

De Maastrichtse leden van de beoordelingscommissie, de professoren Arends, Janknegt en Spaans bedankt voor hun beoordeling van het manuscript. I would like to thank professor Christiansen and professor Madoff for carefully evaluating this thesis. Many thanks as well to all the other doctors who gave their valuable comments and inspired us to continue with our work.

Een behandeling als de dynamische gracilis plastiek is niet afgelopen als de operaties zijn uitgevoerd. Een individuele training en controle van zowel de spier als de geïmplanteerde neurostimulator vragen om een nauwe en goede samenwerking van patiënt en arts. Vanaf deze plaats wil ik graag alle pariënten bedanken voor het in ons gestelde vertrouwen en de pretrige samenwerking. 
Vincent en Peter bedankt voor de perfecte ondersteuning bij de dierexperimenten.

Alhoewel ik overtuigd ben van de bittere noodzaak om dierexperimenteel onderzoek te verrichten teneinde een behandelingsmethode te verbeteren, moet ik elke keer weer over een drempel om een dier aan een experiment te onderwerpen. Het onvermogen een dier uit te leggen over het wat en waarom van een experiment doet pijn. Ik hoop van harte dat ik de dieren geen ondraagbaar leed heb toebedeeld en dat hun opoffering heeft mogen bijdragen aan een verbetering van de techniek en een beter begrip van de problemen die ermee gepaard gaan.

Papa en mama die mij altijd met raad en daad hebben bijgestaan en moreel hebben ondersteund, wat een geweldige ouders zijn jullie toch! Papa tevens bedankt voor het meegaan op late en donkere avonden om, gewapend met landkaart en zaklamp, op zoek te gaan naar biggen in de binnenlanden van Limburg en Brabant.

Myriam, die mij altijd met interesse volgde, vele malen alleen was en soms zelfs knorrende biggetjes op de slaapkamer moest dulden. Ik hoop dit de komende jaren weer goed te kunnen maken. 


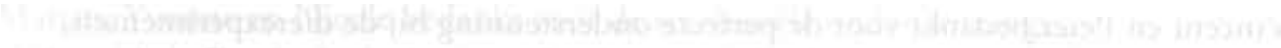

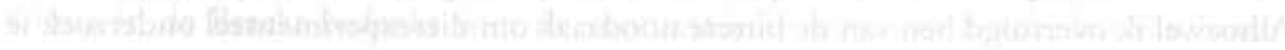

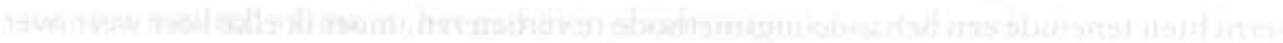

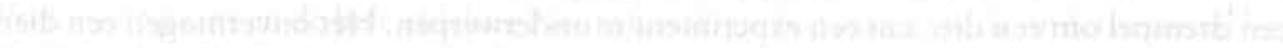

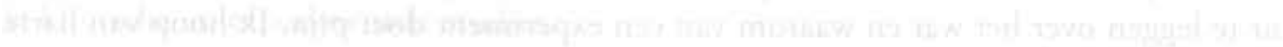

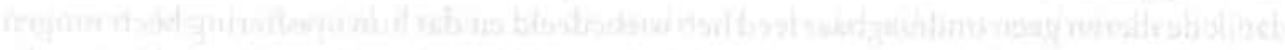

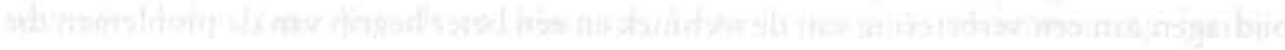

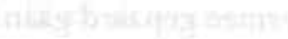

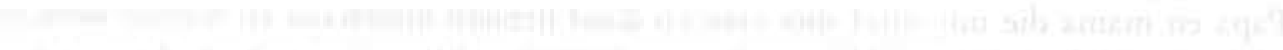

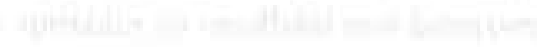




\section{Publications}

1. Dynamic myoplasty in growing dogs as a feasibility study for treatment of fecal incontinence. Konsten J, Geerdes BP, Baeten CGMI, Heineman E, Arends JW, Pette D, Soeters PB. J of Pediatric Surgery 30(4):580-4; 1995

2. Dynamic graciloplasty for restoration of continence after traumatic destruction of the rectum and sphincters. Report of a case. Konsten J, Geerdes BP, Versluis P, Heineman E, Baeten CGMI. J Trauma 38(1):11-3; 1995

3. Defecographic Evaluation of Dynamic Graciloplasty for fecal incontinence. Versluis P, Konsten J, Geerdes BP, Baeten CGMI, Oei R. Dis Colon Rectum 1995;38(5):468-73.

4. Anal Dynamic Graciloplasty in the treatment of intractable fecal incontinence. Baeten CGMI, Geerdes BP, Adang EMM, Heineman E, Konsten J, Engel E, Kester ADM, Spaans F, Soeters PB. New Engl J Med 1995;332:1600-5.

5. Double Dynamic Graciloplasty and colo-perineal pull through after abdominoperineal resection. Geerdes BP, Zoetmulder FAN, Baeten CGMI. Eur I Canc 1995;31A:1248-52.

6. Fecal Incontinence and the Dynamic graciloplasty. Geerdes BP, Baeten CGMI. Perspectives in Colon and Rectal Surgery. (in press)

7. Dynamic graciloplasty: Complications and Management. (ieerdes BP, Heincman E, Konsten J, and Baeten CGMI. Dis Colon Rectum 1996;39:912-17.

8. De dubbele dynamische M. gracilisplastiek: alternaticf voor een colostoma nat een volledig verlies van het anorectum. Geerdes BP. Heineman E, Zoetmulder FAN, Adang EMM, Vos E en Baeten CGMI. NTVG 1996;140(14):773-7

9. Electrical Stimulated Graciloplasty in the Male Goat; An Animal Model for Urethral Pressure Measurement. Heesakkers JPFA, Wen Jianguo, Geerdes BP, Baeten CGMI and Janknegt RA. Neurourology and Urodynumics 1996;15:545-553.

10. Total Anorectal Reconstruction with a double dynamic graciloplasty after abdominoperineal resection for low rectal cancer. Geerdes BP, Zoctmulder F, Hcineman E, Vos EJ, Rongen MJ, Baeten CGMI. Dis Colon Rectum (in press)

11. Vascular and stimulation delays in dynamic musculoplasty. (jeerdes BP', Heineman E, Freling G, Keizer HA, Woloszko J, Baeten CGMI. Surgery (in press) 
12. Location of external anal sphincter motoneurons in the sacral cord of the female domestic pig. Blok BFM, Roukema GR, Geerdes BP, Holstege G. Neuroscience Letters 1996;216:203-6.

13. Effecten van elektrische stimulatie op skeletspierweefsel na gracilistranspositie. Paulissen J, Geerdes BP, Baeten CGMI, Freling G. Histotechniek Cyto-Visie. 1996;2:17-22

14. Simultaneous treatment of faecal and urinary incontinence in children with spina bifida using a double dynamic graciloplasty. Geerdes BP, Heesakkers JPFA, Heineman E, Spaans F, Janknegt RA, Baeten CGMI. Br J Surg (in press)

15. Bilateral gracilis neosphincter construction for treatment of faecal incontinence. Geerdes BP, Konsten J, Baeten CGMI. Br J Surg 1996:83:1015 (letter)

16. Constipation after dynamic graciloplasty. Geerdes BP, Konsten J, Baeten CGMI. Dis Colon Rectum 1996;39:943 (letter)

17. Assessment of ischaemia of the distal part of the gracilis muscle during transposition for anal dynamic graciloplasty. Geerdes BP, Kurvers HAJM, Konsten J, Heineman E, Baeten CGMI. BrJ Surg (in press)

18. Tissue reactions to implantable leads surface-modified to induce infection-resistency. Wachem v PB, Luyn v MJA, Vries de- Hospers, Geerdes BP, Woloszko J, Verhoeven MLPM, Hendriks M, Cahalan PT. (submitted)

19. Economical evaluation of a new surgical technique: the dynamic graciloplasty. Adang EMM, Geerdes BP, Engel E, Baeten CGMI. (submitted)

20. Functional and histological evaluation of the modified alfa-loop dynamic graciloplasty in rabbits. Heesakkers JPFA, Janknegt RA, Geerdes BP and Baeten CGMI. (submitted)

21. Diagnosis and Treatment of Anorectal Incontinence In Children. Geerdes BP, Heineman E, Baeten CGMI. (submitted)

22. Complications in Dynamic Graciloplasty for Anal Incontinence. Geerdes BP, Heineman E, Konsten J, Baeten CGMI, Soeters PB. Proceedings 4th International muscle symposium, Zurich: 218-21; 1995

23. Dynamic Urinary Graciloplasty in Humans. Heesakkers JPFA, Janknegt RA, Geerdes BP and Baeten CGMI. Proceedings 4th International muscle symposium, Zurich: 222-25; 1995

24. Dynamic Graciloplasty for fecal incontinence. Geerdes BP, Baeten CGMI. Proceedings of the 5th ECCP congress. 1995:29-32 


\section{Curriculum Vitae}

Bas Geerdes was born on January $18^{\text {th }} 1965$ in Heerlen, The Netherlands. He graduated from the Sint Michiel scholengemeenschap in 1984 in Geleen. He attended the first year of physiotherapy at the Academy for Physiotherapy in Heerlen. In 1985 he continued his study at the Medical School of the Erasmus University Rotterdam and received his Medical Degree in 1992. From March 1992 until September 1992 he worked as a research fellow at the Department of Surgery (Prof. dr. M. Brunner) of the University of Maryland Ar Baltimore and as a clinical observer at the Department of Pediatric Surgery (Prof. dr. A. Haller) Johns Hopkins Medical School, Baltimore, USA. From September until November 1992 he worked as a clinical fellow at the Department of Pediatric Surgery of the hospital Hautepierre Strasbourg, France (Prof. dr. Sauvage). From January 1993 until June 1993 he worked as a Senior House Officer in Surgery in Yorkshire, United Kingdom. From July 1993 until July 1996 he worked on the dynamic graciloplasty as a research fellow of Dr. C. Baeten at the Department of Surgery of the University Hospital Maastriche, The Netherlands (head: Prof. dr. G. Kootstra). In July 1996 he started his surgical training at the Diaconessenhuis in Eindhoven, The Netherlands (head: Dr. W. Prakken). 
Financial support for the publication of this thesis was generously provided by:

B. Braun Medical B.V.

- Coloplast

- Combicare

- ConvaTec

- GlaxoWellcome

- Medacs Healthcare Services PLC

- MediReva

- Medtronic Interstim

S.C.A. Mölnlycke B.V. Clinical Products

- Spruyt hillen bv

- Synectics Medical

- Koninklijke Utermöhlen NV 
